\title{
The renal cell cancer methylome: tumor biology and clinical applications
}

Citation for published version (APA):

van Vlodrop, I. J. H. (2012). The renal cell cancer methylome: tumor biology and clinical applications. [Doctoral Thesis, Maastricht University]. Maastricht University. https://doi.org/10.26481/dis.20120323iv

Document status and date:

Published: 01/01/2012

DOI:

10.26481/dis.20120323iv

Document Version:

Publisher's PDF, also known as Version of record

\section{Please check the document version of this publication:}

- A submitted manuscript is the version of the article upon submission and before peer-review. There can be important differences between the submitted version and the official published version of record.

People interested in the research are advised to contact the author for the final version of the publication, or visit the DOI to the publisher's website.

- The final author version and the galley proof are versions of the publication after peer review.

- The final published version features the final layout of the paper including the volume, issue and page numbers.

Link to publication

\footnotetext{
General rights rights.

- You may freely distribute the URL identifying the publication in the public portal. please follow below link for the End User Agreement:

www.umlib.nl/taverne-license

Take down policy

If you believe that this document breaches copyright please contact us at:

repository@maastrichtuniversity.nl

providing details and we will investigate your claim.
}

Copyright and moral rights for the publications made accessible in the public portal are retained by the authors and/or other copyright owners and it is a condition of accessing publications that users recognise and abide by the legal requirements associated with these

- Users may download and print one copy of any publication from the public portal for the purpose of private study or research.

- You may not further distribute the material or use it for any profit-making activity or commercial gain

If the publication is distributed under the terms of Article $25 \mathrm{fa}$ of the Dutch Copyright Act, indicated by the "Taverne" license above, 
The renal cell cancer methylome: tumor biology and clinical applications 
The renal cell cancer methylome: tumor biology and clinical applications Iris J.H. van Vlodrop

ISBN:

978-90-8570-973-2

Cover: $\quad$ Rob W.J. Frischen

Lay-out: $\quad$ Yvonne Leenders

Printed by: Wöhrmann Print Service

(C) 2012, Iris van Vlodrop

All rights reserved. No part of this thesis may be reproduced or transmitted in any form or by any means, electronic or mechanical, including photocopying, recording or any information storage or retrieval system, without permission in writing from the author, or, when appropriate, from the publishers of the publications. 


\title{
The renal cell cancer methylome: tumor biology and clinical applications
}

\author{
PROEFSCHRIFT \\ Ter verkrijging van de graad van doctor \\ aan de Universiteit Maastricht, \\ op gezag van de Rector Magnificus, \\ Prof. mr. G.P.M.F. Mols, \\ volgens het besluit van het College van Decanen, \\ in het openbaar te verdedigen \\ op vrijdag 23 maart 2012 om 14.00 uur
}

door

Iris Johanna Helena van Vlodrop

Geboren op 20 februari 1983 te Heerlen 


\section{Promotor:}

Prof. dr. M. van Engeland

\section{Copromotores:}

Dr. M.M.L.L. Baldewijns

Dr. P.M.M.B. Soetekouw

\section{Beoordelingscommissie:}

Prof. dr. F.C.S. Ramaekers (voorzitter)

Prof. dr. J.B.A.G. Haanen (Nederlands Kanker Instituut -

Antoni van Leeuwenhoek ziekenhuis te Amsterdam)

Prof. dr. J.A. Schalken (Radboud Universitair Medisch Centrum Nijmegen)

Prof. dr. M.A.M. van Steensel

Prof. dr. M.A.G.G. Vooijs

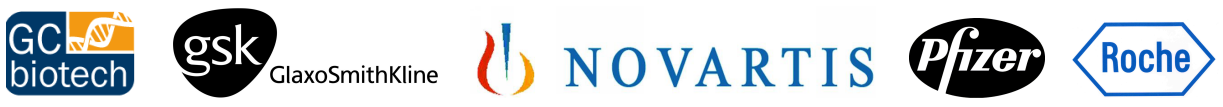

Financial support by GC Biotech, GlaxoSmithKline, Novartis, Pfizer and Roche for the publication of this thesis is gratefully acknowledged. 


\section{List of abbreviations}

\begin{tabular}{|c|c|}
\hline AIC & Akaike information criterion \\
\hline AJCC & American Joint Committee on Cancer \\
\hline $\mathrm{BC}$ & breast cancer \\
\hline $\mathrm{BMI}$ & body mass index \\
\hline BMP & bone morphogenetic protein \\
\hline BPE & bovine pituitary extract \\
\hline BSseq & bisulfite sequencing \\
\hline ccRCC & clear cell renal cell carcinoma \\
\hline cDNA & copy deoxyribonucleic acid \\
\hline chrRCC & chromophobe renal cell carcinoma \\
\hline $\mathrm{Cl}$ & confidence interval \\
\hline $\mathrm{CIN}$ & chromosomal instability \\
\hline COBRA & combined bisulfite restriction analysis \\
\hline CRC & colorectal cancer \\
\hline DAC & 5-aza-2'-deoxycitidine \\
\hline DMEM & Dulbecco's modified Eagle medium \\
\hline DNA & deoxyribonucleic acid \\
\hline DNMT & DNA methylatransferase \\
\hline ECOG & Eastern Cooperative Oncology Group \\
\hline $\mathrm{ECP}$ & endothelial cell proliferation \\
\hline EGF & epidermal growth factor \\
\hline EMT & epithelial to mesenchymal transition \\
\hline FBS & fetal bovine serum \\
\hline FDA & Food and Drug Administration \\
\hline FFPE & formalin-fixed paraffin-embedded \\
\hline HDAC & histone deacytelases \\
\hline HLA & human leukocyte antigen \\
\hline HMT & histone methyl transferase \\
\hline $\mathrm{HPH}$ & HIF prolyl hydroxylase \\
\hline$H R$ & hazard ratio \\
\hline HRE & hypoxia responsive element \\
\hline HUVEC & human umbilical vein endothelial cells \\
\hline IUAC & International Union Against Cancer \\
\hline K-SFM & Keratinocyte serum free medium \\
\hline LLN & lower limit normal \\
\hline $\mathrm{LOH}$ & loss of heterozygosity \\
\hline LRES & long-range epigenetic silencing \\
\hline MBD & methyl binding domain \\
\hline MFS & metastasis free survival \\
\hline MIRA & methylated-CpG island recovery assay \\
\hline $\mathrm{mRCC}$ & metastatic renal cell carcinoma \\
\hline mRNA & messenger ribonucleic acid \\
\hline MSI & microsatellite instability \\
\hline MSKCC & Memorial Sloan-Kettering Cancer Cente \\
\hline
\end{tabular}




$\begin{array}{ll}\text { MSP } & \text { methylation-specific PCR } \\ \text { mTOR } & \text { mammalian target of rapamycin } \\ \text { MVD } & \text { microvessel density } \\ \text { NCI-EORTC } & \text { National Cancer Institute - European Organization for Research and Treat } \\ & \text { ment of Cancer } \\ \text { NGS } & \text { next-generation sequencing } \\ \text { NLCS } & \text { Netherlands cohort on diet and cancer } \\ \text { OR } & \text { odds ratio } \\ \text { OS } & \text { overall survival } \\ \text { PBS } & \text { phosphate buffered saline } \\ \text { PCR } & \text { polymerase chain reaction } \\ \text { pRCC } & \text { papillary renal cell carcinoma } \\ \text { PTX } & \text { paclitaxel } \\ \text { (q)RT-PCR } & \text { (quantitative) reverse transcriptase PCR } \\ \text { RCC } & \text { renal cell carcinoma } \\ \text { RCT } & \text { randomized clinical trial } \\ \text { REMARK } & \text { REporting recommendations for tumor MARKer prognostic studies } \\ \text { RIN } & \text { RNA integrity number } \\ \text { RNA } & \text { ribonucleic acid } \\ \text { RNAi } & \text { RNA interference } \\ \text { RPMI } & \text { Roswell Park Memorial Institute medium } \\ \text { RR } & \text { risk ratio } \\ \text { TCP } & \text { tumor cell proliferation } \\ \text { TGF- } \beta & \text { transforming growth factor- } \beta \\ \text { TKI } & \text { tyrosine kinase inhibitor } \\ \text { TNM } & \text { tumor node metastasis } \\ \text { TSA } & \text { Trichostatin A } \\ \text { TSG } & \text { tumor suppressor gene } \\ \text { TSS } & \text { transcription start site } \\ \text { ULN } & \text { upper limit normal } \\ \text { VSMC } & \text { vascular smooth muscle cells } \\ \text { WHO } & \text { World Health Organization } \\ & \end{array}$




\section{Contents}

Pg:

Chapter 1 General introduction 9

$\begin{array}{lll}\text { Chapter } 2 \text { Genetics and epigenetics of renal cell cancer } & 17\end{array}$

Chapter 3 Prognostic significance of Gremlin1 (GREM1) promoter 55

$\mathrm{CpG}$ island hypermethylation in clear cell renal cell carcinoma

Chapter 4 Analysis of promoter $\mathrm{CpG}$ island hypermethylation in cancer: location, location, location!

Chapter 5 A four gene promoter CpG island methylation marker panel predicts survival of clear cell renal cell cancer patients

Chapter 6 Comprehensive comparison of the clear cell renal cell cancer methylome with the colorectal and breast cancer methylomes identifies conserved targeting of critical pathways through unique epigenetic events

Chapter 7 General discussion

Summary

Samenvatting (summary in Dutch)

Dankwoord (acknowledgement in Dutch) 



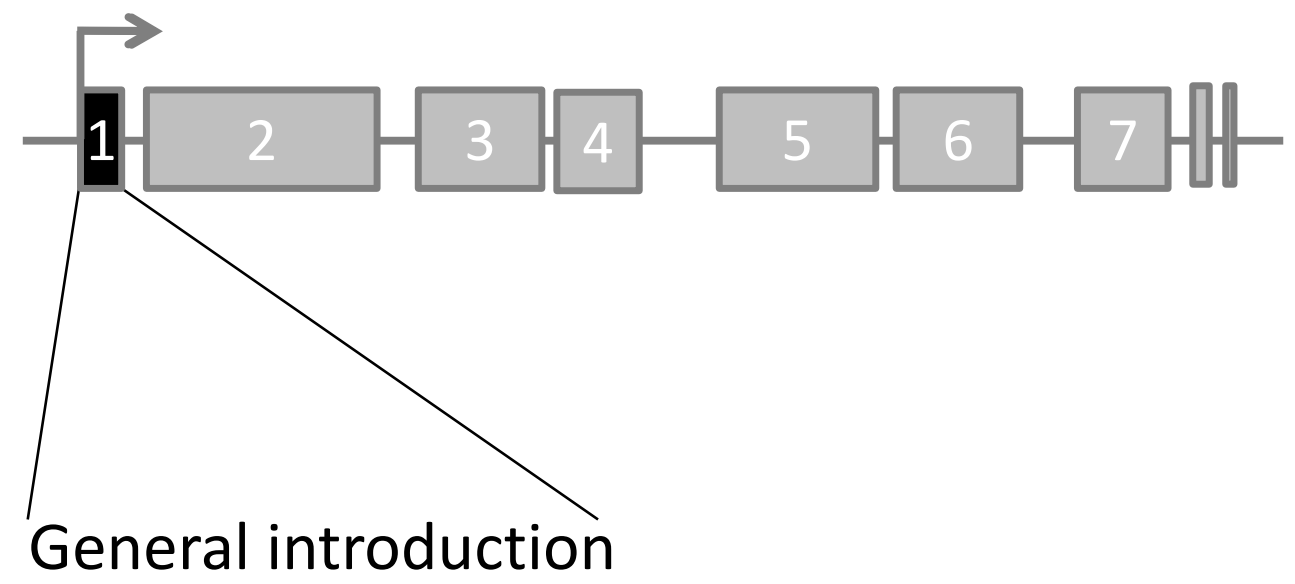




\section{Renal cell cancer in the year 2011}

Kidney tumors account for approximately $2 \%$ of all adult malignancies and in 2008, worldwide more than 270,000 new cases have been diagnosed and more than 115,000 people died of this disease ${ }^{1}$. Renal cell cancer (RCC) represents the vast majority (80$85 \%$ ) of all kidney tumors and is histologically classified into clear cell (ccRCC, 60-80\%), papillary (pRCC type I and type II, 10-15\%), chromophobe (chrRCC, 5-10\%), and some less frequent subtypes like collecting duct carcinoma and medullary carcinomas $(<1 \%)$. In case of localized disease, RCC is curable with surgery, but for those patients with distant metastases the prognosis is poor. Approximately $30 \%$ of all RCC patients have metastatic disease at time of diagnosis and in another $30 \%$ of patients recurrence develops after complete resection of the primary tumor. Current surgical and pharmaceutical interventions have limited success in treating patients with advanced RCC. From 1992 until 2005, interleukin 2 (IL-2) and interferon $\alpha$ (IFN $\alpha$ ) immunotherapy has been the treatment of choice for metastatic RCC (mRCC) but with limited efficacy. Only about $5 \%$ to $15 \%$ of cases of $\mathrm{mRCC}$ respond to immunotherapy and most of these responses are partial or of short duration ${ }^{2,3}$, although for (the highly toxic) IL-2 in some patients a complete remission has been reported.

Since 2005, the high angiogenic potential of RCC has become the first target of choice for treatment options. Tumor angiogenesis is one of the major hallmarks of cancer in general $^{4}$ and the high angiogenic potential of (advanced) RCC provided a strong rationale to investigate targeted therapy in this type of tumors. Abnormal functioning of the von Hippel-Lindau (VHL) gene plays a key role in induced angiogenesis through a hypoxia-driven pathway (accumulation of hypoxia-inducible factor (HIF)) and is the predominant genetic aberration in RCC. The vascular endothelial growth factor (VEGF) and the mammalian target of rapamycin (mTOR) signal transduction pathways have particularly been exploited. Thanks to this improved understanding of the molecular biology of $\mathrm{mRCC}$, its treatment has recently evolved from predominantly cytokinebased to the use of drugs targeting VEGF and its receptor (VEGFR), platelet derived growth factor (PDGF) and its receptor (PDGFR) or mTOR. Since 2005, agents such as the tyrosine kinase inhibitors (TKIs) sorafenib, sunitinib, and pazopanib, the anti-VEGF monoclonal antibody bevacizumab (in combination with IFN $\alpha$ ), and the mTOR inhibitors temsirolimus, everolimus dominate the mRCC treatment protocols and more are yet to come. Figure 1 shows the timeline of registration of these agents in the USA and Europe and indicates the targets within the angiogenesis-related pathway.

The significant progress in unraveling the biology of RCC and the treatment opportunities identified through this knowledge for mRCC generate possibilities for a personalized approach and tools to improve management of the disease (see Figure 1) are being developed. Currently, patient performance status, TNM stage and Fuhrman nuclear grade are the most useful predictors of patient outcome ${ }^{5}$. In metastatic RCC a prognostic model was developed by Motzer et al. at the Memorian Sloan Kettering Cancer, which is known as the MSKCC risk system, or informally known as the "Motzer criteria" ${ }^{\prime}$. This model is widely used as standard prognostic criteria for selecting patients to participate in clinical trials and for recommending treatment options to patients not enrolled in trials. However, this system, only used for RCC patients with metastatic disease, was derived in the cytokine era leading to importance of re- 
evaluation of prognostic markers in the current era of 'targeted' therapy. In order to better identify subgroups of patients with different clinical outcome, the increasing knowledge of the biology of cancer and the identification of molecular markers for targeted therapy provide opportunities for medical oncologists to better manage RCC. Although defective $\mathrm{VHL}$ functioning is a key event in the development $\mathrm{CCRCCs}{ }^{7-9}$, alterations in the structure ${ }^{9,10}$ or regulation of the $V H L$ gene ${ }^{11,12}$ do not appear to be directly associated with tumor cell proliferation and patient prognosis ${ }^{13,14}$. Therefore a need exists for molecular markers predicting prognosis (so-called prognostic markers) and for molecular markers predicting response to therapy (so-called predictive markers). These markers should provide a personal tumor profile to guide personalized therapy of RCC and prevent the serious treatment-related toxicity experienced by a large group of RCC patients as a consequence of 'trial and error' treatment.

Molecular alterations in cancer provide opportunities to develop specific biomarkers. Genetic aberrations have been characterized in RCC and for each subtype one or more important mutations have been described, like VHL in CCRCC, the MET proto-oncogene and fumarate hydratase (FH) tumor suppressor gene (TSG) in pRCC, Birt-Hogg-Dubé (BHD) in chrRCC, and tuberous sclerosis complex 1 (TSC1) and 2 (TSC2) TSGs in all three subgroups. So far, additional genomic research in RCC has not yet revealed genetic marks in a significant portion of RCCs with a biomarker potential.

Besides genetic alterations, epigenetic abnormalities (heritable changes in gene expression by processes other than altered DNA sequence) have been recognized at the level of DNA (postreplicative DNA methylation), RNA (RNA interference (RNAi)), and protein (posttranslational histone modifications and polycomb group complexes). DNA methylation is the most widely studied epigenetic modification in humans and of importance in maintaining normal development and biology. The most common sequence context where this epigenetic mark is found is the CpG dinucleotide. Many diseases are associated with the addition of methyl (CH3)-groups to cytosine bases at the wrong time or at the wrong place, especially cancer ${ }^{15}$. Cancer cells are characterized by a massive global loss of DNA methylation ${ }^{16,17}$ and, in contrast, at the same time by specific patterns of hypermethylation at CpG-rich regions (CpG islands) of certain gene promoters. 


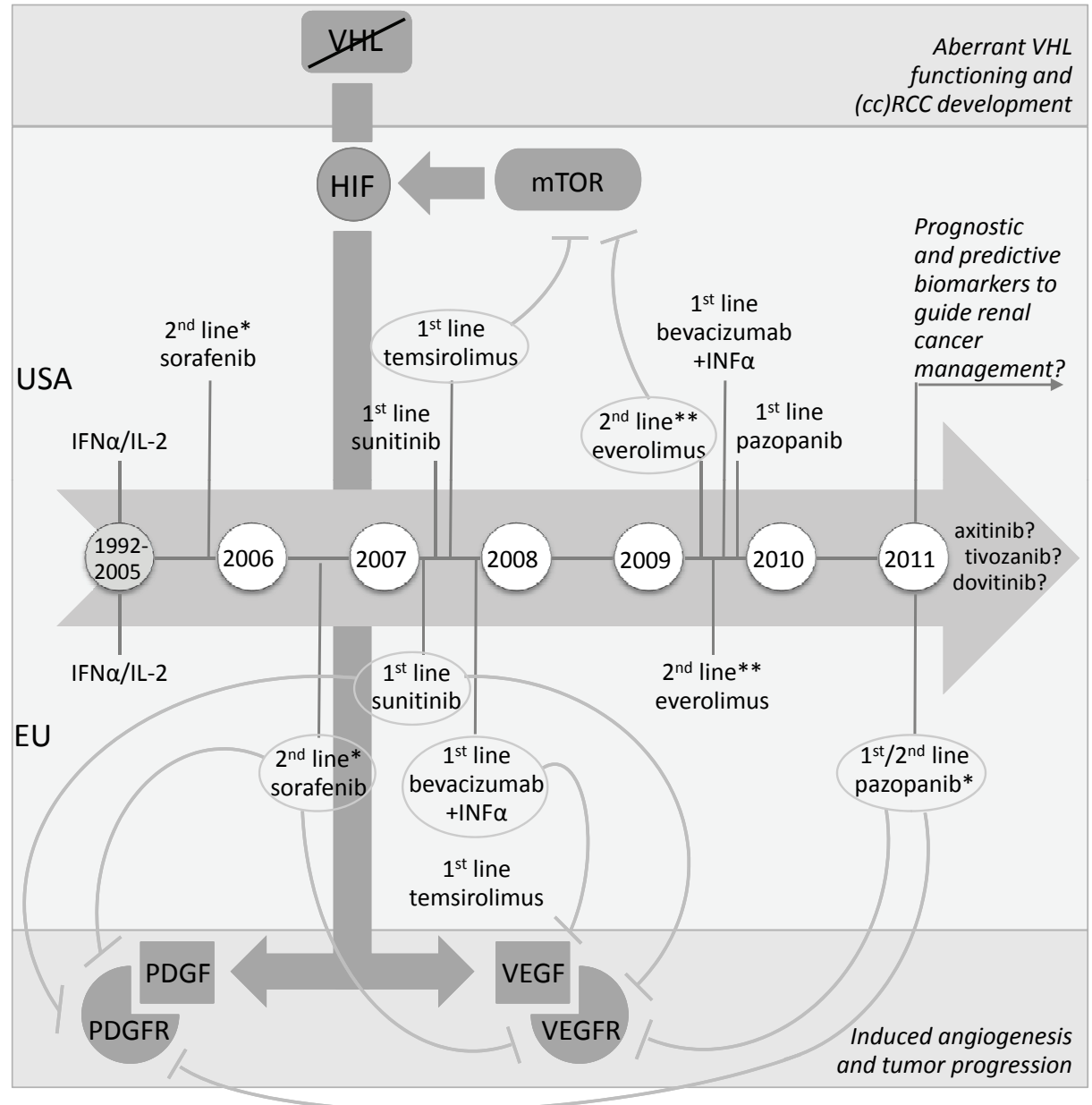

Figure 1. Timeline of targeted therapy registration for $\mathrm{mRCC}$ in the USA and Europe

Chronology of registered molecular-targeted agents in metastatic renal cell carcinoma in the U.S. and Europe is depicted in relation to their targets. VHL functioning is abnormal in most ccRCCs and deregulates the HIF-pathway. Targeted agents have been developed against one or more of the players in this pathway. Since December 2005 and July 2006 targeted therapies have been registered for the treatment of (cc)RCC in the USA and Europe, respectively. Sequence of therapy administration and several other agents are still under investigation. From now it is important to personalize these treatments and development of biomarkers is needed to guide renal cancer management. Prognostic biomarkers should indicate which patients benefit from adjuvant therapy, while predictive biomarkers should indicate from which therapy (and in what dose) an individual patient would benefit, with the lowest toxicity. ${ }^{*} 2^{\text {nd }}$ line therapy after 1 st line IFNa, ${ }^{* *} 2^{\text {nd }}$ line therapy after 1 st line TKI.

Genomic research in RCC has revealed that, in contrast to other tumor types, candidate TSGs are mutated in less than ten per cent of the RCCs with the exception of $V H L^{18}$ and the recently identified SWI/SNF chromatin remodeling complex gene PBRM1, which showed truncating mutations in $41 \%$ of cases ${ }^{19}$. However, a much larger number of candidate TSGs is frequently silenced by cancer-specific promoter hypermethylation $^{20,21}$. The stability and the frequency of aberrant DNA hypermethylation in cancer, the possibility to determine hypermethylation in formalin fixed paraffinembedded (FFPE) tissue, and the simple and low cost tests that are available for as- 
sessing DNA hypermethylation, make these epigenetic marks promising potential biomarkers $^{22}$. Proof of principle for the clinical value of hypermethylation markers in cancer has been reported for early detection and classification of cancer $^{23-33}$, risk assessment and prognosis ${ }^{31,34-36}$ and prediction of therapy response ${ }^{37-39}$, with some already having demonstrated their importance in (pre)clinical practice. Increasing interest in epigenetics and especially in DNA hypermethylation has resulted in rapid technological progress to analyze methylation loci in a high-throughput manner. Moreover, current methods enable unbiased profiling of DNA methylation in a genome-wide scale identifying a so-called methylome. Comprehensively exploring the RCC methylome will be a major step towards a better understanding of how the RCC genome works and provides opportunities to identify and develop clinically relevant biomarkers. In order to personalize treatment protocols for RCC patients, prognostic and predictive methylation markers are urgently needed.

\section{Hypothesis, aim and outline of the thesis}

As the biology of RCC is incompletely understood and biomarkers for RCC are lacking, we decided to address these issues in this thesis. We hypothesized that exploration of the renal cancer methylome will identify methylation marks that are associated with prognosis of RCC patients and can be developed into clinically useful disease markers. Therefore, the aim of this thesis was to comprehensively study the renal cancer methylome, specifically clear cell renal cell carcinoma, the most common type of renal cell cancer, to gain insight into RCC biology and to identify novel prognostic biomarkers.

In chapter 2 we review the current knowledge on RCC, including the epidemiology, clinical presentation, risk factors, classification, prognosis and therapy. We highlight the genetic presentation of the common RCC subtypes and comprehensively describe the current role of epigenetics and the reported hypermethylation of putative TSGs involved in RCC development.

Using a well established method to identify hypermethylated TSGs (expression microarrays on pharmacological demethylated cells $)^{40}$, we identified tumor specific promoter CpG island hypermethylation of Gremlin1 (GREM1). In chapter 3 we describe its prognostic significance in two large series of cCRCC. Investigating methylation of the GREM1 promoter in detail, we discovered that the clinical relevance of methylated CpG dinucleotides is strongly dependent on the location in the promoter CpG island. We show that only hypermethylation of so-called 'core-regions' is correlated with prognosis, while hypermethylation at other regions does not have any clinical impact. This led us to evaluate the general importance of the location of CpG dinucleotide hypermethylation in regulating gene expression and associations with clinicopathological characteristics in cancer (chapter 4). We clarify the misconception and oversimplification of the topic of hypermethylation and gene silencing in cancer. Appreciating the significance of location in methylation-based research, we comprehensively explored the RCC methylome by integrating expression arrays following pharmaceutical demethylation and genome-wide methylation specific next-generation sequencing. Chapter 5 covers the gene discovery and the clinical and biological validation of the identified candidate genes identified by this methodology. In chapter 6 we investigate the simi- 
larities and differences between several cancer methylomes as assessed by the method used in the previous chapter. We hypothesized that the methylome of RCC is distinct from that of extensively studied epithelial cancers such as colorectal or breast cancer. Finally, the general discussion in chapter 7 summarizes and discusses the major findings of the studies performed and builds upon the putative role of methylation markers in RCC and its treatment. 


\section{References}

1. Ferlay, J., et al., Estimates of worldwide burden of cancer in 2008: GLOBOCAN 2008. 2010. p. NA.

2. Yagoda, A., D. Petrylak, and S. Thompson, Cytotoxic chemotherapy for advanced renal cell carcinoma. Urol Clin North Am, 1993. 20(2): p. 303-21.

3. Muss, H.B., et al., Recombinant alfa interferon in renal cell carcinoma: a randomized trial of two routes of administration. J Clin Oncol, 1987. 5(2): p. 286-91.

4. Hanahan, D. and Robert A. Weinberg, Hallmarks of Cancer: The Next Generation. Cell. 144(5): p. 646-674.

5. Gelb, A.B., Renal cell carcinoma: current prognostic factors. Union Internationale Contre le Cancer (UICC) and the American Joint Committee on Cancer (AJCC). Cancer, 1997. 80(5): p. 981-6.

6. Motzer, R.J., et al., Survival and prognostic stratification of 670 patients with advanced renal cell carcinoma. J Clin Oncol, 1999. 17(8): p. 2530-40.

7. Kaelin, W.G., Jr., The von Hippel-Lindau tumor suppressor gene and kidney cancer. Clin Cancer Res, 2004. 10(18 Pt 2): p. 6290S-5S.

8. van Dijk, B.A., et al., Cigarette smoking, von Hippel-Lindau gene mutations and sporadic renal cell carcinoma. Br J Cancer, 2006. 95(3): p. 374-7.

9. Gnarra, J.R., et al., Post-transcriptional regulation of vascular endothelial growth factor mRNA by the product of the VHL tumor suppressor gene. Proc Natl Acad Sci U S A, 1996. 93(20): p. 10589-94.

10. Richards, F.M., Molecular pathology of von HippelLindau disease and the VHL tumour suppressor gene. Expert Rev Mol Med, 2001. 2001: p. 1-27.

11. Banks, R.E., et al., Genetic and epigenetic analysis of von Hippel-Lindau (VHL) gene alterations and relationship with clinical variables in sporadic renal cancer. Cancer Res, 2006. 66(4): p. 2000-11.

12. Herman, J.G., et al., Silencing of the VHL tumor-suppressor gene by DNA methylation in renal carcinoma. Proc Natl Acad Sci U S A, 1994. 91(21): p. 9700-4.

13. Schraml, P., et al., VHL mutations and their correlation with tumour cell proliferation, microvessel density, and patient prognosis in clear cell renal cell carcinoma. J Pathol, 2002. 196(2): p. 186-93.

14. Smits, K.M., et al., Genetic and epigenetic alterations in the von hippel-lindau gene: the influence on renal cancer prognosis. Clin Cancer Res, 2008. 14(3): p. 782-7.

15. Esteller, M. and J.G. Herman, Cancer as an epigenetic disease: DNA methylation and chromatin alterations in human tumours. J Pathol, 2002. 196(1): p. 1-7.

16. Goelz, S.E., et al., Hypomethylation of DNA from benign and malignant human colon neoplasms. Science, 1985. 228(4696): p. 187-90.

17. Wilson, A.S., B.E. Power, and P.L. Molloy, DNA hypomethylation and human diseases. Biochim Biophys Acta, 2007. 1775(1): p. 138-62.

18. Dalgliesh, G.L., et al., Systematic sequencing of renal carcinoma reveals inactivation of histone modifying genes. Nature, 2010. 463(7279): p. 360-3.

19. Varela, I., et al., Exome sequencing identifies frequent mutation of the SWI/SNF complex gene PBRM1 in renal carcinoma. Nature, 2011. 469(7331): p. 539-542.

20. Morris, M.R., et al., Genome-wide methylation analysis identifies epigenetically inactivated candidate tumour suppressor genes in renal cell carcinoma. Oncogene, 2010.

21. Morris, M.R. and E.R. Maher, Epigenetics of renal cell carcinoma: the path towards new diagnostics and therapeutics. Genome Med, 2010. 2(9): p. 59.

22. Laird, P.W., The power and the promise of DNA methylation markers. Nat Rev Cancer, 2003. 3(4): p. 253-66. 
23. Melotte, V., et al., N-Myc downstream-regulated gene 4 (NDRG4): a candidate tumor suppressor gene and potential biomarker for colorectal cancer. J Natl Cancer Inst, 2009. 101(13): p. 916-27.

24. Hellebrekers, D.M., et al., GATA4 and GATA5 are potential tumor suppressors and biomarkers in colorectal cancer. Clin Cancer Res, 2009. 15(12): p. 3990-7.

25. Glockner, S.C., et al., Methylation of TFPI2 in stool DNA: a potential novel biomarker for the detection of colorectal cancer. Cancer Res, 2009. 69(11): p. 4691-9.

26. Kim, M.S., et al., Promoter DNA methylation of oncostatin $\mathrm{m}$ receptor-beta as a novel diagnostic and therapeutic marker in colon cancer. PLoS One, 2009. 4(8): p. e6555.

27. Ebert, M.P., et al., Aristaless-like homeobox-4 gene methylation is a potential marker for colorectal adenocarcinomas. Gastroenterology, 2006. 131(5): p. 1418-30.

28. Lofton-Day, C., et al., DNA methylation biomarkers for blood-based colorectal cancer screening. Clin Chem, 2008. 54(2): p. 414-23.

29. Jeronimo, C., et al., Quantitation of GSTP1 methylation in non-neoplastic prostatic tissue and organ-confined prostate adenocarcinoma. J Natl Cancer Inst, 2001. 93(22): p. 1747-52.

30. An, Q., et al., Detection of $\mathrm{p} 16$ hypermethylation in circulating plasma DNA of non-small cell lung cancer patients. Cancer Lett, 2002. 188(1-2): p. 109-14.

31. Lee, T.L., et al., Detection of gene promoter hypermethylation in the tumor and serum of patients with gastric carcinoma. Clin Cancer Res, 2002. 8(6): p. 1761-6.

32. Wong, I.H., et al., Detection of aberrant p16 methylation in the plasma and serum of liver cancer patients. Cancer Res, 1999. 59(1): p. 71-3.

33. Esteller, M., et al., Detection of aberrant promoter hypermethylation of tumor suppressor genes in serum DNA from non-small cell lung cancer patients. Cancer Res, 1999. 59(1): p. 67-70.

34. Veeck, J., et al., Aberrant methylation of the Wnt antagonist SFRP1 in breast cancer is associated with unfavourable prognosis. Oncogene, 2006. 25(24): p. 3479-88.

35. van Vlodrop, I.J., et al., Prognostic significance of Gremlin1 (GREM1) promoter CpG island hypermethylation in clear cell renal cell carcinoma. Am J Pathol, 2010. 176(2): p. 575-84.

36. Brock, M.V., et al., DNA methylation markers and early recurrence in stage I lung cancer. $\mathrm{N}$ Engl J Med, 2008. 358(11): p. 1118-28.

37. Esteller, M., et al., Inactivation of the DNA-repair gene MGMT and the clinical response of gliomas to alkylating agents. N Engl J Med, 2000. 343(19): p. 1350-4.

38. Hegi, M.E., et al., Clinical trial substantiates the predictive value of O-6-methylguanine-DNA methyltransferase promoter methylation in glioblastoma patients treated with temozolomide. Clin Cancer Res, 2004. 10(6): p. 1871-4.

39. Veeck, J., et al., BRCA1 CpG island hypermethylation predicts sensitivity to poly(adenosine diphosphate)-ribose polymerase inhibitors. J Clin Oncol, 2010. 28(29): p. e563-4; author reply e565-6.

40. Schuebel, K.E., et al., Comparing the DNA hypermethylome with gene mutations in human colorectal cancer. PLoS Genet, 2007. 3(9): p. 1709-23. 


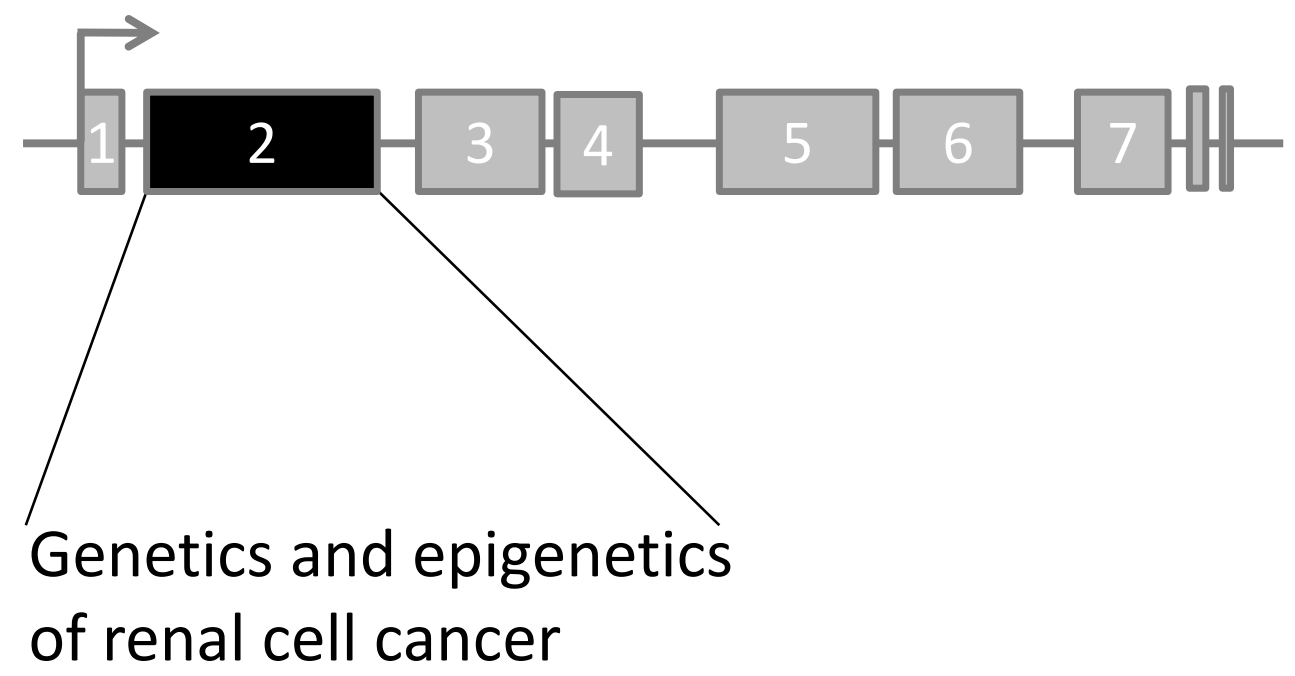

Marcella M.L.L. Baldewijns, Iris J.H. van Vlodrop, Leo J.

Schouten, Patricia M.M.B Soetekouw, Adriaan P. de Bruïne, Manon van Engeland

Biochimica et Biophysica Acta-Reviews on Cancer. 2008;1785(2):133-55 


\begin{abstract}
Renal cell carcinoma (RCC) is not a single disease, but comprises a group of tumors of renal epithelial origin, each with a different histology, displaying a different clinical course and caused by different genetic alterations. Since cure rates are inversely associated with stage and response to the available treatment regimes is limited to a subgroup of patients, diagnostic methods facilitating early detection and new therapeutic modalities are necessary. Increased knowledge of the underlying pathophysiology of RCC has resulted in the identification of genetic alterations involved in renal cell cancer carcinogenesis. Promising agents to target these pathways, especially the angiogenesis pathway, are being developed, some of which are already standard of care. In addition to genetics, knowledge on epigenetics in the process of renal tumorigenesis has been significantly increased in the last decades. Epigenetics will play an increasing role in the development of new therapeutic modalities and may deliver new prognostic and early diagnostic markers.

In this review we discuss the background of RCC and the clinical applications of RCC genetics and epigenetics.
\end{abstract}




\section{Introduction}

\section{Descriptive epidemiology}

In 2002, worldwide about 210,000 cases of kidney cancer have been diagnosed and 102,000 persons died because of kidney cancer ${ }^{1}$. In the European Union and in the United States, kidney cancer is the $9^{\text {th }}$ most common cancer. Incidence and mortality rates are approximately twice as high for men as for women ${ }^{1}$.

Incidence rates for renal cell cancer have been rising steadily each year in Europe and the United States over the past three decades ${ }^{2}$. This increase cannot be explained completely by the observed decrease in mean tumor size, indicating improved detection $^{3}$, since an increasing incidence of late-stage renal cell cancers also has been observed $^{2,4}$. Rates of renal cancer vary internationally more than tenfold, suggesting a strong role for environmental risk factors. Incidence is generally highest in several Western and Eastern European countries and Scandinavia, as well as in parts of Italy, in North America and in Australia/New Zealand. The lowest rates are reported in Asia and Africa ${ }^{1}$.

\section{Risk factors}

Several factors have been investigated in association with the risk of renal cell carcinoma (RCC). Some risk factors, such as cigarette smoking ${ }^{5-8}$, obesity ${ }^{5,6,8,9}$, hypertension and/or use of antihypertensive medication ${ }^{7,10,11}$ were consistently reported to be positively associated with RCC risk, although risk ratios (RRs, see appendix I for explanation) were only moderately increased.

A recent meta-analysis on cigarette smoking in relation to RCC concluded that inhaled tobacco smoke is clearly implicated in the etiology of RCC. Risk was increased for former (RR: $1.21 ; 95 \% \mathrm{Cl}: 1.07-1.36$ ) and current (RR: $1.45 ; 1.26-1.66)$ smokers with a strong dose-dependent increase in risk ${ }^{12}$. Most studies observed increasing risks, not only with the number of cigarettes smoked per day but also with the number of years smoked and decreasing risks with number of years since cessation, as is also shown in a meta-analysis by Hunt et al. ${ }^{12}$.

A positive association between body weight and risk of renal cell cancer has been observed in almost all case-control and cohort studies ${ }^{7}$. In a quantitative review, a cumulative risk per $1 \mathrm{~kg} / \mathrm{m} 2$ increase in $\mathrm{BMI}$ of 1.07 (95\% Cl: 1.05-1.09) was found for men and women ${ }^{13}$. The attributable proportion of RCC for excess body weight is estimated to be 25 percent for both men and women in the European Union ${ }^{14}$.

Hypertension and antihypertensive medication have been found to be risk factors for RCC in many epidemiological studies ${ }^{10,11}$. In a meta-analysis ${ }^{10}$ based on 13 case-control studies a pooled adjusted odds ratio of 1.75 (95\% Cl, 1.61-1.90) was calculated for the association between hypertension and RCC. In another meta-analysis, a pooled odds ratio was calculated for use of diuretics and risk of $\mathrm{RCC}^{11}$. Based on nine case-control studies, an average odds ratio was calculated of $1.55(95 \% \mathrm{Cl}, 1.42-1.71)$. It is unclear, whether the increased risk is caused by hypertension itself, or by the use of antihypertensive medication. Some recent studies showed that diuretic medication is no longer a risk factor after controlling for the diagnosis of hypertension ${ }^{15,16}$, suggesting that not medication but hypertension is a risk factor for RCC. It is also conceivable that hyper- 
tension acts as biomarker for another underlying disease that might be causally associated with RCC.

Furthermore, dialysis patients with acquired cystic disease of the kidney showed a 30 times greater risk than in the general population for developing $\mathrm{RCC}^{17}$. Whether prolonged ingestion of analgesic combinations (phenacetin, aspirin), leading to chronic renal failure, enhances the incidence of RCC remains controversial ${ }^{18-20}$.

Several studies have been conducted investigating whether occupational exposures are associated with RCC risk. Exposure to asbestos, polycyclic aromatic hydrocarbons, gasoline have not been shown to be consistently associated with RCC risk ${ }^{21}$. Interestingly, occupational exposure to trichloroethylene has been shown to be associated with specific mutations in the $V H L$ gene in $\mathrm{RCC}^{22,23}$.

Reports on other factors showed less consistent associations with RCC risk. These factors include alcohol consumption, vegetable and fruit consumption, intake of micronutrients and vitamins $s^{5,6,8,9}$. Most studies on alcohol consumption and RCC risk observe null associations ${ }^{24-30}$ while some more recent studies suggest an inverse association ${ }^{31-}$ ${ }^{34}$, although this effect may be limited to women ${ }^{35}$. In a recent, pooled analysis of 12 prospective cohort studies, intake of alcohol was associated with a decreased risk of renal cell cancer. Compared to non-drinkers, alcohol consumption of $\geq 15$ grams/day was associated with a pooled RR of $0.72(95 \% \mathrm{Cl}: 0.60-0.86)^{36}$.

Finally, patients with certain inherited disorders such as von Hippel-Lindau disease, hereditary papillary renal cancer, a hereditary leiomyoma RCC syndrome and BirtHogg-Dubé syndrome, show an enhanced risk of $\mathrm{RCC}^{37-39}$. These inherited disorders show specific genetic abnormalities (see also the genetic section).

\section{Classification}

The majority of kidney cancers (80-85\%) are RCCs originating from the renal parenchyma. The remaining $15-20 \%$ are mainly transitional cell carcinomas of the renal pelvis. Other less frequent malignant tumors of the kidney are metanephric adenosarcomas, mesenchymal tumors, mixed mesenchymal and epithelial tumors, neuroendocrine tumors, hematopoietic and lymphoid tumors, germ cell tumors and metastatic tumors. Though nephroblastomas (Wilms tumor) are the most common renal tumors of childhood, few cases have been reported in adulthood ${ }^{40-42}$.

RCC is almost exclusively a cancer of adults and is rare in the first two decades of life, comprising only $2 \%$ of pediatric renal tumors.

RCC is not a single entity (see figure 1), but comprises a group of tumors, which arise from the epithelium of renal tubules. Extensive histological and molecular evaluation has resulted in the development of a consensus classification of different RCC subtypes. In 1996, the Heidelberg classification of RCC was proposed, which intends to integrate the understanding of genetic alterations and readily recognizable histological criteria $^{43}$. In this classification, three major histological subtypes of RCC, clear cell (ccRCC), papillary (pRCC) and chromophobe (chrRCC) RCC have been identified in addition to some less frequent subtypes such as multilocular ccRCC, collecting duct carcinomas, medullary carcinomas and unclassified types. The latest WHO classification of 2002 is more comprehensive and includes, in addition to the previous subtypes, renal 
carcinoma associated with neuroblastoma and two recent added subtypes, the Xp11 translocation carcinomas and mucinous tubular and spindle cell carcinoma (Table 1).
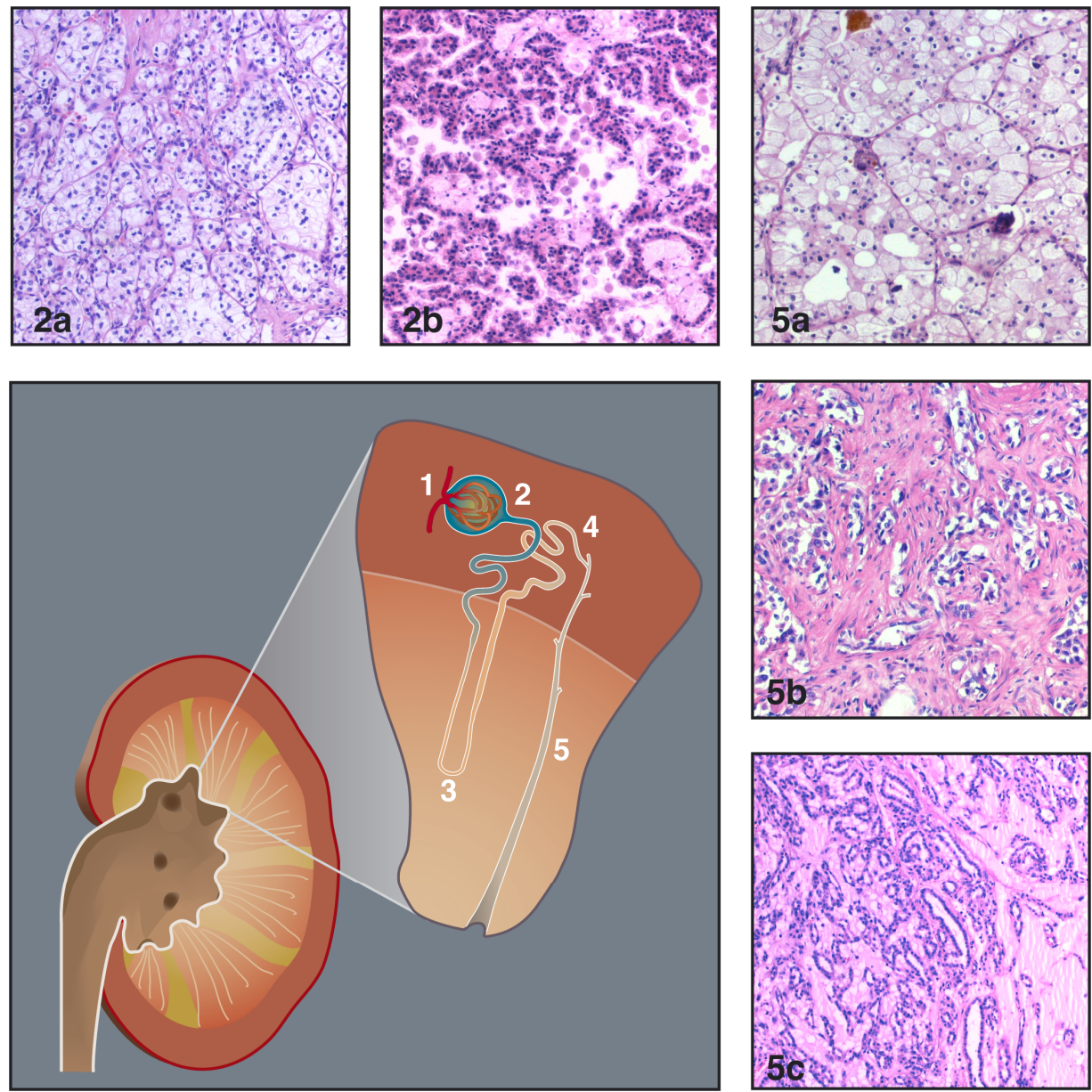

Figure 1. Classification of RCC subtypes: cell of origin

The nephron, consists of the renal corpuscle (1) and renal tubule, which is divided into four histo-physiological zones: proximal convoluted tubule (2), loop of Henle (3), distal convoluted tubule (4) and collecting tubule (5). The different RCC subtypes are thought to originate from different parts of the renal tubular system: mainly the proximal convoluted tubule ( $2 a$ clear cell RCC and $2 b$ papillary RCC) and the collecting tubule (5a chromophobe RCC, $5 b$ collecting duct carcinoma, and $5 \mathrm{c}$ mucinous tubular and spindle cell carcinoma). 
Table 1. Histological subtypes of RCC (WHO classification, 2002)

\begin{tabular}{lllll}
\hline & $\begin{array}{l}\text { Frequency } \\
(\%)\end{array}$ & Age & $\begin{array}{l}\text { Male/female } \\
\text { ratio }\end{array}$ & Ref. \\
\hline Clear cell renal cell carcinoma & 70 & $61^{\text {a }}$ & & 43,251 \\
Papillary renal cell carcinoma & $10-15$ & $61^{\mathrm{a}}$ & $1.8 / 1$ to $3.8 / 1$ & $43,44,57,252$ \\
Chromophobe renal cell carcinoma & 5 & $60^{\mathrm{a}}$ & $1 / 1$ & 43,58 \\
Renal cell carcinoma unclassified & $4-5$ & & & 43,62 \\
Multilocular clear cell carcinoma & $<5$ & $51^{\mathrm{a}}$ & $3 / 1$ & 43,253 \\
Carcinoma of the collecting ducts of Bellini & $<1$ & $55^{\mathrm{a}}$ & $2 / 1$ & 43 \\
Renal medullary carcinoma & $<1$ & $22^{\mathrm{a}}$ & $2 / 1$ & $61,254,255$ \\
Xp11 translocation carcinomas & $<1$ & $15^{\mathrm{b}}$ & $4 / 7$ & 63,64 \\
Carcinoma associated with neuroblastoma & $<1$ & $13.5^{\mathrm{b}}$ & $1 / 1$ & 66 \\
Mucinous tubular and spindle cell carcinoma & $<1$ & $53^{\mathrm{a}}$ & $1 / 4$ & 65 \\
\hline a mean age (years) & & & &
\end{tabular}

Clear cell carcinoma (70\% of all RCCs) and pRCC (10-15\%) account for the majority of RCCs. They are thought to arise from cells in the proximal convoluted renal tubule ${ }^{38,43 \text {, }}$ ${ }^{44}$. Most cases of ccRCC are unilateral and unifocal. Invasion of perirenal and sinusoidal fat and/or extension into the renal vein occurs in about $45 \%$ of $\operatorname{ccRCC}^{45}$. ccRCC most commonly metastasize hematogeneously via the vena cava primarily to the lung, although in $7 \%$ to $17 \%$ lymphatic metastases occur ${ }^{46,47}$. In $5 \%$ of ccRCCs a predominantly cystic growth pattern is seen. These tumors are called multilocular cystic RCCs. This RCC subtype mostly present with low Fuhrman grade and stage at diagnosis and display a favorable outcome, suggesting a tumor with low malignant potential ${ }^{48-53}$. Though no recurrences or metastasis have been reported, additional outcome based research is needed because of the rarity of this subtype and the limited number of patients reported so far in the literature.

pRCC is subclassified in two subtypes depending on the morphology of the tumor cells covering the papillary lesions ${ }^{54}$. Type 1 tumors have papillae covered by a single layer of small cells with scant cytoplasm, whereas in type 2 tumors the papillary cores are covered by pseudostratified epithelium with a larger amount of eosinophilic cytoplasm and often higher nuclear grade. Up to $70 \%$ of pRCCs are intrarenal at diagnosis ${ }^{55,56}$. Type 1 tumors are usually of lower grade and stage than type 2 tumors ${ }^{56,57}$. Bilateral and multifocal tumors are more common in pRCC than in the other malignant subtypes. The chromophobe variant of RCC accounts for 5 percent of all cases of RCC and is thought to originate from type $B$ intercalated cells of renal collecting ducts ${ }^{44,58}$. Only $10 \%$ of chrRCC show extension through the renal capsule into the surrounding adipose tissue and in only $4 \%$ there is involvement of the renal vein ${ }^{58}$. Collecting duct (Bellini duct) carcinomas are thought to arise from the collecting ducts within the renal medul$\mathrm{la}^{44,59}$. These tumors may present at any age, although they tend to occur in younger patients than the former subtypes. These tumors are very aggressive, one third exhibiting metastases at the time of presentation. Approximately two-thirds of patients die of this disease within two years of diagnosis ${ }^{60}$. A variant of the collecting duct carcino$\mathrm{ma}$ is the so-called medullary carcinoma ${ }^{61}$, which develops preferentially in young patients with sickle trait. These tumors are now widely regarded as a more aggressive variant of collecting duct carcinoma, with a mean survival time after surgery of 15 weeks $^{60}$. The unclassified RCCs are a diagnostic category of renal tumors which do not fit into one of the other subtypes. In surgical series, this group often amounts to $4-5 \%$ of all cases ${ }^{43,44}$. Many of the tumors from this category are high cytomorphologic 
grade and show aggressive clinical behavior ${ }^{62}$. Translocation-associated RCC affect predominantly children and young adults and present at advanced stage ${ }^{63,64}$. Mucinous tubular and spindle cell carcinoma is recently identified as a novel entity of lowgrade renal epithelial neoplasm, characterized by an indolent course and, in contrast with the other subtypes, female predominance. Its immunohistochemical and ultrastructural features are consistent with distal nephron origin ${ }^{65}$. Finally, RCC associated with neuroblastoma occurs in long-term survivors of childhood neuroblastoma, by which males and females are equally affected. These RCCs are morphologically heterogeneous and prognosis correlates with tumor grade and stage ${ }^{66}$.

Most cases of RCC occur sporadically. An inherited predisposition to renal cancer accounts for only $1-4 \%$ of all cases ${ }^{38}$. Inherited renal neoplasms are more likely to be diagnosed at an younger age and are more likely to be multifocal and bilateral.

\section{Prognosis}

A gradual improvement in prognosis has been observed over time, with 5 -year relative survival rates for RCC as high as $64 \%$ in 2002 , compared with less than $40 \%$ in the early $1960 s^{67}$. The clinical behavior of RCC results from complex interactions between multiple prognostic factors. Currently, patient performance status, tumor stage and grade are the most useful, clinical available predictors of patient outcome ${ }^{68-70}$. The performance status is measured using the Eastern Cooperative Oncology Group (ECOG) assessment scale. This scoring system stratifies patients on the basis of ambulatory status, in order to denote the impact of disease on the overall health of the patient ${ }^{71}$.

Currently, the most commonly used staging system is the International Union Against Cancer (IUAC) and the American Joint Committee on Cancer (AJCC) tumor-nodemetastases (TNM) staging system. The 2002 modification of this system (sixth edition) has recently been confirmed to have a better prognostic ability than the previous 1997 staging system ${ }^{72}$. Using the 2002 staging system, the 5-year cancer specific survival rates ranged from $97 \%$ for $\mathrm{pT} 1 \mathrm{~A}$ to $20 \%$ for pT4. Presence of lymph node metastases predicts a poor prognosis, with cancer-specific survival rates of $5-30 \%$ and $0-5 \%$ at 5 and 10 years, respectively ${ }^{73}$. Metastases to other organs (lung, brain, bone) are associated with survival rates of $50 \%, 5-30 \%$ and $0-5 \%$ at 1,5 and 10 years respectively. Grading is based on the Fuhrman system, which consists of four grades, based on the nuclear size, contour and conspicuousness of nucleoli ${ }^{74}$.

Kim et al. examined a cohort of 1,046 patients with localized and metastatic RCC and identified hypoalbuminemia, weight loss, anorexia and malaise as independent predictors of poor prognosis ${ }^{75}$. The presence of thrombocytosis (platelet count > $400,000 / \mathrm{mm}^{3}$ ) has been shown to be an independent predictor of poor outcome in patients with metastatic RCC treated with nephrectomy and adjuvant therapy ${ }^{76}$. Whether different histologic RCC subtypes have different clinical behavior and outcome remains a topic of discussion. Some reports demonstrated worse outcome for cCRCC compared with pRCC and chrRCC $^{77,78}$. However, in multivariate analyses, TNM stage, Fuhrman grade and ECOG, but not histology, were retained as independent prognostic variables ${ }^{69}$. Tumor necrosis was found to be a strong independent predictor of poor outcome for clear cell but not for chromophobe or papillary $\mathrm{RCC}^{79,80}$. Micro- 
vascular invasion and presence of sarcomatoid features are reported negative prognostic indicators ${ }^{81,82}$.

Since multiple factors affect prognosis, many centers have aimed to integrate independent prognostic indicators into comprehensive outcome models for both nonmetastatic and metastatic RCC to assist clinicians in patient counseling, management decisions and also for clinical trial comparisons ${ }^{80,83-94}$. The most widely accepted prognostic system is the Memorial Sloan Kettering system for clinical trial assessment and treatment assignment. This model was based on a study of 670 patients with advanced RCC treated in 24 separate clinical trials at Memorial Sloan-Kettering Cancer Center (MSKCC; New York, NY) between 1975 and $1996^{92}$. Initially, five prognostic variables associated with poor survival: low performance status (Karnofsky $<80 \%$ ), high serum lactate dehydrogenase ( $>1.5$ times the upper limit of normal), low hemoglobin (less than the lower limit of normal), high corrected serum calcium ( $>10 \mathrm{mg} / \mathrm{dL}$ ), and absence of prior nephrectomy were identified using uni- and multivariate analysis. The number of risk factors present is used to stratify patients into favorable- (zero risk factors), intermediate- (one or two risk factors), and poor-risk groups (three or more risk factors). In a subsequent analysis of 463 interferon alfa (IFN $\alpha$ ) treated patients, the MSKCC model remained the same, except time from diagnosis to treatment with IFN $\alpha$ of less than 1 year was found to be a better predictor of short survival compared with absence or prior nephrectomy ${ }^{91}$. This MSKCC-model is nowadays used in counseling and stratification of patients in phase III trials.

Recent identification and incorporation of molecular markers into current staging systems may result in better prognostic tools. By measuring protein expression or gene copy number, several molecular factors have been identified as independent risk factors for developing RCC, including B7-H1, Smac/DIABLO, survivin, PTEN, p27 and VEGF ${ }^{95-99}$. Other reported prognostic indicators are HIF-1 $\alpha$, CAIX, Ki 67, gelsolin, vimentin, p53 and EphrinA $2^{100-102}$. Until now, there have been no molecular markers for RCC that meet the College of American Pathologists criteria for a marker to be used generally in patient management or even to have been studied sufficiently biologically to provide for any degree of acceptance ${ }^{103}$.

\section{Therapy}

Current treatments of patients with RCC can be divided in local therapy and systemic therapy.

\section{Local therapy}

For patients with localized tumors larger than four centimeters in diameter regardless of histological subtype, radical nephrectomy is currently the therapy of choice ${ }^{104}$. Partial nephrectomy has gained acceptance for treating tumors smaller than four centimeter in diameter or indications such as solitary kidney, bilateral renal tumor localization, renal insufficiency as well as the presence of hypertension, diabetes or hereditary renal cell carcinoma syndromes ${ }^{104}$.

In $20-25 \%$ of patients, metastases are present at the time of diagnosis of the disease. Based on the results of two randomized studies, showing a survival advantage of $3^{105}$ to 10 months ${ }^{106}$ nephrectomy as cytoreductive treatment before embarking on sys- 
temic therapy with cytokines has been accepted as standard care. However, since high dose interleukin-2 (IL-2) can be effective in patients with high metastatic burden and a relatively small primary tumor, some reports suggest that nephrectomy should not be offered in this specific group of patients ${ }^{107}$. In patients who will be treated with targeted therapy, the role of cytoreductive surgery is not yet known and needs to be reassessed.

The response rate of RCC to radiotherapy is $50 \%$ and it may be useful as palliative therapy in patients who are not eligible for surgery or in case of bone or central nervous system metastases ${ }^{108}$.

\section{Systemic therapy}

Hormonal and chemotherapy are not standard treatment in RCC because response rates of these agents are low $^{109}$. Drug resistance may be related to the expression of the multidrug resistance transporter in the proximal tubule cells, from which ccRCC and pRCC originate ${ }^{110,111}$. For more than 20 years, immunotherapy has been the leading treatment for metastatic RCC. Prolonged stabilization of disease in the absence of systemic therapy and rare spontaneous regressions suggest that host immune mechanisms play a role in tumor growth regulation ${ }^{112}$. Therefore, RCC became attractive to test immunologic interventions, e.g. IL-2, IFN $\alpha$, stem cell transfusions from HLAcompatible siblings following immunoablative chemotherapy ${ }^{113}$ and tumor vaccines ${ }^{114}$. Approximately 5 to $15 \%$ of cases of metastatic ccRCC respond to IFN $\alpha$, however most of these responses are partial or of short duration ${ }^{115}$, 116 . Treatment with IL-2, the current Food and Drug Administration (FDA)-approved agent for patients with advanced renal carcinoma is associated with a complete response in $10 \%$ and partial response in $11 \%$ of patients ${ }^{61}$. Given the toxicity, expense and variable response to IL-2 among patients with metastatic RCC, several clinical, histological and molecular response predictors have been evaluated ${ }^{107,}{ }^{117}$. Cytokine based therapy currently remains an option for patients with metastatic ccRCC and good prognosis according to MSKCC-risk classification $^{118}$.

Targeted agents, such as Sunitinib, Sorafenib and Temsirolimus have shown efficacy in phase III trials, and were recently approved by the US FDA for treatment of metastatic RCC and are currently included in clinical practice.

Sunitinib (SU11248) is a multi-targeted tyrosine kinase inhibitor (TKI) inhibiting the receptor tyrosine kinases VEGFR2, PDGFR, FMS-like tyrosine kinase 3 (FLT-3) and C-KIT. Sunitinib was the first therapy to demonstrate superiority over standard cytokine therapy (IFN $\alpha$ ) as first line treatment in 750 patients with mainly good and intermediate prognosis according to MSKCC-risk classification ${ }^{119}$.

Another oral multi-targeted TKI is Sorafenib (BAY 43-9006) which inhibits the nonreceptor serine threonine kinases $B R A F$ and $C R A F$ and the receptor tyrosine kinases VEGFR2, VEGFR3, FLT-3, c-KIT and PDGFR. Sorafenib showed clinical benefit as compared to placebo in patients with intermediate risk or low risk status according to MSKCC-prognostic score120.

Temsirolimus is an inhibitor of the non-receptor tyrosine kinase mTOR which revealed activity against metastatic RCC with MSKCC-poor risk characteristics ${ }^{121}$.

An additional drug in the near future may be Bevacizumab, a monoclonal antibody directed against VEGF. Compared to placebo this drug improved progression free sur- 
vival ${ }^{122}$. Results of two randomized trials comparing a combination of IFN $\alpha$ with Bevacizumab with IFN $\alpha$ monotherapy or with a placebo are underway.

\section{Genetics of RCC}

During the past two decades, genetic and clinical studies have shown that RCCs are not only heterogeneous in their histology and clinical behavior, but also in their genetic alterations. The identification of families with distinct histological subtypes of RCC has permitted a better understanding of the molecular mechanism of carcinogenesis of the different subtypes, and for each subtype one or more important mutations have been described.

Clear cell, papillary, and chromophobe RCC cover the majority of all renal cancers and are mostly investigated, therefore (genetic) knowledge of the other subtypes, with a very low prevalence, is limited. The genetics of the three most common subtypes will be discussed in this review.

\section{Clear cell renal cell carcinoma - von Hippel-Lindau (VHL) tumor suppressor gene}

The most and probably best studied adult renal neoplasm is CCRCC, and particularly the inherited form, related to the von Hippel-Lindau (VHL) syndrome. RCC in the heritable $V H L$-syndrome is uniformly of the clear cell subtype ${ }^{123,124}$. In 1988 the $V H L$ gene was mapped to the short arm of chromosome 3 by linkage analysis ${ }^{125}$ and in 1993 the gene was identified as a result of positional cloning strategies performed in $\mathrm{VHL}$ kindreds ${ }^{126}$. Heritable ccRCC is caused by a germline mutation of one allele $(80 \%$ is inherited of one of the parents and $20 \%$ is a 'de novo' mutation) and an acquired mutation of the second allele. Germline $V H L$ mutations are identified in nearly $100 \%$ of $V H L$-families ${ }^{127}$. The $V H L$ gene has been found to have characteristics of a tumor suppressor gene (TSG), in which >150 different germline mutations linked to VHL disease have been identified since $1993^{123,124,128,129}$. VHL mutations are extremely heterogeneous and are distributed throughout the coding sequence, except that mutations are rarely observed within the first 50 codons $^{124,130}$.

In the majority (50\%-75\%) $)^{130-132}$ of sporadic ccRCCs, VHL inactivation of both alleles have been observed ${ }^{133}$, whereby loss of heterozygosity (LOH) of a VHL allele is detected in almost all $(90 \%)$ sporadic clear cell tumors ${ }^{134}$. Inactivation can be a result of somatic mutations, deletions, $\mathrm{LOH}$ or epigenetic inactivation such as promoter DNA methylation (see also the epigenetic section). Although mutations in the $\mathrm{VHL}$ gene are mostly restricted to $\mathrm{CCRCC}^{135}$, van Houwelingen et al. reported mutations in the other sporadic RCC subtypes, although in much smaller proportions ${ }^{130}$.

Heritable and sporadic ccRCC often show two inactivated or silenced VHL alleles, which indicates that the loss of function of the VHL gene is an important event in the pathogenesis of $\mathrm{CCRCC}^{132}$.

The VHL protein ( $\mathrm{pVHL}$ ) is the product of the VHL gene. Cultured cells produce two proteins, a protein consisting of 213 amino acid residues with a molecular weight of 30 $\mathrm{kDa}\left(\mathrm{pVHL}_{30}\right)$ and a variant which corresponds to $\mathrm{pVHL}$ residues $54-213$ of $\mathrm{pVHL}_{30}$. The 
latter migrates with a molecular weight of $18 / 19 \mathrm{kDa}\left(\mathrm{pVHL}_{18 / 19}\right)$ and is most likely generated by internal transcription initiation from the second methionine start site within the $V H L$ open reading frame (Met-54) $)^{136-138}$.

Insights into the function of $\mathrm{pVHL}$ have come from studying the effects of reintroducing the wildtype $V H L$ gene into cultures of cells which lack functional $p V H L^{129,135,139}$. In these experiments, several aspects of cellular behavior, related to tumor suppressor function, like growth inhibiting, cell cycle arrest, and increased susceptibility to apoptosis, were restored upon reintroduction of the wildtype $V H L$ gene ${ }^{129,135}$.

Probably the best known alteration in $V H L$ defective cells is the failure to (poly)ubiquitinate and degrade hypoxia inducible factor $\alpha$ (HIF- $\alpha$ ) in the presence of oxygen. HIF- $1 \alpha$ and HIF- $2 \alpha$, which are unstable but continuously transcribed and translated, are key mediators in the complex cellular and systemic oxygen adaptation cascade triggered by hypoxia ${ }^{140}$. Under normoxic conditions, HIF- $\alpha$ subunits become hydroxylated, enabling binding and ubiquitination by pVHL. Under hypoxic conditions, HIF- $\alpha$ subunits remain non-hydroxylated and are able to complex with stable $\beta$ subunits. HIF $\alpha-\beta$ heterodimers bind DNA at hypoxia responsive elements (HREs) and transcriptionally activate genes involved in acute and chronic adaptation to hypoxia, normally inhibited by $\mathrm{pVHL}^{140,141}$. The proteins regulated by hypoxia-inducible genes are involved in angiogenesis (vascular endothelial growth factor (VEGF)), cell growth (transforming growth factor $\alpha$ (TGF- $\alpha$ ) and platelet derived growth factor (PDGF)), glucose uptake (glucose transporter GLUT-1), and acid-base balance (carbonic anhydrase IX (CAIX)). Thus, like in hypoxic conditions, absence of (functional) pVHL leads to accumulation of HIF- $\alpha$ subunits, forming heterodimers with HIF- $\beta$, resulting in overexpression of the above mentioned proteins, which creates a microenvironment favorable for tumor proliferation ${ }^{135,140}$. In addition, the above mentioned proteins act on the neighboring vasculature to promote tumor angiogenesis ${ }^{135}$.

Both $V H L$ gene products, $\mathrm{pVHL}_{30}$ and $\mathrm{pVHL}_{18 / 19}$, can inhibit the production of the hypoxia-inducible proteins when reintroduced into renal carcinoma cells that lack the wild-type $V H L$ allele. Therefore, mutations $5^{\prime}$ of codon 54 may not lead to a functionally inactive protein, however mutations in the first 50 codons are rarely observed ${ }^{130}$. It has been observed early that RCCs are highly angiogenic tumors with aberrant expression of HIF proteins, however, Maxwell et al. were the first to report (1999) the relationship between $V H L$ disease and HIF- $\alpha$ in $\mathrm{RCC}^{142}$. They reported that cells lacking pVHL are unable to degrade HIF- $\alpha$ under both normoxic and hypoxic conditions, thus cells deficient in pVHL behave as being hypoxic (pseudohypoxia), even in normoxic conditions, due to continuous HIF- $\alpha$ activation ${ }^{131,135,142}$.

Although the HIF- $\alpha$ accumulation is important for pathogenesis or progression, it is not per se sufficient to induce tumorigenesis of ccRCC. In VHL disease only a subgroup of VHL mutation carriers develops RCC. ${ }^{135,}{ }^{143}$ In addition, in approximately $25 \%-50 \%$ of sporadic ccRCC no alteration in the $V H L$ gene was detected ${ }^{130-132}$. This suggests involvement of other genes that may also predispose to tumorigenesis of ccRCC, possibly affecting the same signaling pathway as $V H L$, or other mechanisms to inactivate $V H L$. 


\section{Papillary renal cell carcinoma - MET proto-oncogene}

The second most prevalent kidney cancer is pRCC, which was first reported by Zbar et al in $1994^{144}$, who observed kidney cancer in a family setting, which differed in several aspects from familial ccRCC. All tumors displayed a papillary histology without evidence of $V H L$ mutations. A novel inherited form of kidney cancer was detected, namely hereditary papillary renal cell carcinoma ${ }^{144,145}$. Genetic studies in kindreds of familial pRCC led to the identification of the MET proto-oncogene gene, located on the long arm of chromosome $7^{146}$. Patients with (germline) mutations in the MET gene develop so-called pRCC type 1 tumors. Activating (gain of function) germline mutations in the tyrosine kinase domain of MET were found in familial pRCC patients ${ }^{132,147}$. MET encodes a transmembrane receptor tyrosine kinase with hepatocyte growth factor (HGF) as its ligand ${ }^{128,145}$. Activation of MET by HGF activates the tyrosine kinase activity, which initiates several signal transduction cascades, resulting in multiple cellular processes like mitogenesis and migration ${ }^{145}$.

Only a small percentage $(\sim 5 \%)^{146,147}$ of sporadic PRCC cases have MET mutations ${ }^{132,146 \text {, }}$ 147 . Cytogenetically, trisomy of chromosome 7 is observed in $\sim 75 \%$ of the sporadic papillary cases ${ }^{135}$. Since this chromosome is harboring the MET gene, the gene dose is increased. Pathogenesis of pRCC is different in the heritable and sporadic form, and as in $\mathrm{CCRCC}$ there may be a role for other genes in the tumorigenesis.

\section{Papillary renal cell carcinoma - fumarate hydratase (FH) tumor suppressor gene}

In addition to the MET gene, a second gene involved in $\mathrm{pRCC}$ has been identified; the fumarate hydratase $(F H)$ gene, located on chromosome 1q42.3-43. This gene encodes $\mathrm{FH}$, an enzyme part of the tricarboxylic acid (Krebs) cycle, catalyzing the conversion of fumarate to malate. Little is known on the etiology and pathogenesis of these cancers: the gene is thought to act as a tumor suppressor gene ${ }^{123,148}$ as loss of the wildtype allele is found frequently in pRCC. Tomlinson et al. evaluated seven familial pRCCs of which five showed allelic loss, one family had a 2-bp deletion and one family carried a missense mutation $^{149}$.

In patients with (germline) $\mathrm{FH}$ mutations, papillary tumors are of type 2. Tumors of affected families have reduced or undetectable $\mathrm{FH}$ activity, and show an angiogenic phenotype $^{149}$. These renal tumors overexpress HIF proteins as well as products of the HIF-regulated target genes (like VEGF and GLUT1). Isaacs et al. reported that excess intracellular fumarate, due to loss of FH, upregulates VEGF and GLUT1 transcripts in a HIF-dependent manner ${ }^{150}$. They further demonstrated a link between fumarate dysregulation and impaired HIF hydroxylation, due to inhibited HIF prolyl hydroxylase (HPH) activity by fumarate. Because VHL recognition of HIF requires hydroxylation by HPH, which is impaired in $\mathrm{FH}$ mutation-bearing tumors, HIF proteins accumulate and contribute to the development of these renal tumors ${ }^{150}$. Pollard et al. confirmed this pseudohypoxia phenomenon in a Fh1 "knock-out" mouse model showing induction of hypoxia pathway components, resulting from HIF protein overexpression, as a direct consequence of Fh1 inactivation ${ }^{151}$.

It is clear that $F H$ germline mutations are associated with the development of pRCC, but the role of $F H$ alterations in sporadic kidney cancer remains to be determined since 
there is no conclusive evidence that somatic mutations of $F H$ have a significant role in sporadic kidney cancers ${ }^{148}$.

\section{Chromophobe renal cell carcinoma - Birt-Hogg-Dubé (BHD) tumor suppressor gene}

Birt-Hogg-Dubé (BHD) is a hereditary cancer syndrome characterized by kidney tumors in $15-25 \%$ of the affected patients ${ }^{152}$. BHD syndrome was first characterized in $1977,{ }^{153}$ but renal manifestations were not described as part of $B H D$ until Roth et al ${ }^{154}$ suggested an association in 1993. In 1999, Toro et al ${ }^{155}$ denominated $B H D$ as a novel marker of kidney neoplasia. The predominant pathology of $B H D$-related kidney tumors is chromophobe ${ }^{145}$.

The $B H D$ gene, or $F L C N$, is located on the short arm of chromosome 17. In approximately $80 \%$ of $B H D$ kindreds, a germline mutation is found. The gene contains a hotspot for germline mutations in a mononucleotide tract of eight cytosines at exon 11 and approximately all these mutations result in truncated $B H D$ protein, folliculin ${ }^{145,}{ }^{152}$. Folliculin is suggested to have a tumor suppressor function, since germline mutations combined with somatic mutations or $\mathrm{LOH}$ resulted in truncation mutants of the folliculin protein. In addition, low to undetectable levels of $B H D$ mRNA were found by Warren et al in kidney tumors from $B H D$ patients, suggesting a classical TSG ${ }^{156}$.

The identification of candidate genes involved in familial kidney cancers may provide insight into sporadic kidney cancers. Examination of the possible role of the $B H D$ gene in sporadic chrRCC confirmed alteration of chromosome 17, but mutations in the $B H D$ gene could not be detected ${ }^{157,158}$. Recently Gad et al. published the (first) report of four different somatic BHD mutations in two (out of $46 \mathrm{chrRCC}$ ) sporadic chrRCC ${ }^{159}$. Interestingly, no exon 11 hotspot mutations as reported in $B H D$ patients have been observed, indicating difference in tumorigenesis in the familial and sporadic form, as in pRCC.

A lack (or low incidence) of somatic mutations in the $B H D$ gene suggests that the folliculin pathway may contain other causative genes in sporadic chrRCC, or other mechanisms of inactivation may be involved.

Renal cell carcinoma in tuberous sclerosis - Tuberous sclerosis complex 1 (TSC1) and 2 (TSC2) tumor suppressor genes

Tuberous sclerosis complex (TSC) patients have an increased risk for development of malignant $\mathrm{RCC}^{160,161}$. In contrast to the other genetic syndromes, renal carcinomas in TSC constitute a heterogeneous group, including ccRCC, pRCC, and $\mathrm{chrRCC}^{162}$.

TSC has been linked to the germline inactivating mutations of either of two tumor suppressor genes TSC1 (9q34), encoding hamartin or TSC2 (16p13.3), encoding tuberin. TSC2 forms a complex with TSC1 which functions to integrate growth factor, nutrient, and energy depletion signals with the energy requiring protein translation apparatus through the regulation of the mTOR (mammalian target of rapamycin) protein ${ }^{160,161}$ The TSC1/TSC2 protein complex inhibits $\mathrm{mTOR}$ and is involved in signaling pathways that regulate cell growth ${ }^{162}$. 
Only small numbers of TSC patients with RCC have been studied because of the very low prevalence ${ }^{163-165}$. However, rodent models (the Eker rat/knockout mice) show evidence for a role of the TSC1 and TSC2 orthologues in RCC ${ }^{166,167}$.

A report concerning TSC mutations in sporadic RCC did not support a role for TSC inactivation in sporadic tumorigenesis ${ }^{168}$.

Interestingly, Liu et al. reported that loss of Tsc-2 tumor suppressor gene, in Eker rats which retain wild-type $\mathrm{Vhl}$, up-regulates VEGF via a HIF2 $\alpha$-mediated mechanism. In contrast to human RCC, the Tsc-2 tumor suppressor gene is the primary target for RCC in rodents. They suggest that loss of TsC-2 and VHL tumor suppressor gene function have similar consequences in Eker rats and humans respectively. This marks the HIFregulated pathway to be important for the development of RCC in different species and in tumors with different molecular etiologies ${ }^{169}$.

\section{Clinical applications}

A growing understanding of the underlying molecular biology of RCC has established new potential therapies. The most significant progress has been made in the area of agents targeting the angiogenesis pathway.

It has been suggested that the resistance of RCC to chemo- and radiotherapy might be partly due to increased levels of the transcription factor nuclear factor KB (NFKB) ${ }^{170,171}$. Loss of VHL leads, through HIF- $\alpha$ dependent and HIF- $\alpha$ independent pathways, to increased NFKB activity and resistance to apoptosis ${ }^{172-175}$. These findings support the idea that drugs targeting HIF or HIF-responsive gene products should be effective in the treatment of renal carcinomas. A number of drugs have been identified that indirectly down-regulate HIF- $\alpha$, including drugs that inhibit $\mathrm{mTOR}^{176}, \mathrm{HSP}^{177}$ and histone deacetylases $^{178}$. mTOR is a downstream component in the PI3K/Akt pathway and has been identified as an upstream activator of HIF, enhancing translation of the HIF mRNA and preventing degradation ${ }^{179,180}$. Overexpressed wild-type histone deacetylase 1 downregulates expression of TP53 and VHL tumor suppressor genes and stimulates angiogenesis $^{178}$. HSP90 stabilizes HIF-1 $\alpha$, EGFR and c-MET ${ }^{181}$.

Other VEGFR targeted tyrosine kinase inhibitors (Pazopanib, AG013736, VEGF-trap) and mTOR inhibitor (RAD001) are still under study in RCC $^{182-184}$. Through combining agents that target different points in the VHL-hypoxia-inducible gene pathway the activity of the targeted approach to RCC therapy may be enhanced ${ }^{185}$.

In addition, a number of approaches are under study to block the signal transduction pathway in c-Met associated tumors ${ }^{186,187}$. Small molecules inhibiting C-MET (PHA665752 , SU11274) have been shown to inhibit proliferation and growth of c-METoverexpressing cell lines in mouse xenograft models ${ }^{188,189}$.

Further gene expression profiling of tumor specimens will help to identify new candidate genes or patterns of gene expression that can predict response to new and preexisting therapies, leading to an appropriate patient selection for certain therapies.

Combinations of FDA-approved and other targeted therapies may overcome resistance that develops with single-agent therapy. Also combinations of targeted agents and cytokine therapy are under investigation. Phase I and II trials evaluating the safety and efficacy of these combinations are underway. 


\section{Epigenetics of RCC}

Recently, it has become clear that gene function can be altered by epigenetic alterations. Epigenetics refers to mechanisms that initiate and maintain heritable (reversible) changes of gene expression and gene function in an inheritable manner without changing the sequence of the genome ${ }^{190,191}$. Epigenetic regulation of gene expression is organized at the level of DNA (postreplicative DNA methylation), RNA (RNA interference (RNAi)), and protein (posttranslational histone modifications and polycomb group $(\mathrm{PcG})$ protein complexes, the latter mediate long-term transcriptional silencing $)^{190-193}$.

DNA methylation is the most widely investigated epigenetic hallmark involving a postreplicative covalent DNA modification, whereby a methyl group is added to the cytosine ring by DNA methyltransferases (DNMTs) to form methyl-cytosine. In mammalian cells, DNA methylation occurs at so-called CpG dinucleotides, cytosines preceding a guanine $^{194}$. CpG dinucleotides are not uniformly distributed throughout the human genome, the prevalence is low, except in CpG-rich regions called CpG islands, which span the $5^{\prime}$ end region (promoter, untranslated region, exon 1) of approximately half of all genes, and within repeat sequences and transposable elements ${ }^{195}$. Methylation of cytosines enables the formation of a complex of proteins, including methyl cytosinebinding proteins (MBDs), DNMTs, histone deacetylases (HDACs), and histone methyl transferases (HMTs) (see figure 2) to mediate the transcriptional repressive activities of DNA methylation ${ }^{191,194,196-198 .}$.

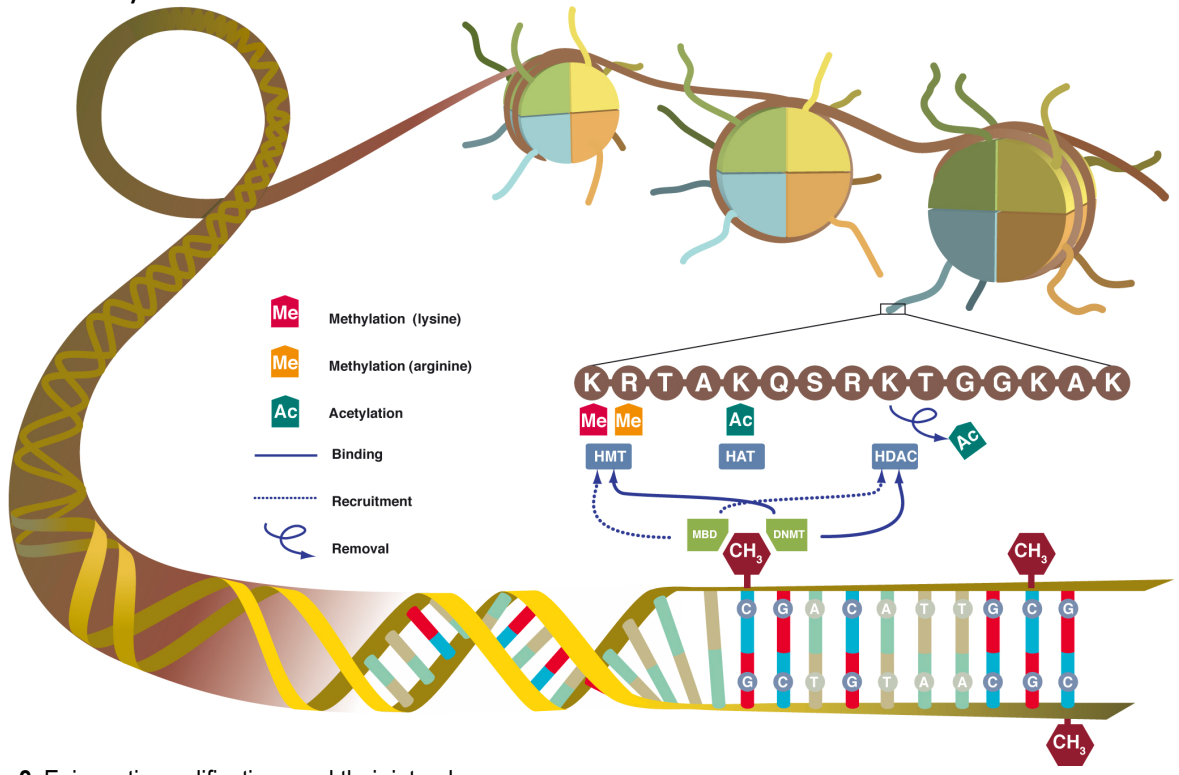

Figure 2. Epigenetic modifications and their interplay

The two main epigenetic hallmarks are postreplicative DNA methylation and posttranslational histone modifications, which both play a role in gene silencing and interact to repress gene transcription. (Additional histone modifications are known but not depicted here; histone methylation and acetylation are the most understood.)

DNA methylation is catalyzed by DNA methyltransferases (DNMTs) and characterized by the addition of a methyl group $\left(\mathrm{CH}_{3}\right)$ to a cytosine preceding a guanine $(\mathrm{CpG})$. Histone (de)acetylation results from an imbalance between histone deacetylases (HDACs) and histone acetyltransferases (HATs), whereby deacetylation is associated with gene repression. HDACs and histone methyltransferases (HMTs) are recruited by methyl-binding proteins (MBPs), which bind methylated CpGs, or are directly bound to DNMTs to epigenetically modify histone tail residues and regulate gene expression. 
DNA methylation is linked to aberrant patterns of post-translational histone modifications $^{197,199}$, including acetylation, methylation, phosphorylation, ubiquitination, and sumoylation $^{190,191,197}$. These modifications occur primarily at specific positions within the $\mathrm{N}$-terminal histone tails ${ }^{200}$. Specific combinations of histone modifications confer to the overall expression status of a certain chromatin region, which is known as the "histone code' hypothesis ${ }^{197}$. Modifications on histones are dynamic and rapidly changing, depending on the signaling conditions within the cell ${ }^{200}$.

The vast majority of all modifications remain poorly understood, although considerable progress in the understanding of histone (de)acetylation and (de)methylation has been made recently. An imbalance between histone deacetylases (HDACs) and histone acetyltransferases (HATs) results in (de)acetylation of histone lysine residues, whereby deacetylation is associated with gene repression. In addition, histone lysine methylation (mono-, di-, and trimethyl lysine) and arginine methylation (mono-, and (a)symmetrical dimethyl arginine) are catalyzed by histone methyltransferases (HMTs). Unlike histone acetylation, histone methylation has long been considered as a permanent modification. However, recent discovery of more than ten (potential) histone demethylases, mediating the reversal of methylation at specific histone residues, has been documented ${ }^{201,202}$.

Both histone modifications contribute to both active and repressive effects on chromatin function, depending on which residue is modified ${ }^{203}$. HDACs and HMTs are both associated with complexes involving DNMTs and MBDs, mediating DNA packaging and gene expression ${ }^{198}$. Depending on the histone residue modified, and the interaction with DNA methylation to form a complex regulatory network, it correlates (among other effects) with chromatin structure/accessibility, transcriptional activity and genome function ${ }^{192,200,204}$.

The importance of epigenetics in the process of tumorigenesis has been increasingly discovered during the last decades and has been accepted as a true alternative for mutations and deletions associated with a loss of gene function that can provide a selective advantage for neoplastic cells. Epigenetic changes could well be as important as changes in DNA sequence or copy number in altering gene expression, and the interplay between genetics and epigenetics during the progression of cancer is becoming more and more a focus of research interest ${ }^{205-207}$.

Regarding RCC, mutations do not cover $100 \%$ of the cases and are less often found in sporadic RCC compared to heritable RCC. Also, sporadic cancers are known to arise from multiple (epi)genetic events, and additional aberrations remain to be discovered. Therefore, promoter hypermethylation of genes is thought to be involved in sporadic and/ or hereditary forms of RCC.

Here, we are focusing on the role of promoter methylation of tumor suppressor genes in the three most prevalent histological types of RCC, cCRCC, pRCC and chrRCC.

Recently, many (candidate) tumor suppressor genes silenced by DNA methylation and associated with one or more histological subtypes have been reported for primary RCC cases (Table 2a) and/or analyzed in RCC cell lines (Table 2b). Different techniques to analyze methylation were used to obtain the gene promoter-specific methylation data. An initial approach includes restriction enzyme digestion with Southern hybridization techniques, based on the (in)ability of methylation sensitive restriction enzymes to 
digest methylated cytosines. Later, bisulfite treatment of DNA, which converts unmethylated cytosines to uracil, whereas methylated cytosines remain unchanged, allowed combined bisulfite restriction analysis (COBRA), (nested) methylation specific PCR (MSP), and bisulfite sequencing ${ }^{197}$. MSP is a very sensitive approach to detect DNA methylation, enabling detection of one methylated allele in a background of 1,000 unmethylated alleles, while nested MSP allows detection of one methylated allele in 50,000 unmethylated alleles ${ }^{208}$.

The genes reported to be associated with RCC (tables $2 \mathrm{a}$ and $2 \mathrm{~b}$ ) can be grouped by the biological function/pathways involved in tumorigenesis and/or may be important targets for anti tumor therapy, i.e. interference in cell cycle, DNA-repair mechanisms, extra-cellular matrix molecules with adhesion and/or invasion mechanisms, angiogenesis, apoptosis, metabolism, proliferation, transport, WNT-signaling, or genes with a known role in the oncogenesis of other types of cancer, without a known specific function. 


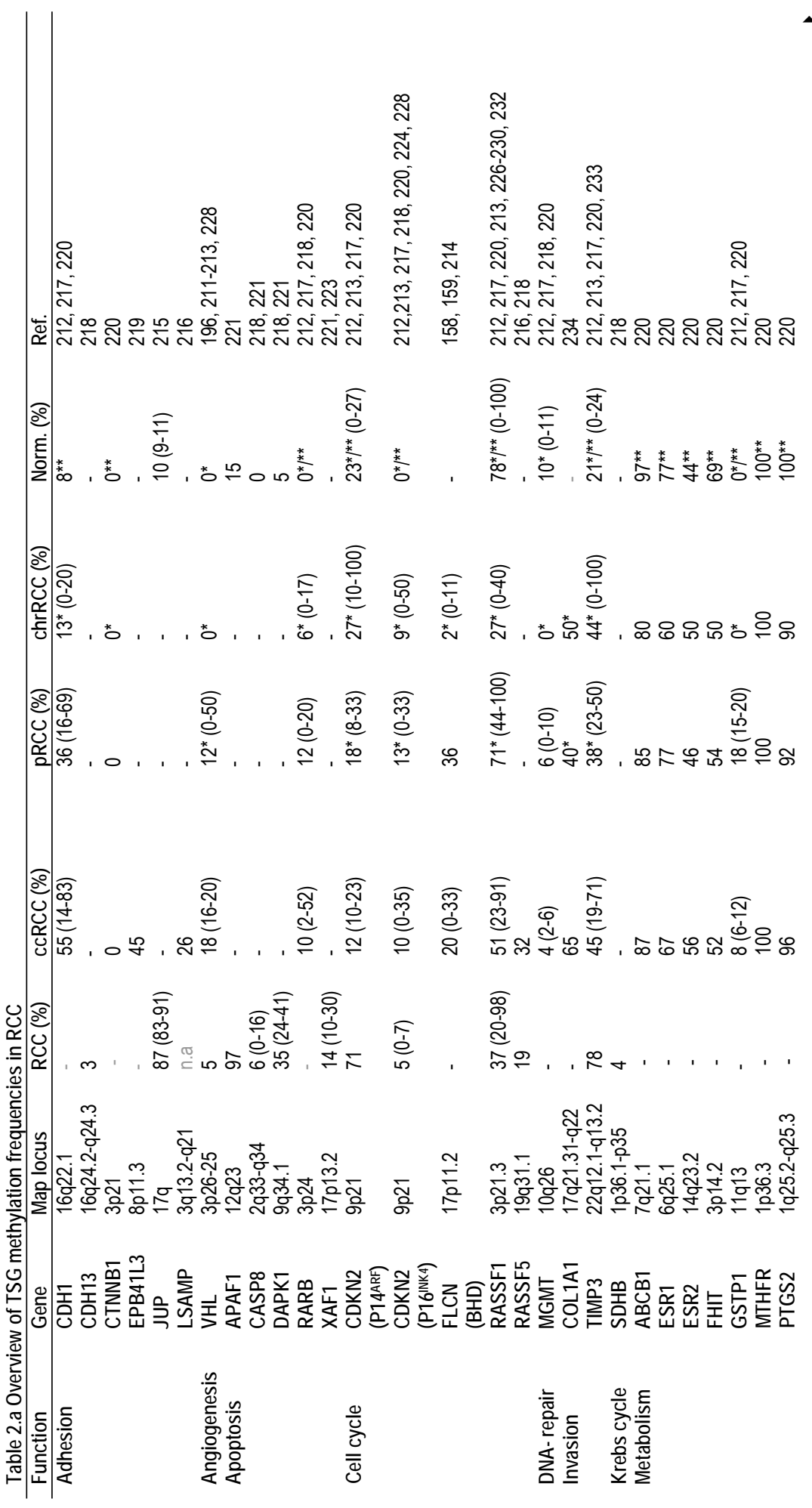




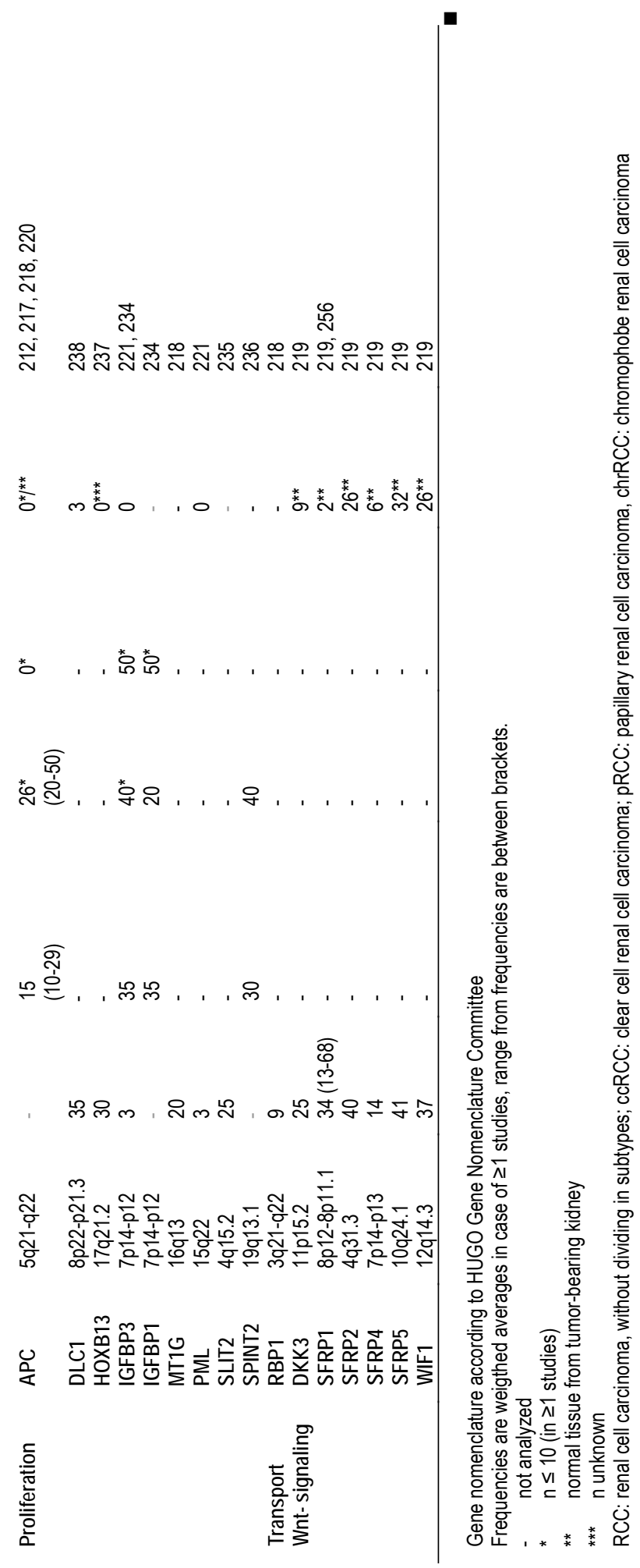


Table 2.b Overview of TSG methylation frequencies in RCC cell lines vs primary RCC

\begin{tabular}{lccllllll}
\hline Gene & \multicolumn{2}{c}{ Cell line } & Ref. & RCC (\%) & cCRCC (\%) & pRCC (\%) & chrRCC (\%) & Ref. \\
& $(\%)$ & $\mathrm{n}$ & & & & & \\
\hline DLC1 & 14 & 7 & 238 & 35 & - & - & - & 238 \\
EPB41L3 & 47 & 19 & 219 & - & 45 & - & - & 219 \\
FLCN & 0 & $6-9$ & 158,214 & - & $20(0-33)$ & 36 & $2(0-11)$ & $158,159,214$ \\
(BHD) & & & & & & & & \\
HOXB13 & 73 & 15 & 237 & 30 & - & - & - & 237 \\
JUPa & 100 & 3 & 215 & 83 & - & - & - & 215 \\
LSAMP & 78 & 9 & 216 & - & 26 & - & - & 216 \\
RARB & 33 & 6 & 257 & - & $18(8-52)$ & 20 & $17^{*}$ & 212,217 \\
RASSF5 & 67 & 9 & 216 & 19 & 32 & - & - & 216,218 \\
SPINT2 ${ }^{b}$ & 45 & 11 & 236 & - & 30 & 40 & - & 236 \\
TIMP3 & 33 & 12 & 223,233 & 78 & $60(54-71)$ & $46^{*}(45-$ & $100^{*}$ & $212,213,217$, \\
& & & & & & $50)$ & & 233 \\
AF1a & 67 & 15 & 223 & $14(10-30)$ & - & - & - & 222,223 \\
\hline
\end{tabular}

Gene nomenclature according to HUGO Gene Nomenclature Committee

Frequencies are weigthed averages in case of $\geq 1$ studies, range from frequencies are between brackets.

- not analyzed

${ }^{*} \mathrm{n} \leq 10$ (in $\geq 1$ studies)

a indirect measurement of methylation status; (mRNA) expression measurements

b indirect measurement of methylation status; upregulation after demethylation treatment

RCC: renal cell carcinoma, without dividing in subtypes; ccRCC: clear cell renal cell carcinoma; pRCC: papillary renal cell carcinoma, chrRCC: chromophobe renal cell carcinoma

\section{Methylation of the VHL promoter}

Somatic VHL mutations are found in $50-75 \%$ of sporadic $c \operatorname{cRCC}^{131-133,209}$. The absence of VHL mutations in a proportion of sporadic ccRCCs indicates a role for alternative methods of VHL inactivation ${ }^{210}$. Herman et al. investigated VHL promoter CpG island methylation and associated inactivation by RT-PCR and restriction enzyme analysis and Southern hybridization techniques ${ }^{196}$. None of the examined VHL hypermethylated tumors expressed the VHL gene and treatment of a renal cell culture line with 5-aza-2'deoxycytidine (5-aza-dc, a demethylating agent) resulted in reexpression of the $V H L$ gene. Methylation analysis of the wildtype $V H L$ alleles revealed promoter methylation in $19 \%$ of the examined RCC tumors. These were the first data suggesting that aberrant DNA methylation of the $V H L$ gene, in addition to $\mathrm{LOH}$ or gene mutations, is involved in ccRCC carcinogenesis. These data were confirmed by other groups reporting VHL methylation in $20 \%{ }^{211}, 16 \%{ }^{212}$, and $17 \%{ }^{213}$ in cCRCC.

In addition to ccRCC, involvement of $V H L$ promoter hypermethylation in other subtypes is mostly unknown ${ }^{212,213}$. As Van Houwelingen et al. reported VHL mutations also in other subtypes of $\mathrm{RCC}^{130}$, Banks et al. reported methylation of VHL in pRCC analyzed by $\mathrm{MSP}^{211}$.

\section{Methylation of the FH promoter}

One report regarding epigenetic silencing of $F H$ in renal cancers has been published, indicating absence of $\mathrm{FH}$ promoter $\mathrm{CpG}$ island methylation as analyzed by bisulfite sequencing, in fifteen pRCCs ${ }^{212}$. 


\section{Methylation of the BHD promoter}

So far, only three groups investigated BHD (FLCN) promoter methylation and associated silencing in chrRCC ${ }^{158,159,214}$. da Silva et al. analyzed promoter methylation in twenty primary RCCs by COBRA and bisulfite sequencing. Promoter hypermethylation was not detected in the primary RCCs ${ }^{214}$ and six tested RCC cell lines. In addition, no significant changes in expression after treatment of the demethylating agent 5-aza$\mathrm{dc}^{214}$ were observed. In contrast, Khoo et al. observed methylation in a wide spectrum of primary renal tumors, using MSP: $11 \%$ of chrRCC $(n=9), 36 \%$ in pRCC $(n=11)$, and $33 \%$ in ccRCC $(n=12)$, while none of the tested kidney cancer cell lines showed methylation ${ }^{158}$. On the other hand, Gad et al. analyzed methylation status of the BHD promoter using restriction enzyme analysis on 39 chrRCC and seven ccRCC, but no evidence of promoter methylation was found ${ }^{159}$.

\section{Methylation of other tumor suppressor gene promoters}

In addition to the genes described above, other TSGs have been investigated (mainly by MSP), which are known to be involved in common cancer types, or which have been identified by microarray studies (see table $2 \mathrm{a}$ and $2 \mathrm{~b}$ for details).

Several adhesion molecules (CDH1, CDH13, CTNNB1, EPB41L3, JUP, and LSAMP) were analyzed for promoter methylation in RCC, revealing methylation frequencies ranging from 3\% (CDH13) to $87 \%(J U P)^{212,215-220}$.

Many genes associated with apoptosis (APAF1, CASP8, DAPK1, RARB, and XAF1) have been recently investigated for their methylation frequencies in $\mathrm{RCC}$, and approximately $10-30 \%$ methylation is observed for the majority of genes, except for APAF1, which is methylated in $97 \%$ of the tested RCCs ${ }^{212,217,218,220-223}$.

The cell cycle genes CDKN2a $\left(p 14^{A R F}\right.$ and $\left.p 16^{I N K 4 A}\right)$ were methylated in $\sim 10-20 \%$ of the RCC cases, while normal renal tissue was mostly unmethylated ${ }^{212,213,217,218,220,224}$. The RAS association domain family 1A (RASSF1) gene at 3p21.3, thought to be involved in the cell cycle, apoptosis and/or proliferation ${ }^{225}$, has been implicated in the pathogenesis of a wide spectrum of tumors ${ }^{225}$, including different RCC subtypes. Methylation is observed in $\sim 40-50 \%$ (weighted mean) in $\mathrm{RCC}^{212,213,217,220,226-230}$, however some studies detect high methylation frequencies in normal renal tissues. These histological normal samples were obtained from tumor-bearing kidneys, therefore a field effect ${ }^{231}$ can cause this methylation and/or as reported before RASSF1 might be an early marker for RCC tumorigenesis ${ }^{232}$. In addition, RASSF1 methylation was detected in urine obtained from kidney cancer patients ${ }^{217}$. Potential importance of RASSF1 in early diagnosis is already highlighted in breast/lung cancer patients ${ }^{225}$. For a second RAS association domain family member, 5 (RASSF5), a methylation frequency of $\sim 20-30 \%$ has been observed $^{216,218}$.

The DNA-repair gene 06-methylguanine-DNA methyltransferase (MGMT) is methylated in $\sim 5 \%$ of the renal tumors $212,217,218,220$.

Genes involved in invasion/metastasis, such as COL1A1 and TIMP3, showed methylation in a high percentage ( $50 \%)$ in all RCC subtypes ${ }^{212,213,217,220,233,234 .}$.

For the Krebs cycle gene $(S D H B)$ a very low methylation percentage (4\%) was observed $^{218}$. 
The role of the detoxification gene Glutathione S-Transferase P1 (GSTP1) is not clear in RCC, but is it is methylated in $10-15 \%$ of the tumors ${ }^{212,217,220}$. Several other metabolism genes (ABCB1, ESR1, ESR2, FHIT, MTHFR, and PTGS2) have been analyzed by Costa et al. by MSP, which are all methylated in high percentages ( $\geq 50 \%)$, however, also the normal renal samples show frequent methylation ${ }^{220}$.

A methylation frequency of $\sim 30 \%$ is reported for several proliferation genes (see table $2 a$ for details) $212,217,218,220,221,234-238$. Also a gene involved in transport of retinol (RBP1) was analyzed and a methylation frequency of $9 \%$ was observed ${ }^{218}$.

Very recently, Urakami et al reported methylation analyses of six WNT- antagonist family genes (SFRP1, SFRP2, SFRP4, SFRP5, WIF1, and DKK3) in RCC (mostly cCRCC), analyzed by MSP. In this study all Wnt antagonist genes had significantly higher methylation frequencies in RCC compared to matched normal renal tissue. Methylation frequencies RCC versus normal were: SFRP1: $13 \%$ vs. $1,5 \%$, SFRP2: $40 \%$ vs. $25.5 \%$, SFRP4: $13.5 \%$ vs. $5.5 \%$, SFRP5: $41 \%$ vs. $31.5 \%$, WIF1: $37 \%$ vs. $25.5 \%$, and DKK3: $25.5 \%$ vs. $9 \%$ (all $p<0.005$ ). mRNA expression for most WNT-antagonists was increased in two (out of two) RCC cell lines after treatment with 5-aza-2'deoxycytidine and confirmed to be methylated by bisulfite sequencing ${ }^{239}$.

\section{Variables in promoter methylation studies}

Comparison of data from different studies on methylated tumor suppressor genes in RCC (see tables $2 \mathrm{a}$ and $2 \mathrm{~b}$ ) is complicated by a considerable number of variables. First, instead of considering different subtypes of kidney cancer, RCC is considered as one single entity in some studies. Since RCCs are heterogeneous in histology, clinical behavior, genotype, prognosis and response to therapy, data should be presented for the different subtypes. An interpretation of the diagnostic or therapeutic value of these results is only possible when subtyping is taken into account. Recently, Costa et al. emphasized this importance of subtyping by reporting a gene panel which could discriminate between RCC subtypes by the presence/absence of methylation ${ }^{220}$. In addition to subtyping, consideration of tumor grade/stage is of importance in interpreting (epi)genetic alterations in RCC. The composition of tumor series used to study (epi)genetic alterations in RCC varies between different research groups, therefore it is important to include this variable.

In addition, different methods of measuring promoter methylation can account for part of the differences in results. Since MSP is very sensitive, especially when nested PCR has been performed ${ }^{208}$, results might differ from those obtained by restriction enzyme-based methods. Furthermore, the position of measuring promoter methylation in a certain $\mathrm{CpG}$ island might differ between studies. Therefore, optimal and consensus primer location and design is critical to achieve reliable results ${ }^{240}$.

Finally, when analyzing promoter methylation, the origin of normal renal tissue should be considered ${ }^{231}$, and the number of RCC cases investigated should be sufficient to draw valid conclusions.

\section{Clinical applications}

DNA methylation markers have a promising future in clinical diagnostics, since DNA methylation changes have been reported to occur early in carcinogenesis ${ }^{241}$ and early 
detection of disease results in an improved clinical outcome. In case of RCC, clinical signs and symptoms are often not useful in making an early diagnosis. The classic triad of pain, hematuria and a palpable flank mass is encountered in only $10 \%$ of patients and is usually associated with advanced disease ${ }^{242}$. Since identification of patients with organ-confined RCC is important for long-term disease-free survival after radical or partial nephrectomy ${ }^{243}$, development of novel diagnostic noninvasive approaches for the early detection of kidney cancer is imperative, especially in patients with inherited predisposition. Cancer specific DNA methylation patterns can be found in detached tumor cells in bodily fluids, such as blood and urine and detection of methylated DNA by the very sensitive (nested) MSP is noninvasive and relatively cheap.

Table 3 shows the results of studies of DNA methylation markers in urine and serum from patients with $\operatorname{RCC}^{213,217,239}$.

Table 3. Studies of DNA methylation markers in urine and serum from patients with RCC

\begin{tabular}{|c|c|c|c|c|c|c|}
\hline Samples & $\begin{array}{l}\text { DNA } \\
\text { source }\end{array}$ & Markers & $\begin{array}{l}\text { Analytical } \\
\text { sensitivity (\%) }\end{array}$ & $\begin{array}{l}\text { Clinical } \\
\text { Sensitivity (\%) }\end{array}$ & Specificity (\%) & Ref. \\
\hline \multirow[t]{2}{*}{$\begin{array}{l}23 \text { ccRCC, } \\
1 \text { pRCC, } \\
1 \text { chrRCC, } \\
1 \text { collecting duct }\end{array}$} & urine & $\begin{array}{l}\text { APC } \\
\text { CDH1 } \\
\text { GSTP1 } \\
\text { MGMT } \\
\text { P16 } \\
\text { RARB } \\
\text { RASSF1 }\end{array}$ & $\begin{array}{l}4 / 5(80) \\
6 / 10(60) \\
1 / 2(50) \\
0 / 1(0) \\
4 / 6(67) \\
4 / 9(44) \\
11 / 15(73)\end{array}$ & $\begin{array}{l}10 / 26(38) \\
10 / 26(38) \\
4 / 26(15) \\
2 / 26(8) \\
9 / 26(35) \\
8 / 26(31) \\
17 / 26(65)\end{array}$ & $\begin{array}{l}96 \\
95 \\
100 \\
100 \\
100 \\
91 \\
89\end{array}$ & 217 \\
\hline & serum & $\begin{array}{l}\text { APC } \\
\text { CDH1 } \\
\text { GSTP1 } \\
\text { MGMT } \\
\text { P14 } \\
\text { P16 } \\
\text { RARB } \\
\text { RASSF1 }\end{array}$ & $\begin{array}{l}1 / 5(20) \\
06 / 10(60) \\
0 / 2(0) \\
0 / 1(1) \\
1 / 4(25) \\
3 / 6(50) \\
1 / 9(11) \\
2 / 15(13)\end{array}$ & $\begin{array}{l}1 / 18(6) \\
6 / 18(33) \\
1 / 18(6) \\
0 / 18(0) \\
1 / 18(6) \\
4 / 18(22) \\
1 / 18(6) \\
2 / 18(11)\end{array}$ & $\begin{array}{l}97 \\
93 \\
100 \\
97 \\
97 \\
100 \\
100 \\
97\end{array}$ & \\
\hline $\begin{array}{l}35 \text { ccRCC, } \\
6 \text { pRCC, } \\
2 \text { chrRCC }\end{array}$ & urine & $\begin{array}{l}\text { APC } \\
\text { P14 } \\
\text { P16 } \\
\text { RASSF1 } \\
\text { TIMP3 } \\
\text { VHL }\end{array}$ & $\begin{array}{l}7 / 7(100) \\
8 / 8(100) \\
4 / 5(80) \\
23 / 24(95) \\
23 / 26(88) \\
6 / 6(101)\end{array}$ & $\begin{array}{l}9 / 50(18) \\
9 / 50(18) \\
5 / 50(10) \\
26 / 50(52) \\
30 / 50(60) \\
6 / 50(12)\end{array}$ & $\begin{array}{l}100 \\
100 \\
100 \\
100 \\
100 \\
100\end{array}$ & 213 \\
\hline $33 \mathrm{RCC}$ & serum & $\begin{array}{l}\text { DKK3 } \\
\text { SFRP1 } \\
\text { SFRP2 } \\
\text { SFRP4 } \\
\text { SFRP5 } \\
\text { WIF1 }\end{array}$ & $\begin{array}{l}6 / 10(60) \\
5 / 8(62) \\
12 / 13(92) \\
5 / 15(33) \\
9 / 16(56) \\
5 / 13(38)\end{array}$ & $\begin{array}{l}9 / 33(27) \\
9 / 33(27) \\
7 / 33(21) \\
8 / 33(24) \\
15 / 33(45) \\
9 / 33(27)\end{array}$ & $\begin{array}{l}100 \\
100 \\
100 \\
100 \\
100 \\
100\end{array}$ & 239 \\
\hline
\end{tabular}

Gene nomenclature according to HUGO Gene Nomenclature Committee

Analytical sensitivity is defined as the fraction of cases in which methylation of a marker is found in serum or urine for cases with confirmed methylation of the same marker in the associated tumor.

Clinical sensitivity is defined as the fraction of confirmed cases of disease, in which methylation of a marker is found in serum or urine, regardless of whether methylation of that marker is present in the associated tumor.

Specificity is defined as the fraction of controls without the disease that show a lack of detectable methylation in serum or urine.

RCC: renal cell carcinoma, without dividing in subtypes; ccRCC: clear cell renal cell carcinoma; pRCC: papillary renal cell carcinoma, chrRCC: chromophobe renal cell carcinoma 
Furthermore, Urakami et al reported a higher frequency of methylation in serum DNA from RCC patients with higher-grade/stage tumors compared to lower-grade/stage tumors, indicating putative progression markers ${ }^{239}$. Other studies have demonstrated independent prognostic values for DNA methylation markers in RCC $\left(P T E N^{244}, J U P^{215}\right.$, EPB41L3 ${ }^{219}, A P A F 1$ and DAPK1 ${ }^{221}$ ), being predictors of poor prognostic outcome. Inactivation of RASSF1 is often because of promoter methylation and this gene has the potential to be used as a marker for early detection and tumor surveillance/monitoring of (RCC) cancer patients (along with a panel of other TSGs to obtain a higher sensitivity).

Obviously, methylation markers with a high sensitivity and specificity in urine and/or serum would be a significant improvement, as this would offer a non-invasive method for (early) diagnosis, prognosis, or response on therapy ${ }^{231}$.

The quest for DNA methylation markers that are predictive for therapy response is still in its infancy ${ }^{245-247}$, and such markers in RCC have not been reported. A better understanding of the molecular pathways involved in renal carcinogenesis and insight into the functional significance of methylation changes, will allow development of new therapeutic approaches by use of demethylating agents. Resistance of several tumor types, including RCC, for certain anti-cancer agents such as chemotherapeutics, might be a result of epigenetic mechanisms that regulate genes involved in resistance, e.g. proapoptotic genes silenced by DNA methylation and/or histone acetylation. Demethylating agents or HDAC inhibitors might reverse these repressive effects ${ }^{248}$.

Reu et al. demonstrated augmentation of immune response by DNA methyltransferase 1 inhibitors, through reactivation of apoptosis-associated Interferon response gene $X A F 1^{249}$. The overcoming of resistance to Interferon-induced apoptosis in RCC cells by demethylating agents may have clinical significance for cytokine therapy response. Shang et al. reported a synergistic growth suppression of RCC (in vitro), caused by the DNA methyltransferase inhibitor, 5-aza-2'-deoxycytidine, and a chemotherapeutic agent, Paclitaxel (PTX). They suggest that 5-aza-2'-deoxycytidine could increase the susceptibility of RCC to PTX and that combination chemotherapy with this inhibitor and PTX might be a novel strategy to improve the clinical response rate of $\operatorname{RCC}^{250}$. 


\section{Conclusion}

RCC is the most important tumor of the kidney in adults. In etiological, biological and clinical characteristics it represents a heterogeneous entity, which, through lack of clinical symptoms, may be difficult to detect in an early stage. Surgery is the first treatment of choice, and most successful if the tumor is confined to the kidney. Systemic treatment of RCC has made considerable progress in patients with metastatic RCC, e.g. by development of new emerging strategies (targeted agents) in recent years. Further studies are needed to address the questions regarding the efficacy of new targets and the efficacy of combination treatments.

Developing knowledge of genetic and epigenetic changes implicated in tumor development and behavior is becoming increasingly important for advancing the efficacy of disease management.

Defective VHL functioning appears to be the key event, in both hereditary and sporadic cases. However, the variable nature of the resulting neoplasm is most likely strongly determined by the complex interplay of additional downstream modifications, among which the role of epigenetic alteration of gene expression is becoming more and more acknowledged.

Elucidation of epigenetic modifications in RCC holds great promise for early detection, prediction of sensitivity for non-surgical therapy, but also for therapeutical interventions through reversal of epigenetic gene silencing. However, for definitive progress to be made in this field of research, uniformity in study design and consensus in clinicopathological definitions and scientific methods is a prerequisite. 


\section{Appendix I:}

Odds ratio (OR): The OR is a measure of association between exposure and disease that can be calculated in case-control studies. An OR $>1$ denotes an increased risk, an OR of $<1$ denotes a decreased risk, and an OR of 1 points at no association between the exposure and the disease.

Pooled OR or RR: A pooled OR or RR can be calculated when individual studies are pooled and a OR or RR is calculated using either the outcomes of the data (metaanalysis) or the individual data from the studies.

Relative risk or relative rate (RR): the RR is the ratio of the risk of an event occurring in an exposed group versus a non-exposed group. A RR $>1$ denotes an increased risk, a RR of $<1$ denotes a decreased risk, and a RR of 1 points at no association between the exposure and the disease. A RR can be calculated in cohort studies and randomized controlled trials. 


\section{References}

1. Ferlay, J., et al., GLOBOCAN 2002: Cancer incidence, mortalitity and prevalence worldwide. Vol. IARC CancerBase No. 5. version 2.0. 2004, Lyon: IARCPress.

2. Mathew, A., et al., Global increases in kidney cancer incidence, 1973-1992. Eur J Cancer Prev, 2002. 11(2): p. 171-8.

3. Nguyen, M.M., I.S. Gill, and L.M. Ellison, The evolving presentation of renal carcinoma in the United States: trends from the Surveillance, Epidemiology, and End Results program. J Urol, 2006. 176(6 Pt 1): p. 2397-400; discussion 2400.

4. Hock, L.M., J. Lynch, and K.C. Balaji, Increasing incidence of all stages of kidney cancer in the last 2 decades in the United States: an analysis of surveillance, epidemiology and end results program data. J Urol, 2002. 167(1): p. 57-60.

5. Dhote, R., et al., Risk factors for adult renal cell carcinoma: a systematic review and implications for prevention. BJU Int, 2000. 86(1): p. 20-7.

6. Lindblad, P., Epidemiology of renal cell carcinoma. Scand J Surg, 2004. 93(2): p. 88-96.

7. McLaughlin, J.K., Lipworth, L., Tarone, R.E., Blot, W.J., Cancer epidemiology and prevention, ed. J.F.F. Schottenfeld D, editors. 2006, Oxford: Oxford University Press. 1087-1100.

8. Mellemgaard, A., Human renal-cell carcinoma--epidemiological and mechanistic aspects. IARC Sci Publ, 1999(147): p. 69-80.

9. Wolk, A., P. Lindblad, and H.O. Adami, Nutrition and renal cell cancer. Cancer Causes Control, 1996. 7(1): p. 5-18.

10. Grossman, E., et al., Is there an association between hypertension and cancer mortality? Am J Med, 2002. 112(6): p. 479-86.

11. Grossman, E., F.H. Messerli, and U. Goldbourt, Does diuretic therapy increase the risk of renal cell carcinoma? Am J Cardiol, 1999. 83(7): p. 1090-3.

12. Hunt, J.D., et al., Renal cell carcinoma in relation to cigarette smoking: meta-analysis of 24 studies. Int J Cancer, 2005. 114(1): p. 101-8.

13. Bergstrom, A., et al., Obesity and renal cell cancer--a quantitative review. Br J Cancer, 2001. 85(7): p. 984-90.

14. Bergstrom, A., et al., Overweight as an avoidable cause of cancer in Europe. Int J Cancer, 2001. 91(3): p. 421-30.

15. McLaughlin, J.K., et al., International renal-cell cancer study. VIII. Role of diuretics, other anti-hypertensive medications and hypertension. Int J Cancer, 1995. 63(2): p. 216-21.

16. Shapiro, J.A., et al., Hypertension, antihypertensive medication use, and risk of renal cell carcinoma. Am J Epidemiol, 1999. 149(6): p. 521-30.

17. Brennan, J.F., et al., Acquired renal cystic disease: implications for the urologist. Br J Urol, 1991. 67(4): p. 342-8.

18. Chow, W.H., et al., Use of analgesics and risk of renal cell cancer. Int J Cancer, 1994. 59(4): p. 467-70.

19. Lornoy, W., et al., Renal cell carcinoma, a new complication of analgesic nephropathy. Lancet, 1986. 1(8492): p. 1271-2.

20. McCredie, M., et al., International renal-cell cancer study. II. Analgesics. Int J Cancer, 1995. 60(3): p. 345-9.

21. McLaughlin, J.K., Lipworth, L., Tarone, R.E., Blot, W.J., Kidney cancer. Cancer epidemiology and prevention, ed. J.F. Fraumeni. 2006, Oxford: Oxford University Press. 1087-1100.

22. Brauch, H., et al., Trichloroethylene exposure and specific somatic mutations in patients with renal cell carcinoma. J Natl Cancer Inst, 1999. 91(10): p. 854-61.

23. Brauch, H., et al., VHL mutations in renal cell cancer: does occupational exposure to trichloroethylene make a difference? Toxicol Lett, 2004. 151(1): p. 301-10.

24. Yu, M.C., et al., Cigarette smoking, obesity, diuretic use, and coffee consumption as risk factors for renal cell carcinoma. J Natl Cancer Inst, 1986. 77(2): p. 351-6. 
25. Pelucchi, C., et al., Alcohol drinking and renal cell carcinoma in women and men. Eur J Cancer Prev, 2002. 11(6): p. 543-5.

26. Brownson, R.C., A case-control study of renal cell carcinoma in relation to occupation, smoking, and alcohol consumption. Arch Environ Health, 1988. 43(3): p. 238-41.

27. Maclure, M. and W. Willett, A case-control study of diet and risk of renal adenocarcinoma. Epidemiology, 1990. 1(6): p. 430-40.

28. McLaughlin, J.K., et al., Risk factors for renal-cell cancer in Shanghai, China. Int J Cancer, 1992. 52(4): p. 562-5.

29. Benhamou, S., et al., Risk factors for renal-cell carcinoma in a French case-control study. Int J Cancer, 1993. 55(1): p. 32-6.

30. Kreiger, N., et al., Risk factors for renal cell carcinoma: results of a population-based casecontrol study. Cancer Causes Control, 1993. 4(2): p. 101-10.

31. Hu, J., Y. Mao, and K. White, Diet and vitamin or mineral supplements and risk of renal cell carcinoma in Canada. Cancer Causes Control, 2003. 14(8): p. 705-14.

32. Rashidkhani, B., et al., Major dietary patterns and risk of renal cell carcinoma in a prospective cohort of Swedish women. J Nutr, 2005. 135(7): p. 1757-62.

33. Nicodemus, K.K., C. Sweeney, and A.R. Folsom, Evaluation of dietary, medical and lifestyle risk factors for incident kidney cancer in postmenopausal women. Int J Cancer, 2004. 108(1): p. 115-21.

34. Mahabir, S., et al., Prospective study of alcohol drinking and renal cell cancer risk in a cohort of finnish male smokers. Cancer Epidemiol Biomarkers Prev, 2005. 14(1): p. 170-5.

35. Parker, A.S., et al., Gender, alcohol consumption, and renal cell carcinoma. Am J Epidemiol, 2002. 155(5): p. 455-62.

36. Lee, J.E., et al., Alcohol intake and renal cell cancer in a pooled analysis of 12 prospective studies. J Natl Cancer Inst, 2007. 99(10): p. 801-10.

37. Lamiell, J.M., F.G. Salazar, and Y.E. Hsia, von Hippel-Lindau disease affecting 43 members of a single kindred. Medicine (Baltimore), 1989. 68(1): p. 1-29.

38. Pavlovich, C.P. and L.S. Schmidt, Searching for the hereditary causes of renal-cell carcinoma. Nat Rev Cancer, 2004. 4(5): p. 381-93.

39. Washecka, R. and M. Hanna, Malignant renal tumors in tuberous sclerosis. Urology, 1991. 37(4): p. 340-3.

40. Breslow, N., et al., Age distribution of Wilms' tumor: report from the National Wilms' Tumor Study. Cancer Res, 1988. 48(6): p. 1653-7.

41. Gallagher, D.J., A. Duffy, and J. McCaffrey, Wilms' tumour in adults: a case report and review of the literature. Ir J Med Sci, 2007. 176(1): p. 49-51.

42. Huser, J., et al., Adult Wilms' tumor: a clinicopathologic study of 11 cases. Mod Pathol, 1990. 3(3): p. 321-6.

43. Kovacs, G., et al., The Heidelberg classification of renal cell tumours. J Pathol, 1997. 183(2): p. 131-3.

44. Storkel, S., et al., Classification of renal cell carcinoma: Workgroup No. 1. Union Internationale Contre le Cancer (UICC) and the American Joint Committee on Cancer (AJCC). Cancer, 1997. 80(5): p. 987-9.

45. Moch, H., et al., Prognostic utility of the recently recommended histologic classification and revised TNM staging system of renal cell carcinoma: a Swiss experience with 588 tumors. Cancer, 2000. 89(3): p. 604-14.

46. Matsuyama, $\mathrm{H}$., et al., Clinical significance of lymph node dissection in renal cell carcinoma. Scand J Urol Nephrol, 2005. 39(1): p. 30-5.

47. Minervini, A., et al., Regional lymph node dissection in the treatment of renal cell carcinoma: is it useful in patients with no suspected adenopathy before or during surgery? BJU Int, 2001. 88(3): p. 169-72. 
48. Nassir, A., et al., Multilocular cystic renal cell carcinoma: a series of 12 cases and review of the literature. Urology, 2002. 60(3): p. 421-7.

49. Eble, J.N. and S.M. Bonsib, Extensively cystic renal neoplasms: cystic nephroma, cystic partially differentiated nephroblastoma, multilocular cystic renal cell carcinoma, and cystic hamartoma of renal pelvis. Semin Diagn Pathol, 1998. 15(1): p. 2-20.

50. Corica, F.A., et al., Cystic renal cell carcinoma is cured by resection: a study of 24 cases with long-term followup. J Urol, 1999. 161(2): p. 408-11.

51. Gong, K., et al., Multilocular cystic renal cell carcinoma: an experience of clinical management for 31 cases. J Cancer Res Clin Oncol, 2007.

52. Murad, T., et al., Multilocular cystic renal cell carcinoma. Am J Clin Pathol, 1991. 95(5): p. 633-7.

53. Suzigan, S., et al., Multilocular cystic renal cell carcinoma : a report of 45 cases of a kidney tumor of low malignant potential. Am J Clin Pathol, 2006. 125(2): p. 217-22.

54. Delahunt, B. and J.N. Eble, Papillary renal cell carcinoma: a clinicopathologic and immunohistochemical study of 105 tumors. Mod Pathol, 1997. 10(6): p. 537-44.

55. Lager, D.J., et al., Papillary renal tumors. Morphologic, cytochemical, and genotypic features. Cancer, 1995. 76(4): p. 669-73.

56. Amin, M.B., et al., Papillary (chromophil) renal cell carcinoma: histomorphologic characteristics and evaluation of conventional pathologic prognostic parameters in 62 cases. Am J Surg Pathol, 1997. 21(6): p. 621-35.

57. Delahunt, B., et al., Morphologic typing of papillary renal cell carcinoma: comparison of growth kinetics and patient survival in 66 cases. Hum Pathol, 2001. 32(6): p. 590-5.

58. Crotty, T.B., G.M. Farrow, and M.M. Lieber, Chromophobe cell renal carcinoma: clinicopathological features of 50 cases. J Urol, 1995. 154(3): p. 964-7.

59. Rumpelt, H.J., et al., Bellini duct carcinoma: further evidence for this rare variant of renal cell carcinoma. Histopathology, 1991. 18(2): p. 115-22.

60. Srigley, J.R. and J.N. Eble, Collecting duct carcinoma of kidney. Semin Diagn Pathol, 1998. 15(1): p. 54-67.

61. Swartz, M.A., et al., Renal medullary carcinoma: clinical, pathologic, immunohistochemical, and genetic analysis with pathogenetic implications. Urology, 2002. 60(6): p. 1083-9.

62. Zisman, A., et al., Unclassified renal cell carcinoma: clinical features and prognostic impact of a new histological subtype. J Urol, 2002. 168(3): p. 950-5.

63. Argani, P., et al., PRCC-TFE3 renal carcinomas: morphologic, immunohistochemical, ultrastructural, and molecular analysis of an entity associated with the $t(X ; 1)(p 11.2 ; q 21)$. Am J Surg Pathol, 2002. 26(12): p. 1553-66.

64. Argani, P., et al., Primary renal neoplasms with the ASPL-TFE3 gene fusion of alveolar soft part sarcoma: a distinctive tumor entity previously included among renal cell carcinomas of children and adolescents. Am J Pathol, 2001. 159(1): p. 179-92.

65. Ferlicot, S., et al., A novel entity: low-grade mucinous tubular renal carcinoma. Histopathology, 2005. 47(2): p. 218-9.

66. Koyle, M.A., et al., Long-term urological complications in survivors younger than 15 months of advanced stage abdominal neuroblastoma. J Urol, 2001. 166(4): p. 1455-8.

67. Novick AC, C.S., Renal tumors, chapter 75. 2002: p. 2672-2731.

68. Pantuck, A.J., A. Zisman, and A.S. Belldegrun, The changing natural history of renal cell carcinoma. J Urol, 2001. 166(5): p. 1611-23.

69. Patard, J.J., et al., Prognostic value of histologic subtypes in renal cell carcinoma: a multicenter experience. J Clin Oncol, 2005. 23(12): p. 2763-71.

70. Smits, K.M., Schouten, L.J., van Dijk, B.A.C., Hulsbergen-van de Kaa, C.A., Wouters, K.A.D., Oosterwijk, E., van Engeland, M., vanden Brandt, P.A., Genetic and epigenetic alterations in the von Hippel-Lindau gene: the influence on renal cancer progosis. Clin Cancer Res, in press. 
71. Oken, M.M., et al., Toxicity and response criteria of the Eastern Cooperative Oncology Group. Am J Clin Oncol, 1982. 5(6): p. 649-55.

72. Frank, I., et al., Independent validation of the 2002 American Joint Committee on cancer primary tumor classification for renal cell carcinoma using a large, single institution cohort. J Urol, 2005. 173(6): p. 1889-92.

73. Eble JN, S.G., Epstein JI, Sesterhenn IA, WHO classification of tumours. Pathology and genetics. Tumours of the urinary system and male genital organs. 2004.

74. Fuhrman, S.A., L.C. Lasky, and C. Limas, Prognostic significance of morphologic parameters in renal cell carcinoma. Am J Surg Pathol, 1982. 6(7): p. 655-63.

75. Kim, H.L., et al., Paraneoplastic signs and symptoms of renal cell carcinoma: implications for prognosis. J Urol, 2003. 170(5): p. 1742-6.

76. Symbas, N.P., et al., Poor prognosis associated with thrombocytosis in patients with renal cell carcinoma. BJU Int, 2000. 86(3): p. 203-7.

77. Amin, M.B., et al., Prognostic impact of histologic subtyping of adult renal epithelial neoplasms: an experience of 405 cases. Am J Surg Pathol, 2002. 26(3): p. 281-91.

78. Cheville, J.C., et al., Comparisons of outcome and prognostic features among histologic subtypes of renal cell carcinoma. Am J Surg Pathol, 2003. 27(5): p. 612-24.

79. Sengupta, S., et al., Histologic coagulative tumor necrosis as a prognostic indicator of renal cell carcinoma aggressiveness. Cancer, 2005. 104(3): p. 511-20.

80. Frank, I., et al., An outcome prediction model for patients with clear cell renal cell carcinoma treated with radical nephrectomy based on tumor stage, size, grade and necrosis: the SSIGN score. J Urol, 2002. 168(6): p. 2395-400.

81. Cangiano, T., et al., Sarcomatoid renal cell carcinoma: biologic behavior, prognosis, and response to combined surgical resection and immunotherapy. J Clin Oncol, 1999. 17(2): p. 523-8.

82. Van Poppel, H., et al., Microscopic vascular invasion is the most relevant prognosticator after radical nephrectomy for clinically nonmetastatic renal cell carcinoma. J Urol, 1997. 158(1): p. 45-9.

83. Eggener, S.E., et al., Renal cell carcinoma recurrence after nephrectomy for localized disease: predicting survival from time of recurrence. J Clin Oncol, 2006. 24(19): p. 3101-6.

84. Elson, P.J., R.S. Witte, and D.L. Trump, Prognostic factors for survival in patients with recurrent or metastatic renal cell carcinoma. Cancer Res, 1988. 48(24 Pt 1): p. 7310-3.

85. Kattan, M.W., et al., A postoperative prognostic nomogram for renal cell carcinoma. J Urol, 2001. 166(1): p. 63-7.

86. Lam, J.S., et al., Postoperative surveillance protocol for patients with localized and locally advanced renal cell carcinoma based on a validated prognostic nomogram and risk group stratification system. J Urol, 2005. 174(2): p. 466-72; discussion 472; quiz 801.

87. Leibovich, B.C., et al., A scoring algorithm to predict survival for patients with metastatic clear cell renal cell carcinoma: a stratification tool for prospective clinical trials. J Urol, 2005. 174(5): p. 1759-63; discussion 1763.

88. Leibovich, B.C., et al., Scoring algorithm to predict survival after nephrectomy and immunotherapy in patients with metastatic renal cell carcinoma: a stratification tool for prospective clinical trials. Cancer, 2003. 98(12): p. 2566-75.

89. Maldazys, J.D. and J.B. deKernion, Prognostic factors in metastatic renal carcinoma. J Urol, 1986. 136(2): p. 376-9.

90. Mekhail, T.M., et al., Validation and extension of the Memorial Sloan-Kettering prognostic factors model for survival in patients with previously untreated metastatic renal cell carcinoma. J Clin Oncol, 2005. 23(4): p. 832-41.

91. Motzer, R.J., et al., Interferon-alfa as a comparative treatment for clinical trials of new therapies against advanced renal cell carcinoma. J Clin Oncol, 2002. 20(1): p. 289-96. 
92. Motzer, R.J., et al., Survival and prognostic stratification of 670 patients with advanced renal cell carcinoma. J Clin Oncol, 1999. 17(8): p. 2530-40.

93. Negrier, S., et al., Prognostic factors of survival and rapid progression in 782 patients with metastatic renal carcinomas treated by cytokines: a report from the Groupe Francais d'Immunotherapie. Ann Oncol, 2002. 13(9): p. 1460-8.

94. Zisman, A., et al., Improved prognostication of renal cell carcinoma using an integrated staging system. J Clin Oncol, 2001. 19(6): p. 1649-57.

95. Thompson, R.H., et al., Costimulatory B7-H1 in renal cell carcinoma patients: Indicator of tumor aggressiveness and potential therapeutic target. Proc Natl Acad Sci U S A, 2004. 101(49): p. 17174-9.

96. Mizutani, Y., et al., Downregulation of Smac/DIABLO expression in renal cell carcinoma and its prognostic significance. J Clin Oncol, 2005. 23(3): p. 448-54.

97. Parker, A.S., et al., High expression levels of survivin protein independently predict a poor outcome for patients who undergo surgery for clear cell renal cell carcinoma. Cancer, 2006. 107(1): p. 37-45.

98. Velickovic, M., et al., Intragenic PTEN/MMAC1 loss of heterozygosity in conventional (clearcell) renal cell carcinoma is associated with poor patient prognosis. Mod Pathol, 2002. 15(5): p. 479-85.

99. Jacobsen, J., et al., Vascular endothelial growth factor as prognostic factor in renal cell carcinoma. J Urol, 2000. 163(1): p. 343-7.

100. Lidgren, A., et al., The expression of hypoxia-inducible factor 1alpha is a favorable independent prognostic factor in renal cell carcinoma. Clin Cancer Res, 2005. 11(3): p. 1129-35.

101. Bui, M.H., et al., Carbonic anhydrase IX is an independent predictor of survival in advanced renal clear cell carcinoma: implications for prognosis and therapy. Clin Cancer Res, 2003. 9(2): p. 802-11.

102. Kim, H.L., et al., Using protein expressions to predict survival in clear cell renal carcinoma. Clin Cancer Res, 2004. 10(16): p. 5464-71.

103. Gelb, A.B., et al., Appraisal of intratumoral microvessel density, MIB-1 score, DNA content, and $\mathrm{p} 53$ protein expression as prognostic indicators in patients with locally confined renal cell carcinoma. Cancer, 1997. 80(9): p. 1768-75.

104. Leibovich, B.C. and M.L. Blute, Surgical management of renal cell carcinoma. Semin Oncol, 2006. 33(5): p. 552-62.

105. Flanigan, R.C., et al., Nephrectomy followed by interferon alfa- $2 \mathrm{~b}$ compared with interferon alfa-2b alone for metastatic renal-cell cancer. N Engl J Med, 2001. 345(23): p. 1655-9.

106. Mickisch, G.H., et al., Radical nephrectomy plus interferon-alfa-based immunotherapy compared with interferon alfa alone in metastatic renal-cell carcinoma: a randomised trial. Lancet, 2001. 358(9286): p. 966-70.

107. McDermott, D.F., et al., Randomized phase III trial of high-dose interleukin-2 versus subcutaneous interleukin-2 and interferon in patients with metastatic renal cell carcinoma. J Clin Oncol, 2005. 23(1): p. 133-41.

108. Drucker, B.J., Renal cell carcinoma: current status and future prospects. Cancer Treat Rev, 2005. 31(7): p. 536-45.

109. Yagoda, A., B. Abi-Rached, and D. Petrylak, Chemotherapy for advanced renal-cell carcinoma: 1983-1993. Semin Oncol, 1995. 22(1): p. 42-60.

110. Horio, M., M.M. Gottesman, and I. Pastan, ATP-dependent transport of vinblastine in vesicles from human multidrug-resistant cells. Proc Natl Acad Sci U S A, 1988. 85(10): p. 35804.

111. Mignogna, C., et al., Prognostic significance of multidrug-resistance protein (MDR-1) in renal clear cell carcinomas: a five year follow-up analysis. BMC Cancer, 2006. 6: p. 293. 
112. Oliver, R.T., A.B. Nethersell, and J.M. Bottomley, Unexplained spontaneous regression and alpha-interferon as treatment for metastatic renal carcinoma. Br J Urol, 1989. 63(2): p. 12831.

113. Childs, R., et al., Regression of metastatic renal-cell carcinoma after nonmyeloablative allogeneic peripheral-blood stem-cell transplantation. N Engl J Med, 2000. 343(11): p. 7508.

114. Kubler, H. and J. Vieweg, Vaccines in renal cell carcinoma. Semin Oncol, 2006. 33(5): p. 61424.

115. Yagoda, A., D. Petrylak, and S. Thompson, Cytotoxic chemotherapy for advanced renal cell carcinoma. Urol Clin North Am, 1993. 20(2): p. 303-21.

116. Muss, H.B., et al., Recombinant alfa interferon in renal cell carcinoma: a randomized trial of two routes of administration. J Clin Oncol, 1987. 5(2): p. 286-91.

117. McDermott, D.F. and M.B. Atkins, Interleukin-2 therapy of metastatic renal cell carcinoma-predictors of response. Semin Oncol, 2006. 33(5): p. 583-7.

118. Yang, J.C., et al., Randomized study of high-dose and low-dose interleukin-2 in patients with metastatic renal cancer. J Clin Oncol, 2003. 21(16): p. 3127-32.

119. Motzer, R.J., et al., Sunitinib versus interferon alfa in metastatic renal-cell carcinoma. N Engl J Med, 2007. 356(2): p. 115-24.

120. Escudier, B., et al., Sorafenib in advanced clear-cell renal-cell carcinoma. N Engl J Med, 2007. 356(2): p. 125-34.

121. Hudes, G., et al., Temsirolimus, interferon alfa, or both for advanced renal-cell carcinoma. $\mathrm{N}$ Engl J Med, 2007. 356(22): p. 2271-81.

122. Yang, J.C., et al., A randomized trial of bevacizumab, an anti-vascular endothelial growth factor antibody, for metastatic renal cancer. N Engl J Med, 2003. 349(5): p. 427-34.

123. Linehan, W.M., et al., Genetic basis of cancer of the kidney: disease-specific approaches to therapy. Clin Cancer Res, 2004. 10(18 Pt 2): p. 6282S-9S.

124. Kim, W.Y. and W.G. Kaelin, Role of VHL gene mutation in human cancer. J Clin Oncol, 2004. 22(24): p. 4991-5004.

125. Seizinger, B.R., et al., Von Hippel-Lindau disease maps to the region of chromosome 3 associated with renal cell carcinoma. Nature, 1988. 332(6161): p. 268-9.

126. Latif, F., et al., Identification of the von Hippel-Lindau disease tumor suppressor gene. Science, 1993. 260(5112): p. 1317-20.

127. Stolle, C., et al., Improved detection of germline mutations in the von Hippel-Lindau disease tumor suppressor gene. Hum Mutat, 1998. 12(6): p. 417-23.

128. Choyke, P.L., et al., Hereditary renal cancers. Radiology, 2003. 226(1): p. 33-46.

129. Mandriota, S.J., et al., HIF activation identifies early lesions in VHL kidneys: evidence for site-specific tumor suppressor function in the nephron. Cancer Cell, 2002. 1(5): p. 459-68.

130. van Houwelingen, K.P., et al., Prevalence of von Hippel-Lindau gene mutations in sporadic renal cell carcinoma: results from The Netherlands cohort study. BMC Cancer, 2005. 5(1): p. 57.

131. Weiss, R.H. and P.Y. Lin, Kidney cancer: identification of novel targets for therapy. Kidney Int, 2006. 69(2): p. 224-32.

132. Zbar, B., R. Klausner, and W.M. Linehan, Studying cancer families to identify kidney cancer genes. Annu Rev Med, 2003. 54: p. 217-33.

133. Gnarra, J.R., et al., Mutations of the VHL tumour suppressor gene in renal carcinoma. Nat Genet, 1994. 7(1): p. 85-90.

134. Kondo, K., et al., Comprehensive mutational analysis of the VHL gene in sporadic renal cell carcinoma: relationship to clinicopathological parameters. Genes Chromosomes Cancer, 2002. 34(1): p. 58-68.

135. Cohen, H.T. and F.J. McGovern, Renal-cell carcinoma. N Engl J Med, 2005. 353(23): p. 247790. 
136. Blankenship, C., et al., Alternate choice of initiation codon produces a biologically active product of the von Hippel Lindau gene with tumor suppressor activity. Oncogene, 1999. 18(8): p. 1529-35.

137. Iliopoulos, O., M. Ohh, and W.G. Kaelin, Jr., pVHL19 is a biologically active product of the von Hippel-Lindau gene arising from internal translation initiation. Proc Natl Acad Sci U S A, 1998. 95(20): p. 11661-6.

138. Schoenfeld, A., E.J. Davidowitz, and R.D. Burk, A second major native von Hippel-Lindau gene product, initiated from an internal translation start site, functions as a tumor suppressor. Proc Natl Acad Sci U S A, 1998. 95(15): p. 8817-22.

139. Kondo, K. and W.G. Kaelin, Jr., The von Hippel-Lindau tumor suppressor gene. Exp Cell Res, 2001. 264(1): p. 117-25.

140. Gordan, J.D. and M.C. Simon, Hypoxia-inducible factors: central regulators of the tumor phenotype. Curr Opin Genet Dev, 2007. 17(1): p. 71-7.

141. Kaelin, W.G., Jr., The von Hippel-Lindau tumor suppressor protein and clear cell renal carcinoma. Clin Cancer Res, 2007. 13(2 Pt 2): p. 680s-684s.

142. Maxwell, P.H., et al., The tumour suppressor protein VHL targets hypoxia-inducible factors for oxygen-dependent proteolysis. Nature, 1999. 399(6733): p. 271-5.

143. Clifford, S.C., et al., Contrasting effects on HIF-1alpha regulation by disease-causing PVHL mutations correlate with patterns of tumourigenesis in von Hippel-Lindau disease. Hum Mol Genet, 2001. 10(10): p. 1029-38.

144. Zbar, B., et al., Hereditary papillary renal cell carcinoma. J Urol, 1994. 151(3): p. 561-6.

145. Sudarshan, S. and W.M. Linehan, Genetic basis of cancer of the kidney. Semin Oncol, 2006. 33(5): p. 544-51.

146. Schmidt, L., et al., Germline and somatic mutations in the tyrosine kinase domain of the MET proto-oncogene in papillary renal carcinomas. Nat Genet, 1997. 16(1): p. 68-73.

147. Schmidt, L., et al., Novel mutations of the MET proto-oncogene in papillary renal carcinomas. Oncogene, 1999. 18(14): p. 2343-50.

148. Sudarshan, S., et al., Mechanisms of disease: hereditary leiomyomatosis and renal cell cancer--a distinct form of hereditary kidney cancer. Nat Clin Pract Urol, 2007. 4(2): p. 10410.

149. Tomlinson, I.P., et al., Germline mutations in FH predispose to dominantly inherited uterine fibroids, skin leiomyomata and papillary renal cell cancer. Nat Genet, 2002. 30(4): p. 40610.

150. Isaacs, J.S., et al., HIF overexpression correlates with biallelic loss of fumarate hydratase in renal cancer: novel role of fumarate in regulation of HIF stability. Cancer Cell, 2005. 8(2): p. 143-53.

151. Pollard, P.J., et al., Targeted inactivation of fh1 causes proliferative renal cyst development and activation of the hypoxia pathway. Cancer Cell, 2007. 11(4): p. 311-9.

152. Linehan, W.M. and B. Zbar, Focus on kidney cancer. Cancer Cell, 2004. 6(3): p. 223-8.

153. Birt, A.R., G.R. Hogg, and W.J. Dube, Hereditary multiple fibrofolliculomas with trichodiscomas and acrochordons. Arch Dermatol, 1977. 113(12): p. 1674-7.

154. Roth, J.S., et al., Bilateral renal cell carcinoma in the Birt-Hogg-Dube syndrome. J Am Acad Dermatol, 1993. 29(6): p. 1055-6.

155. Toro, J.R., et al., Birt-Hogg-Dube syndrome: a novel marker of kidney neoplasia. Arch Dermatol, 1999. 135(10): p. 1195-202.

156. Warren, M.B., et al., Expression of Birt-Hogg-Dube gene mRNA in normal and neoplastic human tissues. Mod Pathol, 2004. 17(8): p. 998-1011.

157. Nagy, A., et al., Lack of mutation of the folliculin gene in sporadic chromophobe renal cell carcinoma and renal oncocytoma. Int J Cancer, 2004. 109(3): p. 472-5.

158. Khoo, S.K., et al., Inactivation of BHD in sporadic renal tumors. Cancer Res, 2003. 63(15): p. 4583-7. 
159. Gad, S., et al., Mutations in BHD and TP53 genes, but not in HNF1beta gene, in a large series of sporadic chromophobe renal cell carcinoma. Br J Cancer, 2006.

160. Dorai, T., et al., Role of carbonic anhydrases in the progression of renal cell carcinoma subtypes: proposal of a unified hypothesis. Cancer Invest, 2006. 24(8): p. 754-79.

161. Mak, B.C. and R.S. Yeung, The tuberous sclerosis complex genes in tumor development. Cancer Invest, 2004. 22(4): p. 588-603.

162. Henske, E.P., Tuberous sclerosis and the kidney: from mesenchyme to epithelium, and beyond. Pediatr Nephrol, 2005. 20(7): p. 854-7.

163. Rakowski, S.K., et al., Renal manifestations of tuberous sclerosis complex: Incidence, prognosis, and predictive factors. Kidney Int, 2006. 70(10): p. 1777-82.

164. O'Callaghan, F.J., et al., An epidemiological study of renal pathology in tuberous sclerosis complex. BJU Int, 2004. 94(6): p. 853-7.

165. O'Callaghan, F.J., et al., Prevalence of tuberous sclerosis estimated by capture-recapture analysis. Lancet, 1998. 351(9114): p. 1490.

166. Kobayashi, T., et al., A germline insertion in the tuberous sclerosis (Tsc2) gene gives rise to the Eker rat model of dominantly inherited cancer. Nat Genet, 1995. 9(1): p. 70-4.

167. Kobayashi, T., et al., Renal carcinogenesis, hepatic hemangiomatosis, and embryonic lethality caused by a germ-line Tsc2 mutation in mice. Cancer Res, 1999. 59(6): p. 1206-11.

168. Parry, L., et al., Analysis of the TSC1 and TSC2 genes in sporadic renal cell carcinomas. Br J Cancer, 2001. 85(8): p. 1226-30.

169. Liu, M.Y., L. Poellinger, and C.L. Walker, Up-regulation of hypoxia-inducible factor 2alpha in renal cell carcinoma associated with loss of Tsc-2 tumor suppressor gene. Cancer Res, 2003. 63(10): p. 2675-80.

170. Oya, M., et al., Increased nuclear factor-kappa B activation is related to the tumor development of renal cell carcinoma. Carcinogenesis, 2003. 24(3): p. 377-84.

171. Oya, M., et al., Constitutive activation of nuclear factor-kappaB prevents TRAIL-induced apoptosis in renal cancer cells. Oncogene, 2001. 20(29): p. 3888-96.

172. An, J., M. Fisher, and M.B. Rettig, VHL expression in renal cell carcinoma sensitizes to bortezomib (PS-341) through an NF-kappaB-dependent mechanism. Oncogene, 2005. 24(9): p. 1563-70.

173. $\mathrm{Qi}, \mathrm{H}$. and M. Ohh, The von Hippel-Lindau tumor suppressor protein sensitizes renal cell carcinoma cells to tumor necrosis factor-induced cytotoxicity by suppressing the nuclear factor-kappaB-dependent antiapoptotic pathway. Cancer Res, 2003. 63(21): p. 7076-80.

174. An, J. and M.B. Rettig, Mechanism of von Hippel-Lindau protein-mediated suppression of nuclear factor kappa B activity. Mol Cell Biol, 2005. 25(17): p. 7546-56.

175. Makino, Y., et al., Inhibitory PAS domain protein is a negative regulator of hypoxia-inducible gene expression. Nature, 2001. 414(6863): p. 550-4.

176. Thomas, G.V., et al., Hypoxia-inducible factor determines sensitivity to inhibitors of mTOR in kidney cancer. Nat Med, 2006. 12(1): p. 122-7.

177. Neckers, L., Hsp90 inhibitors as novel cancer chemotherapeutic agents. Trends Mol Med, 2002. 8(4 Suppl): p. S55-61.

178. Kim, M.S., et al., Histone deacetylases induce angiogenesis by negative regulation of tumor suppressor genes. Nat Med, 2001. 7(4): p. 437-43.

179. Hudson, C.C., et al., Regulation of hypoxia-inducible factor 1alpha expression and function by the mammalian target of rapamycin. Mol Cell Biol, 2002. 22(20): p. 7004-14.

180. Semenza, G.L., Targeting HIF-1 for cancer therapy. Nat Rev Cancer, 2003. 3(10): p. 721-32.

181. Isaacs, J.S., et al., Hsp90 regulates a von Hippel Lindau-independent hypoxia-inducible factor-1 alpha-degradative pathway. J Biol Chem, 2002. 277(33): p. 29936-44.

182. Rini B, R.O., Bukowski R, AG-013736, a multi-target tyrosine kinase receptor inhibitor, demonstrates anti-tumor activity in a Phase 2 study of cytokine-refractory, metastatic renal cancer (RCC). J clin oncol, 2005. 23(380s). 
183. Amato RJ, M.A., Khan M, A Phase II trial of RAD001 in patients with metastaic renal cell carcinoma (MRCC). J clin oncol, 2006. 24(224s).

184. Dupont J, C.D., Gordon M, Phase I study of VEGF Trap in patients with solid tumors and lymphoma. Proc Am Soc Clin Oncol, 2003. 22: p. 194.

185. Kaelin, W.G., Jr., The von Hippel-Lindau tumor suppressor gene and kidney cancer. Clin Cancer Res, 2004. 10(18 Pt 2): p. 6290S-5S.

186. Kong-Beltran, M., J. Stamos, and D. Wickramasinghe, The Sema domain of Met is necessary for receptor dimerization and activation. Cancer Cell, 2004. 6(1): p. 75-84.

187. Zhang, Y.W., et al., Met decoys: will cancer take the bait? Cancer Cell, 2004. 6(1): p. 5-6.

188. Christensen, J.G., et al., A selective small molecule inhibitor of c-Met kinase inhibits c-Metdependent phenotypes in vitro and exhibits cytoreductive antitumor activity in vivo. Cancer Res, 2003. 63(21): p. 7345-55.

189. Sattler, M., et al., A novel small molecule met inhibitor induces apoptosis in cells transformed by the oncogenic TPR-MET tyrosine kinase. Cancer Res, 2003. 63(17): p. 5462-9.

190. Callinan, P.A. and A.P. Feinberg, The emerging science of epigenomics. Hum Mol Genet, 2006. 15 Spec No 1: p. R95-101.

191. Esteller, M., The necessity of a human epigenome project. Carcinogenesis, 2006. 27(6): p. 1121-5.

192. Bernstein, B.E., A. Meissner, and E.S. Lander, The mammalian epigenome. Cell, 2007. 128(4): p. 669-81.

193. Brock, M.V., J.G. Herman, and S.B. Baylin, Cancer as a manifestation of aberrant chromatin structure. Cancer J, 2007. 13(1): p. 3-8.

194. Herman, J.G. and S.B. Baylin, Gene silencing in cancer in association with promoter hypermethylation. N Engl J Med, 2003. 349(21): p. 2042-54.

195. Wilson, A.S., B.E. Power, and P.L. Molloy, DNA hypomethylation and human diseases. Biochim Biophys Acta, 2007. 1775(1): p. 138-62.

196. Herman, J.G., et al., Silencing of the VHL tumor-suppressor gene by DNA methylation in renal carcinoma. Proc Natl Acad Sci U S A, 1994. 91(21): p. 9700-4.

197. Esteller, M., Cancer epigenomics: DNA methylomes and histone-modification maps. Nat Rev Genet, 2007. 8(4): p. 286-98.

198. Ting, A.H., K.M. McGarvey, and S.B. Baylin, The cancer epigenome--components and functional correlates. Genes Dev, 2006. 20(23): p. 3215-31.

199. Fahrner, J.A., et al., Dependence of histone modifications and gene expression on DNA hypermethylation in cancer. Cancer Res, 2002. 62(24): p. 7213-8.

200. Kouzarides, T., Chromatin modifications and their function. Cell, 2007. 128(4): p. 693-705.

201. Lan, F., et al., A histone H3 lysine 27 demethylase regulates animal posterior development. Nature, 2007.

202. Tan, H., et al., The JMJD2 members of histone demethylase revisited. Mol Biol Rep, 2007.

203. Klose, R.J. and Y. Zhang, Regulation of histone methylation by demethylimination and demethylation. Nat Rev Mol Cell Biol, 2007. 8(4): p. 307-18.

204. Li, B., M. Carey, and J.L. Workman, The role of chromatin during transcription. Cell, 2007. 128(4): p. 707-19.

205. Balmain, A., J. Gray, and B. Ponder, The genetics and genomics of cancer. Nat Genet, 2003. 33 Suppl: p. 238-44.

206. Jones, P.A. and S.B. Baylin, The fundamental role of epigenetic events in cancer. Nat Rev Genet, 2002. 3(6): p. 415-28.

207. Schuebel, K.E., et al., Comparing the DNA Hypermethylome with Gene Mutations in Human Colorectal Cancer. PLoS Genet, 2007. 3(9): p. e157.

208. Derks, S., et al., Methylation-specific PCR unraveled. Cell Oncol, 2004. 26(5-6): p. $291-9$.

209. Foster, K., et al., Somatic mutations of the von Hippel-Lindau disease tumour suppressor gene in non-familial clear cell renal carcinoma. Hum Mol Genet, 1994. 3(12): p. 2169-73. 
210. Clifford, S.C., et al., Inactivation of the von Hippel-Lindau (VHL) tumour suppressor gene and allelic losses at chromosome arm $3 p$ in primary renal cell carcinoma: evidence for a VHL-independent pathway in clear cell renal tumourigenesis. Genes Chromosomes Cancer, 1998. 22(3): p. 200-9.

211. Banks, R.E., et al., Genetic and epigenetic analysis of von Hippel-Lindau (VHL) gene alterations and relationship with clinical variables in sporadic renal cancer. Cancer Res, 2006. 66(4): p. 2000-11.

212. Dulaimi, E., et al., Promoter hypermethylation profile of kidney cancer. Clin Cancer Res, 2004. 10(12 Pt 1): p. 3972-9.

213. Battagli, C., et al., Promoter hypermethylation of tumor suppressor genes in urine from kidney cancer patients. Cancer Res, 2003. 63(24): p. 8695-9.

214. da Silva, N.F., et al., Analysis of the Birt-Hogg-Dube (BHD) tumour suppressor gene in sporadic renal cell carcinoma and colorectal cancer. J Med Genet, 2003. 40(11): p. 820-4.

215. Breault, J.E., et al., Methylation of the gamma-catenin gene is associated with poor prognosis of renal cell carcinoma. Clin Cancer Res, 2005. 11(2 Pt 1): p. 557-64.

216. Chen, J., et al., The t $(1 ; 3)$ breakpoint-spanning genes LSAMP and NORE1 are involved in clear cell renal cell carcinomas. Cancer Cell, 2003. 4(5): p. 405-13.

217. Hoque, M.O., et al., Quantitative detection of promoter hypermethylation of multiple genes in the tumor, urine, and serum DNA of patients with renal cancer. Cancer Res, 2004. 64(15): p. 5511-7.

218. Morris, M.R., et al., Multigene methylation analysis of Wilms' tumour and adult renal cell carcinoma. Oncogene, 2003. 22(43): p. 6794-801.

219. Yamada, D., et al., Promoter hypermethylation of the potential tumor suppressor DAL1/4.1B gene in renal clear cell carcinoma. Int J Cancer, 2006. 118(4): p. 916-23.

220. Costa, V.L., et al., Quantitative promoter methylation analysis of multiple cancer-related genes in renal cell tumors. BMC Cancer, 2007. 7(1): p. 133.

221. Christoph, F., et al., Promoter hypermethylation profile of kidney cancer with new proapoptotic p53 target genes and clinical implications. Clin Cancer Res, 2006. 12(17): p. 5040-6.

222. Kempkensteffen, C., et al., Gene expression and promoter methylation of the XIAPassociated Factor 1 in renal cell carcinomas: Correlations with pathology and outcome. Cancer Lett, 2007.

223. Lee, M.G., et al., Promoter CpG hypermethylation and downregulation of XAF1 expression in human urogenital malignancies: implication for attenuated p53 response to apoptotic stresses. Oncogene, 2006. 25(42): p. 5807-22.

224. Sanz-Casla, M.T., et al., Loss of heterozygosity and methylation of p16 in renal cell carcinoma. Urol Res, 2003. 31(3): p. 159-62.

225. Agathanggelou, A., W.N. Cooper, and F. Latif, Role of the Ras-association domain family 1 tumor suppressor gene in human cancers. Cancer Res, 2005. 65(9): p. 3497-508.

226. Dreijerink, K., et al., The candidate tumor suppressor gene, RASSF1A, from human chromosome 3p21.3 is involved in kidney tumorigenesis. Proc Natl Acad Sci U S A, 2001. 98(13): p. 7504-9.

227. Gonzalgo, M.L., et al., Molecular profiling and classification of sporadic renal cell carcinoma by quantitative methylation analysis. Clin Cancer Res, 2004. 10(21): p. 7276-83.

228. Hori, Y., et al., Oxidative stress and DNA hypermethylation status in renal cell carcinoma arising in patients on dialysis. J Pathol, 2007. 212(2): p. 218-26.

229. Morrissey, C., et al., Epigenetic inactivation of the RASSF1A 3p21.3 tumor suppressor gene in both clear cell and papillary renal cell carcinoma. Cancer Res, 2001. 61(19): p. 7277-81.

230. Yoon, J.H., R. Dammann, and G.P. Pfeifer, Hypermethylation of the CpG island of the RASSF1A gene in ovarian and renal cell carcinomas. Int J Cancer, 2001. 94(2): p. 212-7.

231. Cairns, P., Gene methylation and early detection of genitourinary cancer: the road ahead. Nat Rev Cancer, 2007. 7(7): p. 531-43. 
232. Peters, I., et al., RASSF1A promoter methylation and expression analysis in normal and neoplastic kidney indicates a role in early tumorigenesis. Mol Cancer, 2007. 6(1): p. 49.

233. Bachman, K.E., et al., Methylation-associated silencing of the tissue inhibitor of metalloproteinase-3 gene suggest a suppressor role in kidney, brain, and other human cancers. Cancer Res, 1999. 59(4): p. 798-802.

234. Ibanez de Caceres, I., et al., Identification of novel target genes by an epigenetic reactivation screen of renal cancer. Cancer Res, 2006. 66(10): p. 5021-8.

235. Astuti, D., et al., SLIT2 promoter methylation analysis in neuroblastoma, Wilms' tumour and renal cell carcinoma. Br J Cancer, 2004. 90(2): p. 515-21.

236. Morris, M.R., et al., Tumor suppressor activity and epigenetic inactivation of hepatocyte growth factor activator inhibitor type 2/SPINT2 in papillary and clear cell renal cell carcinoma. Cancer Res, 2005. 65(11): p. 4598-606.

237. Okuda, H., et al., Epigenetic inactivation of the candidate tumor suppressor gene HOXB13 in human renal cell carcinoma. Oncogene, 2006. 25(12): p. 1733-42.

238. Zhang, Q., et al., Aberrant methylation of the $8 \mathrm{p} 22$ tumor suppressor gene DLC1 in renal cell carcinoma. Cancer Lett, 2006.

239. Urakami, S., et al., Wnt antagonist family genes as biomarkers for diagnosis, staging, and prognosis of renal cell carcinoma using tumor and serum DNA. Clin Cancer Res, 2006. 12(23): p. 6989-97.

240. Brandes, J.C., H. Carraway, and J.G. Herman, Optimal primer design using the novel primer design program: MSPprimer provides accurate methylation analysis of the ATM promoter. Oncogene, 2007.

241. Laird, P.W., Oncogenic mechanisms mediated by DNA methylation. Mol Med Today, 1997. 3(5): p. 223-9.

242. Baylin, S.B., et al., Alterations in DNA methylation: a fundamental aspect of neoplasia. Adv Cancer Res, 1998. 72: p. 141-96.

243. Pantuck, A.J., et al., Incidental renal tumors. Urology, 2000. 56(2): p. 190-6.

244. Kim, H.L., et al., Using tumor markers to predict the survival of patients with metastatic renal cell carcinoma. J Urol, 2005. 173(5): p. 1496-501.

245. Wei, S.H., et al., Methylation microarray analysis of late-stage ovarian carcinomas distinguishes progression-free survival in patients and identifies candidate epigenetic markers. Clin Cancer Res, 2002. 8(7): p. 2246-52.

246. Esteller, M., et al., Inactivation of the DNA-repair gene MGMT and the clinical response of gliomas to alkylating agents. N Engl J Med, 2000. 343(19): p. 1350-4.

247. Esteller, M., et al., Hypermethylation of the DNA repair gene O(6)-methylguanine DNA methyltransferase and survival of patients with diffuse large B-cell lymphoma. J Natl Cancer Inst, 2002. 94(1): p. 26-32.

248. Bar-Sela, G., K.M. Jacobs, and D. Gius, Histone deacetylase inhibitor and demethylating agent chromatin compaction and the radiation response by cancer cells. Cancer J, 2007. 13(1): p. 65-9.

249. Reu, F.J., et al., Overcoming resistance to interferon-induced apoptosis of renal carcinoma and melanoma cells by DNA demethylation. J Clin Oncol, 2006. 24(23): p. 3771-9.

250. Shang, D., et al., Demethylating agent 5-aza-2'-deoxycytidine enhances susceptibility of renal cell carcinoma to paclitaxel. Urology, 2007. 69(5): p. 1007-12.

251. Reuter, V.E. and J.C. Presti, Jr., Contemporary approach to the classification of renal epithelial tumors. Semin Oncol, 2000. 27(2): p. 124-37.

252. Reuter, V.E., The pathology of renal epithelial neoplasms. Semin Oncol, 2006. 33(5): p. 53443.

253. Zisman, A., et al., Risk group assessment and clinical outcome algorithm to predict the natural history of patients with surgically resected renal cell carcinoma. J Clin Oncol, 2002. 20(23): p. 4559-66. 
254. Khan, A., et al., Renal medullary carcinoma: sonographic, computed tomography, magnetic resonance and angiographic findings. Eur J Radiol, 2000. 35(1): p. 1-7.

255. Davis, C.J., Jr., F.K. Mostofi, and I.A. Sesterhenn, Renal medullary carcinoma. The seventh sickle cell nephropathy. Am J Surg Pathol, 1995. 19(1): p. 1-11.

256. Dahl, E., et al., Frequent loss of SFRP1 expression in multiple human solid tumours: association with aberrant promoter methylation in renal cell carcinoma. Oncogene, 2007.

257. Wang, X.F., et al., Epigenetic modulation of retinoic acid receptor beta2 by the histone deacetylase inhibitor MS-275 in human renal cell carcinoma. Clin Cancer Res, 2005. 11(9): p. 3535-42. 


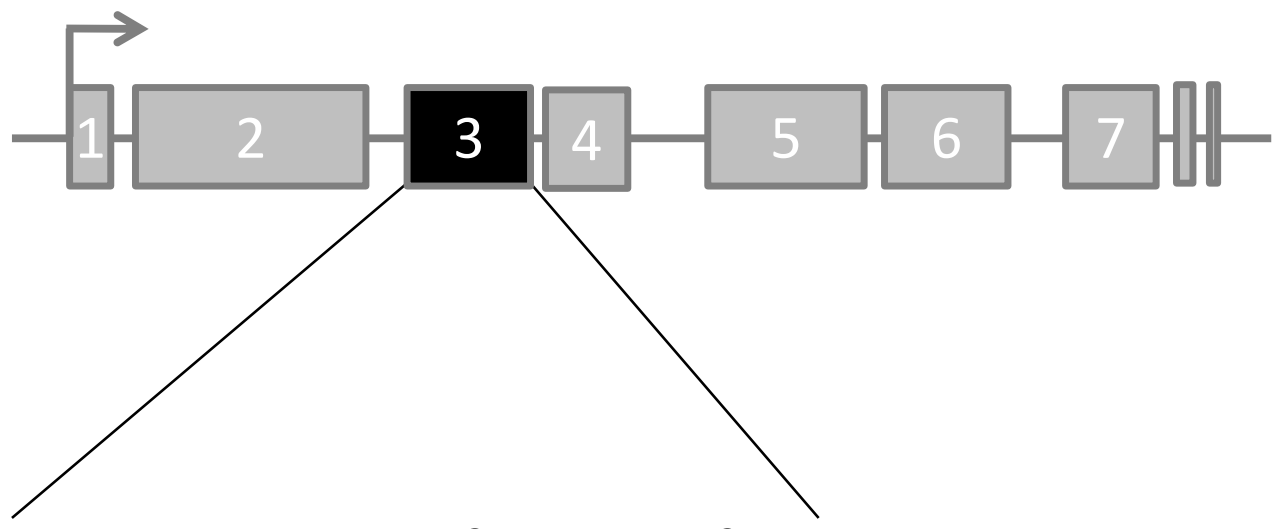

Prognostic significance of

Gremlin1 (GREM1) promoter

CpG island hypermethylation

in clear cell renal cell

carcinoma

Iris J.H. van Vlodrop, Marcella M.L.L. Baldewijns, Kim M.

Smits, Leo J. Schouten, Leander van Neste, Wim van

Criekinge, Hendrik van Poppel, Evelyne Lerut, Kornel E.

Schuebel, Nita Ahuja, James G. Herman, Adriaan P. de

Bruïne, Manon van Engeland

American Journal of Pathology. 2010;176(2):575-84 


\begin{abstract}
Gremlin1 (GREM1), a bone morphogenetic protein antagonist and putative angiogenesis-modulating gene, is silenced by promoter hypermethylation in human malignancies. Here we study GREM1 methylation in clear cell renal cell carcinoma (ccRCC) and its impact on tumor characteristics and clinical outcome. Three GREM1 promoter CpG island regions(i, ii, iii) were analyzed by methylation specific PCR and/or bisulfite sequencing in ccRCC cell lines and ccRCCs from two independent patient series. Results were correlated with clinicopathological- and angiogenic parameters. Bisulfite sequencing of ccRCC cell lines showed GREM1 methylation, associated with absence of GREM1 mRNA. GREM1 methylation prevalence in cCRCCs varied between regions: $55 \%, 24 \%$ and $20 \%$ for regions-i, -ii and -iii respectively. GREM1-region-iii methylation was associated with increased tumor size $(p=0.02)$, stage $(p=0.013)$, grade $(p=0.04)$, tumor- $(p=0.001)$ and endothelial cell $(p=0.0001)$ proliferation and decreased mean vessel density $(p=0.001)$ in a hospital-based ccRCC series $(n=150)$. In univariate analysis, GREM1-region-iii methylated ccRCCs had a significant worse survival when compared to unmethylated ccRCCs (hazard ratio $(H R)=2.35$, 95\% Cl:1.29-4.28), but not in multivariate analysis ( $\mathrm{HR}=0.88,95 \% \mathrm{Cl}: 0.45-1.74)$. In a population-based validation series(n=185), GREM1-region-iii methylation was associated with increased Fuhrman grade $(p=0.03)$ and decreased overall survival $(p=0.001)$ in univariate and multivariate analysis ( $\mathrm{HR}=2.32,95 \% \mathrm{Cl}: 1.52-3.53$ and $\mathrm{HR}=2.27,95 \% \mathrm{Cl}: 1.44-3.59$, respectively). The strong correlation between GREM1-region-iii promoter methylation and increased malignancy and its correlation with active angiogenesis indicates a role for GREM1 in ccRCC carcinogenesis and tumor angiogenesis.
\end{abstract}




\section{Introduction}

Clear cell renal cell carcinoma (ccRCC) accounts for $\sim 75 \%$ of all cases of renal cell can$\mathrm{cer}^{1}$, and is characterized by increased vascularization and an unclear clinical prognosis. Currently, patient performance status, tumor size, nodal and distant metastasis (TNM)-stage and Fuhrman nuclear grade are the most useful predictors of patient outcome ${ }^{2}$. However, interest in additional prognostic molecular markers is growing. Inactivation of the von Hippel-Lindau (VHL) gene has been shown to be a common and early event in the carcinogenesis of $c C R C C^{3-5}$. 50 to $70 \%$ of cCRCC tumors harbor a $\mathrm{VHL}$ mutation $^{5,6}$ and in 5 to $20 \%$ of cCRCCs VHL is silenced by promoter CpG island hypermethylation $^{7,8}$. Although defective $\mathrm{VHL}$ functioning is a key event in the development in both sporadic and hereditary ccRCCs, alterations in the structure or regulation of the $V H L$ gene do not appear to be directly associated with tumor cell proliferation and patient prognosis ${ }^{9,10}$, suggesting a complex interplay of additional genetic and epigenetic changes which may accumulate during RCC development.

One intriguing candidate gene in this development may be the highly conserved Gremlin1 (GREM1) which we have identified to be expressed upon 5'aza-2-deoxycytidine (DAC) treatment in four ccRCC cell lines in a epigenome-wide screen. GREM1 is a secreted glycoprotein that binds and antagonizes bone morphogenetic proteins (BMPs) $2,-4$, and -7 , thereby preventing the ability of these ligands to interact with their receptors resulting in inhibition of downstream transforming growth factor- $\beta$ (TGF- $\beta$ ) signaling $^{11-13}$. BMPs, the largest subfamily of the TGF- $\beta$ superfamily, are pleiotropic growth factors serving multiple functions in many cell and tissue types including angiogenesis, proliferation, apoptosis, differentiation, chemotaxis, and extracellular matrix production during development as well as in adult life ${ }^{14}$. BMPs and BMP-antagonists such as Gremlin1, have been demonstrated in regulating renal development ${ }^{15-18}$ and in the pathogenesis of nephropathy ${ }^{19-21}$. BMP-independent activities of GREM1 in can$\operatorname{cer}^{12,22}$ and angiogenesis ${ }^{23}$ have also been demonstrated. However, the role of GREM1 in renal cancer pathogenesis and the mechanisms by which GREM1 gene expression is regulated remains incompletely understood.

GREM1 has been identified as one of the targets of Polycomb Repressive Complex 2 (PCR2) subunit protein SUZ12 ${ }^{24}$, which marks repressive chromatin during early stages of embryonic stem cell differentiation. Compared to unmarked stem cell genes, Polycomb group (PcG) targets have up to 12 -fold increased susceptibility to develop cancer-specific promoter CpG island hypermethylation ${ }^{25}$, suggesting that epigenetic mechanisms may play a key role in regulating GREM1 expression. Further evidence that this mechanism is important in cancer development has recently been provided by the observations that GREM1 promoter CpG island methylation is prevalent in other tumor types such as gastric ${ }^{26}$, bladder- and prostate cancer ${ }^{27}$.

The aim of this study was to investigate GREM1 promoter CpG island methylation and its association with clinicopathological- and angiogenesis parameters in CCRCC. 


\section{Materials and Methods}

\section{Cell lines, study populations, and clinical specimens}

Four ccRCC cell lines (SKRC1, SKRC10, SKRC52, SKRC59), kindly provided by Dr. E. Oosterwijk, Nijmegen Center for Molecular Life Sciences (NCMLS), Nijmegen, The Netherlands, were cultured in RPMI 1640 media (Invitrogen, Breda, the Netherlands) supplemented with $10 \%$ heat-inactivated fetal bovine serum (HyClone, Etten-Leur, the Netherlands).

Formalin-fixed and paraffin embedded tumor samples $(n=150)$ from patients with sporadic ccRCC, treated with radical or partial nephrectomy without any neo-adjuvant therapy, were collected retrospectively and further referred to as hospital-based series. Of 50 ccRCC patients also histological normal renal tissue was available. In addition, histological normal renal tissue samples (formalin-fixed, paraffin embedded) of 61 non-RCC patients was collected. All samples were derived from the archives of the Department of Histopathology, University Hospital of Leuven and Department of Pathology, Maastricht University Medical Center. Hematoxylin eosin-stained slides were revised by an experienced genitourinary pathologist to confirm nuclear Fuhrman grading. Tissues were sectioned into $20 \mu \mathrm{m}$ slides and genomic DNA was isolated and purified using the Puregene DNA purification kit according to the manufacturer's instructions (BIOzym, Landgraaf, The Netherlands). Data of postoperative follow-up (median follow-up 64 months, range 1-153 months) at regular intervals by means of physical examination, chest X-ray, abdominal computed tomography or ultrasound, and when indicated a bone scan, was available (for patient characteristics see table 1).

A second independent, population-based validation series of formalin-fixed, paraffin embedded ccRCC samples ( $n=185$ ) was obtained from the Netherlands Cohort Study on diet and cancer (NLCS) ${ }^{28}$ and collected from 51 pathology laboratories throughout the Netherlands with a median follow-up period of 79 months, range 0-218 months. This series will be further referred to as population-based series. Tissue collection and DNA isolation have been described in detail elsewhere ${ }^{29}$. Hematoxylin eosin-stained slides were revised by an experienced genitourinary pathologist. Information on tumor size and stage was available from the pathological reports and cancer registries. Follow-up was accomplished by record linkage to the municipal population registry and the causes of death registry from Statistics Netherlands ${ }^{10}$ (for patient characteristics see table 2). This study was approved by the Medical Ethical Committee of the Maastricht University Medical Center. 
Table 1. GREM1 promoter CpG island methylation associated with clinical, histopathological, and angiogenesis-related patient characteristics (hospital-based series)

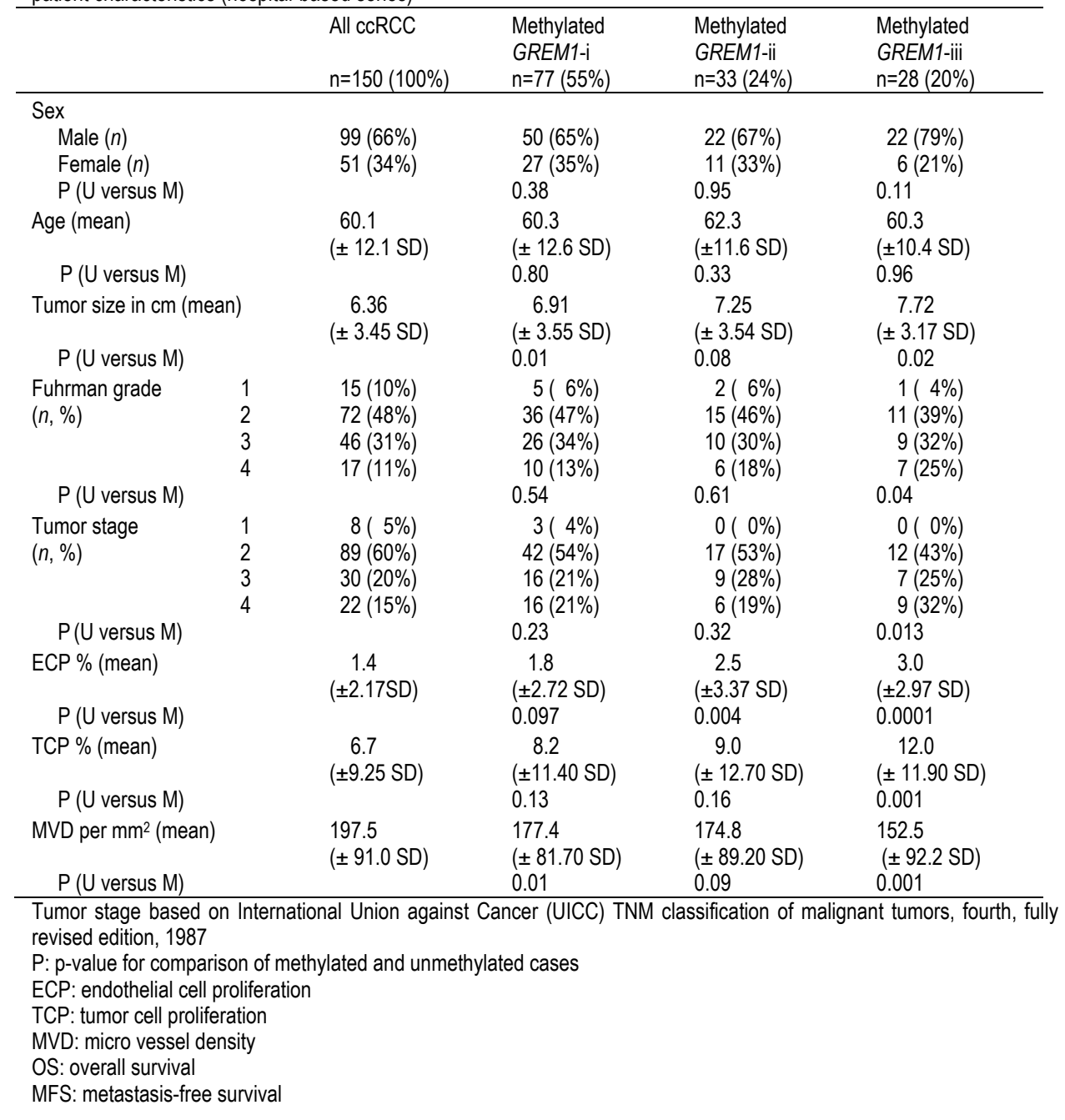


Table 2. GREM1 promoter CpG island methylation associated with clinical, histopathological, and angiogenesis-related patient characteristics (population-based series)

\begin{tabular}{|c|c|c|c|}
\hline & & $\begin{array}{l}\text { All ccRCC } \\
n=185(100 \%)\end{array}$ & $\begin{array}{l}\text { Methylated } \\
\text { GREM1-iii } \\
\mathrm{n}=68(40 \%)\end{array}$ \\
\hline \multicolumn{4}{|l|}{ Sex } \\
\hline \multicolumn{2}{|l|}{ Male $(n)$} & $108(59 \%)$ & $44(65 \%)$ \\
\hline \multicolumn{2}{|l|}{ Female $(n)$} & $74(41 \%)$ & $24(35 \%)$ \\
\hline \multicolumn{2}{|c|}{$\mathrm{P}(\mathrm{U}$ versus $\mathrm{M})$} & & 0.32 \\
\hline \multicolumn{2}{|c|}{ Age (mean) } & $\begin{array}{c}67.4 \\
( \pm 4.7 \mathrm{SD})\end{array}$ & $\begin{array}{c}67.2 \\
( \pm 5.2 \mathrm{SD})\end{array}$ \\
\hline \multicolumn{2}{|c|}{$\mathrm{P}(\mathrm{U}$ versus $\mathrm{M})$} & & 0.49 \\
\hline \multicolumn{2}{|c|}{ Tumor size in $\mathrm{cm}$ (mean) } & $\begin{array}{c}7.9 \\
( \pm 3.9 \mathrm{SD})\end{array}$ & $\begin{array}{c}7.5 \\
( \pm 3.17 \mathrm{SD})\end{array}$ \\
\hline \multicolumn{2}{|c|}{$\mathrm{P}$ (U versus $\mathrm{M})$} & & 0.16 \\
\hline & 1 & $42(23 \%)$ & $10(15 \%)$ \\
\hline \multirow{3}{*}{$(n, \%)$} & 2 & $66(36 \%)$ & $22(32 \%)$ \\
\hline & 3 & $47(26 \%)$ & $23(34 \%)$ \\
\hline & 4 & $27(15 \%)$ & $13(19 \%)$ \\
\hline \multicolumn{2}{|c|}{$\mathrm{P}$ (U versus $\mathrm{M})$} & & 0.03 \\
\hline Tumor stage & 1 & $4(2 \%)$ & $0(0 \%)$ \\
\hline \multirow[t]{3}{*}{$(n, \%)$} & 2 & $81(45 \%)$ & $27(40 \%)$ \\
\hline & 3 & $63(35 \%)$ & $23(34 \%)$ \\
\hline & 4 & $32(18 \%)$ & $18(26 \%)$ \\
\hline \multicolumn{2}{|c|}{$\mathrm{P}(\mathrm{U}$ versus $\mathrm{M})$} & & 0.08 \\
\hline
\end{tabular}

\section{Drug treatment and gene expression analysis}

cCRCC cell lines SKRC1, SKRC10, SKRC52, and SKRC59 were treated with 5'aza-2deoxycytidine (DAC) or Trichostatin A (TSA), which inhibit DNA methylation and histone deacetylases, respectively. 10\% confluent RCC cells were cultured in RPMI 1640 media containing $10 \%$ FBS with $5 \mu \mathrm{M}$ (DAC) (DAC; Sigma, St. Louis, MO; stock solution: $1 \mathrm{mmol} / \mathrm{L}$ in PBS) for 96 hours, replacing media and DAC every 24 hours. Cell treatment with 300nM TSA (Sigma; stock solution: $5 \mathrm{mM}$ dissolved in ethanol) was performed for 18 hours, starting at $\sim 30 \%$ cell confluency. Mock treated cells were grown in parallel with the DAC treatment by addition of equal volumes of PBS without drugs.

RNA of mock-, DAC-, and TSA-treated cells was isolated using the RNeasy kit (Qiagen, Valencia, CA) according to the manufacturers' instructions. For real time RT-PCR, $1 \mu \mathrm{g}$ of total RNA was reverse transcribed by using Ready-To-Go ${ }^{\mathrm{TM}}$ You-Prime First-Strand Beads (Amersham Biosciences/GE Health care, Piscataway, NJ) with addition of random hexamers $(0.2 \mu \mathrm{g}$ per reaction). RNA of a subset of the hospital-based series primary ccRCCs and normal renal tissue from non-cancerous patients was isolated from frozen tissue using the GenElute ${ }^{\mathrm{TM}}$ Total RNA kit (Sigma) according to the manufacturers' instructions. For real time RT-PCR, $1 \mu \mathrm{g}$ of total RNA was reverse transcribed by using the iScript ${ }^{\mathrm{TM}}$ CDNA synthesis kit (Bio-Rad, Veenendaal, the Netherlands). (Primer sequences and PCR conditions are provided in table 3 ). 


\section{GREM1 methylation-specific PCR and bisulfite sequencing}

The highly conserved human GREM1 gene (accession number NM_013372) is located on chromosome 15q13-q15. For CpG island prediction, EMBOSS (http://bioinfo.hku.hk/EMBOSS) software using the following criteria (Obs/Exp: 0.6, MinPC: 50, length: 200) was used. This resulted in the identification of three closely located CpG islands from $-650 \mathrm{bp}$ to $+1671 \mathrm{bp}$ relative to the transcription start site (TSS) (figure 1.A), which will be further considered as one island. To cover a large part of the promoter region for GREM1 methylation analysis, three different nested methylation-specific PCR (MSP) primer sets (GREM1-region i, -region ii, and -region iii) were designed (see figure 1.A). GREM1 promoter CpG island methylation was determined by chemical modification of genomic DNA with sodium bisulfite and subsequent MSP as described in detail elsewhere ${ }^{30-32}$. In brief, 500 ng of DNA was modified by sodium bisulfite using the EZ DNA methylation kit (Zymo Research, Orange, California) according to the manufacturer's instruction. To facilitate MSP analysis on DNA retrieved from formalin-fixed paraffin embedded tissue, DNA was first amplified with flanking PCR primers that amplify bisulfite-modified DNA but do not preferentially amplify methylated or unmethylated DNA. The resulting fragment was used as a template for the MSP reaction. GREM1-region i, -region ii, and -region iii methylation was analyzed on the hospital-based series of ccRCCs. On the population-based series, GREM1-region iii MSP was performed. All PCRs were performed with controls for unmethylated alleles (DNA from normal lymphocytes or DNA from human umbilical vein endothelial cells (HUVEC), methylated alleles [normal lymphocyte DNA treated in vitro with Sssl methyltransferase (New England Biolabs, Leusden, the Netherlands)], and a control without DNA. Primer sequences and PCR conditions are provided in table 3. Ten $\mu$ l of each MSP reaction was directly loaded onto $2 \%$ agarose gels containing GelStar Nucleic Acid Gel Stain (Cambrex, New Jersey, USA), and visualized under UV illumination. The methylation status of the hospital-based ccRCC series was successfully obtained in $93-95 \%$ (138-141 of 149, one sample failed to provide a sufficient amount of DNA), dependent on the primer set used, and in 91\% (168 of 185) of the population-based series. To assess reproducibility, MSP reactions have been performed in duplicate or triplicate starting from DNA amplification with flanking PCR primers. The reproducibility was $82 \%, 95 \%$, and $97 \%$ for primer set $\mathrm{i}$, ii, and iii, respectively in the hospital-based series and $84 \%$ in the population-based series. Non-concordant MSP results were analyzed a third time and a two out of three concordance was used as end result.

For bisulfite sequencing, PCR products were cloned using the TOPO TA cloning kit (Invitrogen, Breda, the Netherlands), single colonies were sequenced using M13 primer, BigDye Terminator v1.1 Cycle Sequencing Kit in accordance to the manufacturer's instruction. Primer sequences and PCR conditions are provided in table 3.

\section{Assessment of angiogenesis and tumor parameters}

Quantification of micro vessel density (MVD), endothelial cell proliferation (ECP), and tumor cell proliferation (TCP) in the hospital-based series has been described in detail elsewhere ${ }^{33}$.

Briefly, CD34/Ki67 double immunohistochemical staining ${ }^{34}$ was used to analyze MVD, ECP and TCP. One tissue slide was analyzed per tumor. For assessment of the vascular 
density within a tumor tissue slide, 1 hotspot (most vascularized microscopic field) was selected and 4 areas were chosen randomly. Vessel counts were performed at 200x magnification using an optical grid. The presence of a vascular lumen was not necessary to identify a micro vessel. MVD was expressed as vessels per $\mathrm{mm}^{2}$. Next, a total number of at least 500 intratumoral endothelial cells and 500 tumor cells were evaluated in consecutive fields at a 400x magnification and the fractions of proliferating endothelial cells (ECP\%) and tumor cells (TCP\%) were assessed. ECP\% and TCP\% were calculated according to the following formulas: ECP\% = (the number of endothelial cells with Ki67-stained nuclei/total number of endothelial cells evaluated) x 100; TCP\% $=$ (the number of tumor cells with Ki67-stained nuclei/total number of tumor cells evaluated) $\times 100$.
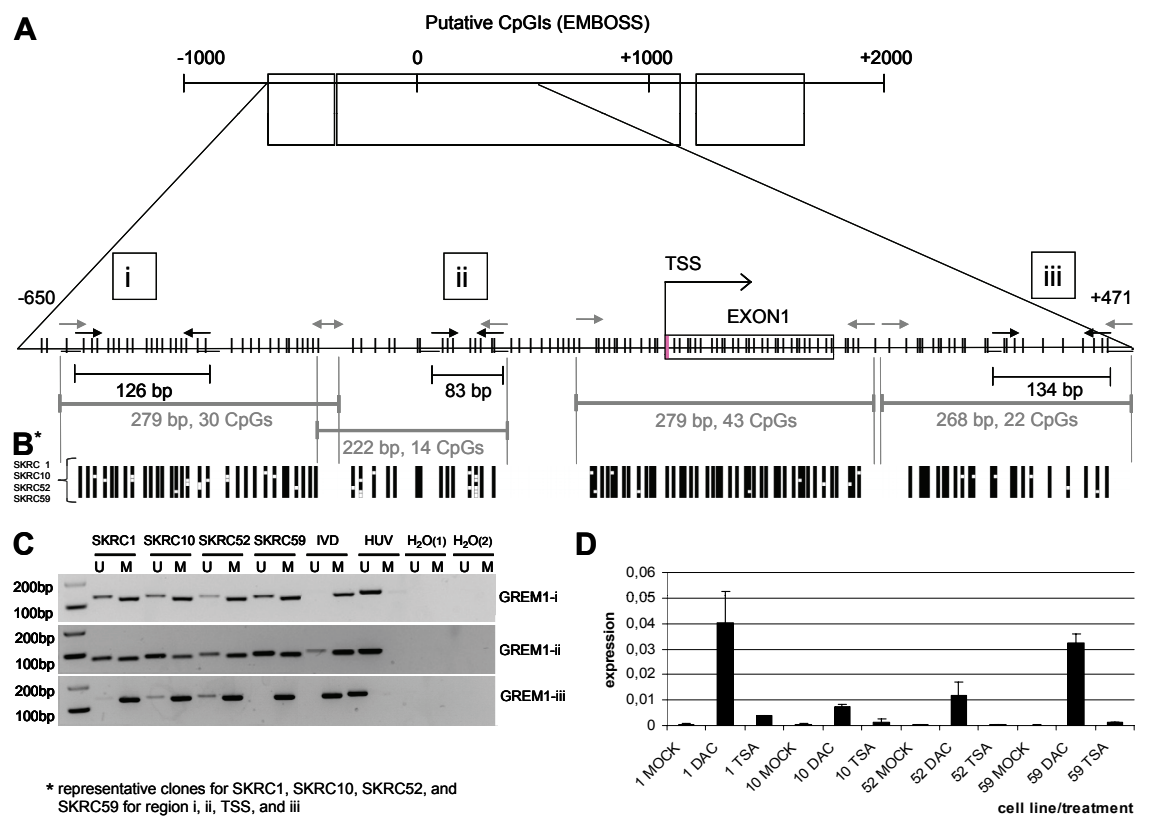

Figure 1. GREM1 promoter $\mathrm{CpG}$ island, methylation analyses, and mRNA expression in ccRCC cell lines GREM1 putative promoter $\mathrm{CpG}$ island relative to the transcription start site (TSS), including the locations of BSseq primer sets (i, ii, TSS, and iii; gray arrows: sequence primer locations) and MSP primer sets i, ii, and iii (underlined: flank PCR primer locations, black arrows: methylation specific PCR primer location, respectively) (A) with representive BSseq (B), MSP (C), and mRNA expression (D) results of ccRCC cell lines SKRC1, SKRC10, SKRC52, SKRC59. mRNA expression data resulted after three independent experiments.

Open/closed squares indicate unmethylated/methylated CpGs. U: unmethylated product; M: methylated product; IVD: methylation positive control; HUV: methylation negative control; $\mathrm{H} 2 \mathrm{O}(1)$ : Flank PCR control without DNA; $\mathrm{H} 2 \mathrm{O}(2)$ : $\mathrm{MSP}$ control without DNA. DAC: 5'aza-2-deoxycytidine, TSA: Trichostatin A. 
Table 3. PCR primers and conditions for GREM1

\begin{tabular}{|c|c|c|c|c|c|c|}
\hline method & & Forward $5^{\prime}>3^{\prime}$ & Reverse $5^{\prime}>3$ ' & $\begin{array}{l}\mathrm{Tm} \\
\left({ }^{\circ} \mathrm{C}\right)\end{array}$ & $\begin{array}{l}\text { cycles } \\
\text { (n) }\end{array}$ & $\begin{array}{l}\text { length } \\
\text { (bp) }\end{array}$ \\
\hline RT & & $\begin{array}{l}\text { CAGCCTA- } \\
\text { CACGGTGGGAGC }\end{array}$ & CTGCTCTGAGTCATTGTGCTGG & 60 & 40 & 128 \\
\hline \multirow[t]{3}{*}{ MSP i } & $\mathrm{FI}$ & $\begin{array}{l}\text { TGGYGA- } \\
\text { TAGGTTTTTGTTGG }\end{array}$ & $\begin{array}{l}\text { CCCCTCTAAAAAAAACRAAAC- } \\
\text { TA }\end{array}$ & 56 & 35 & 156 \\
\hline & $U$ & $\begin{array}{l}\text { GTTTTTGTTGGTGG } \\
\text { TTAGTGAGTTT }\end{array}$ & $\begin{array}{l}\text { AACAAAACTACAAAA- } \\
\text { TACTCTAATCAAACA }\end{array}$ & 62 & 30 & 134 \\
\hline & M & $\begin{array}{l}\text { TGTTGGCGGTTAGC } \\
\text { GAGTTC }\end{array}$ & $\begin{array}{l}\text { GAAACTACGAAA- } \\
\text { TACTCTAATCGAACG }\end{array}$ & 62 & 30 & 126 \\
\hline \multirow[t]{3}{*}{ MSP ii } & $\mathrm{Fl}$ & $\begin{array}{l}\text { TTTTGGGGTGATTTT } \\
\text { TTTTAGT }\end{array}$ & САССССТССТАСТТСССС & 56 & 35 & 96 \\
\hline & $U$ & $\begin{array}{l}\text { GTGATTTTTTTTTAGT } \\
\text { TGGTTTGGGT }\end{array}$ & АССССТССТАСТТССССАСА & 64 & 35 & 88 \\
\hline & M & $\begin{array}{l}\text { ATTTTTTTTAGTCGG } \\
\text { TTCGGGC }\end{array}$ & СССТССТАСТTCCCCGCG & 64 & 35 & 83 \\
\hline \multirow[t]{3}{*}{ MSP iii } & $\mathrm{FI}$ & $\begin{array}{l}\text { GGGGTTTTTTTTTGTT } \\
\text { GAGGT }\end{array}$ & $\begin{array}{l}\text { CTACTACCACCAACAC- } \\
\text { CAAAAAC }\end{array}$ & 56 & 35 & 161 \\
\hline & $U$ & $\begin{array}{l}\text { TTTTTTTGTTGAGGT } \\
\text { TGTGGATATT }\end{array}$ & $\begin{array}{l}\text { CAAAAACATATT- } \\
\text { CAAAAACCTCCA }\end{array}$ & 65 & 25 & 140 \\
\hline & M & $\begin{array}{l}\text { TTTGTTGAGGTCGC } \\
\text { GGATATC }\end{array}$ & AAAACGTATTCGAAAACCTCCG & 65 & 25 & 134 \\
\hline BSseq i & & $\begin{array}{l}\text { TGGYGA- } \\
\text { TAGGTTTTTGTTGG }\end{array}$ & СССАААТСТАААСТТТСССТАТС & 60 & 35 & 279 \\
\hline BSseq ii & & $\begin{array}{l}\text { GATAGG- } \\
\text { GAAAGTTTA- } \\
\text { GATTTGGG }\end{array}$ & САССССТССТАСТТСССС & 64 & 35 & 222 \\
\hline BSseq iii & & $\begin{array}{l}\text { AGGGTYGTAAAT- } \\
\text { TAATTTAGGATT }\end{array}$ & $\begin{array}{l}\text { CTACTACCACCAACAC- } \\
\text { CAAAAAC }\end{array}$ & 60 & 40 & 268 \\
\hline BSseq TSS & & $\begin{array}{l}\text { GGYGTTTGGTTAAT } \\
\text { GGAGAGG }\end{array}$ & CRCCCACTCACATCCCTACC & 62 & 35 & 279 \\
\hline
\end{tabular}

RT: real-time reverse transcriptase PCR; MSP i, ii, iii: methylation specific PCR GREM1-region i, GREM1-region ii, GREM1-region iii, respectively; M: methylation sensitive primers; U: non-methylation sensitive primers; BSseq i, ii, iii, TSS: bisulfite sequencing GREM1-region i, ii, iii, and around transcription start site.

\section{Statistical analysis}

Cause-specific survival was defined as the time from cancer diagnosis until renal cancer-related death or until the end of follow-up. Differences in clinicopathological and angiogenesis characteristics between ccRCCs with and without GREM1 promoter CpG island methylation were evaluated with the Student's t-tests and Pearson's $\chi^{2}$ tests. Kaplan-Meier analyses and log-rank tests were used to estimate the overall influence of GREM1 promoter CpG island methylation on cause-specific survival. Hazard ratios (HR) and corresponding 95\% confidence interval $(\mathrm{Cl})$ were assessed by use of Cox proportional hazard models. Factors were considered possible confounders if they were known prognostic factors for renal cancer and influenced the crude HR. Possible confounders that were included in the model for both series were sex, age at diagnosis, cancer stage, tumor size and nuclear grade. The proportional hazard assumption was tested using the Schoenfeld residuals. Analyses were performed by use of the statistical package STATA 9.0. All reported $P$ values are two-sided and $P$ values $\leq 0.05$ were considered statistically significant. 


\section{Results}

Promoter CPG island methylation and down regulation of GREM1 mRNA expression in ccRCC cell lines

GREM1 promoter $\mathrm{CpG}$ island methylation and mRNA expression were analyzed by MSP and real time RT-PCR in the cCRCC cell lines SKRC1, SKRC10, SKRC52, SKRC59. All four cell lines were heavily methylated at region $\mathrm{i}$, region $\mathrm{ii}$, and region iii of the $\mathrm{CpG}$ island (figure 1.C). MSP data were confirmed by bisulfite sequencing of region i (279 bp, 30 CpGs), region ii (222 bp, 14 CpGs) and region iii (268 bp, 22 CpGs). Methylation at the transcription start site (TSS) (279 bp, $43 \mathrm{CpGs}$ ) was assessed by bisulfite sequencing (figure 1.B). As shown in figure 1.D, little or no mRNA expression is observed in SKRC1, SKRC10, SKRC52, and SKRC59. mRNA expression could be induced in all four cell lines by DAC but not, or to a much lesser extent, by TSA.

\section{GREM1 promoter CPG island hypermethylation in cCRCCs varies at different regions in the promoter $C p G$ island}

To analyze GREM1 promoter CpG island methylation in primary ccRCCs, a hospitalbased series of ccRCCs was analyzed for methylation at three regions in the promoter. $63 \%$ (93/147, 3 samples did not yield a MSP result in region $\mathrm{i}$, region ii and region iii) of the ccRCCs showed methylation of one or more of the three analyzed regions. A decrease of methylation prevalence was seen more downstream in the analyzed area, with $55 \%(77 / 141)$ methylation for region i (-648 - -462), 24\% (33/139) for region ii ($236--140)$, and $20 \%(28 / 138)$ for region iii $(+311-+472)$ (table 1). Methylation in matching histological normal renal tissues was observed in $28 \%(14 / 50), 16 \%(8 / 50)$, and $10 \%(5 / 50)$ for region $\mathrm{i}$, ii, and iii, respectively (data not shown). In histological normal renal tissues from non-cancer patients, $0-16 \%$ methylation was observed in the sub regions (region i: 7/61, region ii: 10/61, region iii: 0/61), data not shown.

\section{GREM1 promoter CPG island methylation at region iii is associated with in- creased tumor size, tumor grade and -stage, angiogenesis and poor prognosis}

Next, we studied the association of GREM1 promoter CpG island methylation and patient characteristics and clinical outcome. In table 1, patient and tumor characteristics for the 150 ccRCC cases included in the GREM1 promoter hypermethylation analyses are presented; methylated cases were stratified by methylation site. No differences among methylated and unmethylated cases were observed in the distribution of age and sex ( $p$-values $>0.05$, see table 1 ). Consistent with the number of methylated cases, associations between GREM1 promoter methylation and clinical-, histopathologicaland angiogenesis related patient characteristics are dependent on the region of methylation. GREM1-region i methylation was associated with tumor size $(\mathrm{p}=0.01)$ and MVD $(p=0.01)$. The median overall survival (OS) and metastasis free survival (MFS) for unmethylated versus methylated cases at region $i$ is 60.5 (1-143) versus 64.5 (range 2$153)$ and 58.5 (1-143) versus 41 months (0-143), respectively. The Kaplan-Meier curve for GREM1-region i methylation (Figure 2.A) shows a borderline statistically significant difference in OS for methylated and unmethylated cases (log-rank, $\mathrm{p}=0.05$ log-rank 
MFS, $p=0.73$, data not shown). Age and sex adjusted Cox proportional hazard analyses show a statistically significant association between GREM1-region i methylation and OS $\left(\mathrm{HR}_{\mathrm{i}}=1.84 ; 95 \% \mathrm{Cl}, 1.02-3.32\right.$, but not for MFS $\left(\mathrm{HR}_{\mathrm{i}}=1.08 ; 95 \% \mathrm{Cl}, 0.76-1.54\right)$. Multivariate analyses however, show no association between GREM1-region $\mathrm{i}$ and OS or MFS $\left(\mathrm{HR}_{\mathrm{i}}=0.66 ; 95 \% \mathrm{Cl}, 0.33-1.33\right.$, and $\mathrm{HR}_{\mathrm{i}}=0.82 ; 95 \% \mathrm{Cl}, 0.55-1.21$, respectively)

GREM1-region ii methylation was only significantly associated with ECP $(p=0.004)$. The median OS and MFS for unmethylated versus methylated cases at region ii is 60.5 (1153) versus 76 (range 1-153) and 56 (1-153) versus 60 months (0-153), respectively. Figure 2.B shows the Kaplan-Meier curve for GREM1-region ii; no difference was observed between methylated and unmethylated cases (log-rank $p=0.84$, log-rank MFS, $\mathrm{p}=0.15$, data not shown). Methylation of GREM1-region ii was not significantly associated with OS or MFS in the age and sex adjusted Cox regression analyses $\left(\mathrm{HR}(\mathrm{OS})_{\mathrm{ii}}=\right.$ $0.93 ; 95 \% \mathrm{Cl}, 0.48-1.80$, and $\left.\mathrm{HR}(\mathrm{MFS})_{\mathrm{ii}}=0.74 ; 95 \% \mathrm{Cl}, 0.49-1.12\right)$ nor in the multivariate analyses $\left(\mathrm{HR}(\mathrm{OS})_{\mathrm{ii}}=0.55 ; 95 \% \mathrm{Cl}, 0.26-1.18\right.$, and $\left.\mathrm{HR}(\mathrm{MFS})_{\mathrm{ii}}=0.56 ; 95 \% \mathrm{Cl}, 0.36-0.87\right)$.

In contrast, ccRCCs methylated at region iii are statistically significant larger in tumor size $(p=0.02)$, and have a statistically significant higher tumor grade $(p=0.04)$, tumor stage $(p=0.013)$, ECP ratio $(p=0.0001)$, and TCP ratio $(p=0.001)$, as compared to tumors unmethylated at region $\mathrm{iii}$, and methylated cases have a lower MVD (per $\mathrm{mm}^{2}$, $\mathrm{p}=0.001$ ). The median OS and MFS for unmethylated versus methylated cases at region iii is 65.5 (1-153) versus 56 (range 2-138) and 60 (1-153) versus 23 months (0-138), respectively. Figure 2.C shows the Kaplan-Meier curve for cause-specific survival and GREM1-region iii methylation, and methylated cases had a statistically significant worse survival as compared to unmethylated cases (log-rank $p=0.002$, log-rank MFS $\mathrm{p}=0.05$, data not shown). Age and sex adjusted Cox proportional hazard analyses also show a significant association between GREM1-region iii methylation and OS (HR= 2.35; 95\% Cl 1.29-4.28); the association with MFS was borderline significant ( $H R=1.54$; 95\% Cl 0.99-2.39). However, in multivariate analyses adjusted for age, sex, grade, stage, and tumor size, GREM1-region iii methylation does not seem to be an independent prognostic factor: $\mathrm{HR}(\mathrm{OS})=0.88,95 \% \mathrm{Cl}: 0.45-1.74$, and $\mathrm{HR}(\mathrm{MFS})=1.04,95 \% \mathrm{Cl}$ : 0.65-1.68. 

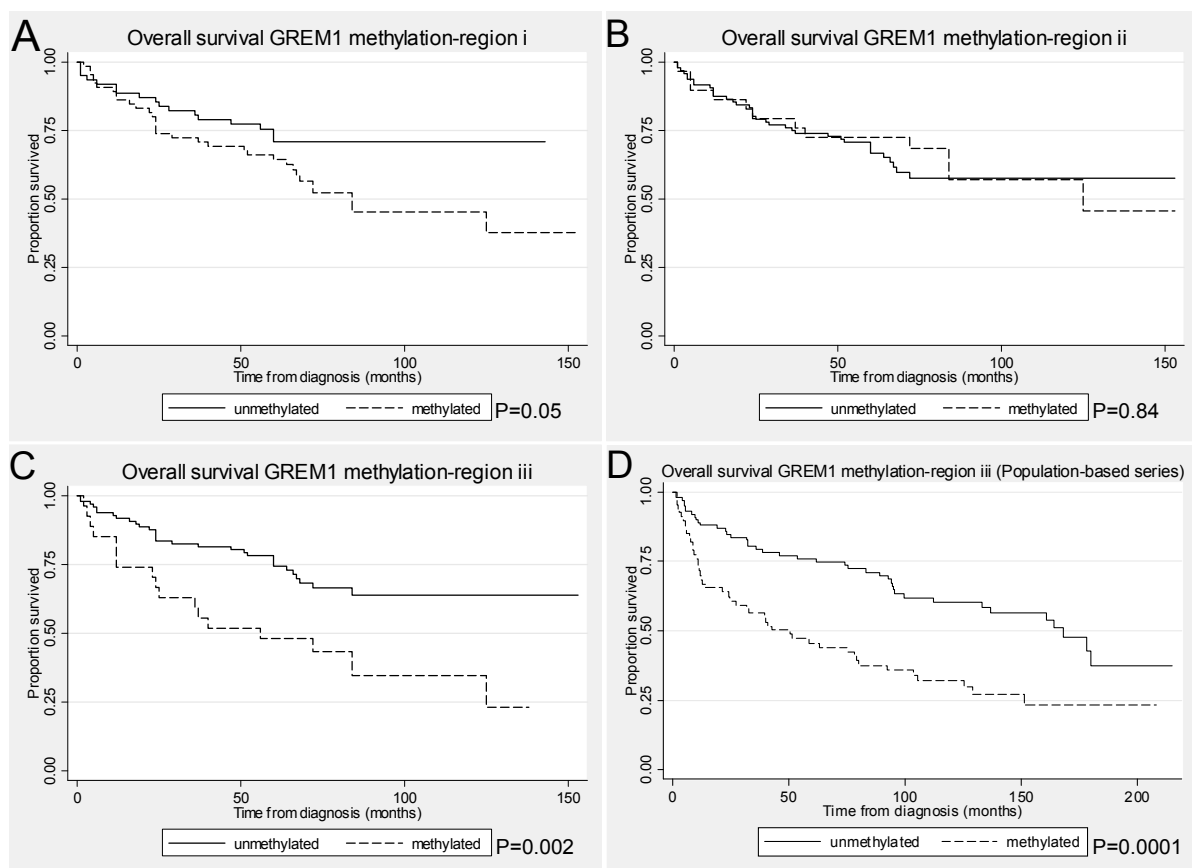

Figure 2. Overall cause-specific survival curves for ccRCC patients according to GREM1 promoter CpG island methylation at region i $(A)$, ii $(B)$, and iii $(C, D)$, with $A, B$, and $C$ for patients of the hospital-based series and $D$ for patients of the population-based series.

Since GREM1 promoter CpG island methylation at region iii was most cancer-specific and because of the result obtained for this region in the hospital-based series, we next aimed to validate the results obtained for GREM1-region iii, in an independent population-based series of ccRCC (table 2). Age and sex were equally distributed among the methylated and unmethylated cases in this series, (P-values $>0.05$, see table 2). $40 \%$ (68 of 168) of the cCRCCs with GREM1-region iii MSP results were methylated and methylated tumors more often had a higher tumor grade $(p=0.03)$ as compared to unmethylated tumors. A similar trend was seen for tumor stage $(p=0.08)$. The median OS for unmethylated versus methylated cases at region iii is 96 (1-218) versus 42 (range 1-212), respectively. Figure 2.D shows the Kaplan-Meier curve for cause-specific survival and GREM1-region iii methylation, and methylated cases had a statistically significant worse survival as compared to unmethylated cases (log-rank test $\mathrm{p}=0.0001$ ). Cox regression analyses also showed a statistically significant association between methylation and OS with an age and sex adjusted HR of 2.32 (95\% $\mathrm{Cl}: 1.52-3.53)$ and a multivariate HR of 2.27 (95\% Cl: 1.44-3.59, adjusted for age and sex, grade, stage and size). 


\section{Discussion}

Epigenetic silencing of GREM1 by promoter CpG island methylation is present in ccRCC cell lines, and can be reversed by inhibiting DNA methyltransferases, indicating that DNA methylation is involved in GREM1 silencing. We have also shown an association between GREM1 promoter CPG island hypermethylation and increased malignancy/angiogenesis in primary ccRCCs, while methylation in histological normal renal tissue is an infrequent event.

Interestingly, GREM1 promoter CpG island methylation in primary ccRCCs varies within the $\mathrm{CpG}$ island, with frequencies of $55 \%, 24 \%$, and $20 \%$ for region i, region ii, and region iii, respectively. We showed that within one $\mathrm{CpG}$ island, $\mathrm{CpG}$ methylation at loci only a few hundred base pairs apart can differ strongly. As previously shown for hMLH1 in colorectal cancer, methylation associated transcriptional silencing can occur in a region-specific manner ${ }^{35}$, indicating that also clinical effects may be methylationregion specific. This observation emphasizes that the location of CpG dinucleotides to be analyzed and with this, MSP primer location and -design, can influence the observed methylation prevalence and clinical association ${ }^{36}$.

Analyses of clinicopathological characteristics revealed that significant differences between GREM1 methylated and unmethylated cCRCCs are also dependent on the region analyzed. Only for the most downstream region (iii), CpG methylation was statistically significant associated with increased malignancy, i.e. larger tumors, higher tumor grade and -stage, and a worse prognosis. These data suggest that the effect of GREM1 promoter CpG island methylation on cCRCC biology depends on the region methylated within the $\mathrm{CpG}$ island. Whether GREM1 promoter CpG island methylation initiates at region $\mathrm{i}$ and than spreads downstream towards the TSS and region iii or starts in region iii and than retroverts towards region i can not be deduced from these data.

The second series is derived from the population-based prospective Netherlands Cohort Study, and therefore appropriate for validation of the results. This series confirmed the associations between region iii methylation and tumor grade and prognosis which were found in the hospital-based series. In addition, this validation points to GREM1 as a gene independently influencing the progression of CCRCCs when methylated at region iii (figure 3 lower panel), which was not found in the hospital-based series to the same extent (figure 3 upper panel). Possible differences between the two ccRCC series were not apparent, but could perhaps account for this observation. Nevertheless, both series do indicate a significant effect of GREM1-region iii methylation on increased malignant behavior and a worse prognosis of cCRCC.

Our data also show that GREM1-region iii methylation is significantly associated with increased ECP, TCP and lower MVD, suggesting that GREM1 silencing promotes active angiogenesis, pointing to GREM1 as an anti-angiogenesis factor. Similar observations showing that BMP2 and BMP4 exert angiogenic activity, which may increase with inactivation of the BMP-antagonist GREM1 have been reported ${ }^{37-39}$. However, a recent study by Stabile et al. indicated a BMP-independent, pro-angiogenic function of GREM1 by showing GREM1 expression in human lung tumor endothelium and binding of GREM1 to the endothelial cell surface thereby activating intracellular signaling and cell motility ${ }^{23}$. An angiogenic role of GREM1 may be tissue specific and/or dose- 
dependent. ECP also may be indirectly influenced by GREM1 through its strong correlation with TCP (Rho $=0.82, \mathrm{p}<0.001$ ). Moreover, during tumor progression, cumulative genetic/epigenetic events can activate additional angiogenic growth factors, resulting in an increased tumor driven angiogenesis. Additionally, GREM1 promoter CpG island methylation may affect maturation of intratumoral blood vessels in CCRCC, as Maciel et al. reported induction of vascular smooth muscle cell (VSMC) proliferation and migration by Gremlin ${ }^{40}$. This is supported by the fact that CCRCC with high ECP, representing high grade $c C R C C$, are shown to be characterized by a less stabilized, less mature vasculature $^{33}$. Therefore, GREM1 inactivation may impede tumor vessel maturation, as observed in high grade tumors, in which less differentiated vessels provide an easier access for cancer cells to the circulation.

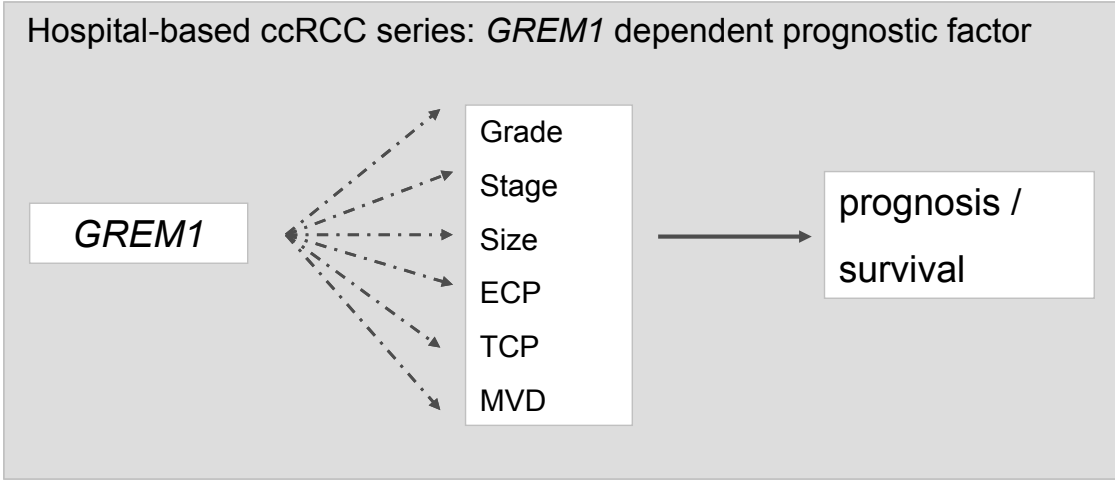

Population-based ccRCC series: GREM1 independent prognostic factor GREM1

prognosis /

survival

Figure 3. Prognostic significance of GREM1 promoter CpG island methylation in hospital-based and population-based ccRCC patient series

Except for sclerostin domain-containing-1 (SOSTDC1), another BMP antagonist which suppresses proliferation of RCC cells and is down regulated in $\mathrm{RCC}^{41}$, no other BMP antagonists have previously been implicated in RCC. GREM1 has been shown to be down regulated in several tumor cell lines i.e. neuroblastoma, fibrosarcoma, colon adenocarcinoma, breast carcinoma, suggesting a tumor suppressor function ${ }^{22,42}$. However, the role of GREM1 in renal carcinogenesis has not yet been elucidated. Silencing of GREM1 by promoter CPG island methylation may play a role in carcinogenesis both by affecting cell cycle and by upregulation of BMP signaling. Earlier studies have linked BMPs and BMP receptors (BMP-RI and BMP-RII) to cancer ${ }^{43-45}$. Biological responses to $B M P$ are cell type-specific and divergent effects with both oncogenic and tumor suppressor activities have been described ${ }^{44}$. Despite the progress achieved in delineating the functional significance of BMP pathways in carcinogenesis in general during the last decade ${ }^{46-50}$, little is known about the importance of BMP signaling in RCC. 
To learn more about the role of GREM1 and the consequence of silencing GREM1 in cCRCC cancer, the relationship between promoter CpG island methylation and gene and protein expression needs to be explored. In this study GREM1 promoter CpG island methylation and mRNA expression did not correlate (see supplemental figure 1). Several explanations can explain these results. First, overall the basal expression level of GREM1 in normal kidney is very low, an observation which has been reported for other (candidate) tumor suppressor genes/biomarkers as well $\left(T P 53^{51}, V^{5} M^{52}\right)$, indicating that the regulation of expression of important cancer-associated genes is complex. Our data are in agreement with the literature consensus on GREM1 expression levels in normal adult renal tissue, which seems to be very low or undetectable ${ }^{53-56}$, see also supplemental figure 1. An explanation for this observation could be that GREM1 is a gene involved in embryogenesis. Many embryologically expressed genes regulate morphogenesis and then become quiescent, which could explain the absence of GREM1 expression in adult normal renal tissue ${ }^{57}$. It is increasingly being appreciated that some developmental genes are reactivated in the adult in diseased tissues. Gremlin expression in the diabetic glomerulus ${ }^{53,54}$ serves to illustrate the complexities and opportunities posed by this emerging paradigm ${ }^{57}$. These literature observations as well as our own data indicate that analyzing epigenetic silencing of GREM1 in cancer tissue as compared to normal epithelial tissue is complex.

An additional complicating factor is the observation that the Gremlin protein belongs to the Dan family of secreted glycosylated proteins ${ }^{13,58}$ and that expression is predominantly observed in the stromal counterpart of other cancers types (skin, lung, esophagus, pancreas, breast, bladder, colon) ${ }^{23,56}$. This complicates studying the correlation between epithelial promoter methylation and epithelial RNA and protein expression. At the same time, Sun et al. reported tissue-specific intracellular interaction between Gremlin and BMP4 ${ }^{59}$, which indicates again the (micro)environment dependency of the expression and actions of Gremlin1.

In conclusion, our results indicate that promoter CpG island methylation of GREM1 has an impact on the biology and outcome of this type of cancer. Notably, GREM1-region iii promoter $\mathrm{CpG}$ island hypermethylation appears to be independently associated with aggressive tumor behavior and increased angiogenesis and therefore could be a candidate tumor suppressor gene and interesting prognostic biomarker in ccRCC. Probably, this prognostic effect is mediated through an increase TCP and ECP. However, the exact mechanism of GREM1 inactivation and its relation to tumor progression as well as its role in angiogenesis need to be further clarified. In addition, further studies are needed to explore whether GREM1 promoter CpG island methylation can also be detected in urine or serum samples for use as a possible noninvasive marker for aggressive ccRCC. 


\section{Acknowledgements}

We would like to thank Dr. Egbert Oosterwijk from the Nijmegen Center for Molecular Life Sciences (NCMLS), Radboud University Nijmegen Medical Center (RUNMC), Nijmegen, The Netherlands for providing the renal carcinoma cell lines. We thank Sean Smith for technical support.

\section{Funding}

This work was supported by the Kootstra-Talent Fellowship Program, Maastricht University Medical Center, Maastricht, The Netherlands.

\section{Supplemental figure 1}

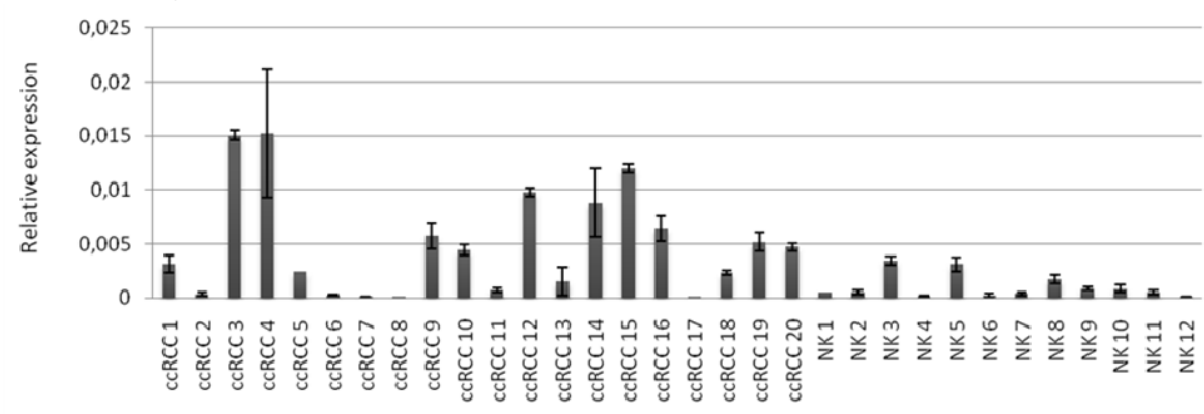




\section{References}

1. Kovacs, G., et al., The Heidelberg classification of renal cell tumours. J Pathol, 1997. 183(2): p. 131-3.

2. Gelb, A.B., Renal cell carcinoma: current prognostic factors. Union Internationale Contre le Cancer (UICC) and the American Joint Committee on Cancer (AJCC). Cancer, 1997. 80(5): p. 981-6.

3. Kaelin, W.G., Jr., The von Hippel-Lindau tumor suppressor gene and kidney cancer. Clin Cancer Res, 2004. 10(18 Pt 2): p. 6290S-5S.

4. van Dijk, B.A., et al., Cigarette smoking, von Hippel-Lindau gene mutations and sporadic renal cell carcinoma. Br J Cancer, 2006. 95(3): p. 374-7.

5. Gnarra, J.R., et al., Molecular cloning of the von Hippel-Lindau tumor suppressor gene and its role in renal carcinoma. Biochim Biophys Acta, 1996. 1242(3): p. 201-10.

6. Richards, F.M., Molecular pathology of von HippelLindau disease and the VHL tumour suppressor gene. Expert Rev Mol Med, 2001. 2001: p. 1-27.

7. Banks, R.E., et al., Genetic and epigenetic analysis of von Hippel-Lindau (VHL) gene alterations and relationship with clinical variables in sporadic renal cancer. Cancer Res, 2006. 66(4): p. 2000-11.

8. Herman, J.G., et al., Silencing of the VHL tumor-suppressor gene by DNA methylation in renal carcinoma. Proc Natl Acad Sci U S A, 1994. 91(21): p. 9700-4.

9. Schraml, P., et al., VHL mutations and their correlation with tumour cell proliferation, microvessel density, and patient prognosis in clear cell renal cell carcinoma. J Pathol, 2002. 196(2): p. 186-93.

10. Smits, K.M., et al., Genetic and epigenetic alterations in the von hippel-lindau gene: the influence on renal cancer prognosis. Clin Cancer Res, 2008. 14(3): p. 782-7.

11. Hsu, D.R., et al., The Xenopus dorsalizing factor Gremlin identifies a novel family of secreted proteins that antagonize BMP activities. Mol Cell, 1998. 1(5): p. 673-83.

12. Topol, L.Z., et al., Identification of drm, a novel gene whose expression is suppressed in transformed cells and which can inhibit growth of normal but not transformed cells in culture. Mol Cell Biol, 1997. 17(8): p. 4801-10.

13. Topol, L.Z., et al., Biosynthesis, post-translation modification, and functional characterization of Drm/Gremlin. J Biol Chem, 2000. 275(12): p. 8785-93.

14. Hogan, B.L., Bone morphogenetic proteins: multifunctional regulators of vertebrate development. Genes Dev, 1996. 10(13): p. 1580-94.

15. Miyazaki, Y., et al., Bone morphogenetic protein 4 regulates the budding site and elongation of the mouse ureter. J Clin Invest, 2000. 105(7): p. 863-73.

16. Miyazaki, Y., et al., Evidence that bone morphogenetic protein 4 has multiple biological functions during kidney and urinary tract development. Kidney Int, 2003. 63(3): p. 835-44.

17. Dudley, A.T., K.M. Lyons, and E.J. Robertson, A requirement for bone morphogenetic protein-7 during development of the mammalian kidney and eye. Genes Dev, 1995. 9(22): p. 2795-807.

18. Luo, G., et al., BMP-7 is an inducer of nephrogenesis, and is also required for eye development and skeletal patterning. Genes Dev, 1995. 9(22): p. 2808-20.

19. McMahon, R., et al., IHG-2, a mesangial cell gene induced by high glucose, is human gremlin. Regulation by extracellular glucose concentration, cyclic mechanical strain, and transforming growth factor-beta1. J Biol Chem, 2000. 275(14): p. 9901-4.

20. Michos, O., et al., Gremlin-mediated BMP antagonism induces the epithelial-mesenchymal feedback signaling controlling metanephric kidney and limb organogenesis. Development, 2004. 131(14): p. 3401-10.

21. Khokha, M.K., et al., Gremlin is the BMP antagonist required for maintenance of Shh and Fgf signals during limb patterning. Nat Genet, 2003. 34(3): p. 303-7. 
22. Topol, L.Z., et al., DRM/GREMLIN (CKTSF1B1) maps to human chromosome 15 and is highly expressed in adult and fetal brain. Cytogenet Cell Genet, 2000. 89(1-2): p. 79-84.

23. Stabile, H., et al., Bone morphogenic protein antagonist Drm/gremlin is a novel proangiogenic factor. Blood, 2007. 109(5): p. 1834-40.

24. Lee, T.I., et al., Control of developmental regulators by Polycomb in human embryonic stem cells. Cell, 2006. 125(2): p. 301-13.

25. Widschwendter, M., et al., Epigenetic stem cell signature in cancer. Nat Genet, 2007. 39(2): p. 157-8.

26. Yamashita, S., et al., Chemical genomic screening for methylation-silenced genes in gastric cancer cell lines using 5-aza-2'-deoxycytidine treatment and oligonucleotide microarray. Cancer Sci, 2006. 97(1): p. 64-71.

27. Suzuki, M., et al., DNA methylation-associated inactivation of TGFbeta-related genes DRM/Gremlin, RUNX3, and HPP1 in human cancers. Br J Cancer, 2005. 93(9): p. 1029-37.

28. van den Brandt, P.A., et al., A large-scale prospective cohort study on diet and cancer in The Netherlands. J Clin Epidemiol, 1990. 43(3): p. 285-95.

29. van Houwelingen, K.P., et al., Prevalence of von Hippel-Lindau gene mutations in sporadic renal cell carcinoma: results from The Netherlands cohort study. BMC Cancer, 2005. 5(1): p. 57.

30. Derks, S., et al., Methylation-specific PCR unraveled. Cell Oncol, 2004. 26(5-6): p. 291-9.

31. Herman, J.G., et al., Methylation-specific PCR: a novel PCR assay for methylation status of CpG islands. Proc Natl Acad Sci U S A, 1996. 93(18): p. 9821-6.

32. van Engeland, M., et al., K-ras mutations and RASSF1A promoter methylation in colorectal cancer. Oncogene, 2002. 21(23): p. 3792-5.

33. Baldewijns, M.M., et al., High-grade clear cell renal cell carcinoma has a higher angiogenic activity than low-grade renal cell carcinoma based on histomorphological quantification and qRT-PCR mRNA expression profile. Br J Cancer, 2007. 96(12): p. 1888-95.

34. Van den Eynden, G.G., et al., Angiogenesis and hypoxia in lymph node metastases is predicted by the angiogenesis and hypoxia in the primary tumour in patients with breast cancer. Br J Cancer, 2005. 93(10): p. 1128-36.

35. Deng, G., et al., Methylation of hMLH1 promoter correlates with the gene silencing with a region-specific manner in colorectal cancer. Br J Cancer, 2002. 86(4): p. 574-9.

36. Baldewijns, M.M., et al., Genetics and epigenetics of renal cell cancer. Biochim Biophys Acta, 2008. 1785(2): p. 133-55.

37. Langenfeld, E.M. and J. Langenfeld, Bone morphogenetic protein-2 stimulates angiogenesis in developing tumors. Mol Cancer Res, 2004. 2(3): p. 141-9.

38. Rothhammer, T., et al., Functional implication of BMP4 expression on angiogenesis in malignant melanoma. Oncogene, 2007. 26(28): p. 4158-70.

39. Raida, M., et al., Bone morphogenetic protein 2 (BMP-2) and induction of tumor angiogenesis. J Cancer Res Clin Oncol, 2005. 131(11): p. 741-50.

40. Maciel, T.T., et al., Gremlin promotes vascular smooth muscle cell proliferation and migration. J Mol Cell Cardiol, 2007.

41. Blish, K.R., et al., A Human Bone Morphogenetic Protein Antagonist Is Down-Regulated in Renal Cancer. Mol Biol Cell, 2008. 19(2): p. 457-464.

42. Chen, B., et al., Drm/Gremlin transcriptionally activates p21(Cip1) via a novel mechanism and inhibits neoplastic transformation. Biochem Biophys Res Commun, 2002. 295(5): p. 1135-41.

43. Alarmo, E.L., et al., Bone morphogenetic protein 7 is widely overexpressed in primary breast cancer. Genes Chromosomes Cancer, 2006. 45(4): p. 411-9.

44. Hsu, M.Y., et al., Bone morphogenetic proteins in melanoma: angel or devil? Cancer Metastasis Rev, 2005. 24(2): p. 251-63. 
45. Miyazaki, H., et al., BMP signals inhibit proliferation and in vivo tumor growth of androgeninsensitive prostate carcinoma cells. Oncogene, 2004. 23(58): p. 9326-35.

46. Franzen, A. and N.E. Heldin, BMP-7-induced cell cycle arrest of anaplastic thyroid carcinoma cells via p21(CIP1) and p27(KIP1). Biochem Biophys Res Commun, 2001. 285(3): p. 773-81.

47. Ghosh-Choudhury, N., et al., Bone morphogenetic protein-2 blocks MDA MB 231 human breast cancer cell proliferation by inhibiting cyclin-dependent kinase-mediated retinoblastoma protein phosphorylation. Biochem Biophys Res Commun, 2000. 272(3): p. 705-11.

48. Haudenschild, D.R., et al., Bone morphogenetic protein (BMP)- 6 signaling and BMP antagonist noggin in prostate cancer. Cancer Res, 2004. 64(22): p. 8276-84.

49. He, X.C., et al., BMP signaling inhibits intestinal stem cell self-renewal through suppression of Wnt-beta-catenin signaling. Nat Genet, 2004. 36(10): p. 1117-21.

50. Pardali, K., et al., Smad pathway-specific transcriptional regulation of the cell cycle inhibitor p21(WAF1/Cip1). J Cell Physiol, 2005. 204(1): p. 260-72.

51. Vousden, K.H., Activation of the p53 tumor suppressor protein. Biochim Biophys Acta, 2002. 1602(1): p. 47-59.

52. Chen, W.D., et al., Detection in fecal DNA of colon cancer-specific methylation of the nonexpressed vimentin gene. J Natl Cancer Inst, 2005. 97(15): p. 1124-32.

53. Dolan, V., et al., Expression of gremlin, a bone morphogenetic protein antagonist, in human diabetic nephropathy. Am J Kidney Dis, 2005. 45(6): p. 1034-9.

54. Mezzano, S., et al., Expression of gremlin, a bone morphogenetic protein antagonist, in glomerular crescents of pauci-immune glomerulonephritis. Nephrol Dial Transplant, 2007. 22(7): p. 1882-90.

55. Namkoong, $\mathrm{H}_{\text {., }}$ et al., The bone morphogenetic protein antagonist gremlin 1 is overexpressed in human cancers and interacts with YWHAH protein. BMC Cancer, 2006. 6: p. 74.

56. Sneddon, J.B., et al., Bone morphogenetic protein antagonist gremlin 1 is widely expressed by cancer-associated stromal cells and can promote tumor cell proliferation. Proc Natl Acad Sci U S A, 2006. 103(40): p. 14842-7.

57. Lappin, D.W., et al., Gremlin: an example of the re-emergence of developmental programmes in diabetic nephropathy. Nephrol Dial Transplant, 2002. 17 Suppl 9: p. 65-7.

58. Pearce, J.J., G. Penny, and J. Rossant, A mouse cerberus/Dan-related gene family. Dev Biol, 1999. 209(1): p. 98-110.

59. Sun, J., et al., BMP4 activation and secretion are negatively regulated by an intracellular gremlin-BMP4 interaction. J Biol Chem, 2006. 281(39): p. 29349-56. 


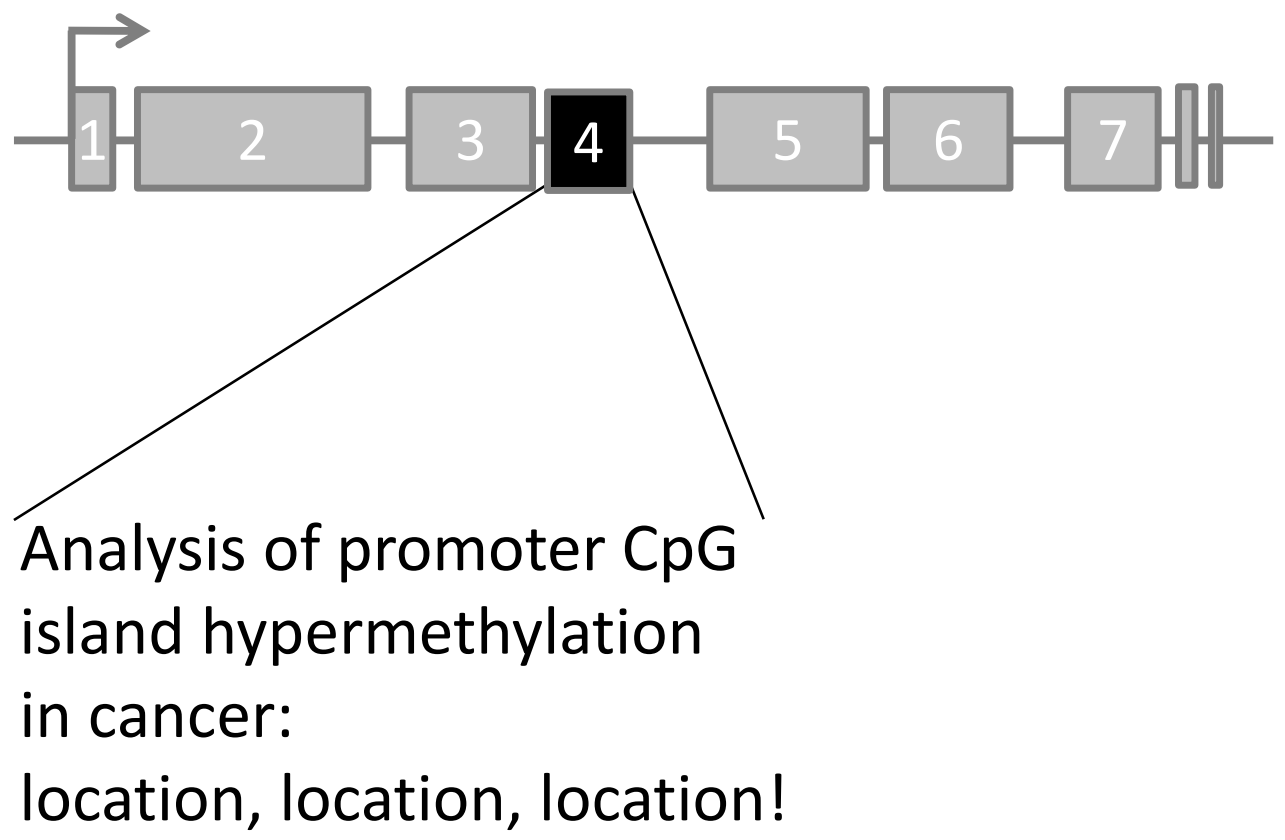

Iris J.H. van Vlodrop, Hanneke E.C. Niessen, Sarah Derks, Marcella M.L.L. Baldewijns, Wim van Criekinge, James G. Herman and Manon van Engeland

Clinical Cancer Research. 2011;17(13):4225-31 


\begin{abstract}
The genetic and epigenetic alterations that underlie cancer pathogenesis are rapidly being identified. This provides novel insights in tumor biology as well as in potential cancer biomarkers. The somatic mutations in cancer genes that have been implemented in clinical practice are well defined and very specific. For epigenetic alterations, and more specifically aberrant methylation of promoter $\mathrm{CpG}$ islands, evidence is emerging that these markers could be used for the early detection of cancer as well as prediction of prognosis and response to therapy. However, the exact location of biologically and clinically relevant hypermethylation has not been identified for the majority of methylation markers. The most widely used approaches to analyze DNA methylation are based on primer- and probe-based assays that provide information for a limited number of CpG dinucleotides and thus for only part of the information available in a given CpG island. Validation of the current data and implementation of hypermethylation markers in clinical practice require a more comprehensive and critical evaluation of DNA methylation and limitations of the techniques currently used in methylation marker research. Here, we discuss the emerging evidence on the importance of the location of $\mathrm{CpG}$ dinucleotide hypermethylation in relation to gene expression and associations with clinicopathologic characteristics in cancer.
\end{abstract}




\section{Introduction}

DNA methylation is involved in regulating gene expression in normal physiology (e.g., by managing imprinting, $\mathrm{X}$-chromosome activation, and tissue-specific gene expression) and disease (e.g., neurodevelopmental and degenerative disorders, autoimmune diseases, and cancer) ${ }^{1}$. DNA hypermethylation-induced silencing of tumor suppressor and DNA repair genes is a frequent phenomenon affecting the hallmarks of cancer ${ }^{2,3}$. Aberrant DNA methylation often occurs around the transcription start site (TSS) within a CpG island, and as was recently shown, even outside of the traditionally defined islands $s^{4,5}$. These hypermethylation markers are promising tools to detect cancer cells in tissue and body fluids ${ }^{6,7}$ with the use of simple PCR technology ${ }^{8-10}$. Proof of principle for the clinical value of methylation markers has been reported for early detection and classification of cancer ${ }^{11-21}$, risk assessment and prognosis ${ }^{18,22-24}$, and prediction of therapy response ${ }^{25-27}$, with some already having shown their importance in (pre)clinical practice. Thus, the promise of methylation changes to become a powerful diagnostic and predictive tool ${ }^{6}$ is becoming a reality.

Nevertheless, the clinical value of biomarkers depends on the accuracy and prognostic or predictive value of the marker. The CpG islands of a variety of cancer-associated genes have been evaluated for methylation, and positive, negative, and null associations with gene expression and clinical characteristics are reported. Here, we discuss emerging evidence on the importance of the location of aberrant $\mathrm{CpG}$ dinucleotide methylation in relation to gene expression and its clinical value in cancer.

\section{Location of biologically relevant methylation in promoter CpG islands}

The dogma that promoter $\mathrm{CpG}$ island methylation generally induces gene silencing is currently being specified. Specific regions within the promoter CpG islands, designated as core regions crucial for regulating gene expression, are rapidly being identified. As illustrated in Figure 1, these regions are often situated around the TSS within a CpG island but can also be observed more upstream or downstream of the TSS.

One of the first studies to show that hypermethylation of a specific locus is critical for transcriptional repression was conducted in the human bladder cancer cell line T24. Treatment with the demethylating agent 5-aza-2'-deoxycytidine resulted in different expression levels of cyclin-dependent kinase inhibitor $2 \mathrm{~A}(C D K N 2 A)$ in the acquired subclones. No direct correlation between the degree of methylation and gene expression was observed. However, demethylation of a specific region upstream of exon 1 did correlate with reexpression, whereas CpGs in the vicinity of this region showed methylation in all subclones ${ }^{28}$. Similarly, expression of human telomerase reverse transcriptase ( $h T E R T)$ was reported in a variety of cancer cell lines despite dense promoter hypermethylation at the region initially analyzed (upstream of TSS) ${ }^{29}$. A more detailed analysis of the promoter CpG island region around the TSS revealed that silencing of hTERT expression was associated with dense methylation at, or in close proximity to, the TSS and is independent of methylation more upstream of TSS ${ }^{29}$. Similar observations have been reported for the TGF- $\beta$ signaling target $R U N X 3^{30}$ and the T-cell differentiation protein $M A L^{31}$ in gastric cancer cell lines and primary gastric cancers.

Core regions have also been observed outside the direct TSS region. A small region proximal to the MLH1 TSS has been identified to regulate expression by methylation in 
24 colorectal cancer cell lines ${ }^{32}$, whereas hypermethylation upstream of this region did not influence $M L H 1$ expression ${ }^{32}$ and was later suggested to be age-related ${ }^{33}$. The same correlation was observed in 64 primary colorectal cancers ${ }^{34}$ as well as in 123 patients with colorectal cancer in an independent study ${ }^{35}$. Similarly, mapping of WIF-1 promoter $\mathrm{CpG}$ island hypermethylation reveals regional methylation just proximal to the TSS that correlates with transcriptional silencing, whereas other more upstream regions do not ${ }^{36}$.

CpG island methylation analyses of SOCS1 in hepatocellular carcinoma cell lines revealed one unmethylated cell line without SOCS1 expression. More detailed analyses by bisulfite sequencing of a larger region revealed regional and clustered hypermethylation more downstream of the initially analyzed region, indicating a silencing effect by methylation in this critical $3^{\prime}$-TSS region ${ }^{37}$.

Interestingly, a recent study showed transcriptional silencing of TTP in liver cancer by hypermethylation of a specific single CpG site. One specific CpG dinucleotide, located at the 5'-boundary of the CpG island, was exclusively hypermethylated in transcriptionally silenced cell lines ${ }^{38}$. This observation narrows down the core region for hypermethylation-induced silencing of TTP to just one CpG dinucleotide.

These studies show that transcriptional silencing does not require hypermethylation of the entire CpG island, but that methylation of a few gene-specific core CpG dinucleotides, most likely associated with transcription, may be sufficient. It is important to realize that data obtained solely in cell lines can be biased, as they exhibit significantly more $\mathrm{CpG}$ island methylation than the primary tumors they represent ${ }^{39}$ and thus proof of principle in primary tumors is required. Identifying the core regions regulating gene expression is essential for evaluation of the clinical value of DNA hypermethylation (Figure 1). For example, two regions within the MAL promoter were analyzed for methylation in gastric cancer samples. Hypermethylation of both regions occurred in $71 \%$ and $80 \%$, respectively; however, only methylation at the region closest to the TSS was correlated with a better disease-free survival ${ }^{31}$. In addition, increased expression of $M A L$ in serous ovarian cancer patients with a poor prognosis is associated with decreased methylation of a specific region of the MAL promoter ${ }^{40}$.

We recently described a region in the promoter CpG island of GREM1 that was specifically associated with poor prognosis in clear cell renal cell carcinoma. Three regions were analyzed for hypermethylation, but only one was correlated with poor survival ${ }^{23}$. This indicates that location of hypermethylation is also important for marker discovery. These studies clearly indicate that the biological and clinical consequences of promoter CpG island hypermethylation are strongly dependent on silencing of expressionregulating core regions in the CpG island. Although clinically relevant hypermethylation of a specific locus is not always perfectly associated with gene expression and might serve as a surrogate marker for functional hypermethylation of another locus, we expect that the best validated markers will be those for which good correlations between DNA methylation and gene expression exist.

Hypermethylation outside core regions is frequently observed in cancer cells but sometimes also in normal cells ${ }^{41-44}$ and is correlated with aging and chronic inflammation $^{41-43,45,46}$. This is hypothesized to progress toward the core region, initiating gene silencing ${ }^{47}$. For example, a demarcation has been observed between RASSF1A hypermethylation in exon 1 and in its immediate upstream promoter region. 


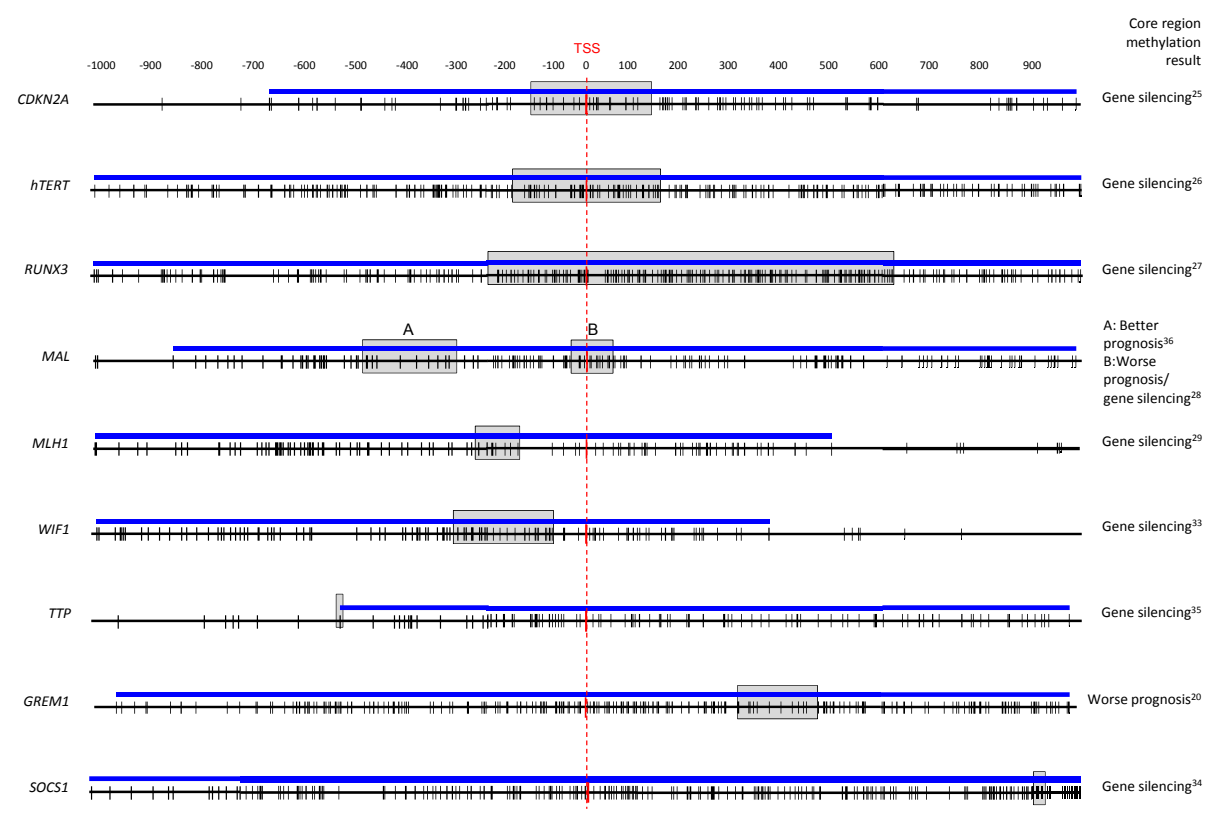

\section{Legend to Figure 1.}

Location of biologically relevant methylation in promoter $\mathrm{CpG}$ islands. Promoter regions from $-1,000$ to $+1,000 \mathrm{bp}$ are depicted relative to the TSS (at 0 in red) with $\mathrm{CpG}$ islands in blue. Vertical lines represent $\mathrm{CpG}$ sites, and gray boxes show the relevant regions (core regions) for expression or progression. All genes are presented in a forward fashion and are grouped by core region position relative to the TSS: top genes are around TSS, middle genes are pre-TSS, and bottom genes are post-TSS. Top, core region of cell-cycle regulating gene CDKN2A was identified from -121 to +123 relative to the TSS. The catalytic subunit of telomerase, $h T E R T$, showed a core region from -150 to +150 , relative to TSS. The important region in the human runt-related transcription factor 1, RUNX1, was reported from -194 to +451 relative to the TSS. Methylation at MAL promoter from -92 to -7 relative to the first ATG correlated with expression and survival (B). Another region was found at -452 to -266 relative to the TSS, which showed a correlation with worse prognosis $(A)$. Middle, the region -248 to -178 relative to the TSS of the mismatch repair gene MLH1 was identified as the core region. For the Wnt-pathway antagonist Wnt inhibitory factor-1 (WIF-1), the core region is reported to be proximal to the TSS from -295 to -95 . TTP, a negative post-transcriptional regulator of c-Myc, uniquely showed one CpG at -500 bp at the 5'boundary of the CpG island, as the core dinucleotide. Bottom, for the bone morphogenetic protein (BMP) pathway antagonist GREM1, the region +311 to +471 relative to the TSS showed clinical correlations when methylated. The core region of a negative regulator of the Janus-activated kinase (JAK)/STAT pathway SOCS1 was identified at +901 to +924 (relative to new TSS). Note: differences in location as compared with Yoshikawa and colleagues (ref. 37 ) are due to a repositioning of the predicted TSS after publishing (680 bp more upstream according to the previous predicted TSS position). Original reported core region at +221 to +244 .

In normal breast tissue, exon 1 is methylated without affecting gene expression, whereas in breast cancer samples, hypermethylation is observed in both exon 1 and its immediate upstream promoter region that is associated with RASSF1A silencing. A progressive spreading from exon 1 upstream is proposed, which can occur early in breast tumorigenesis ${ }^{48}$. Additional evidence for spreading of hypermethylation in the promoter $\mathrm{CpG}$ island region has been observed for $C D K N 2 B$ in leukemia ${ }^{49}, C D K N 2 A^{50}$, $M G M T^{51}$, and $N D R G 4^{19}$ in colorectal cancer, and for $R U N X^{30}$ in gastric cancer.

Spreading of DNA methylation is often consistent with increasing density of methylation, but whether density itself or spreading toward (expression regulating) specific regions is correlated with gene silencing is currently not clear. 


\section{Location of DNA methylation initiation}

It might be speculated that the core region for which hypermethylation is associated with gene silencing and clinical consequences has specific (sequence) characteristics. To study this hypothesis, Feltus and colleagues applied DNA pattern recognition techniques in a DNA cytosine-5-methyltransferase 1 (DNMT1) overexpressing human cell culture model and showed that methylation-prone and methylation-resistant CpG islands can be distinguished by an underlying sequence signature based on 13 DNA motifs $^{52,53}$. These motifs were proposed to represent protein-binding sites involved in the susceptibility to or prevention of DNA methylation. Although the methylationprone motifs do not obviously resemble a transcription factor consensus sequence or protein-binding site, transcription factors PML-RAR ${ }^{54}$ and $\mathrm{c}-M y c^{55}$ have shown the ability to initiate DNA hypermethylation by the recruitment of DNA methyltransferase enzymes (DNMT) to specific loci. The opposite is observed for the presence of Alu elements ${ }^{52}$ and Sp1-binding sites ${ }^{56,57}$, as well as binding of the insulator protein $\mathrm{CTCF}^{58}$, which are all associated with resistance to DNA hypermethylation. Subsequent studies have shown that genes with a methylation-prone sequence motif and genes characterized by Polycomb group (PcG) protein occupancy in embryonic stem cells are strongly related $^{59}$. PcG proteins have been shown to mark target genes in the progenitor or stem cell state by targeting H3K27 histone methylation. Several observations indicate that there could be a functional link between PcG protein binding and CpG island hypermethylation. First, the reported percentage of PcG-binding sites that correspond to $\mathrm{CpG}$ islands ranges from $50 \%$ to $88 \%{ }^{60,61}$. Second, direct interactions have been described between PcG proteins and DNMTs ${ }^{62,63}$. Third, PcG target genes are up to 12 times more likely to have cancer-specific promoter hypermethylation than non-PcG targets $^{64-66}$. These observations make it tempting to speculate that PcG proteins recruit DNMTs to their target genes and thereby induce aberrant transcriptional silencing of promoter CpG islands by DNA hypermethylation.

\section{Location of methylation outside of classical promoter CpG Islands}

DNA methylation studies in cancer initially focused on gene promoter CpG island hypermethylation. However, recent research revealed novel insights on the location of DNA hypermethylation. Hypermethylation of intra- and intergenic CpG dinucleotides might contribute to regulating gene expression by functioning as alternative promoters ${ }^{5}$. For example, in-depth investigation of the human SHANK3 locus ( $\left.60 \mathrm{~kb}\right)$ showed hypermethylation-regulated intragenic promoter activity, expressing alternative transcripts in a tissue- (brain) and cell-type (primary cortical astrocyte)-specific manner ${ }^{5}$. In addition, other gene-regulating regions such as enhancers, which are cisregulatory DNA sequences that increase transcription independent of their orientation and distance relative to the TSS, can be regulated by hypermethylation ${ }^{67,68}$. For example, hypermethylation-dependent enhancer-like activity, located at a $\mathrm{CpG}$ island in EGFR2 intron 1, is suggested to regulate transcription ${ }^{69}$.

Evidence is accumulating that $\mathrm{CpG}$ island hypermethylation in bidirectional promoters is correlated with silencing of both genes, thereby possibly accelerating tumorigenesis, for example, in the gene pairs WNT9A/CD558500, CTDSPL/BC040563, 
KCNK15/BF195580, and MLH1/EPM2AIP1 ${ }^{70,71}$. Even in promoters without a classical CpG island (low CpG density), hypermethylation still can regulate expression, as has been shown for Maspin in breast cancer ${ }^{72}$.

Although the impact of DNA hypermethylation has been studied mainly in CpG islands located at $\mathrm{TSSs}^{73}$, Irizarry and colleagues recently introduced the term "CpG island shores" ${ }^{4}$, regions with a relatively low CpG density located within $2 \mathrm{~kb}$ of traditional CpG islands. Aberrant methylation in these shores was reported to segregate tissue subtypes and cancerous tissue from matched normal tissues ${ }^{4}$. These observations change the current focus from exclusively CpG islands in promoter regions to much larger regions of interest, which potentially possess regulatory regions previously characterized.

The biological relevance of hypermethylation throughout the gene locus by means of long-range interactions with the promoter region has recently been shown by Tiwari and colleagues ${ }^{74}$. They reported DNA methylation at 6 of $7 \mathrm{CpG}$ islands, including the island spanning the TSS, throughout the GATA4 gene. Chromatin looping can enable long-range interactions of these islands around a single gene. This can cluster aberrant methylation of $\mathrm{CpG}$ islands and other epigenetic markers, thereby facilitating and enhancing transcriptional repression ${ }^{74}$. These findings demand mapping of DNA hypermethylation of genes in higher-order chromatin structures as there might be an additional role for chromatin looping in mediating gene expression.

Frigola and colleagues showed for the first time that clusters of genes could be coordinately repressed by epigenetic mechanisms, a concept termed long-range epigenetic silencing (LRES) ${ }^{75}$. They identified an epigenetically repressed 4-Mb spanning region of chromosome 2q14.2. Genes located in this cytogenetic region are affected by hypermethylation of clusters of neighboring $\mathrm{CpG}$ islands and coordinately inactivated by chromatin remodeling. Similar LRES mechanisms have been observed by others in chromosomal regions $3 q 22^{76}$ and $5 q 35.2^{77}$. Recently, 47 LRES regions were identified in prostate cancer, typically spanning about $2 \mathrm{Mb}$ and harboring approximately 12 genes $^{78}$. Global gene silencing by LRES is comparable with genetic deletions by LOH, as large regions become simultaneously inactivated. Therefore, LRES provides an efficient silencing mechanism in cancer development.

Furthermore, nucleosome organization, location, and dynamics are critical for gene regulation. Lin and colleagues studied $M L H 1$ silencing by hypermethylation and nucleosomal occupancy in cancer ${ }^{70}$. They showed nucleosome depletion just upstream of each start site on the active $M L H 1$ promoter in normal cells, whereas 3 nucleosomes were present on the hypermethylated, inactive promoter. Moreover, gene reactivation induced by the demethylating agent 5-aza-2'-deoxycytidine involved promoter nucleosome removal, suggesting that epigenetic silencing may involve the (reversible) movement of nucleosomes into previously vacant positions ${ }^{70}$. Changes in nucleosomal occupancy not only occur at TSS regions but also at enhancers acting at variable distances from the start site ${ }^{79}$. 


\section{Conclusions and perspectives: reflect on location}

The above-described location-related complexities of gene expression regulation by aberrant DNA methylation can all, separately or combined, result in unexpected or misinterpreted information on the associations among DNA hypermethylation, gene expression, and clinical parameters. Promoter CpG islands of genes have often been reported as "unmethylated" or "hypermethylated," based on the data of only a small number of CpG dinucleotides independent of location or the assays that have been used. Because it now has become clear that the location of core regions and the density of methylation required for gene silencing can vary per gene, a broader view than just the classical dogma of promoter CpG island methylation and gene silencing is needed to interpret data on DNA hypermethylation, gene expression, and clinicopathologic associations. Unexpected results do not per se contradict this dogma regarding the complexity and the number of parameters involved in epigenetic silencing. In addition, all the above-mentioned phenomena might be tissue, cell-type, cancer type, genomic region, or gene specific, thereby complicating data analysis, interpretation, and validation of results and conception of the literature.

These considerations underscore the importance of detailed analysis of $\mathrm{CpG}$ dinucleotide analysis and careful data analysis, with regard to diverse techniques and/or primer and probe design. Results of analyses at the same region are dependent on the detection method, that is, primer (design), reagents, detectors, equipment, and protocols, which all influence sensitivity and specificity. Frequently used technologies are restriction enzyme- and/or bisulfite-based analyses, the results of which are highly dependent on primer- and/or probe/microarray design-like methylated-specific PCR (MSP) ${ }^{80}$, methylated DNA immunoprecipitation (MeDIP) ${ }^{81}$, methylated-CpG island recovery assay (MIRA) ${ }^{82}$, and Illumina Infinium methylation assay ${ }^{83}$. Limitations of these techniques can introduce bias; for example, MSP only assesses 2 to 4 CpG dinucleotides per oligo and thus needs to perfectly cover the core region of interest. Methylationsensitive restriction enzyme digestion can introduce recognition site bias and is prone to false-positive results because of incomplete digestion. Techniques using DNA hybridization to microarrays introduce ascertainment bias (for an extensive overview of the resolution and limitations of the most widely used techniques to analyze DNA methylation, see ref. $\left.{ }^{84}\right)$. The recently developed novel technologies that enable (semi)epigenome-wide analyses such as bisulfite deep sequencing ${ }^{85}$ or methyl-binding protein domain (MBD)-sequencing ${ }^{86}$ are promising in this respect. However the technical limitations (such as sensitivity/specificity and resolution, but also bisulfite conversion, CpG coverage, number of methylated CpG sites, choice of region analyses, etc.) have to be considered, especially when reporting methylation data. Furthermore, hydroxymethylcytosine $(\mathrm{hmC})$ has been discovered recently, but its role is as yet unknown. It is hypothesized that the presence of hmC in DNA can inhibit methyl-binding proteins, enzymatic functions, and gene expression. Enzymatic- or bisulfite-based approaches cannot discriminate between hydroxy- and 5-methylcytosine because of structural similarity ${ }^{87}$. Therefore, the possible presence of $\mathrm{hmC}$ should be considered in future methylation assay design.

The future discovery of clinically relevant hypermethylation markers would preferably be genome-wide and location- and CpG density-independent. In contrast, subsequent 
sequence-specific methylation analyses would need to be core-region specific. Careful and thorough experiment and assay design will lead to the development of sensitive and specific hypermethylation markers that can be used for early detection of cancer and prediction of prognosis and response to anticancer therapy. These methods enable independent validation by studying the same core regions, accurate identification of the biologically relevant location of hypermethylation, and translation of data into an accurate biomarker assay. 


\section{References}

1. Portela, A. and M. Esteller, Epigenetic modifications and human disease. Nat Biotechnol, 2010. 28(10): p. 1057-68.

2. Esteller, M., Epigenetics in cancer. N Engl J Med, 2008. 358(11): p. 1148-59.

3. Herman, J.G. and S.B. Baylin, Gene silencing in cancer in association with promoter hypermethylation. N Engl J Med, 2003. 349(21): p. 2042-54.

4. Irizarry, R.A., et al., The human colon cancer methylome shows similar hypo- and hypermethylation at conserved tissue-specific CpG island shores. Nat Genet, 2009. 41(2): p. 178-86.

5. Maunakea, A.K., et al., Conserved role of intragenic DNA methylation in regulating alternative promoters. Nature, 2010. 466(7303): p. 253-257.

6. Laird, P.W., The power and the promise of DNA methylation markers. Nat Rev Cancer, 2003. 3(4): p. 253-66.

7. Mulero-Navarro, S. and M. Esteller, Epigenetic biomarkers for human cancer: the time is now. Crit Rev Oncol Hematol, 2008. 68(1): p. 1-11.

8. Eads, C.A., et al., MethyLight: a high-throughput assay to measure DNA methylation. Nucleic Acids Res, 2000. 28(8): p. E32.

9. Herman, J.G., et al., Methylation-specific PCR: a novel PCR assay for methylation status of CpG islands. Proc Natl Acad Sci U S A, 1996. 93(18): p. 9821-6.

10. Uhlmann, K., et al., Evaluation of a potential epigenetic biomarker by quantitative methylsingle nucleotide polymorphism analysis. ELECTROPHORESIS, 2002. 23(24): p. 4072-4079.

11. An, Q., et al., Detection of $\mathrm{p} 16$ hypermethylation in circulating plasma DNA of non-small cell lung cancer patients. Cancer Lett, 2002. 188(1-2): p. 109-14.

12. Ebert, M.P., et al., Aristaless-like homeobox-4 gene methylation is a potential marker for colorectal adenocarcinomas. Gastroenterology, 2006. 131(5): p. 1418-30.

13. Esteller, M., et al., Detection of aberrant promoter hypermethylation of tumor suppressor genes in serum DNA from non-small cell lung cancer patients. Cancer Res, 1999. 59(1): p. 67-70.

14. Glockner, S.C., et al., Methylation of TFPI2 in stool DNA: a potential novel biomarker for the detection of colorectal cancer. Cancer Res, 2009. 69(11): p. 4691-9.

15. Hellebrekers, D.M., et al., GATA4 and GATA5 are potential tumor suppressors and biomarkers in colorectal cancer. Clin Cancer Res, 2009. 15(12): p. 3990-7.

16. Jeronimo, C., et al., Quantitation of GSTP1 methylation in non-neoplastic prostatic tissue and organ-confined prostate adenocarcinoma. J Natl Cancer Inst, 2001. 93(22): p. 1747-52.

17. Kim, M.S., et al., Promoter DNA methylation of oncostatin $m$ receptor-beta as a novel diagnostic and therapeutic marker in colon cancer. PLoS One, 2009. 4(8): p. e6555.

18. Lee, T.L., et al., Detection of gene promoter hypermethylation in the tumor and serum of patients with gastric carcinoma. Clin Cancer Res, 2002. 8(6): p. 1761-6.

19. Melotte, V., et al., N-Myc downstream-regulated gene 4 (NDRG4): a candidate tumor suppressor gene and potential biomarker for colorectal cancer. J Natl Cancer Inst, 2009. 101(13): p. 916-27.

20. Wong, I.H., et al., Detection of aberrant p16 methylation in the plasma and serum of liver cancer patients. Cancer Res, 1999. 59(1): p. 71-3.

21. Lofton-Day, C., et al., DNA methylation biomarkers for blood-based colorectal cancer screening. Clin Chem, 2008. 54(2): p. 414-23.

22. Brock, M.V., et al., DNA methylation markers and early recurrence in stage I lung cancer. $\mathrm{N}$ Engl J Med, 2008. 358(11): p. 1118-28.

23. van Vlodrop, I.J., et al., Prognostic significance of Gremlin1 (GREM1) promoter CpG island hypermethylation in clear cell renal cell carcinoma. Am J Pathol, 2010. 176(2): p. 575-84.

24. Veeck, J., et al., Aberrant methylation of the Wnt antagonist SFRP1 in breast cancer is associated with unfavourable prognosis. Oncogene, 2006. 25(24): p. 3479-88. 
25. Esteller, M., et al., Inactivation of the DNA-repair gene MGMT and the clinical response of gliomas to alkylating agents. N Engl J Med, 2000. 343(19): p. 1350-4.

26. Hegi, M.E., et al., Clinical trial substantiates the predictive value of O-6-methylguanine-DNA methyltransferase promoter methylation in glioblastoma patients treated with temozolomide. Clin Cancer Res, 2004. 10(6): p. 1871-4.

27. Veeck, J., et al., BRCA1 CpG island hypermethylation predicts sensitivity to poly(adenosine diphosphate)-ribose polymerase inhibitors. J Clin Oncol, 2010. 28(29): p. e563-4; author reply e565-6.

28. Gonzalgo, M.L., et al., The role of DNA methylation in expression of the p19/p16 locus in human bladder cancer cell lines. Cancer Res, 1998. 58(6): p. 1245-52.

29. Zinn, R.L., et al., hTERT is expressed in cancer cell lines despite promoter DNA methylation by preservation of unmethylated DNA and active chromatin around the transcription start site. Cancer Res, 2007. 67(1): p. 194-201.

30. Homma, N., et al., Spreading of methylation within RUNX3 CpG island in gastric cancer. Cancer Sci, 2006. 97(1): p. 51-6.

31. Buffart, T.E., et al., MAL promoter hypermethylation as a novel prognostic marker in gastric cancer. Br J Cancer, 2008. 99(11): p. 1802-7.

32. Deng, G., et al., Methylation of $\mathrm{CpG}$ in a small region of the hMLH1 promoter invariably correlates with the absence of gene expression. Cancer Res, 1999. 59(9): p. 2029-33.

33. Nakagawa, H., et al., Age-related hypermethylation of the $5^{\prime}$ region of MLH1 in normal colonic mucosa is associated with microsatellite-unstable colorectal cancer development. Cancer Res, 2001. 61(19): p. 6991-5.

34. Deng, G., et al., Methylation of hMLH1 promoter correlates with the gene silencing with a region-specific manner in colorectal cancer. Br J Cancer, 2002. 86(4): p. 574-9.

35. Nagasaka, T., et al., Colorectal cancer with mutation in BRAF, KRAS, and wild-type with respect to both oncogenes showing different patterns of DNA methylation. J Clin Oncol, 2004. 22(22): p. 4584-94.

36. Licchesi, J.D., et al., Transcriptional regulation of Wnt inhibitory factor-1 by Miz-1/c-Myc. Oncogene, 2010. 29(44): p. 5923-34.

37. Yoshikawa, H., et al., SOCS-1, a negative regulator of the JAK/STAT pathway, is silenced by methylation in human hepatocellular carcinoma and shows growth-suppression activity. Nat Genet, 2001. 28(1): p. 29-35.

38. Sohn, B.H., et al., Functional switching of TGF-beta1 signaling in liver cancer via epigenetic modulation of a single CpG site in TTP promoter. Gastroenterology, 2010. 138(5): p. 1898908.

39. Smiraglia, D.J., et al., Excessive CpG island hypermethylation in cancer cell lines versus primary human malignancies. Hum Mol Genet, 2001. 10(13): p. 1413-9.

40. Lee, P.S., et al., Elevated MAL expression is accompanied by promoter hypomethylation and platinum resistance in epithelial ovarian cancer. Int J Cancer, 2009. 126(6): p. 1378-89.

41. Ahuja, N., et al., Aging and DNA methylation in colorectal mucosa and cancer. Cancer Res, 1998. 58(23): p. 5489-94.

42. Issa, J.P., et al., Accelerated age-related CpG island methylation in ulcerative colitis. Cancer Res, 2001. 61(9): p. 3573-7.

43. Issa, J.P., et al., Methylation of the oestrogen receptor CpG island links ageing and neoplasia in human colon. Nat Genet, 1994. 7(4): p. 536-40.

44. Waki, T., et al., Age-related methylation of tumor suppressor and tumor-related genes: an analysis of autopsy samples. Oncogene, 2003. 22(26): p. 4128-33.

45. Ahuja, N. and J.P. Issa, Aging, methylation and cancer. Histol Histopathol, 2000. 15(3): p. 835-42.

46. Christensen, B.C., et al., Aging and environmental exposures alter tissue-specific DNA methylation dependent upon CpG island context. PLoS Genet, 2009. 5(8): p. e1000602. 
47. Graff, J.R., et al., Mapping patterns of $\mathrm{CpG}$ island methylation in normal and neoplastic cells implicates both upstream and downstream regions in de novo methylation. J Biol Chem, 1997. 272(35): p. 22322-9.

48. Yan, P.S., et al., Differential distribution of DNA methylation within the RASSF1A CpG island in breast cancer. Cancer Res, 2003. 63(19): p. 6178-86.

49. Cameron, E.E., S.B. Baylin, and J.G. Herman, p15(INK4B) CpG island methylation in primary acute leukemia is heterogeneous and suggests density as a critical factor for transcriptional silencing. Blood, 1999. 94(7): p. 2445-51.

50. Zheng, S., et al., Correlations of partial and extensive methylation at the p14(ARF) locus with reduced mRNA expression in colorectal cancer cell lines and clinicopathological features in primary tumors. Carcinogenesis, 2000. 21(11): p. 2057-64.

51. Nagasaka, T., et al., Methylation pattern of the O6-methylguanine-DNA methyltransferase gene in colon during progressive colorectal tumorigenesis. Int J Cancer, 2008. 122(11): p. 2429-36.

52. Feltus, F.A., et al., Predicting aberrant $\mathrm{CpG}$ island methylation. Proc Natl Acad Sci U S A, 2003. 100(21): p. 12253-8.

53. Feltus, F.A., et al., DNA motifs associated with aberrant $\mathrm{CpG}$ island methylation. Genomics, 2006. 87(5): p. 572-9.

54. Di Croce, L., et al., Methyltransferase recruitment and DNA hypermethylation of target promoters by an oncogenic transcription factor. Science, 2002. 295(5557): p. 1079-82.

55. Brenner, C., et al., Myc represses transcription through recruitment of DNA methyltransferase corepressor. Embo J, 2005. 24(2): p. 336-46.

56. Brandeis, M., Sp1 elements protect a CpG island from de novo methylation. Nature, 1994. 371: p. 435-438.

57. Macleod, D., et al., Sp1 sites in the mouse aprt gene promoter are required to prevent methylation of the CpG island. Genes Dev, 1994. 8(19): p. 2282-92.

58. Burgess-Beusse, B., et al., The insulation of genes from external enhancers and silencing chromatin. Proc Natl Acad Sci U S A, 2002. 99 Suppl 4: p. 16433-7.

59. McCabe, M.T., E.K. Lee, and P.M. Vertino, A multifactorial signature of DNA sequence and polycomb binding predicts aberrant CpG island methylation. Cancer Res, 2009. 69(1): p. 282-91.

60. Ku, M., et al., Genomewide analysis of PRC1 and PRC2 occupancy identifies two classes of bivalent domains. PLoS Genet, 2008. 4(10): p. e1000242.

61. Lee, T.I., et al., Control of developmental regulators by Polycomb in human embryonic stem cells. Cell, 2006. 125(2): p. 301-13.

62. Mohammad, H.P., et al., Polycomb CBX7 promotes initiation of heritable repression of genes frequently silenced with cancer-specific DNA hypermethylation. Cancer Res, 2009. 69(15): p. 6322-30.

63. Vire, E., et al., The Polycomb group protein EZH2 directly controls DNA methylation. Nature, 2006. 439(7078): p. 871-4.

64. Ohm, J.E., et al., A stem cell-like chromatin pattern may predispose tumor suppressor genes to DNA hypermethylation and heritable silencing. Nat Genet, 2007. 39(2): p. 237-42.

65. Schlesinger, Y., et al., Polycomb-mediated methylation on Lys27 of histone H3 pre-marks genes for de novo methylation in cancer. Nat Genet, 2007. 39(2): p. 232-236.

66. Widschwendter, M., et al., Epigenetic stem cell signature in cancer. Nat Genet, 2007. 39(2): p. 157-8.

67. Blackwood, E.M. and J.T. Kadonaga, Going the distance: a current view of enhancer action. Science, 1998. 281(5373): p. 60-3.

68. Bulger, M. and M. Groudine, Looping versus linking: toward a model for long-distance gene activation. Genes Dev, 1999. 13(19): p. 2465-77. 
69. Unoki, M. and Y. Nakamura, Methylation at $\mathrm{CpG}$ islands in intron 1 of EGR2 confers enhancer-like activity. FEBS Letters, 2003. 554(1-2): p. 67-72.

70. Lin, J.C., et al., Role of nucleosomal occupancy in the epigenetic silencing of the MLH1 CpG island. Cancer Cell, 2007. 12(5): p. 432-44.

71. Shu, J., et al., Silencing of bidirectional promoters by DNA methylation in tumorigenesis. Cancer Res, 2006. 66(10): p. 5077-84.

72. Domann, F.E., et al., Epigenetic silencing of maspin gene expression in human breast cancers. International Journal of Cancer, 2000. 85(6): p. 805-810.

73. Irvine, R.A., I.G. Lin, and C.L. Hsieh, DNA methylation has a local effect on transcription and histone acetylation. Mol Cell Biol, 2002. 22(19): p. 6689-96.

74. Tiwari, V.K., et al., PcG proteins, DNA methylation, and gene repression by chromatin looping. PLoS Biol, 2008. 6(12): p. 2911-27.

75. Frigola, J., et al., Epigenetic remodeling in colorectal cancer results in coordinate gene suppression across an entire chromosome band. Nat Genet, 2006. 38(5): p. 540-9.

76. Hitchins, M.P., et al., Epigenetic inactivation of a cluster of genes flanking MLH1 in microsatellite-unstable colorectal cancer. Cancer Res, 2007. 67(19): p. 9107-16.

77. Rodriguez, J., et al., Bivalent domains enforce transcriptional memory of DNA methylated genes in cancer cells. Proc Natl Acad Sci U S A, 2008. 105(50): p. 19809-14.

78. Coolen, M.W., et al., Consolidation of the cancer genome into domains of repressive chromatin by long-range epigenetic silencing (LRES) reduces transcriptional plasticity. Nat Cell Biol, 2010. 12(3): p. 235-46.

79. He, H.H., et al., Nucleosome dynamics define transcriptional enhancers. Nat Genet, 2010. 42(4): p. 343-7.

80. Derks, S., et al., Methylation-specific PCR unraveled. Cell Oncol, 2004. 26(5-6): p. 291-9.

81. Weber, M., et al., Chromosome-wide and promoter-specific analyses identify sites of differential DNA methylation in normal and transformed human cells. Nat Genet, 2005. 37(8): p. 853-862.

82. Rauch, T.A. and G.P. Pfeifer, DNA methylation profiling using the methylated-CpG island recovery assay (MIRA). Methods, 2010. 52(3): p. 213-217.

83. Bibikova, M., et al., Genome-wide DNA methylation profiling using Infinium $\hat{A}^{\circledast}$ assay. Epigenomics, 2009. 1(1): p. 177-200.

84. Jorda, M. and M.A. Peinado, Methods for DNA methylation analysis and applications in colon cancer. Mutat Res, 2010. 693(1-2): p. 84-93.

85. Margulies, M., et al., Genome sequencing in microfabricated high-density picolitre reactors. Nature, 2005. 437(7057): p. 376-380.

86. Serre, D., B.H. Lee, and A.H. Ting, MBD-isolated Genome Sequencing provides a highthroughput and comprehensive survey of DNA methylation in the human genome. Nucleic Acids Res, 2010. 38(2): p. 391-9.

87. Nestor, C., et al., Enzymatic approaches and bisulfite sequencing cannot distinguish between 5-methylcytosine and 5-hydroxymethylcytosine in DNA. Biotechniques, 2010. 48(4): p. 317-9. 


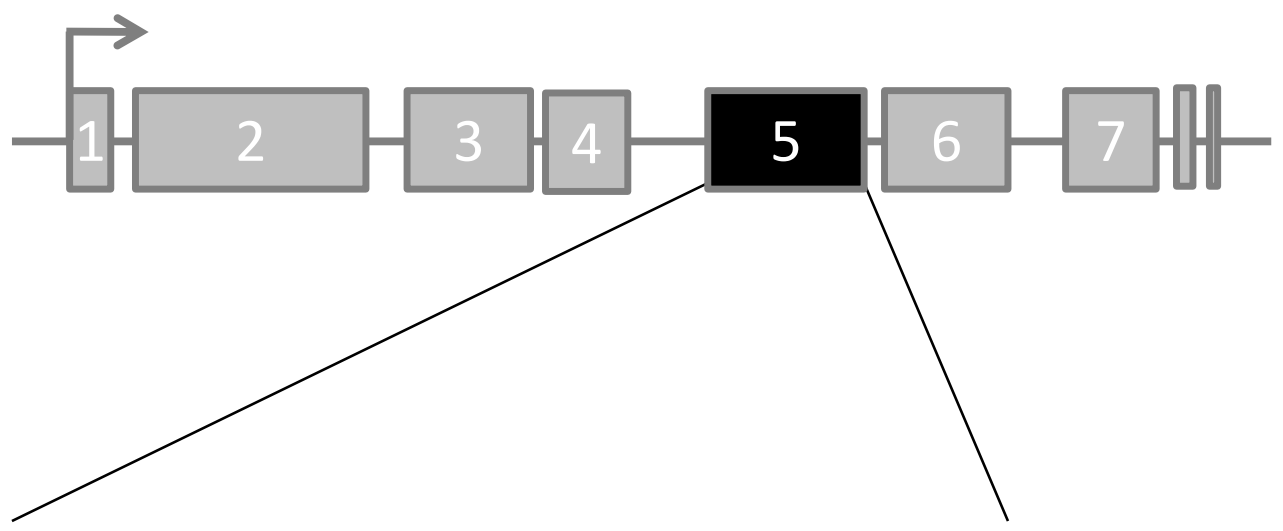

A four gene promoter $\mathrm{CpG}$ island methylation marker panel predicts

survival of clear cell renal cell

cancer patients

Iris J.H. van Vlodrop, Tim de Meyer, Kim M. Smits, Leander van Neste, Veerle Melotte, Marcella M.L.L. Baldewijns, Peter T. Moerkerk, Leo J. Schouten, Piet A. van den Brandt, Joo Mi Yi, Jana Jeschke, Marilia de Freitas Calmon, Kornel E. Schuebel, Nita Ahuja, Stephen B. Baylin, James G. Herman, Patricia M.M.B. Soetekouw, Fre T. Bosman, Wim van Criekinge and Manon van Engeland

Submitted 


\begin{abstract}
Clear cell renal cell carcinoma (ccRCC) is the most common adult renal cancer. Although the molecular characteristics of ccRCC are currently being studied, the biologically and clinically relevant ccRCC methylome remains to be elucidated. To explore the RCC hypermethylome we employed massive sequencing of methyl-binding protein enriched DNA and validated the biological relevance of the identified hypermethylated sites by pharmacological inhibition of DNA methylation. We identified four candidate tumor suppressor genes (GREM1, LAD1, NEFH, and NEURL) of which promoter CpG island hypermethylation was strongly predictive for ccRCC survival in two independent series ( $n=150$ and $n=185$ ) of ccRCC primary samples. The four markers combined are strongly associated with risk for cancer-related death in the test series (HR 3.64, 95\% $\mathrm{Cl}$ 1.02-13.01) as well as, independently of other clinicopathological characteristics, in the validation series (HR 7.54, 95\% Cl 2.68-21.19) using Cox proportional hazard models. According to Harrell's C statistics and the Akaike Information Criterion (AIC) the four marker panel provides the best predictive capacity with the best fit of the model. These results provide novel insights into the ccRCC hypermethylome and identify a strong methylation marker panel to potentially guide personalized ccRCC patient management. Preliminary to implementation of this marker panel into clinical practice, enrollment of these patients in a Phase-III trial to study adjuvant treatment efficacy is essential.
\end{abstract}




\section{Introduction}

Exploring cancer (epi)genomes provides insight in tumorigenesis and this knowledge might be used to develop biomarkers for the early detection of cancer, for the prediction of prognosis and response to therapy as well as for developing novel therapies. Unlike well-characterized cancers such as colorectal and breast cancer, the biology of renal cancer has not yet been extensively studied. The most common adult renal neoplasm is clear cell renal cell carcinoma (ccRCC), histologically characterized by lipid-rich clear cells and high vessel density. Currently, the patient performance status, TNM stage and Fuhrman nuclear grade are the best predictors of patient outcome ${ }^{1}$ but more specific parameters are needed. Although loss of function of the von HippelLindau $(V H L)$ gene is a key event in the development of $\mathrm{ccRCCs}^{2-4}$, alterations in the structure $e^{4,5}$ or regulation of the expression of the $V H L$ gene ${ }^{6,7}$ do not appear to be directly associated with tumor cell proliferation and patient prognosis ${ }^{8,9}$. Except for $V H L$ and the recently identified PBRM1 gene ${ }^{10}$, no genes have been identified that are consistently mutated in a substantial proportion of ccRCCs. Known cancer genes that are frequently mutated in other cancers (RAS genes, TP53, CDKN2A, BRAF, PTEN, etc) do not play an important role in $\mathrm{CCRCC}^{11}$. Clinical management would profit from markers that can predict patient outcome and/or guide treatment decisions.

Promoter $\mathrm{CpG}$ island hypermethylation and subsequent gene silencing are involved in RCC oncogenesis more frequently than genetic alterations ${ }^{11,12}$. This affects numerous cellular processes, including cell cycle checkpoints, apoptosis, signal transduction, cell adhesion, and angiogenesis ${ }^{13}$.

Rapid developments in approaches to analyze the methylome, based on expression microarrays, have facilitated the identification of cancer related genes inactivated by DNA hypermethylation. However, probe- and protocol design in array-based strategies introduce detection bias and influence the sensitivity and specificity of detection. There is emerging evidence that CpG dinucleotide methylation, regulating gene expression, is highly location specific ${ }^{14}$. As current probe-design is location- rather than function oriented, this may hinder identification of relevant methylated genes by microarray-based discovery. Next-generation sequencing (NGS) technology is a more direct method and allows genome-wide sequencing of enriched DNA fractions, which overcomes these limitations ${ }^{15}$.

We comprehensively explored the clear cell renal cell cancer hypermethylome, by integrating methyl-binding domain (MBD) affinity purification based massive parallel sequencing of ccRCC cell lines with global transcript expression array data obtained by pharmacological inhibition of DNA methylation. This allows us to identify those promoter hypermethylated genes that are functionally relevant, i.e. silenced by promoter hypermethylation. A panel of four genes was identified, of which methylation impacts on tumor cell proliferation and invasion and which strongly predicts prognosis of CCRCC patients in a retrospective series and prospective validation series of ccRCC. 


\section{Materials and Methods}

\section{Study populations and clinical specimens}

DNA from formalin-fixed and paraffin embedded primary tumor samples from two independent well characterized ccRCC patient series was used for this study. The first population is a hospital-based series $(n=150)$ derived from the archives of the Department of Histopathology, University Hospital of Leuven and Department of Pathology, Maastricht University Medical Center. The second population $(n=185)$ was obtained from the Netherlands Cohort Study on diet and cancer (NLCS) ${ }^{16}$, a prospective, population-based cohort study in which tumor tissue was collected from 51 pathology laboratories throughout the Netherlands. In addition, histologically normal renal tissue samples (formalin-fixed, paraffin embedded) of 20 non-RCC patients were collected from the archives of the Department of Pathology, Maastricht University Medical Center.

Tissue collection, DNA isolation and patient characteristics (see also Table 3 and Table 4) have been described in detail elsewhere ${ }^{17,18}$. This study was approved by the Medical Ethical Committee of the Maastricht University Medical Center.

\section{Cell culture, drug treatment and microarray analyses}

Four ccRCC cell lines (SKRC1, SKRC10, SKRC52, SKRC59), kindly provided by Dr. E. Oosterwijk, Nijmegen Center for Molecular Life Sciences (NCMLS), Nijmegen, The Netherlands, were cultured in RPMI 1640 media (Invitrogen) supplemented with 10\% heatinactivated fetal bovine serum (FBS). The human kidney 2 cell line (HK-2) was purchased from ATCC and cultured in Keratinocyte Serum Free Medium (K-SFM, GIBCO) supplemented with bovine pituitary extract (BPE) and human recombinant epidermal growth factor (EGF) as recommended.

SKRC1, SKRC10, SKRC52, and SKRC59 cells were treated with 5'aza-2-deoxycytidine (DAC) or Trichostatin A (TSA), which inhibit DNA methylation and histone deacetylation, respectively, as recently described ${ }^{19,20}$. Approximately $10 \%$ confluent RCC cells were cultured in RPMI 1640 media containing 10\% FBS with $5 \mu \mathrm{M}$ (DAC) (Sigma; stock solution: $1 \mathrm{mM}$ in PBS) for 96 hours, replacing media and DAC every 24 hours. Cell treatment with $300 \mathrm{nM}$ TSA (Sigma; stock solution: $5 \mathrm{mM}$ dissolved in ethanol) was performed for 18 hours, starting at approximately $30 \%$ cell confluency. Mock treated cells were grown in parallel with the DAC treatment by adding equal volumes of PBS without drugs.

Microarray expression analyses were performed on mock-, DAC-, or TSA-treated cells (SKRC1, SKRC10, SKRC52, SKRC59), as described by Schuebel et al. ${ }^{19}$. In brief, total RNA was isolated using the RNeasy kit (Qiagen) according to the manufacturers' instructions and quantified using the NanoDrop ND-100 followed by quality assessment with the 2100 Bioanalyzer ( $R I N=10(n=10), 9.9(n=1)$ or $8.9(n=1)$, Agilent Technologies). Sample amplification and labeling procedures were carried out using the Low RNA Input Fluorescent Linear Amplification Kit (Agilent Technologies) according to the manufacturers' instructions. The labeled cRNA was purified using the RNeasy mini kit (Qiagen) and quantified. Cy3 or Cy5 labeled samples were mixed with control targets (Agilent Technologies), assembled on Oligo Microarray, hybridized, and processed 
according to the Agilent microarray protocol. Scanning was performed with the Agilent G2565BA microarray scanner using settings recommended by Agilent Technologies.

Array data were analyzed using $R$ (version 2.10.0) and BioConductor, using the limma package (version 3.2.1) ${ }^{21}$. Median $\mathrm{Cy} 5$ and $\mathrm{Cy} 3$ signals read from the raw data and $\mathrm{M}$ values, i.e. $\log 2(\mathrm{Cy} 5 / \mathrm{Cy} 3)$, were loess normalized. Basal expression was roughly estimated using the single channel $\mathrm{Cy} 3$ values, containing the mock treated samples. Based on the threshold used for basal expression, the specificity could be further increased, with obvious implications on sensitivity.

\section{MBD-affinity NGS}

SKRC1, SKRC10, SKRC52, SKRC59 and HK-2 cells were cultured as described above and DNA was isolated using the Puregene DNA purification kit (BIOzym, Landgraaf, the Netherlands) according to the manufacturer's instructions. Its genomic DNA was fragmented by use of a COVARIS S2 system with AFA fiber micro tubes to obtain fragments with an average length of $200 \mathrm{bp}$. Methylated DNA was captured by the equally efficient (more than 94\%) pull-down using the MethylCollector kit (Active Motif) or MethylCap with High-Salt elution (Diagenode), both based on autologous methyl-binding domains, according to the manufacturer's protocols. Subsequently, fragments were sequenced using the Illumina Genome Analyzer II. The concentration of the fragmented and captured DNA was determined on a Fluostar Optima plate reader with the Quant-iT ${ }^{\mathrm{TM}}$ PicoGreen ${ }^{\circledR}$ dsDNA Assay Kit (Invitrogen P7589) 480/520nm. For all samples together, the paired-end 40bp sequence reads were mapped using BOWTIE ${ }^{22}$ on the human reference genome (NCBI build 37.3). Coverage values were summarized using the map of the human methylome, which consists of putatively independently methylated regions (methylation cores) throughout the genome (manuscript in preparation). For each sample, and each methylation core, the maximum read coverage was used for further analysis. Subsequently, we focused on the broad promoter region for each gene $(-2000$ to $+500 \mathrm{bp})$. A Poisson background model was used to identify significantly methylated regions (alpha $=0.01$ ), with lambda estimated as the sum of the coverage values over all promoter methylation cores divided by the number of promoter methylation cores. This approach takes into account coverage differences between samples, although generally low coverage will result in low sensitivity. For absence of methylation in HK-2 we allowed a maximum coverage value of 2 , corresponding with $\mathrm{P} \leq 0.067$.

\section{DNA methylation and gene expression analyses}

Gene promoter $\mathrm{CpG}$ island methylation was determined by chemical modification of genomic DNA with sodium bisulfite and subsequent methylation-specific PCR (MSP) as described in detail elsewhere ${ }^{23-25}$. In brief, $500 \mathrm{ng}$ of DNA was modified by sodium bisulfite using the EZ DNA methylation kit (Zymo Research, Orange, California) according to the manufacturers' instructions. To facilitate MSP analysis on DNA retrieved from formalin-fixed paraffin embedded tissue, DNA was first amplified with flanking PCR primers that amplify bisulfite-modified DNA but do not preferentially amplify methylated or unmethylated DNA. The resulting fragment was used as a template for the MSP reaction. All PCRs were performed with controls for unmethylated alleles (DNA from normal lymphocytes or DNA from human umbilical vein endothelial cells (HU- 
VEC), methylated alleles [normal lymphocyte DNA treated in vitro with SssI methyltransferase (New England Biolabs)], and a control without DNA. Primer sequences and PCR conditions are available upon request. Ten $\mu$ of each MSP reaction was directly loaded onto 2\% agarose gels containing GelStar Nucleic Acid Gel Stain (Cambrex, New Jersey, USA), and visualized under UV illumination.

RNA of mock-, DAC-, and TSA-treated cells was isolated using the RNeasy mini kit (Qiagen) according to the manufacturers' instructions and treated with RNase-free DNase (Qiagen). Synthesis of complementary DNA (cDNA) was performed using the Iscript cDNA synthesis kit (Bio-Rad, Veenendaal, The Netherlands). Quantitative reverse transcription PCR was performed as described previously ${ }^{26}$ using SYBR Green PCR master mix (Bio-Rad, Veenendaal, The Netherlands). Cyclophillin A was used as a reference gene for normalization. Primer sequences and PCR conditions are available upon request.

\section{Plasmid constructs and cell transfections}

The GREM1 expression construct was made by cloning the full-length human coding region amplified from normal kidney tissue into the pcDNA3 vector. The NEURLpIRESneo3 construct has been described before ${ }^{19}$. Plasmid constructs were verified by sequencing.

SKRC1 and SKRC59 cells were transfected with GREM1-pcDNA3 or empty vector (pcDNA3) using Lipofectamine2000 (Invitrogen), or with NEURL-pIRESneo3 (linearized by Pvul) or empty vector (pIRESneo3) (linearized by Pvul) using Nucleofector Kit $\mathrm{V}$ (Amaxa Biosystems, Gaithersburg, MD) according to the manufacturer's protocols. Following a 24 hours recovery period, transfected SKRC1, and -59 cells were selected in G418 containing medium $(500 \mu \mathrm{g} / \mathrm{mL}$ for SKRC1, $750 \mu \mathrm{g} / \mathrm{mL}$ for SKRC59). Expression was confirmed by qRT-PCR as described above.

\section{In vitro colony formation, cell proliferation, migration, and invasion assays}

SKRC1 and -59 cells were transfected in six-well plates $\left(3 \times 10^{5}\right.$ cells per well) with empty pcDNA3 / GREM1-pcDNA3 or empty pIRESneo3 (linearized by Pvul) / NEURLpIRESneo3 (linearized by Pvul) and selected for 10 or 14 days in G418 containing media as described above. Surviving colonies were stained with Giemsa's azur eosin methylene blue solution (Merck, Darmstadt, Germany) and counted. Cells were transfected in triplicate and colony formation was assessed in three independent experiments.

G418-selected SKRC1 and -59 cells were seeded onto 96 -well plates ( 2500 or 3000 cells per well), and cell numbers were counted 24, 48, 72, and 96 hours later (six wells per time point). In addition, after 96 hours of incubation, the cultures were pulse labeled for 6 hours with [methyl- ${ }^{3} \mathrm{H}$ ]thymidine $(0.3 \mu \mathrm{Ci}$ per well; Amersham Life Science, Roosendaal, the Netherlands). Cells were harvested using a cell harvester, and $\left[{ }^{3} \mathrm{H}\right]$ thymidine activity was measured by liquid scintillation counting. Three independent experiments were performed.

Cell migration and invasion assays were performed using matrigel-coated (invasion assay) or uncoated (migration assay) 24 -well transwell plates (8- $\mu \mathrm{m}$ pore size) (BD Biosciences, Franklin Lakes, NJ), according to the manufacturers' instructions. Briefly, 6 $\times 10^{4}$ SKRC1 cells or $1.2 \times 10^{5}$ SKRC59 cells in RPMI 1640 medium containing $1 \%$ FCS 
were seeded into the upper chamber of each well, and RPMI 1640 containing $10 \%$ FCS was placed in the lower chamber. After 24 hours of incubation and removal of cells on the upper surface of the membrane, cells on the lower surface were fixed with methanol, hematoxylin/eosine stained and counted with the use of a light microscope. Transwell assays were performed in three independent experiments (two replicate wells per experiment).

\section{Data analysis}

Cause-specific survival was defined as the time from cancer diagnosis until renal cancer-related death or end of follow-up. Differences in clinicopathological and angiogenesis characteristics between ccRCCs with and without candidate gene promoter CpG island hypermethylation were evaluated with the Student's $t$ and Pearson's $\chi^{2}$ tests, where appropriate. Kaplan-Meier analyses and log-rank tests were used to estimate the overall influence of candidate gene promoter CpG island hypermethylation on cause-specific survival. Hazard ratios (HR) and corresponding 95\% confidence interval (Cl) were assessed using Cox proportional hazard models. Known prognostic factors for renal cancer were considered possible confounders if they influenced the crude HR by more than $10 \%$. Possible confounders that were included in the model for both series were sex, age at diagnosis, cancer stage, tumor size and nuclear grade. The proportional hazard assumption was tested using the Schoenfeld residuals and the log(-log) hazards plots. Harrell's C statistic and Akaike Information Criterion (AIC) were used to assess the predictive capacity and fit of the models. As a model with a $100 \%$ sensitivity and specificity would yield a Harrell's $C$ statistic of 1.00, the model with the highest Harrell's C statistic was regarded as the best model. If two models had similar Harrell's $C$ statistics, the model with the lowest AIC was chosen as the best model. All analyses were performed with the statistical package STATA 11.0.

The Student $t$-test or the Mann-Whitney rank sum test (in case of normality violation) was used to analyze differences in gene expression, colony formation, $\left[{ }^{3} \mathrm{H}\right]$ thymidine incorporation, migration and invasion. Cell growth curves were analyzed through Kruskal-Wallis one-way analysis of variance. Functional data analyses were performed using PASW statistics 18 (SPSS Inc.). All reported $P$ values are two-sided and $P$ values $\leq 0.05$ were considered statistically significant. 


\section{Results}

Exploring the $c c R C C$ hypermethylome identifies promoter CpG island hypermethylated candidate tumor suppressor genes

In order to identify tumor specific promoter hypermethylation in RCC we combined the novel MBD-affinity based NGS method ${ }^{27}$ with up-regulation after demethylation by DAC. Changes in gene expression following global demethylation or histone deacetylase inhibition of four $\mathrm{CCRCC}$ cell lines are shown in Figure 1.A. The characteristic spikes identify a zone in which gene expression did not increase by TSA (TSA-negative $<1.4$ fold), and was not found in wild-type untreated cells, but increased $>1.4$-fold with DAC treatment (DAC-positive) ${ }^{19,20}$. In total, 1583 unique genes within the spikes were identified with between 508 and 731 unique genes per cell line. The number of cell lines expressing these genes is shown in Figure 1.B.

Differentially methylated DNA sequences were identified by massive sequencing of MBD binding enriched sheared DNA as described earlier ${ }^{27}$. MBD-affinity NGS of the normal renal epithelial cell line HK-2 was performed to identify tumor specific hypermethylation. In total, 7829 unique genes indicated promoter methylation, with 2802 to 5695 unique genes per cell line. The distribution of differentially methylated genes among the cell lines is depicted in Figure 1.C. Figure 1.D shows the similarity and difference in number of genes between the two approaches per cell line, taking into account the lower genome coverage of the expression arrays. Interestingly, using our stringent restrictions, just 5.8 to $8.6 \%$ of the methylated genes were re-expressed after demethylation per cell line, defining the candidates for functional DNA methylation. Genes were selected for functional hypermethylation, defined as MBD-binding and reexpression after demethylation by DAC in $4 / 4$ or $3 / 4$ ccRCC cell lines, but unmethylated in the normal kidney cell line HK-2. This identified candidate genes with a CpG-island in their promoter region (exon1) within the TSA-negative, DAC-positive zone. To increase the possibility of the identification of (renal cell) cancer specific genes, we specifically focused on genes involved in DNA repair, angiogenesis and hypoxia, carbohydrate metabolism, the TGF- $\beta$ or Notch pathway based on GO-terms, and genes known to be mutated in renal cancer ${ }^{10,11}$ or frequently mutated in breast and colorectal cancer ${ }^{28}$. This resulted in 43 candidate genes that have not been reported previously to show promoter hypermethylation in RCC, except for CST6 ${ }^{29}$ and for GREM $1^{18,29}$ (see Figure 2 and for a complete list see Table 1). 

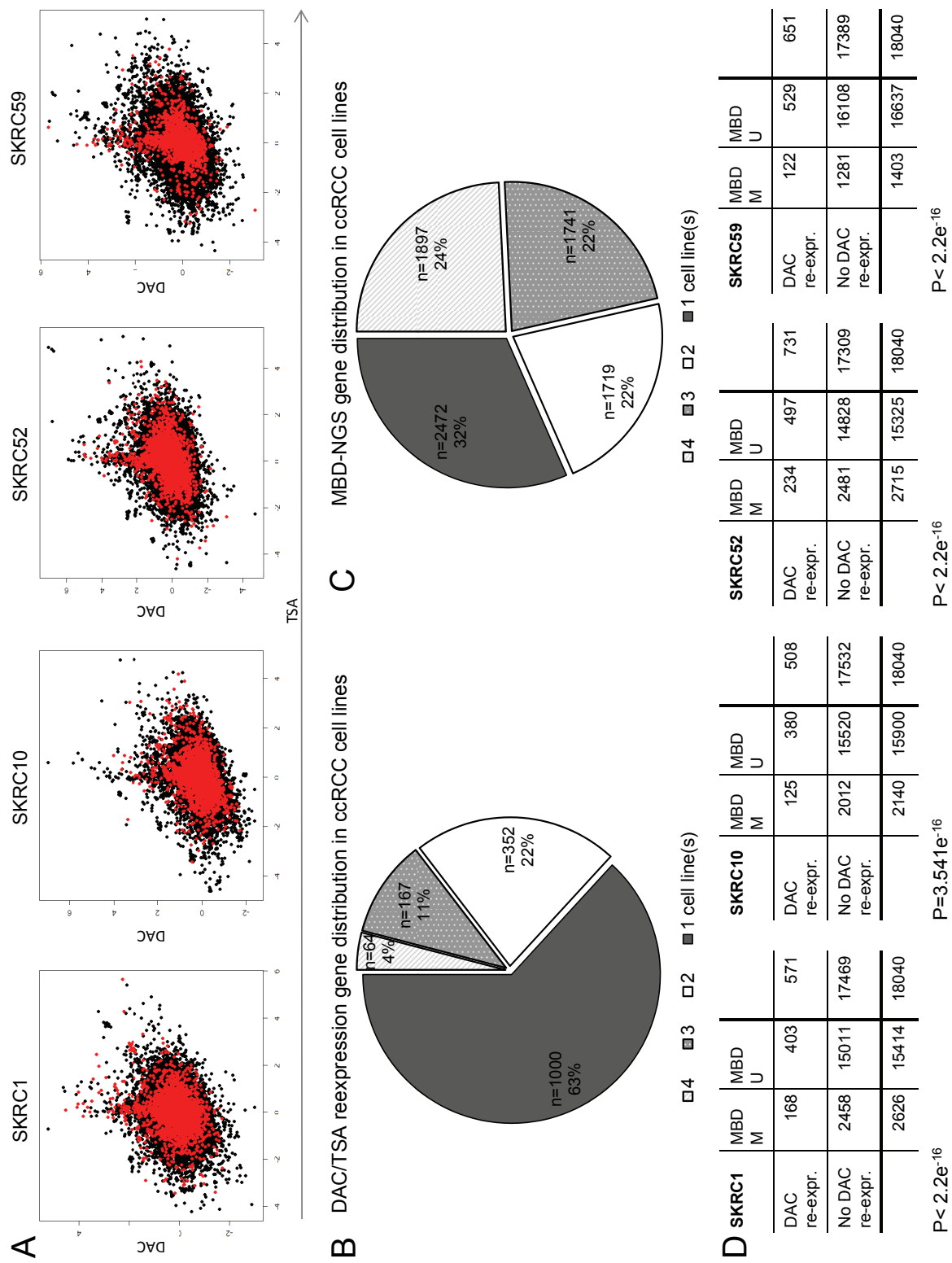


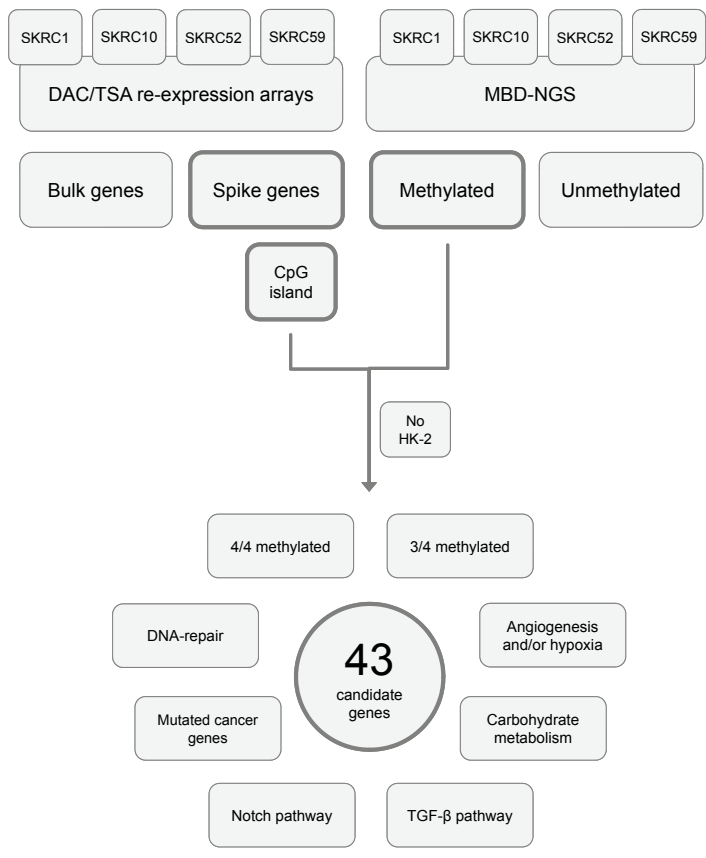

Figure.2. Pipeline to select candidate methylation markers in ccRCC cell lines

Schematic view of developed pipeline applied for the quick identification of biological relevant candidate genes. Promoter $\mathrm{CpG}$ island including genes, identified in ccRCC cell lines as specifically up-regulated after DAC treatment and enriched by MBD-protein(s), but not in HK-2 cells, were considered as candidate promoter hypermethylated genes. Those genes that met the downstream indicated requirements were selected for further analyses.

\section{Validation of methylation and expression status in candidate genes}

In order to validate the approach used, we examined the methylation and expression status of the candidate genes in CCRCC cells, by MSP and qRT-PCR, respectively. As recently illustrated, the location of methylation is of utmost importance ${ }^{14}$. Therefore, we designed MSP primers for all 43 candidate genes at promoter regions which show binding of MBD protein(s) in RCC cell lines, but not in normal kidney epithelium in the MBD affinity-NGS approach. In total, 172 (43 genes times four cell lines) reactions were performed by MSP with methylation in $138 \mathrm{MSP}$ reactions compared to 30 reactions without methylation (see Table 2, four reactions failed due to technical limitations). Validation of the expression microarray data resulted in a sensitivity and specificity of $80 \%$ (111 out of 138 and 24 out of 30, respectively, Table 2). Validation of the MBDNGS data resulted in a sensitivity of $90 \%$ (124 out of 138) and a specificity of $63 \%$ (19 out of 30, Table 2). Similarly, gene up-regulation after demethylation by qRT-PCR was validated in $74 \%$ using a subset $(n=22)$ of genes. 
Table 1. Candidate gene selection

\begin{tabular}{|c|c|c|c|c|c|c|c|}
\hline Gene & Acc. No & Map locus & $\begin{array}{l}\text { Meth. } \\
\text { cell lines }\end{array}$ & $\begin{array}{l}\% \text { Meth. } \\
\text { pilot RCC }\end{array}$ & $\begin{array}{l}\% \text { Meth. } \\
\text { pilot NK }\end{array}$ & $\begin{array}{l}\text { \% Meth. } \\
\text { 1st series }\end{array}$ & $\begin{array}{l}\% \text { Meth. } \\
\text { 2nd series }\end{array}$ \\
\hline CSPG4 & NM_001897 & $15 q 24.2$ & $4 / 4$ & 25 & 0 & 21 & \\
\hline GREM1 & NM_013372 & $15 q 13.3$ & $4 / 4$ & 30 & 0 & 20 & 40 \\
\hline KRT7 & NM_005556 & $12 q 12-q 13$ & $4 / 4$ & 30 & 0 & 19 & \\
\hline LAD1 & NM_005558 & 1q25.1-q32.3 & $4 / 4$ & 30 & 5 & 27 & 37 \\
\hline$N E F H$ & NM_021076 & $22 q 12.2$ & $4 / 4$ & 45 & 0 & 37 & 52 \\
\hline NEURL & NM_004210 & $10 q 25.1$ & $4 / 4$ & 60 & 5 & 44 & 48 \\
\hline QPCT & NM_012413 & $2 p 22.2$ & $4 / 4$ & 30 & 5 & 45 & \\
\hline RGMA & NM_001166283 & $15 q 26.1$ & $4 / 4$ & 20 & 0 & 16 & \\
\hline SORL1 & NM_003105 & 11q23.2-q24.2 & $3 / 4$ & 29 & 10 & 58 & \\
\hline CD109 & NM_133493 & $6 q 13$ & $1 / 4$ & 30 & 0 & 0 & \\
\hline CHRDL2 & NM_015424 & $11 q 14$ & $3 / 4$ & 29 & 6 & 5 & \\
\hline FST & NM_006350 & $5 q 11.2$ & $2 / 4$ & 20 & 6 & 5 & \\
\hline PLXDC1 & NM_020405 & $17 q 21.1$ & $4 / 4$ & 26 & 5 & 2 & \\
\hline RASGEF1A & NM_145313 & $10 q 11.21$ & $3 / 4$ & 20 & 0 & 0 & \\
\hline ACOT4 & NM_152331 & $14 \mathrm{q} 24.3$ & $4 / 4$ & 83 & 80 & & \\
\hline$A L D H 2$ & NM_000690 & $12 \mathrm{q} 24.2$ & $2 / 4$ & 0 & 0 & & \\
\hline ANK1 & NM_020476 & $8 p 11.1$ & $4 / 4$ & 59 & 32 & & \\
\hline APBB1IP & NM_019043 & 10p12.1 & $3 / 4$ & 0 & 0 & & \\
\hline BMP2 & NM_001200 & 20p12 & $4 / 4$ & 83 & 90 & & \\
\hline BMPER & NM_133468 & $7 p 14.3$ & $4 / 4$ & 57 & 86 & & \\
\hline CIDEA & NM_001279 & $18 p 11.21$ & $3 / 4$ & 50 & 17 & & \\
\hline COL1A2 & NM_000089 & $7 q 22.1$ & - & 41 & 45 & & \\
\hline CST6 & NM_001323 & $11 q 13$ & $4 / 4$ & 0 & 0 & & \\
\hline CYB5R2 & NM_016229 & $11 \mathrm{p} 15.4$ & $4 / 4$ & 10 & 21 & & \\
\hline CYP24A1 & NM_000782 & $20 q 13$ & $4 / 4$ & 5 & 0 & & \\
\hline DLL1 & NM_005618 & $6 q 27$ & $4 / 4$ & 56 & 76 & & \\
\hline FLJ40869 & NM_182625 & $2 p 24.2$ & $1 / 4$ & 5 & 0 & & \\
\hline GDF6 & NM_001001557 & $8 q 22.1$ & $1 / 4$ & 0 & 0 & & \\
\hline GPR30 & NM_001505 & $7 p 22.3$ & $3 / 4$ & 0 & 0 & & \\
\hline GPR68 & NM_001177676 & $14 q 31$ & $4 / 4$ & 0 & 0 & & \\
\hline HEYL & NM_014571 & $1 \mathrm{p} 34.3$ & $3 / 4$ & 50 & 40 & & \\
\hline IGFBP4 & NM_001552 & $17 q 12-q 21.1$ & $4 / 4$ & 0 & 0 & & \\
\hline MAPK13 & NM_002754 & $6 p 21.31$ & $4 / 4$ & 50 & 55 & & \\
\hline ME3 & NM_006680 & 11cen-q22.3 & $2 / 4$ & 15 & 0 & & \\
\hline MMP2 & NM_004530 & $16 q 13-q 21$ & $3 / 4$ & 60 & 17 & & \\
\hline MYO5C & NM_018728 & $15 q 21$ & $2 / 4$ & 35 & 30 & & \\
\hline PGF & NM_002632 & $14 q 24.3$ & $2 / 4$ & 5 & 0 & & \\
\hline PON3 & NM_000940 & $7 q 21.3$ & $4 / 4$ & 95 & 90 & & \\
\hline PYCARD & NM_013258 & 16p11.2 & $4 / 4$ & 0 & 0 & & \\
\hline SECTM1 & NM_003004 & $17 q 25$ & $4 / 4$ & 15 & 0 & & \\
\hline SPON2 & NM_012445 & $4 p 16.3$ & $4 / 4$ & 55 & 95 & & \\
\hline TACSTD2 & NM_002353 & 1p32 & $4 / 4$ & 81 & 94 & & \\
\hline ZNF569 & NM_152484 & $19 q 13.12$ & $4 / 4$ & 0 & 0 & & \\
\hline
\end{tabular}

Promoters of 43 selected candidate genes were analyzed for their methylation status in ccRCC cell lines and a pilot of primary ccRCCs and normal kidney samples. 14 genes were further selected for analyses in the hospital-based series and four of them additionally in the population-based series

Table 2. Validation expression microarrays and MBD-NGS by MSP

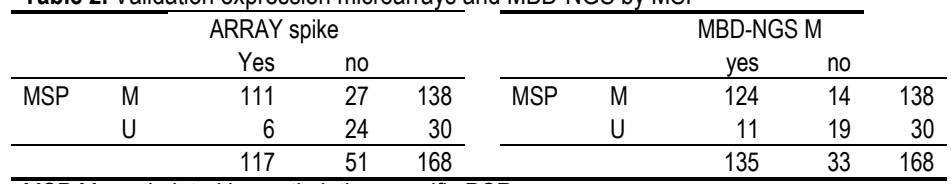

MSP M: methylated by methylation-specific PCR

MSP U: unmethylated by methylation-specific PCR

MBD-NGS M: indicated for methylation by MBD-NGS 


\section{Promoter hypermethylation in primary RCC}

To determine whether promoter CpG island hypermethylation of candidate genes was also present in primary RCC, we initially performed MSP for the 43 candidate genes on 20 primary RCCs and 20 normal kidney samples in which the methylation frequency ranged from $0-95 \%$ (Table 1). To increase the likelihood of relevant gene identification with proper prognostic significance, a high prevalence of tumor-specific methylation is required. Therefore, genes with a promoter methylation frequency of $\leq 20 \%$ in RCC $(n=15)$ or $>10 \%$ in normal kidney $(n=14$, despite correction for kidney tissue specific methylation using HK-2 MBD-NGS data) were not further analyzed. The remaining 14 genes were tested for promoter methylation in the hospital-based series $(n=150)$ (Table 1). Of these, five were eventually excluded as none or only few additional methylated cases were detected in the first half of the series. Thus, the remaining nine genes were analyzed in all 150 ccRCC cases of the hospital-based series and showed hypermethylation frequencies ranging from $16 \%-58 \%$ (Table 1 ).

\section{Promoter CpG island hypermethylation of GREM1, LAD1, NEFH and NEURL has prognostic value in primary cCRCC}

The association between the promoter hypermethylation status of the ten candidate genes and tumor/patient characteristics and clinical outcome in the hospital-based series $(n=150)$ is shown in Table 3, supplemental Table 1 , supplemental Figure $1 \mathrm{~A}-\mathrm{E}$ and supplemental Figure 2 A,C,E,G. Promoter hypermethylation of GREM1, LAD1, NEFH and NEURL showed significant associations with advanced disease and/or poor prognosis (Table 3 ). In addition to GREM1 (as we published earlier, ${ }^{18}$ ), also promoter hypermethylation of LAD1, NEFH and NEURL showed an association with poor survival, although for NEFH this was not statistically significant (log-rank p-value LAD1 0.013, NEURL 0.002 and NEFH 0.173, supplemental Figure 2C,E,G). In addition, promoter hypermethylation of $L A D 1$ and NEURL was associated with tumor size, -grade, and stage, tumor cell proliferation (TCP), endothelial cell proliferation (ECP) and micro vessel density (MVD), although for NEURL less striking than for GREM1 (Table 3).

As shown in Figure 3, the association between poor survival and promoter hypermethylation of GREM1, LAD1, NEFH, and NEURL was also seen in the age- and sexadjusted Cox proportional hazard analyses (HR $\mathrm{HRREM1}_{\text {1 }}$ : 2.3 (95\%-Cl 1.29-4.28), HR $\mathrm{HRAD1}_{\text {LA }}: 2.3$ (95\%-Cl 1.23-4.22), HR $\mathrm{HEFH}_{\text {: }} 1.5$ (95\%-Cl 0.79-2.79), HR $\mathrm{HEURL}_{\text {NE }} 2.5$ (95\%-Cl 1.36-4.47)). Two- and three- marker panels combining GREM1, LAD1, NEFH, and NEURL hypermethylation status showed the best predictive capacity according to the Harrell's C statistic for the two marker combination of GREM1 and LAD1 (age/sex adjusted HR both genes methylated $3.54(95 \%-\mathrm{Cl} 1.58-7.95)$, Harrell's C: 0.6415 , Figure 3$)$, and for the three marker combination of GREM1, LAD1 and NEURL (age/sex adjusted HR three genes methylated 3.61 (95\%-Cl 1.36-9.57), Harrell's C: 0.6436, Figure 3). The model combining all four markers showed a slightly elevated age/sex adjusted HR of 3.64 (95\%-Cl 1.02-13.02, Figure 3) when compared to the best-three marker panel, but the Harrel's C statistic does not indicate a higher predictive capacity of this model (Harrell's C: 0.6212 ) although the fit of the four marker model is better according to the AIC as compared to the three marker model (AIC: 321 for the four marker panel as compared to 346 for the three marker panel). Figure 4 shows the overall cause-specific survival of 
ccRCC patients of the best predictive capacity according to the Harrell's C statistic for the two (A) and three (B) marker panels as compared to the four marker (C) panel. Addition of a methylation marker previously not associated with prognosis such as $V H L^{9}$ did not increase the prognostic value of the 2, 3 and 4 marker panel.

In multivariate analyses adjusted for age, sex, grade, stage and tumor size, however, the association between promoter hypermethylation of GREM1, LAD1, NEFH and/or $N E U R L$ was lost suggesting that these markers might not be independent prognostic factors in this hospital-based population (Table 3).

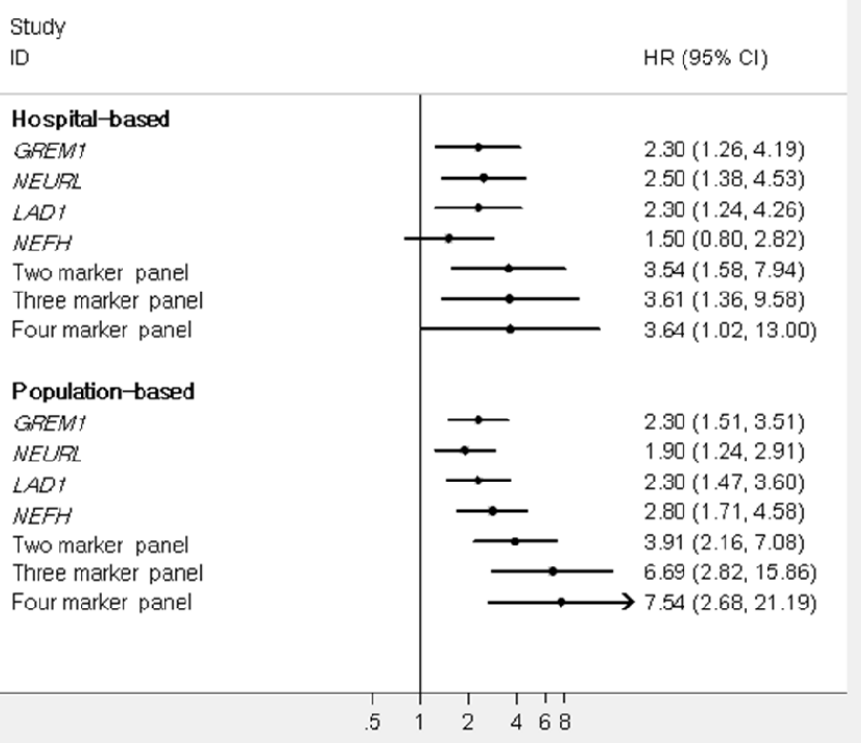

Figure 3. Hazard ratios for RCC-related death for single markers and most prognostic marker panels in hospital- and population-based ccRCC series

Forest plot depicting the increasing risk on RCC-related death by HRs (corrected for sex and age) for GREM1, LAD1, NEFH and NEURL and the two- and three best predictive marker panels according to Harrels $C$ statistic as well as the four marker panel. Two- and three marker combinations hospital-based series: GREM1 and LAD1, and GREM1, LAD1, and NEURL, respectively, and population-based series: GREM1 and LAD1, and, LAD1, NEFH and NEURL, respectively. 


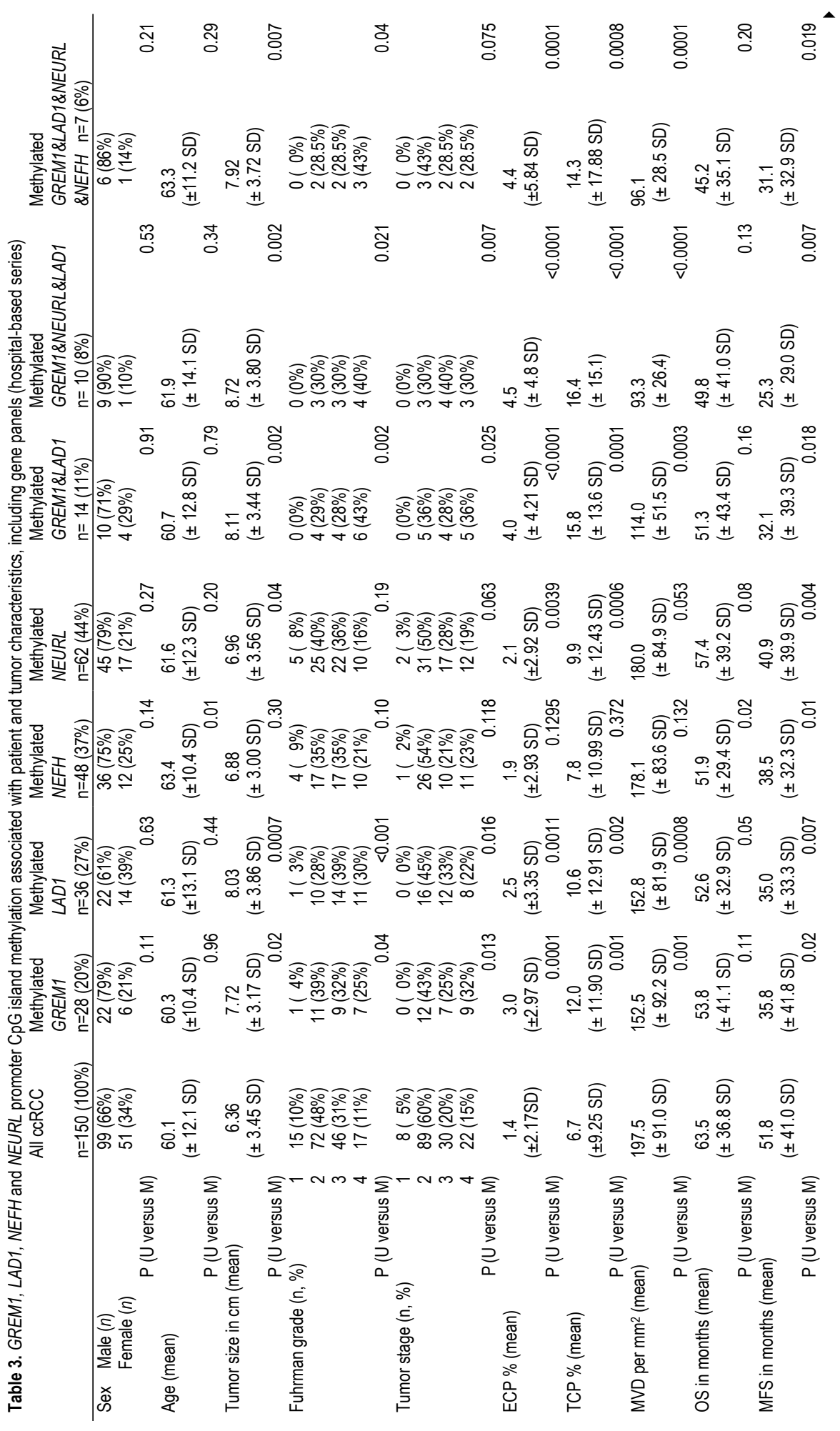




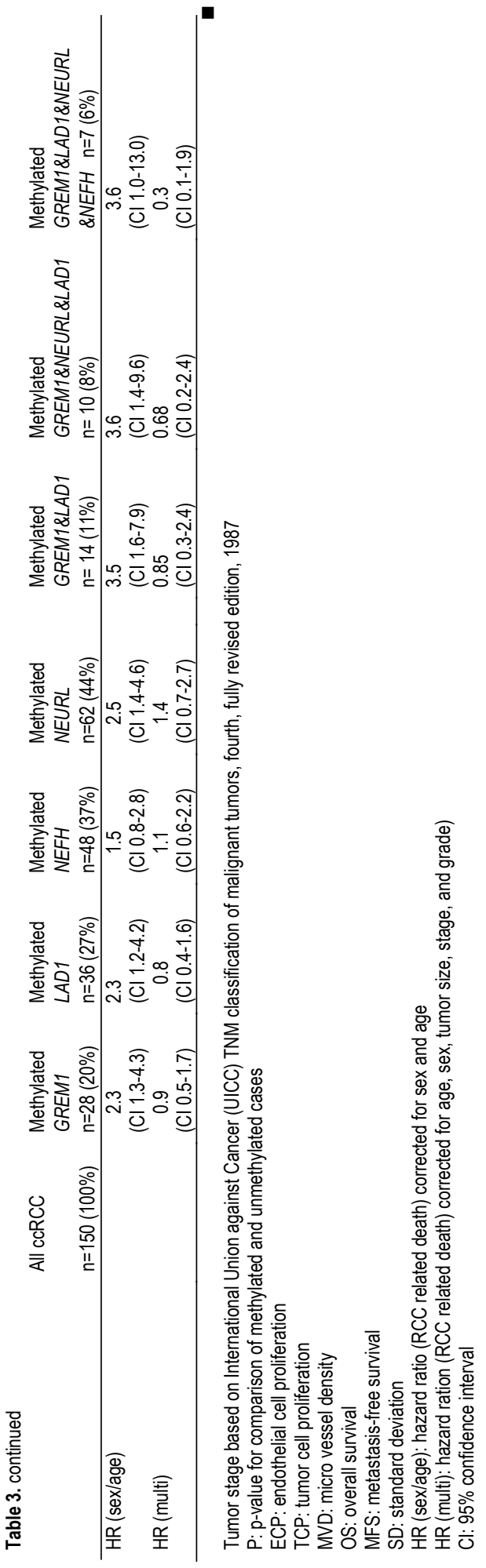




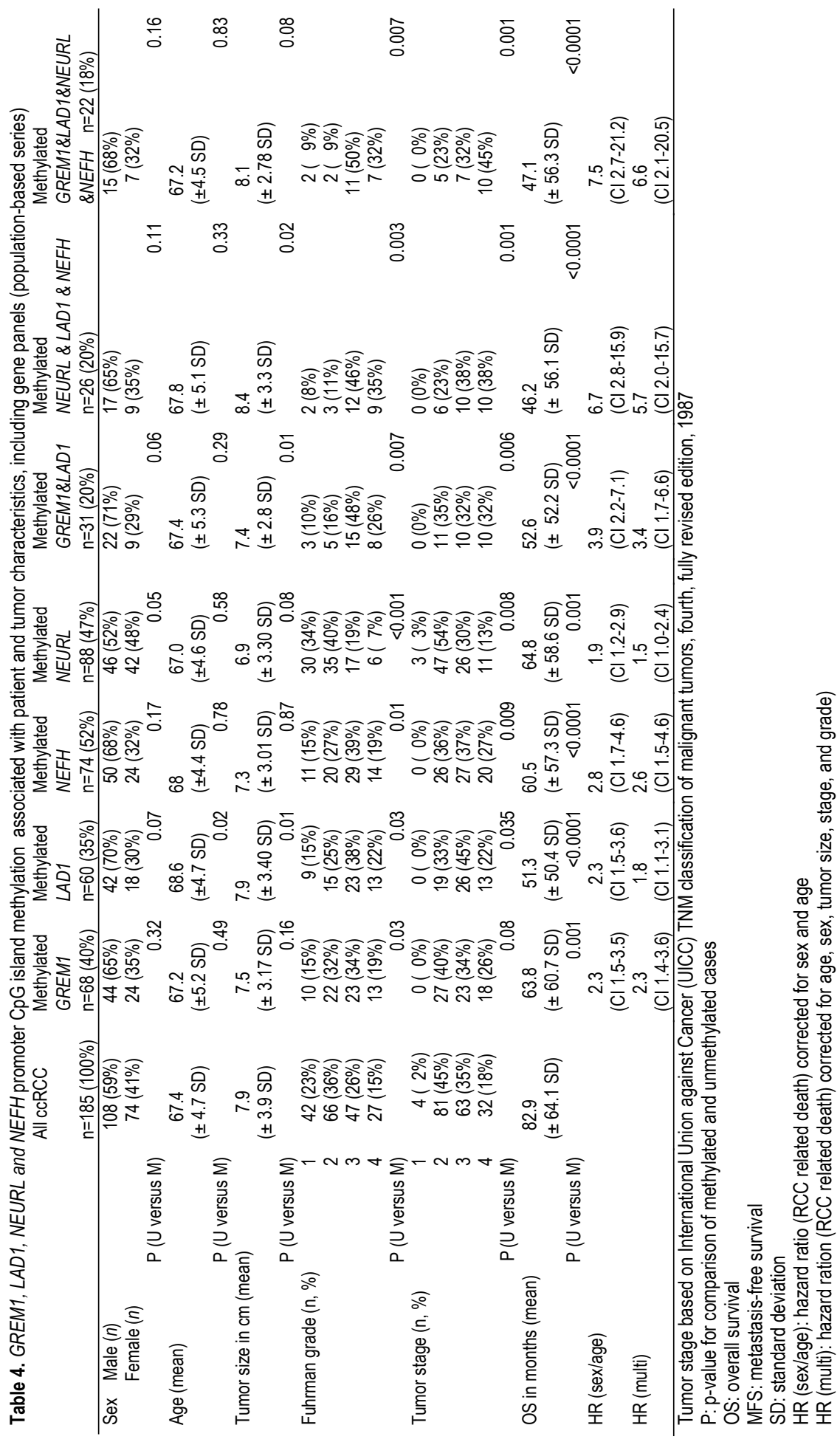




\section{GREM1, LAD1, NEFH and NEURL are strong independent predictors of CCRCC survival}

For the four candidate genes identified in the hospital-based series we studied the methylation status in an independent population-based series of ccRCCs derived from the prospective Netherlands Cohort Study on Diet and Cancer. Table 4 and supplemental Figure $2 \mathrm{~B}, \mathrm{D}, \mathrm{F}, \mathrm{H}$ show that, as reported previously for GREM1, promoter hypermethylation of the single genes $L A D 1, N E U R L$ and NEFH is associated with increased malignancy and poor prognosis (age/sex adjusted $\mathrm{HR}_{\text {GREM1 }}$ : $2.3(95 \%-\mathrm{Cl} 1.52-3.53), \mathrm{HR}_{L A D 1}$ : 2.3 (95\%-Cl 1.48-3.63), HR $\mathrm{HEFH}_{\text {N }}: 2.8$ (95\%-Cl 1.72-4.61), HR $\mathrm{HEURL}_{\text {NEU }} 1.9$ (95\%-Cl 1.24-2.90)) independent of other prognostic factors (multivariate $\mathrm{HR}_{\text {GREM1 }}: 2.3$ (95\%-Cl 1.45-3.61), $\mathrm{HR}_{\text {LAD1 }}: 1.8$ (95\%-Cl 1.10-3.06), HR $\mathrm{H}_{\text {NEFH }}: 2.62$ (95\%-Cl 1.50-4.59), HR $\mathrm{R}_{\text {NEURL }}: 1.5$ (95\%-Cl 0.96-2.42)), although for NEURL only borderline statistical significance was reached. The best two-marker panel according to Harrell's C Statistic, was the panel of GREM1 and LAD1 (age/sex adjusted HR both genes methylated 3.91 (95\%-Cl 2.16-7.08), Harrell's C: 0.6837 , Figure 3 ). In contrast to the hospital-based series, the best three marker panel however appeared to be the combination of LAD1, NEFH and NEURL (age/sex adjusted HR three genes methylated 6.69 (95\%-Cl 2.82-15.85), Harrell's C: 0.7108 , Figure 3), although the second best predictive model, GREM1, LAD1 and NEFH (age/sex adjusted $\mathrm{HR}$ three genes methylated $5.76(95 \%-\mathrm{Cl} 2.61-12.74))$ only had a slightly lower Harrell's C of 0.7073 but also a lower AIC of 551 as compared to 585 for the NEURL, $\angle A D 1$ and NEFH combination. Nevertheless, the four marker panel appeared to be superior in predicting prognosis in cCRCC patients (Figure 3, Harrell's C: 0.7129, AIC: 540 , log-rank $p<0.0001$, age/sex adjusted HR four genes methylated $7.54(95 \%-\mathrm{Cl}$ 2.68-21.17)). Again, adding $V H L$ to the best marker panels did not significantly improve the prediction of prognosis (data not show). Figure 4 shows the overall cause-specific survival of ccRCC patients of the best predictive capacity according to the Harrell's $C$ statistic for the two (D) and three (E) marker panels as compared to the four marker (F) panel.

In contrast with the hospital-based population, the association with poor prognosis in the population-based series remained significant when adjusting for other prognostic factors (multivariate HR best two marker panel 3.36 (95\%-Cl 1.71-6.60); multivariate HR best three marker panel $5.65(95 \%-\mathrm{Cl} 2.03-15.72)$ and multivariate HR four marker panel $6.56(95 \%-\mathrm{Cl} 2.09-20.52)$.

\section{GREM1 and NEURL exhibit tumor suppressor activity in vitro}

To examine whether the identified candidates GREM1 and/or NEURL exhibit tumor suppressor activity in renal cancer cells, we characterized SKRC1 and SKRC59 cells after induced expression (Figure 5 and 6). GREM1 transfectants showed increased expression of GREM1 mRNA compared with control cells transfected with empty vector (SKRC1: $p=0.009$ SKRC59: $p=0.004$, Figure $5 . A, G$ ). In both cell lines, no statistically significant effect was observed on the growth of G418-selected colonies or cell proliferation (Figure 5. B,C,D, and $\mathrm{H}, \mathrm{I}, \mathrm{J}$ ) in GREM1 transfected cells as compared to control transfectants. However, transfection of GREM1 reduced migration (SKRC1: $\mathrm{p}=0.086$, 
SKRC59: $p=0.128$ ) and invasion (SKRC1: $p=0.005$, SKRC59: $p=0.028$ ) in both cell lines, although not statistically significant for migration (Figure 5. E,F and $\mathrm{K} \mathrm{L}$ ).

NEURL transfectants showed increased expression of NEURL mRNA compared with control cells transfected with empty vector (SKRC1: $p=0.009$ SKRC59: $p=0.001$, Figure 6.A,G). A statistically significantly reduced growth of G418-selected colonies (SKRC1: $p=0.003$ SKRC59: $p=0.010$, Figure $6 . \mathrm{B}, \mathrm{H}$ ) and cell proliferation as assessed by cell number (SKRC1: $p=<0.0001$ SKRC59: $p<0.0001$, Figure 6.C,I) and $\left[{ }^{3} \mathrm{H}\right]$-thymidine incorporation (SKRC1: $p<0.0001$ SKRC59: $p=0.021$, Figure 6.D,J) was observed in NEURL transfected cells of both cell lines as compared to control transfectants. Transfection of NEURL showed no statistically significant effect on migration and invasion in both cell lines (Figure 6.E,F and $\mathrm{K}, \mathrm{L}$ ). 
Hospital-based ccRCC series

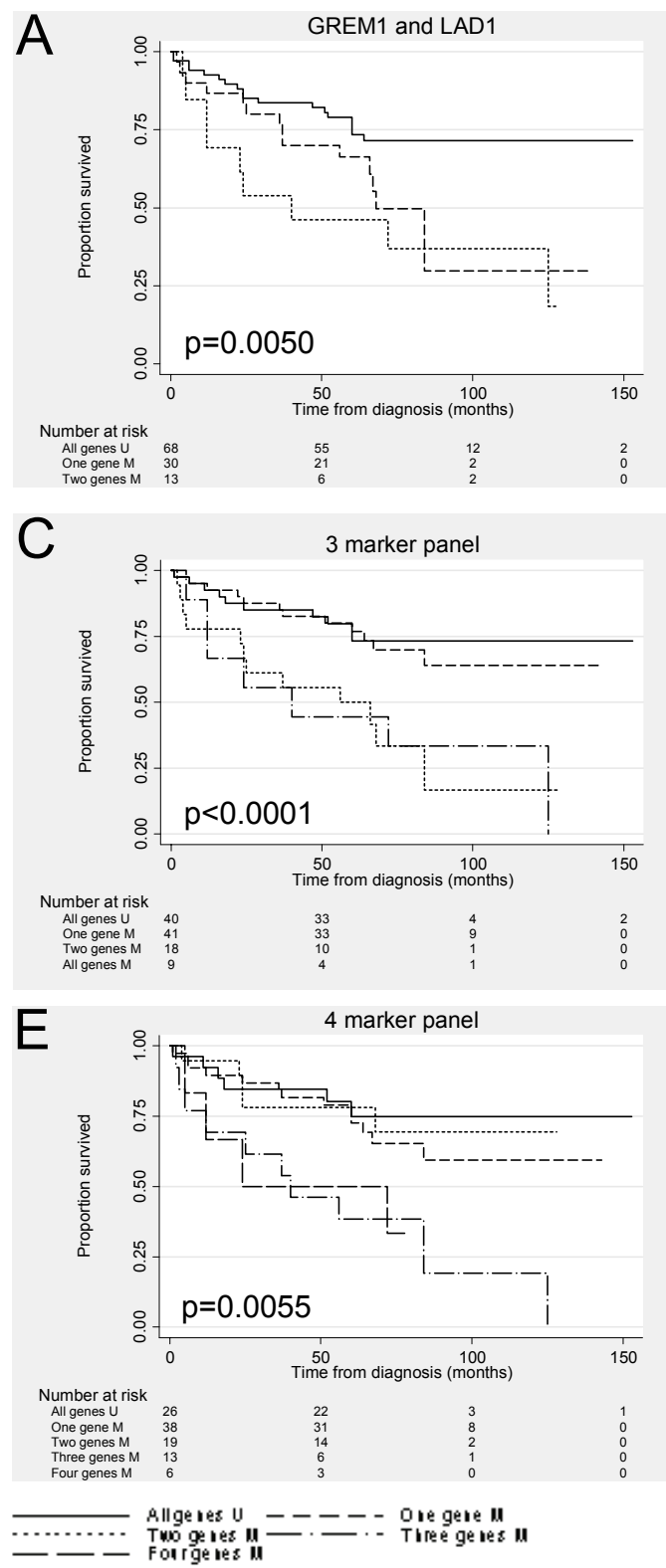

\section{Population-based ccRCC series}

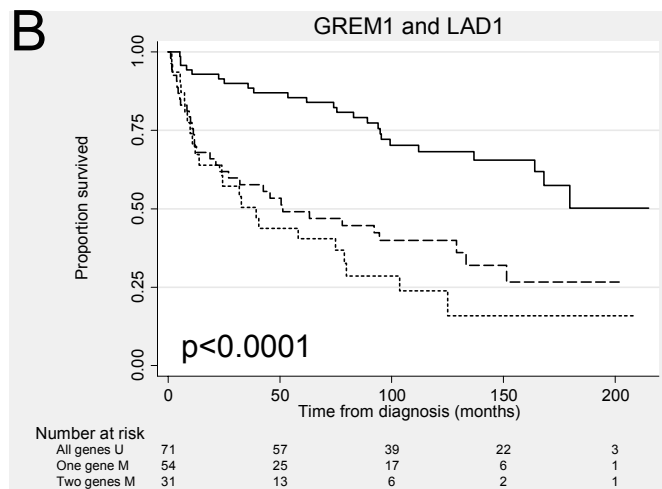

D

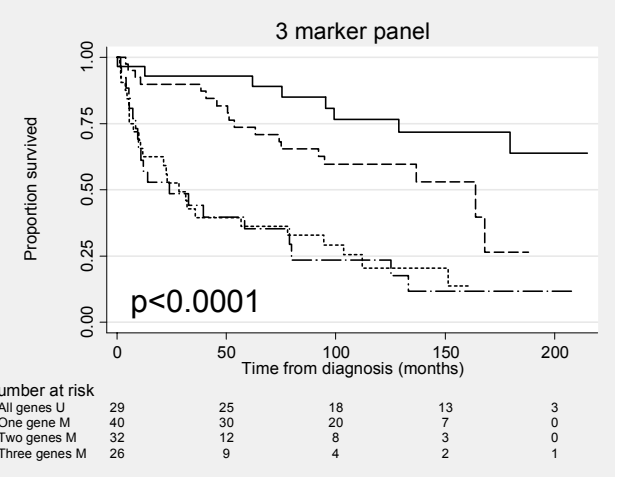

$\mathrm{F}$

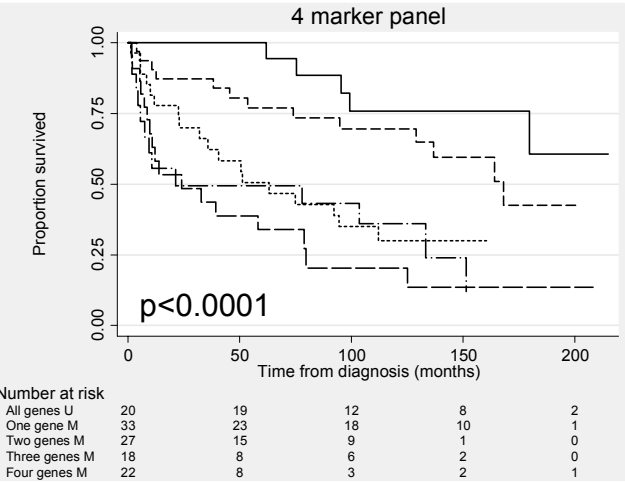

Figure 4. Overall cause-specific survival curves for marker panels in hospital- and population-based ccRCC series Kaplan-Meier curves of the best two-, three and four marker panels in the hospital-based series: GREM1 and LAD1 (A), GREM1, LAD1, and NEURL (B), and GREM1, LAD1, NEFH and NEURL (C), respectively, and population-based series: GREM1 and LAD1 (D), LAD1, NEFH and NEURL (E), and GREM1, LAD1, NEFH and NEURL (F), respectively. 

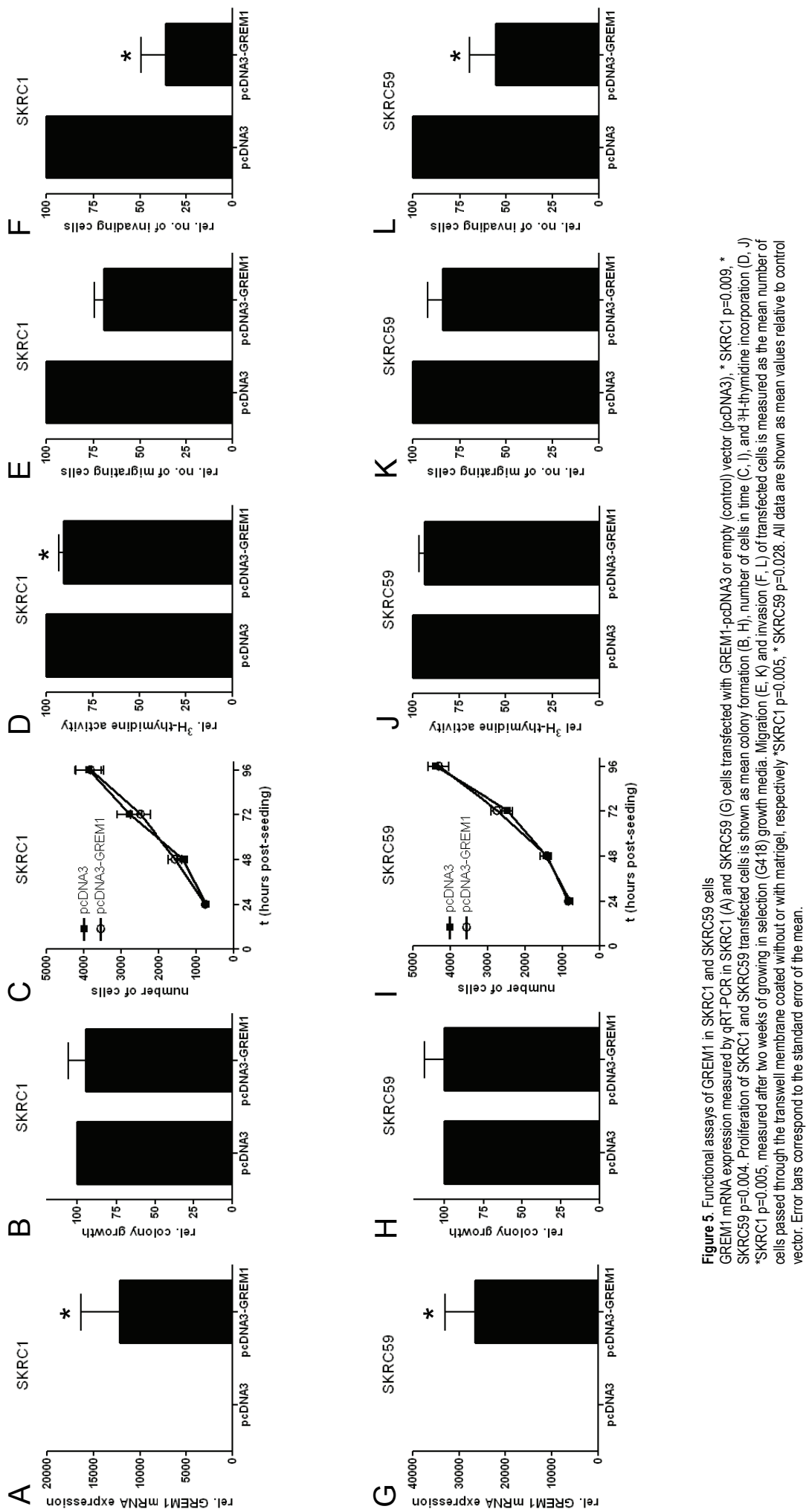

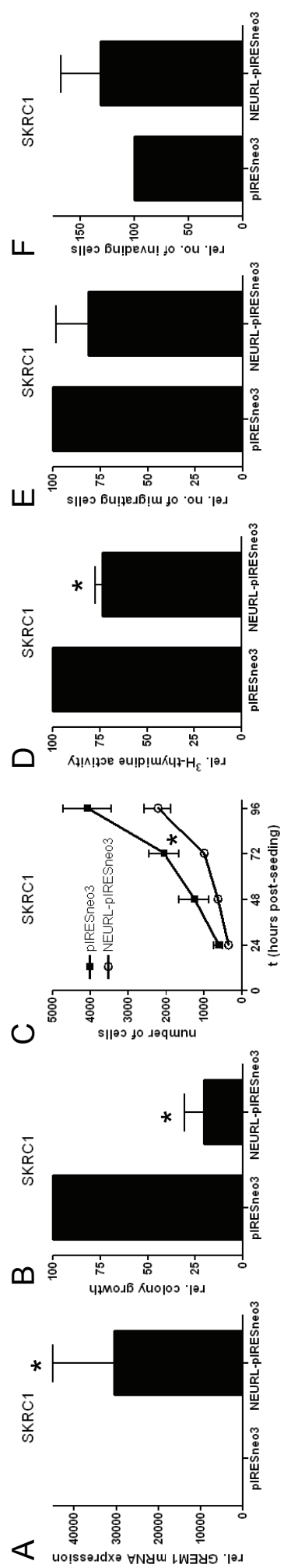
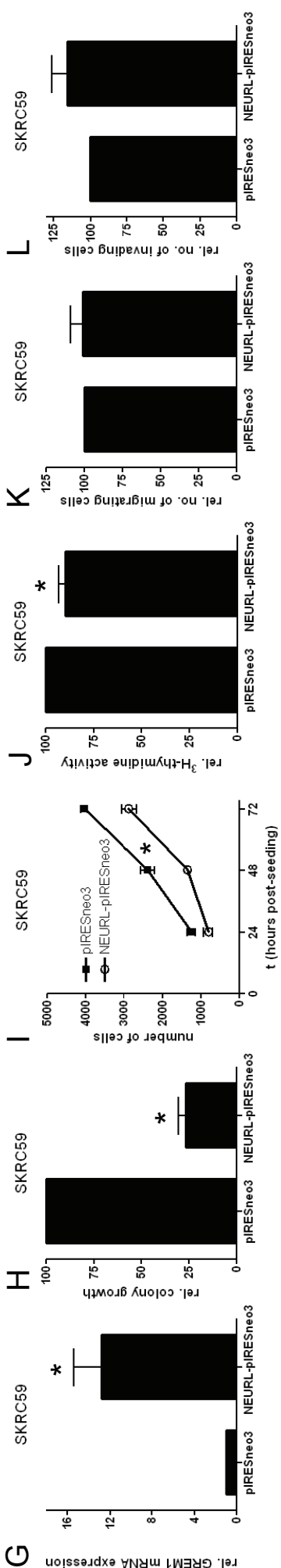

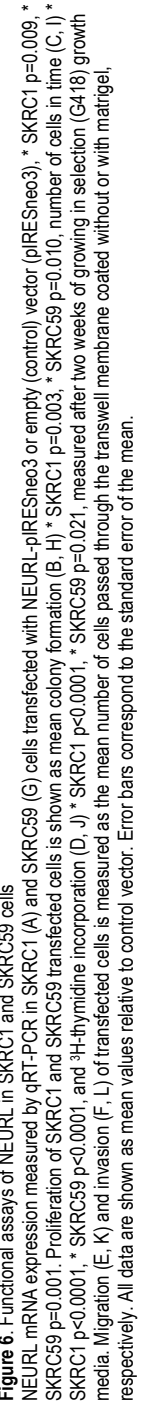




\section{Discussion and conclusion}

Here we integrated global transcript expression microarray data of pharmacologically demethylated ccRCC cells and MBD-affinity NGS to explore the ccRCC hypermethylome, thereby bypassing some of the limitations of previous technologies that prevent an unbiased truly high-throughput and exhaustive profiling of the functional methylome ${ }^{15}$. Although the stringent selected criteria used to identify candidate genes implies exclusion of other potentially interesting methylation markers, our strategy resulted in nine genes showing promoter CpG island hypermethylation in a substantial proportion (16\%-58\%) of tumors from the first (hospital-based) series, but not in normal kidney tissue. Promoter CpG island hypermethylation of four of these genes (GREM1, LAD1, NEFH and NEURL) was strongly associated with increased malignancy and/or poor survival in two independent series ( $n=150$ and $n=185)$ of ccRCC primary samples. To the best of our knowledge promoter CpG island hypermethylation of $\angle A D 1, N E F H$ or NEURL have not yet been described in RCC carcinogenesis.

The biological function of the candidate genes could increase our knowledge of RCC development and progression. For GREM1 and NEURL a known role in embryogenesis and morphogenesis of the kidney is described ${ }^{30-32}$ and we assessed their role in RCC in vitro. GREM1 inhibits the ligands BMP2, 4, and 7, hindering downstream BMPsignaling. We have previously shown that specific GREM1-region-iii promoter hypermethylation was associated with decreased outcome in ccRCC patients ${ }^{18}$. Neuralized is a highly conserved E3 ubiquitin ligase, which acts upon Notch ligands to regulate Notch pathway signaling ${ }^{33}$. Promoter hypermethylation and subsequent down-regulation of the Notch pathway member NEURL has been reported in colorectal cancer in which over-expression caused reduced colony formation in vitro ${ }^{19}$. The results of induced over-expression of GREM1 or NEURL in RCC cells suggest that these genes have complementary tumor suppressor activity in RCC. NEURL over-expression inhibited colonyformation and cell proliferation whereas GREM1 over-expression inhibited migration (trend) and invasion in vitro. In fact, several studies have demonstrated a cross-talk between TGF- $\beta$ and Notch signaling and both synergy and antagonism have been described $^{34-36}$. Both GREM1 and NEURL regulate their pathway ligands ${ }^{37-41}$ and in that way modulate downstream signaling, with which down regulated expression interferes. Our data suggest a possible synergism between GREM1 and NEURL promoter hypermethylation in RCC patients and cell lines, indicative for pathway cross-talk or additive effects of these pathways in renal cancer development. However, a synergistic effect on RCC development or progression needs to be confirmed in vitro. The relatively unknown LAD1 protein encoded by the Ladinin 1 gene is an anchoring filament that is a component of basement membranes. It may contribute to the stability of the association of the epithelial layers with the underlying mesenchyme ${ }^{42}$. LAD1 promoter hypermethylation has not yet been described. The NEFH encoding neurofilament heavy chain is known to be one of the major components of the neuronal cytoskeleton neurofilaments ${ }^{43}$ and promoter hypermethylation of this gene has been described in esophageal carcinoma ${ }^{44}$. Induced over-expression of $L A D 1$ or NEFH in RCC cells did not indicate a significant proliferative, migrative or invasive effect in vitro (data not shown). LAD1 and NEFH could possibly be involved in cell structure and stability, but their role in RCC needs to be further elucidated. 
Synchronous promoter CpG island hypermethylation of GREM1 and NEURL was also significantly correlated with higher risk of cancer-related death (data not shown). Interestingly, patients with tumor specific promoter $\mathrm{CpG}$ island hypermethylation of all four identified candidate genes had a significantly increased probability to cancerrelated death as compared to patients without, or with one, two or three methylated gene promoter(s) (Table 4 and data not shown). Together with the enhancing prognostic effect of promoter hypermethylation of all four genes on survival (Figure 3 and 4), our findings indicate a highly significant prognostic gene panel predicting RCC recurrence and -related death.

Currently, no prognostic molecular markers are available for use in clinical practice for cCRCC $^{1}$. A decade ago, a prognostic model was developed in metastatic RCC by Motzer et al. at the Memorian Sloan Kettering Cancer, which is known as the the MSKCC risk system, or informally known as the "Motzer criteria" (Karnofsky performance score $<80, \mathrm{LDH}>1,5$ fold upper limit of normal (ULN), $\mathrm{Hb}<$ lower limit of normal (LLN), Calcium (corrected for albumine) $>$ ULN, and interval nephrectomy $<1$ year) ${ }^{45}$. This model is widely used as standard criteria both for selecting patients for participation in clinical trials and for recommending treatment options to patients not enrolled in trials. However, this system, only used for RCC patients with metastatic disease, was derived in the cytokine era, leading to importance of re-evaluation of prognostic markers in the current era of 'targeted' therapy. There is an urgent need for criteria predicting prognosis at time of primary RCC diagnosis for those patients (about 70\%) presenting without metastasis. Identification of a distinct patient group with poor prognosis before they present with metastases, would allow medical oncologists to better manage renal cancer, although successful treatments options for RCC are currently still lacking. Therefore a Phase-III trial should clarify whether the targeted therapies, e.g. tyrosine kinase inhibitors or mTOR inhibitors, used for metastatic RCC are also effective in an adjuvant setting for subclinical metastatic disease.

The frequency and stability of DNA methylation, the possibility to determine methylation in formalin fixed paraffin-embedded (FFPE) tissue, and the simple and low cost tests that are available for assessing DNA methylation, make methylation markers excellent candidate biomarkers ${ }^{46}$. In our series, patients with promoter hypermethylation of the four-marker panel represent a clinically distinct group with an up to 6.6 fold increased independent risk of cancer-related death as compared to patients without this hypermethylation. The 5-year survival rate drastically decreased in relation to the methylation degree from $100 \%$ in cases without hypermethylation to $77 \%, 50-52$, and $35 \%$ in cases with one, two or three, or four gene promoters methylated, respectively. Strikingly, patients with promoter hypermethylation of all four genes had a $40 \%$ chance of dying from RCC within the first year and identification of this high risk group could contribute significantly to better management of RCC patients.

In conclusion, our comprehensive analysis using novel MBD technology combined with re-expression arrays identified the renal cell cancer functional hypermethylome. Although we focused on a few relevant pathways and used stringent selection criteria, this hypermethylome will provide novel insights into ccRCC biology and has already identified candidate tumor suppressor genes and clinically relevant markers. This panel of methylation markers strongly predicts patient outcome, which will require addition- 
al validation to determine the potential to implement this into clinical practice. Identification of high risk patients could direct adjuvant treatment trials to patients with subclinical metastatic disease to improve disease management and increase RCC survival.

\section{Acknowledgments}

We thank Dr. Egbert Oosterwijk from Nijmegen Center for Molecular Life Sciences (NCMLS), Radboud University Nijmegen Medical Center, Nijmegen, The Netherlands for providing the renal cell carcinoma cell lines. We like to acknowledge Prof. Dr. Evelyne Lerut and Prof. Dr. Hendrik van Poppel for providing RCC patient material from the university Hospital of Leuven and Geert Trooskens from Ghent University for biostatistical assistance. We thank Sean Smith, Johanna Nedele, and Musinu Zakari for their technical support. 
Supplemental table 1. Candidate gene promoter CpG island methylation associated with patient and tumor characteristics (hospital-based series)

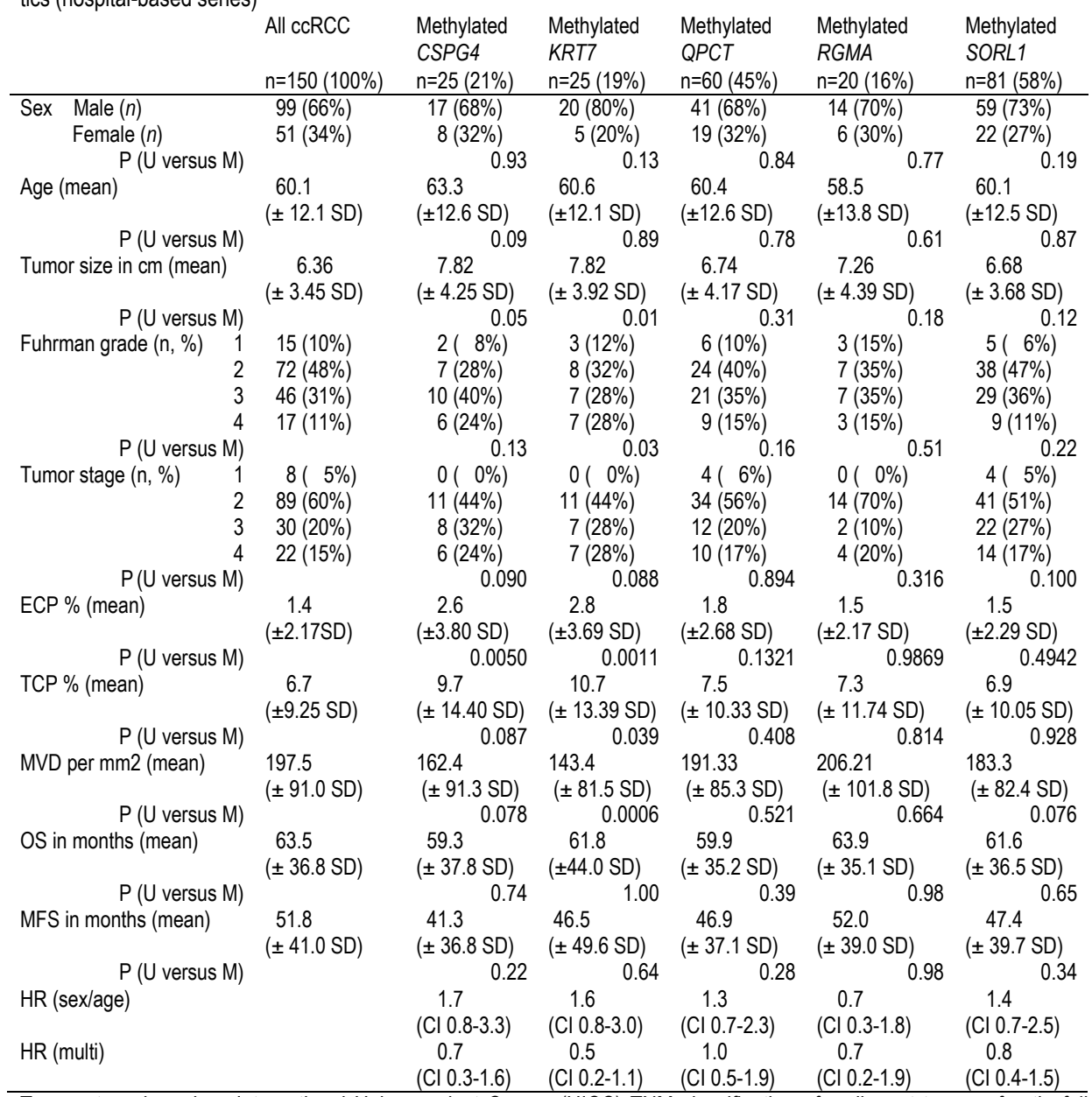

Tumor stage based on International Union against Cancer (UICC) TNM classification of malignant tumors, fourth, fully revised edition, 1987

$\mathrm{P}: \mathrm{p}$-value for comparison of methylated and unmethylated cases

ECP: endothelial cell proliferation

TCP: tumor cell proliferation

MVD: micro vessel density

OS: overall survival

MFS: metastasis-free survival

SD: standard deviation

HR (sex/age): hazard ratio (RCC related death) corrected for sex and age

HR (multi): hazard ration (RCC related death) corrected for age, sex, tumor size, stage, and grade)

$\mathrm{Cl}$ : $95 \%$ confidence interval 

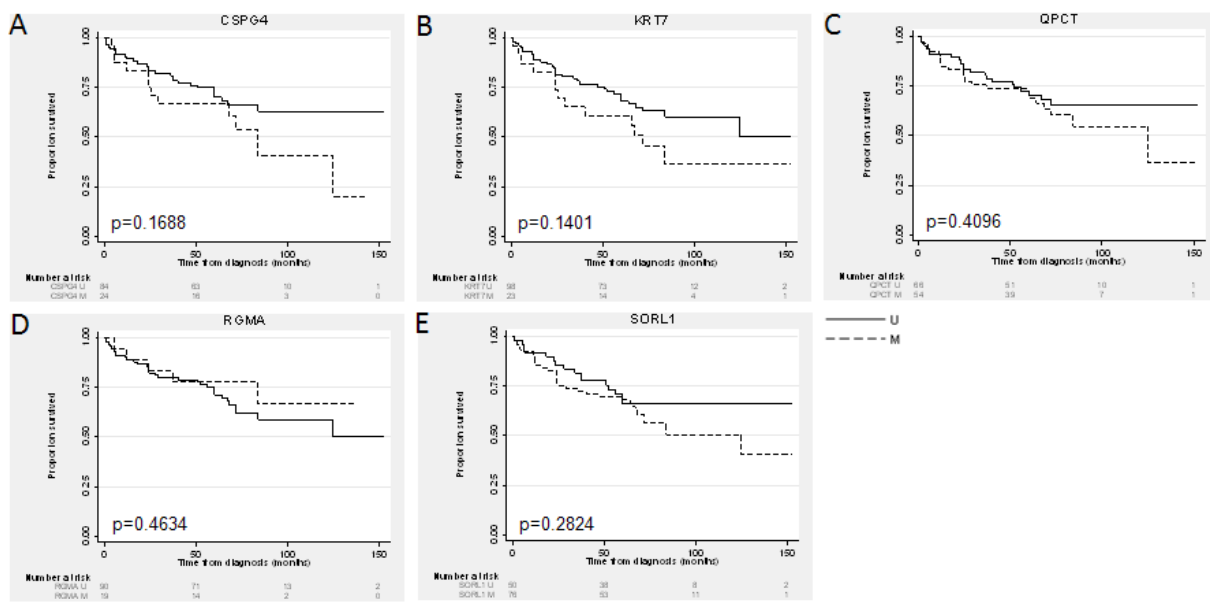

Munber aldak
outt
ord m

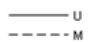

Figure S1. Overall cause-specific survival curves for candidate genes in hospital-based ccRCC series

Kaplan-Meier curves of CSPG4 (A), KRT7 (B), QPCT (C), RGMA (D), and SORL1 (E) analyzed for overall survival in hospital-based series. 

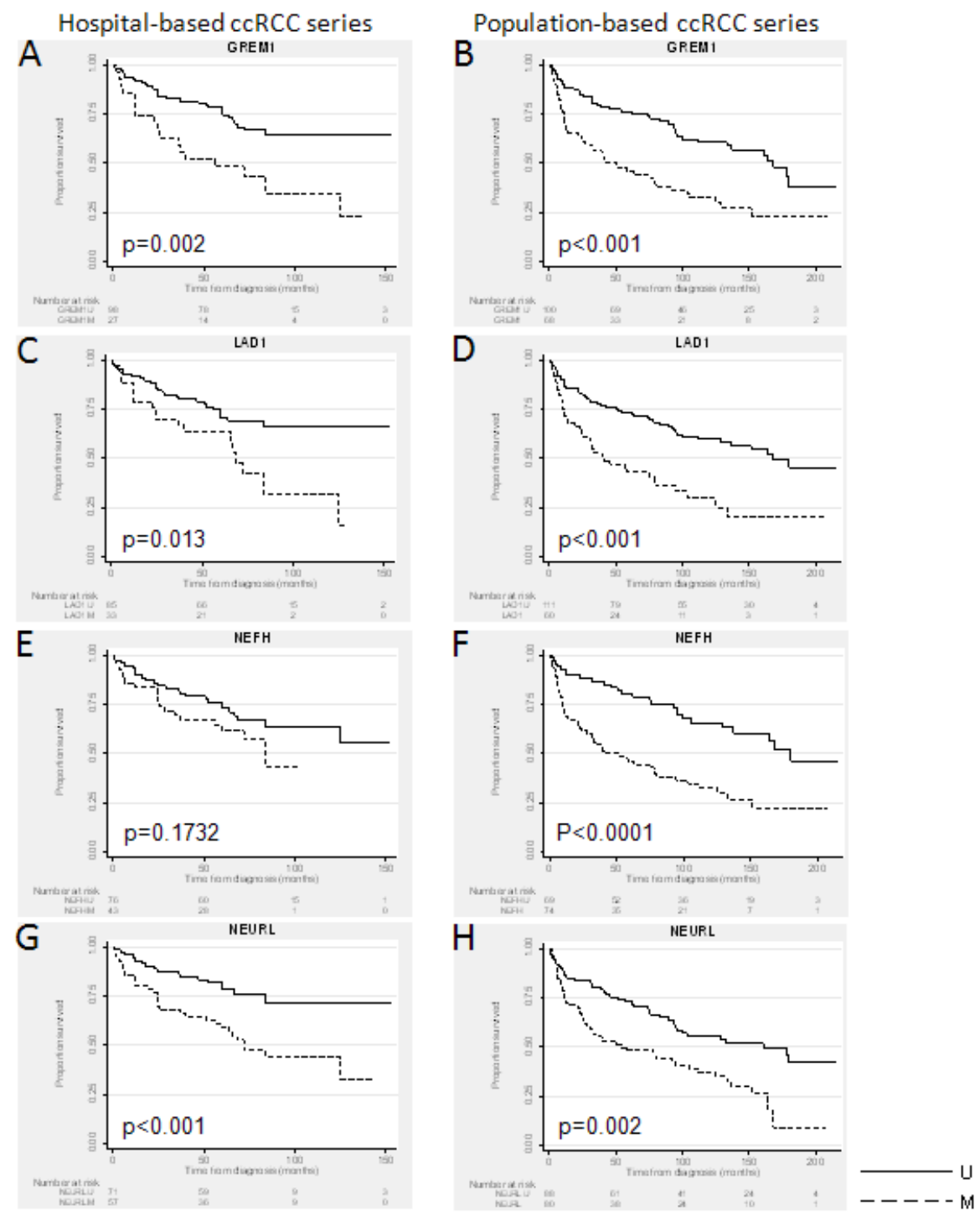

Figure S2. Overall cause-specific survival curves for GREM1, LAD1, NEFH, and NEURL in hospital- and populationbased ccRCC series

Kaplan-Meier curves of GREM1 (A, B), LAD1 (C, D), NEFH (E, F) and NEURL $(G, H)$ analyzed for overall survival in hospital- (left panels) and population-based series (right panels). 


\section{References}

1. Gelb, A.B., Renal cell carcinoma: current prognostic factors. Union Internationale Contre le Cancer (UICC) and the American Joint Committee on Cancer (AJCC). Cancer, 1997. 80(5): p. 981-6.

2. Kaelin, W.G., Jr., The von Hippel-Lindau tumor suppressor gene and kidney cancer. Clin Cancer Res, 2004. 10(18 Pt 2): p. 6290S-5S.

3. van Dijk, B.A., et al., Cigarette smoking, von Hippel-Lindau gene mutations and sporadic renal cell carcinoma. Br J Cancer, 2006. 95(3): p. 374-7.

4. Gnarra, J.R., et al., Post-transcriptional regulation of vascular endothelial growth factor mRNA by the product of the VHL tumor suppressor gene. Proc Natl Acad Sci U S A, 1996. 93(20): p. 10589-94.

5. Morrissey, C., et al., Epigenetic inactivation of the RASSF1A 3p21.3 tumor suppressor gene in both clear cell and papillary renal cell carcinoma. Cancer Res, 2001. 61(19): p. 7277-81.

6. Banks, R.E., et al., Genetic and epigenetic analysis of von Hippel-Lindau (VHL) gene alterations and relationship with clinical variables in sporadic renal cancer. Cancer Res, 2006. 66(4): p. 2000-11.

7. Herman, J.G., et al., Silencing of the VHL tumor-suppressor gene by DNA methylation in renal carcinoma. Proc Natl Acad Sci U S A, 1994. 91(21): p. 9700-4.

8. Schraml, P., et al., VHL mutations and their correlation with tumour cell proliferation, microvessel density, and patient prognosis in clear cell renal cell carcinoma. J Pathol, 2002. 196(2): p. 186-93.

9. Smits, K.M., et al., Genetic and epigenetic alterations in the von hippel-lindau gene: the influence on renal cancer prognosis. Clin Cancer Res, 2008. 14(3): p. 782-7.

10. Varela, I., et al., Exome sequencing identifies frequent mutation of the SWI/SNF complex gene PBRM1 in renal carcinoma. Nature, 2011. 469(7331): p. 539-542.

11. Dalgliesh, G.L., et al., Systematic sequencing of renal carcinoma reveals inactivation of histone modifying genes. Nature, 2010. 463(7279): p. 360-3.

12. Morris, M.R., et al., Genome-wide methylation analysis identifies epigenetically inactivated candidate tumour suppressor genes in renal cell carcinoma. Oncogene, 2010.

13. Baylin, S.B., DNA methylation and gene silencing in cancer. Nat Clin Pract Oncol, 2005. 2 Suppl 1: p. S4-11.

14. van Vlodrop, I.J., et al., Analysis of promoter CpG island hypermethylation in cancer: location, location, location! Clin Cancer Res, 2011.

15. Serre, D., B.H. Lee, and A.H. Ting, MBD-isolated Genome Sequencing provides a highthroughput and comprehensive survey of DNA methylation in the human genome. Nucleic Acids Res, 2010. 38(2): p. 391-9.

16. van den Brandt, P.A., et al., A large-scale prospective cohort study on diet and cancer in The Netherlands. J Clin Epidemiol, 1990. 43(3): p. 285-95.

17. van Houwelingen, K.P., et al., Prevalence of von Hippel-Lindau gene mutations in sporadic renal cell carcinoma: results from The Netherlands cohort study. BMC Cancer, 2005. 5(1): p. 57.

18. van Vlodrop, I.J., et al., Prognostic significance of Gremlin1 (GREM1) promoter CpG island hypermethylation in clear cell renal cell carcinoma. Am J Pathol, 2010. 176(2): p. 575-84.

19. Schuebel, K.E., et al., Comparing the DNA hypermethylome with gene mutations in human colorectal cancer. PLoS Genet, 2007. 3(9): p. 1709-23.

20. McGarvey, K.M., et al., Defining a Chromatin Pattern that Characterizes DNAHypermethylated Genes in Colon Cancer Cells. 2008. p. 5753-5759.

21. Smyth, G.K., Limma: linear models for microarray data. Bioinformatics and Computational Biology Solutions using R and Bioconductor, R. 2005, Springer: New York. p. 397-420.

22. Langmead, B., et al., Ultrafast and memory-efficient alignment of short DNA sequences to the human genome. Genome Biol, 2009. 10(3): p. R25.

23. Derks, S., et al., Methylation-specific PCR unraveled. Cell Oncol, 2004. 26(5-6): p. 291-9. 
24. Herman, J.G., et al., Methylation-specific PCR: a novel PCR assay for methylation status of CpG islands. Proc Natl Acad Sci U S A, 1996. 93(18): p. 9821-6.

25. van Engeland, M., et al., K-ras mutations and RASSF1A promoter methylation in colorectal cancer. Oncogene, 2002. 21(23): p. 3792-5.

26. Thijssen, V.L., et al., Angiogenesis gene expression profiling in xenograft models to study cellular interactions. Exp Cell Res, 2004. 299(2): p. 286-93.

27. Brinkman, A.B., et al., Whole-genome DNA methylation profiling using MethylCap-seq. Methods, 2010. 52(3): p. 232-236.

28. Lin, J., et al., A multidimensional analysis of genes mutated in breast and colorectal cancers. Genome Res, 2007. 17(9): p. 1304-18.

29. Morris, M.R., et al., Identification of candidate tumour suppressor genes frequently methylated in renal cell carcinoma. Oncogene, 2010. 29(14): p. 2104-17.

30. Chen, L. and Q. Al-Awqati, Segmental expression of Notch and Hairy genes in nephrogenesis. American Journal of Physiology - Renal Physiology, 2005. 288(5): p. F939-F952.

31. Michos, O., et al., Reduction of BMP4 activity by gremlin 1 enables ureteric bud outgrowth and GDNF/WNT11 feedback signalling during kidney branching morphogenesis. Development, 2007. 134(13): p. 2397-405.

32. Michos, O., et al., Gremlin-mediated BMP antagonism induces the epithelial-mesenchymal feedback signaling controlling metanephric kidney and limb organogenesis. Development, 2004. 131(14): p. 3401-10.

33. Le Borgne, R., A. Bardin, and F.o. Schweisguth, The roles of receptor and ligand endocytosis in regulating Notch signaling. Development, 2005. 132(8): p. 1751-1762.

34. Itoh, F., et al., Synergy and antagonism between Notch and BMP receptor signaling pathways in endothelial cells. Embo J, 2004. 23(3): p. 541-51.

35. Blokzijl, A., et al., Cross-talk between the Notch and TGF- $\hat{l}^{2}$ signaling pathways mediated by interaction of the Notch intracellular domain with Smad3. The Journal of Cell Biology, 2003. 163(4): p. 723-728.

36. Dahlqvist, C., et al., Functional Notch signaling is required for BMP4-induced inhibition of myogenic differentiation. Development, 2003. 130(24): p. 6089-99.

37. Hsu, D.R., et al., The Xenopus dorsalizing factor Gremlin identifies a novel family of secreted proteins that antagonize BMP activities. Mol Cell, 1998. 1(5): p. 673-83.

38. Topol, L.Z., et al., Biosynthesis, post-translation modification, and functional characterization of Drm/Gremlin. J Biol Chem, 2000. 275(12): p. 8785-93.

39. Topol, L.Z., et al., Identification of drm, a novel gene whose expression is suppressed in transformed cells and which can inhibit growth of normal but not transformed cells in culture. Mol Cell Biol, 1997. 17(8): p. 4801-10.

40. Bray, S.J., Notch signalling: a simple pathway becomes complex. Nat Rev Mol Cell Biol, 2006. 7(9): p. 678-89.

41. Le Borgne, R. and F. Schweisguth, Notch signaling: endocytosis makes delta signal better. Curr Biol, 2003. 13(7): p. R273-5.

42. Moll, R. and I. Moll, Epidermal adhesion molecules and basement membrane components as target structures of autoimmunity. Virchows Archiv, 1998. 432(6): p. 487-504.

43. Lee, M.K. and D.W. Cleveland, Neuronal intermediate filaments. Annu Rev Neurosci, 1996. 19: p. 187-217.

44. Kim, M.S., et al., Neurofilament heavy polypeptide regulates the Akt-beta-catenin pathway in human esophageal squamous cell carcinoma. PLoS One, 2010. 5(2): p. e9003.

45. Motzer, R.J., et al., Survival and prognostic stratification of 670 patients with advanced renal cell carcinoma. J Clin Oncol, 1999. 17(8): p. 2530-40.

46. Laird, P.W., The power and the promise of DNA methylation markers. Nat Rev Cancer, 2003. 3(4): p. 253-66. 


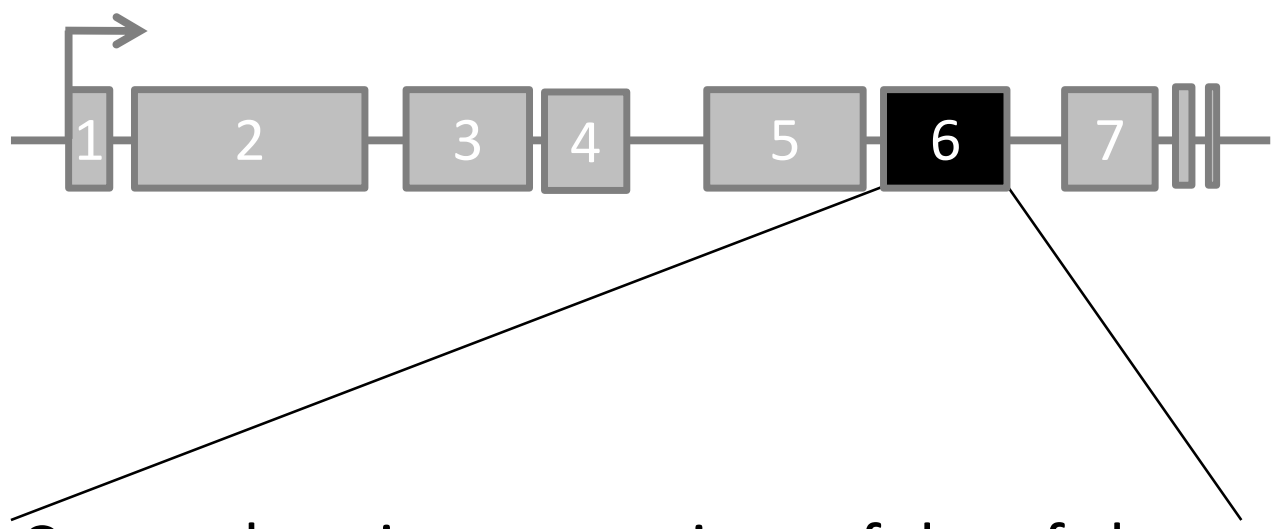

Comprehensive comparison of the of clear cell renal cell cancer methylome with the colorectal and breast cancer methylomes identifies conserved targeting of critical pathways through unique epigenetic events

Iris J.H. van Vlodrop, Leander van Neste, Tim de Meyer, Geert Trooskens, Patricia M.M.B. Soetekouw, Marcella M.M.L. Baldewijns, Veerle Melotte, Linda Bosch, Beatriz Carvalho, Gerrit A. Meijer, Nita Ahuja, Stephen B. Baylin, James G. Herman, Manon van Engeland, Wim van Criekinge and Jürgen Veeck

In preparation 


\section{Abstract}

The renal cell carcinoma (RCC) genome is distinctive from other cancer types. To explore whether this also holds true for the RCC DNA methylome, we examined whether the clear cell RCC subtype (cCRCC) methylome differs from those of colorectal- (CRC) and breast cancer $(\mathrm{BC})$. We integrated $\mathrm{MBD}$-enriched massively parallel sequencing data with data from gene expression microarrays following global pharmacological DNA demethylation of $\operatorname{ccRCC}(n=4), \operatorname{CRC}(n=6)$, and BC $(n=4)$ cell lines to stringently identify functionally relevant promoter hypermethylated genes. In order to assess cancer-specific methylomes only, methylomes of healthy kidney, colon, and breast cells were determined in parallel and subtracted. A comprehensive comparison indicated that the sizes of the functional $\mathrm{CCRCC}, \mathrm{CRC}$ and BC promoter hypermethylomes are approximately of the same magnitude (ccRCC: $n=237$; CRC: $n=327 ; B C: n=269$ ) with only 61 gene promoters being mutually methylated in all three cancer types and 91, 151, and 112 genes showing CCRCC-, CRC- and BC-type specific promoter hypermethylation. Interestingly, pathway analysis indicated that biological processes such as development, immune response, apoptosis and survival are commonly affected by promoter hypermethylation, while the specific genes affected in these pathways are different in each tumor type. Genes (ADSSL1, CDH1, CHRNB1, PIK3CD, SFN and TRPC3) involved in nicotinic acetylcholine receptor ( $\mathrm{nAChR}$ ) signaling and/or linked to phosphoinositide-3-kinase ( $\mathrm{PI} 3 \mathrm{~K}$ ) signaling showed prominent functional hypermethylation in $\mathrm{CCRCC}$ and were not affected in CRC or BC, exposing novel regulations specific for ccRCC carcinogenesis.

In conclusion, our analyses provide a global view of functionally methylated gene promoters and biological processes affected in $\mathrm{CCRCC}, \mathrm{CRC}$, and BC. This leads to a deeper understanding of epigenetic implications in these cancers. We present evidence that overall the functional ccRCC methylome is not distinctive from the CRC and BC methylomes in terms of size, but in its constitution at the gene level. While major cancer hallmarks were similarly affected in all three cancer types, other pathways appear to be specifically deregulated in renal malignancy only, providing novel insights in ccRCC development, novel candidate biomarkers and potential drug targets for these diseases. 


\section{Introduction}

Clear cell RCC (ccRCC) is the most common subtype of adult kidney cancer and most cases (up to $91 \%)^{1}$ are characterized by von Hippel Lindau (VHL) gene alterations, which occur rarely in other RCC subtypes or cancer types. Recently, mutations in PBRM1 were identified in $41 \%$ of renal cell carcinomas, making PBRM1 the second most frequently mutated gene in these cancers after $V H L^{2}$. Mutations in PBRM1 in other malignancies have, as far as we know, only been identified in a small subgroup of breast cancers ${ }^{3}$. Furthermore, a recent screen identified a significant higher proportion of small insertion/deletion mutations throughout protein kinase genes in ccRCC compared to several other cancer types ${ }^{4}$. In contrast, cancer genes that are frequently mutated in other epithelial cancers, including BRAF, CDKN2A, PIC3CA, PTEN, the RAS oncogenes, or TP53 play only a minor role in cCRCC (http://www.sanger.ac.uk/genetics/CGP/cosmic/). This suggests that ccRCC is molecularly distinct from the more common tumor types in adults. It is currently not known whether this distinction of cCRCC is similarly reflected by the epigenome.

Comprehensive exploration of the (cancer) epigenome with many of its epigenetic modifications and variations is currently feasible due to technological improvements and will be a major step towards a better understanding of the role of epigenetics in health and disease.

Here we aim to analyze the ccRCC methylome using next-generation sequencing (NGS)-based technologies. To explore whether the cCRCC promoter methylome is distinctive from the two most studied and best understood cancer methylomes, i.e. colorectal (CRC) and breast cancer $(\mathrm{BC})$, we comprehensively compared these three DNA promoter hypermethylomes. We integrated data obtained by methyl-CpG binding domain protein (MBD)-affinity NGS and microarray-based expression profiling following global pharmacological DNA demethylation, as introduced in chapter 5 . This integrated approach enables the identification and comparison of the functional hypermethylomes of CCRCC, CRC and BC. 


\section{Materials and methods}

\section{Cell culture and drug treatment}

Four cCRCC cell lines (SKRC1, SKRC10, SKRC52, and SKRC59) and the breast cancer cell lines MCF-7 and T47-D were cultured in RPMI 1640 media (Invitrogen) supplemented with $10 \%$ heat-inactivated fetal bovine serum (FBS). The human kidney 2 cell line (HK2) was cultured in Keratinocyte Serum Free Medium (K-SFM, GIBCO) supplemented with bovine pituitary extract (BPE) and human recombinant epidermal growth factor (EGF) as recommended. The CRC (CACO2, COLO320, HCT116, HT29, RKO, and SW480) and breast cancer (MDA-MB468 and MDA-MB231) cell lines were cultured in DMEM medium (Invitrogen) with $10 \%$ heat-inactivated FBS. All BC media were additionally supplemented with $2 \mathrm{mM}$ L-glutamine and $1 \times$ penicilline/streptomycine (Invitrogen). BC RPMI medium was further supplemented with $1 \mathrm{mM}$ sodium pyruvate (Invitrogen). Above mentioned cancer cells were treated with 5'aza-2-deoxycytidine (DAC) or Trichostatin A (TSA), which inhibit DNA methylation and histone deacetylases, respectively, as described by Schuebel et $\mathrm{al}^{5}$. Approximately $10 \%$ confluent RCC cells were cultured in the appropriate total media with $5 \mu \mathrm{M}$ (DAC) (Sigma; stock solution: $1 \mathrm{mM}$ in PBS) for 96 hours, replacing media and DAC every 24 hours. Cell treatment with 300nM TSA (Sigma; stock solution: $5 \mathrm{mM}$ dissolved in ethanol) was performed for 18 hours, starting at approximately $30 \%$ cell confluency. Mock-treated cells were grown in parallel with the DAC or TSA treatment by addition of equal volumes of PBS or ethanol without drugs.

\section{Gene expression microarray analyses}

Microarray expression analyses were performed on mock-, DAC-, or TSA-treated cells, as described previously ${ }^{5,6}$. In brief, total RNA was isolated using TRIzol Reagent (Invitrogen) or the RNeasy kit (Qiagen) according to the manufacturers' instructions and quantified using the NanoDrop ND-100 followed by quality assessment with the 2100 Bioanalyzer (Agilent Technologies). Sample amplification and labeling procedures were carried out using the Low RNA Input Fluorescent Linear Amplification Kit (Agilent Technologies) according to the manufacturer's instructions. The labeled cRNA was purified using the RNeasy mini kit (Qiagen) and quantified. Cy3- or Cy5-labeled samples were mixed with control targets (Agilent Technologies), assembled on Oligo Microarray, hybridized, and processed according to the Agilent microarray protocol. Scanning was performed with the Agilent G2565BA microarray scanner using settings recommended by Agilent Technologies.

Array data were analyzed using $\mathrm{R}$ (version 2.10.0) and BioConductor, using the limma package (version 3.2.1) ${ }^{7}$. Median Cy5 and Cy3 signals read from the raw data and $\mathrm{M}-$ values, i.e. $\log 2(\mathrm{Cy} 5 /$ С 3 ), were loess normalized. Basal expression was roughly estimated using the single channel Cy3 values, containing the mock treated samples. Based on the threshold used for basal expression, the specificity could be further increased, with obvious implications on sensitivity. 


\section{Methyl binding domain-affinity next generation sequencing}

DNA from normal breast tissue, derived from BioChain Institute, Hayward, CA, USA was isolated by proprietary modified guanidine and thiocyanate techniques. DNA from normal colon tissues, derived from the tissue archive of the department of pathology at the VU University medical center, Amsterdam, The Netherlands, was isolated using the QIAamp DNA Micro Kit (Qiagen Benelux, The Netherlands) according to the manufacturer's instructions. DNA from the above described cultured cells was isolated using the Puregene DNA purification kit (BIOzym, Landgraaf, the Netherlands) according to the manufacturer's instructions. Genomic DNA was fragmented by use of a COVARIS S2 system with AFA fiber micro tubes to obtain fragments with an average length of 200 bp. Methylated DNA was captured by performing pull-down using the MethylCollector kit for the cancer cell lines and normal colon and breast samples (Active Motif) or the MethylCap kit with High-Salt elution for the normal kidney sample (Diagenode), according to the manufacturer's protocols. Both are based on autologous methylbinding domains and independent analyses demonstrated that more than $95 \%$ of methylation cores identified by the MethylCollector kit were also identified by the MethylCap kit (manuscript submitted). Subsequently, fragments were sequenced using the Illumina Genome Analyzer II. The concentrations of the fragmented and captured DNA was determined on a Fluostar Optima plate reader with the Quant-iT ${ }^{\mathrm{TM}}$ PicoGreen ${ }^{\circledR}$ dsDNA Assay Kit (Invitrogen P7589) 480/520nm. For all samples together, the paired-end $40 \mathrm{bp}$ sequence reads where mapped using $\mathrm{BOWTIE}^{8}$ on the human reference genome (NCBI build 37.3). Coverage values were summarized using the map of the human methylome, which consists of putatively independently methylated regions (methylation cores) throughout the genome (manuscript in preparation). For each sample, and each methylation core, the maximum read coverage was used for further analysis. Subsequently, we focused on the broad promoter region for each gene $(-2000$ to $+500 \mathrm{bp}$ ). A Poisson background model was used to identify significantly methylated regions (alpha $=0.01$ ), with lambda estimated as the sum of the coverage values over all promoter methylation cores divided by the number of promoter methylation cores. This approach takes into account coverage differences between samples, although generally low coverage will result in low sensitivity.

\section{DNA methylation analyses - methylation-specific PCR}

Genomic DNA (500 ng) was chemically modified by sodium bisulfite using the EZ DNA methylation kit (Zymo Research, Orange, California) according to the manufacturer's instructions. Gene promoter methylation was subsequently determined by methylation-specific PCR (MSP) as described in detail elsewhere ${ }^{9-11}$. Primer sequences and PCR conditions are available upon request. 


\section{Results}

\section{Exploring DNA hypermethylation in $C C R C C, C R C$ and BC identifies functional promoter hypermethylomes of approximately the same magnitude}

Methylated DNA regions of $\operatorname{ccRCC}(n=4), C R C(n=6)$ and $B C(n=4)$ cell lines were identified by massively parallel sequencing of MBD-enriched fragmented DNA, a method which has been described previously ${ }^{12}$. In order to compare the cCRCC functional methylome with those of $C R C$ and $B C$, we integrated promoter methylation data with gene re-expression data after DNA demethylation by DAC, emphasizing on genes in which promoter methylation indeed is associated with gene suppression and thus is likely biologically relevant (Figure $1 \mathrm{~A}$ ).

Using this approach, a total of 7829, 6580, and 7389 genes indicated promoter methylation by MBD-binding in CCRCC, CRC, and BC cells, respectively, ranging from 2802 to 5695 genes per cell line (Table 1). Changes in gene expression following methyltransferase or histone deacetylase inhibition identified a zone (spike) in which gene expression was not increased by TSA (TSA-negative $<1.4$ fold), and was absent in untreated cells, but increased $>1.4$ fold by DAC treatment (DAC-positive) ${ }^{5}$. To reduce false positive results, we used stringent selection criteria within these spike genes ${ }^{6}$, which in total resulted in 1583, 2306, and 2117 upregulated genes in CCRCC, CRC, and BC cells, respectively, ranging from 186 to 1301 genes per cell line (Table 1). Variation in the prevalence of DNA methylation has previously been observed associated with microsatellite (MSI) or chromosomal (CIN) instability in CRC and in specific subtypes of BC. Integrating results from both approaches and excluding genes that did not show a correlation between promoter methylation and gene re-expression within the same cell line, identified 446, 595, and 492 putatively biologically relevant methylated gene promoter regions in $\mathrm{CCRCC}, \mathrm{CRC}$, and BC cells, respectively. Supplemental Figure S1 shows the overlay of genes identified by MBD-sequencing within the expression spikes per cell line. Genes within this spike overlapping with the MBD-sequencing data define the functional hypermethylome for each cell line individually. These stringent criteria for inclusion limit the further characterization to those genes functionally silenced by promoter region DNA methylation. This minimal magnitude of the $\mathrm{CCRCC}, \mathrm{CRC}$ and $\mathrm{BC}$ functional promoter methylomes comprise $1.8-2.2 \%, 2.4-3.0 \%$, and $2.0-2.5 \%$, respectively of the number of estimated protein-coding genes in the human genome $(20,000-$ 25,000 Human Genome Project, http://www.ornl.gov/sci/techresources/Human Genome /home.shtml). Among those genes, 149 (33\%), 238 (40\%) and 171 (35\%) genes are cancer type-specific for $\mathrm{CCRCC}, \mathrm{CRC}$, and BC cells, respectively. Approximately $40-55 \%$ of the genes are overlapping between two cancer types $(270,246$ and 210 genes for CRC-BC, CCRCC-CRC and CCRCC-BC, respectively) and approximately 25-35\% (159 genes) are overlapping between the three cancer types (Figure 1B).

MBD-affinity NGS of the normal renal epithelial cell line HK-2 and normal breast and colon tissues was performed and results were pooled in order to exclude tissue typespecific promoter DNA methylation. Correction for methylated gene promoters in the normal pool resulted in a total of 237,327 , and 269 hypermethylated gene promoter regions among which 91 (38\%), 151 (46\%) and 112 (42\%) showed ccRCC-, CRC- and BCtype specific promoter hypermethylation, respectively (see Supplemental Table S1 for 
specific gene lists). Additionally, approximately $35-50 \%$ are overlapping between two cancer types (124, 113 and 94 genes for CRC-BC, CCRCC-CRC and CCRCC-BC, respectively) and approximately 20-25\% (61 genes; Supplemental table S1) are overlapping between the three cancer types (Figure 1C).

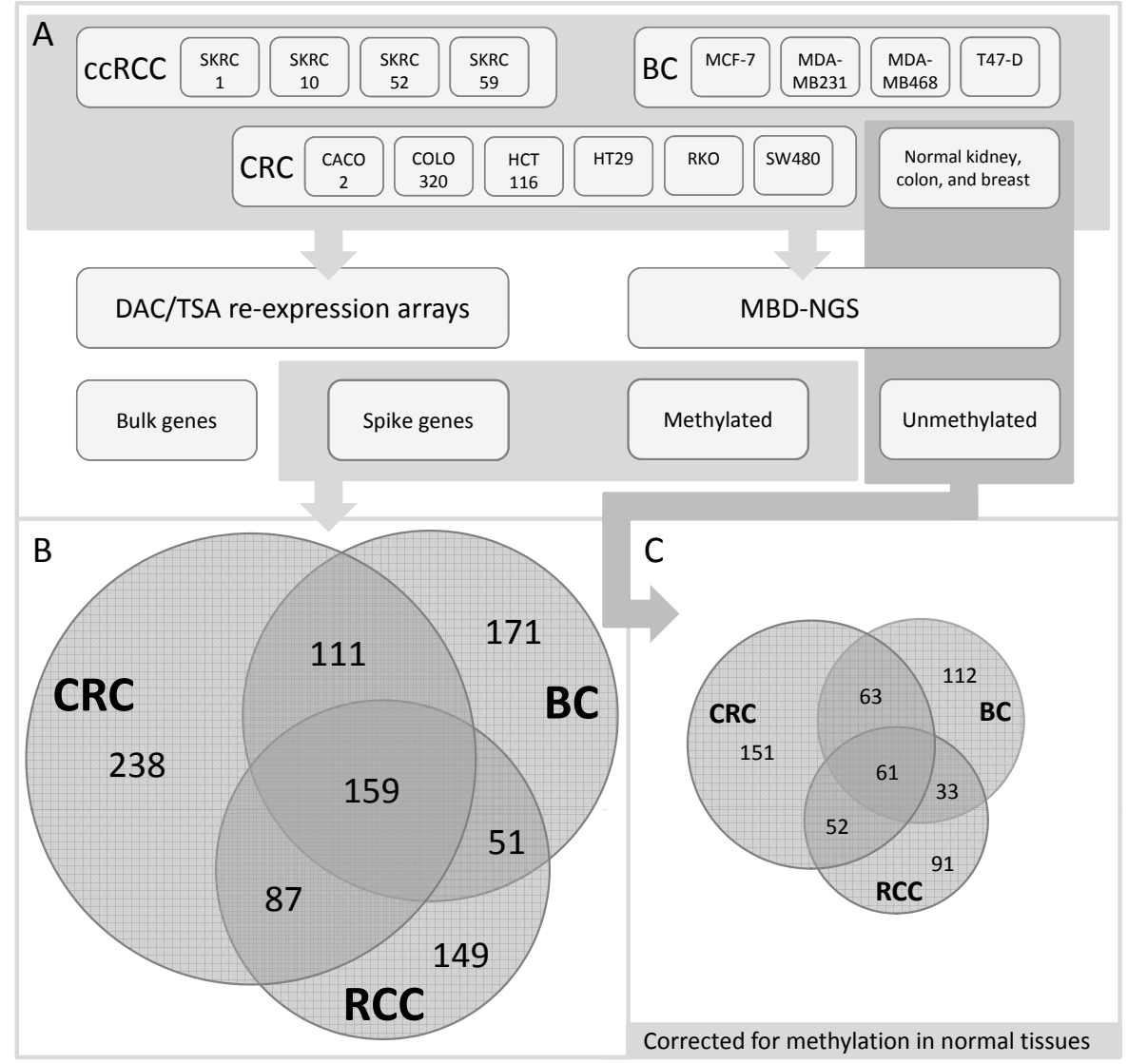

Figure 1. Gene discovery flowchart of $c \mathrm{RCC}, \mathrm{CRC}$ and $\mathrm{BC}$ functional methylomes

Schematic view of the approach applied for the stringent identification of putatively functional ccRCC, CRC and BC methylomes. Four cCRCC, six CRC and four BC cell lines were analyzed for methylation indirectly by DAC/TSA reexpression arrays and by MBD-NGS. Gene promoters that indicated methylation by MBD-binding within the spike of reexpressed genes after DNA demethylation were stringently selected $(A)$ and analyzed for overlap between the three cancer types (B). Genes identified in at least one cell line per cancer type as specifically up-regulated after DNA demethylation and enriched by MBD-protein(s), but not in normal healthy cells, were considered as the differentially methylated functional methylome $(\mathrm{C})$. 
Table 1. Number of genes in ccRCC, $\mathrm{CRC}$ and $\mathrm{BC}$ methylomes

\begin{tabular}{|c|c|c|c|c|c|c|c|c|c|c|c|c|c|c|}
\hline & \multicolumn{4}{|c|}{ ccRCC } & \multicolumn{6}{|c|}{ CRC } & \multicolumn{4}{|c|}{$B C$} \\
\hline & SKRC1 & $\begin{array}{l}\text { SKRC } \\
10\end{array}$ & $\begin{array}{l}\text { SKRC } \\
52\end{array}$ & $\begin{array}{l}\text { SKRC } \\
59\end{array}$ & $\mathrm{CaCo} 2$ & $\begin{array}{l}\text { Co- } \\
\text { lo320 }\end{array}$ & $\begin{array}{l}\text { HCT } \\
116\end{array}$ & $\begin{array}{l}\text { SW } \\
480\end{array}$ & $\begin{array}{l}\text { HT } \\
29\end{array}$ & RKO & $\begin{array}{l}\text { MDA- } \\
\text { MB-468 }\end{array}$ & $\begin{array}{l}\text { MDA- } \\
\text { MB-231 }\end{array}$ & T47D & MCF7 \\
\hline $\begin{array}{l}\mathrm{MBD} / \\
\text { cell line }\end{array}$ & 5438 & 4786 & 5695 & 2802 & 3433 & 3922 & 3430 & 3192 & 3560 & 3355 & 3118 & 4670 & 4762 & 3285 \\
\hline $\begin{array}{l}\text { DAC } \uparrow / \\
\text { cell line }\end{array}$ & 571 & 508 & 731 & 651 & 227 & 663 & 1301 & 186 & 491 & 668 & 612 & 1230 & 234 & 795 \\
\hline $\begin{array}{l}\text { MBD/ } \\
\text { cell type }\end{array}$ & \multicolumn{4}{|c|}{7829} & \multicolumn{6}{|c|}{6580} & \multicolumn{4}{|c|}{7389} \\
\hline $\begin{array}{l}\text { DAC } \uparrow / \\
\text { cell type }\end{array}$ & \multicolumn{4}{|c|}{1583} & \multicolumn{6}{|c|}{2306} & \multicolumn{4}{|c|}{2117} \\
\hline $\begin{array}{l}\text { Overlap } \\
\text { MBD+ } \\
\text { DAC } \uparrow\end{array}$ & \multicolumn{4}{|c|}{541} & \multicolumn{6}{|c|}{778} & \multicolumn{4}{|c|}{669} \\
\hline $\begin{array}{l}\text { Overlap } \\
\text { cell line } \\
\text { specific }\end{array}$ & \multicolumn{4}{|c|}{446} & \multicolumn{6}{|c|}{595} & \multicolumn{4}{|c|}{492} \\
\hline
\end{tabular}

\section{Pathways enriched for promoter hypermethylation in $C C R C C, C R C$ and $B C$}

As the cancer-specific functional hypermethylomes of the three cancer types are apparently in approximately the same order of magnitude, we subsequently examined whether cellular pathways were also similarly affected by functional promoter hypermethylation, or rather in a cancer type-specific manner. Since the net effect of a pathway can be the same independent of the specific activating or other inhibitory components affected, all genes were considered together. The pathway analyses were performed by using the well annotated MetaCore databases (GeneGo). We selected the 50 most relevant pathways associated with functional hypermethylation, first for genes mutually involved in all three cancer types ( $n=61$; Supplemental Table S2) and then separate for the cancer type-specific genes (RCC: $n=91 ; C R C: n=151 ; B C: n=112$; Supplemental Tables S3-S5).

Overall, in the four pathway lists, pathways significantly enriched for promoter hypermethylation and subsequent gene silencing included those controlling development, immune response, apoptosis and survival, transcription, cell cycle, G-protein signaling, neurophysiological process, muscle contraction, cytoskeleton remodeling, cell adhesion and signal transduction (Figure 2). As expected, genes functionally hypermethylated in all three cancer types heavily represented cellular processes related to carcinogenesis. In particular, genes encoding various components of pathways involved in immune response, development and cell adhesion were strongly enriched for functional hypermethylation ( 32 out of 61 genes, Figure 2B).

Interestingly, the cancer type-specific genes also profoundly represented pathways involved in development and immune response (cCRCC: 34/91 (37\%), CRC: 51/151 (34\%) and BC: $31 / 112(28 \%)$, Figure $2 A)$, indicating that these particular pathways are affected both by shared genes in CCRCC, CRC and BC, as also by different genes in a more cancer type-specific fashion. In contrast, cell adhesion was mainly affected by common genes in all three cancer types, but less in a cancer type-specific fashion. Furthermore, the majority of genes were unique for each cancer type. However, they represent mostly the same pathways and processes (Figure 2). Top-ranked pathways involved in development, immune response, G-protein signaling, apoptosis and survival, cell adhesion, cell cycle, cytoskeleton remodeling, and transcription are affected by 
the vast majority of genes in each of the three cancer type-specific gene lists $(62 \%$, $50 \%$ and $44 \%$ for $\mathrm{CCRCC}, \mathrm{CRC}$ and BC, respectively), and therefore by different functionally methylated genes.
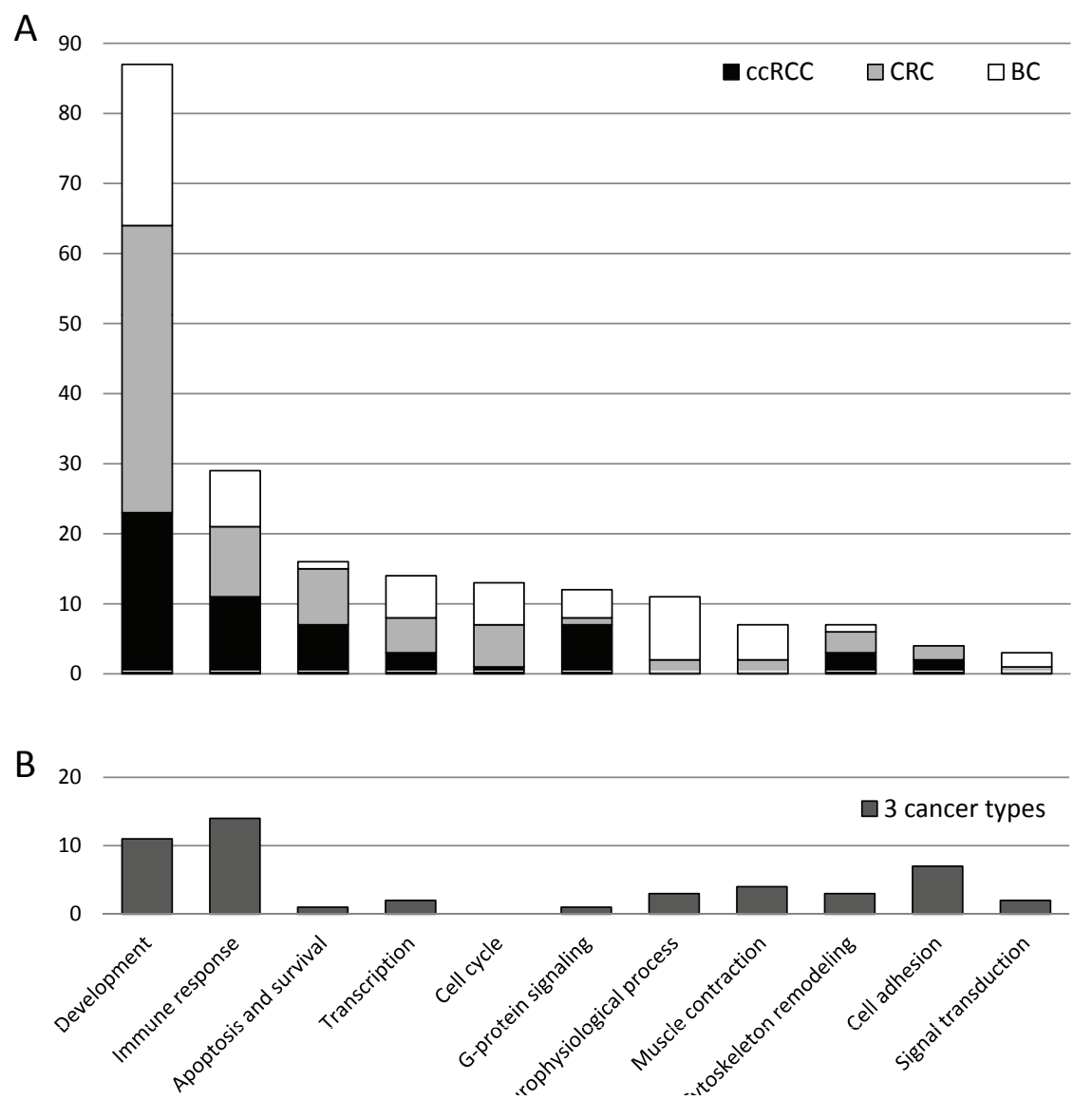

Figure 2. Number of genes involved per pathway in ccRCC, CRC, BC or all three cancer types Methylation enriched pathways with number of genes affected per cancer type $(A)$ and number of mutually affected genes in all three cancer types (B).

\section{Pathways enriched for functional promoter hypermethylation in CCRCC}

Although the uniquely functionally methylated genes in the three cancer types affected similar pathways in general, the specific target(s) within these pathways was (were) mostly different per cancer type. Focusing on ccRCC, the top-ranked pathway, involved in apoptosis and survival, specifically affected the pathway of the nicotinic acetylcholine receptor ( $\mathrm{nAChR}$ ) in apoptosis inhibition and cell cycle progression. In this pathway, the acetylcholine receptor subunit beta (CHRNB1) and phosphoinositide3-kinase, catalytic, delta polypeptide $(P I K 3 C D)$ were functionally methylated in ccRCC 
only. Examining the top 50 pathways remarkably revealed several other pathways linked to the nAChR pathway involving various components of the PI3 kinase and calcium $\left(\mathrm{Ca}^{2+}\right)$ pathway which in turn are linked to the VEGF, MAPK, and EGFR pathway.

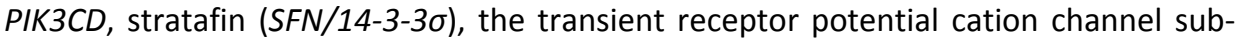
family $\mathrm{C}$ member 3 (TRPC3) and adenylosuccinate synthase like 1 (ADSSL1) are genes involved in one or more of these pathways which indicated functional hypermethylation specifically in ccRCC. Interestingly, six of the top $50 \mathrm{ccRCC}$ pathways were categorized to be linked with epithelial-to-mesenchymal transition (EMT). Again, the PIK3CD gene and in addition the cadherin $1(C D H 1)$ gene, known to be involved in this mechanism, showed functional hypermethylation in ccRCC.

These affected pathways in RCC are also (to a greater or lesser extend) affected in CRC and BC, however by different genes (Supplemental Table S4 and S5). The integrated approach correctly indicated the methylation status as analyzed by MSP in ccRCC (Table 2). If methylation was indicated by both MBD-affinity NGS and the re-expression data, MSP confirmed the methylation status and vice versa in $100 \%$. However, in four cases methylation was only indicated by MBD, without re-expression after demethylation, and two of these were methylated by MSP (Table 2). This underscores the significance of integrating both technologies to correctly identify functional promoter methylation.

Table 2. Validation of MBD-affinity NGS and re-expression microarray data by MSP in ccRCC cell lines

\begin{tabular}{|c|c|c|c|c|c|c|c|c|c|c|c|c|c|c|c|c|c|c|}
\hline & \multicolumn{3}{|c|}{ ADSSL1 } & \multicolumn{3}{|c|}{$\mathrm{CDH1}$} & \multicolumn{3}{|c|}{ CHRNB1 } & \multicolumn{3}{|c|}{ PIK3CD } & \multicolumn{3}{|c|}{ SFN } & \multicolumn{3}{|c|}{ TRPC3 } \\
\hline & MBD & DAC & MSP & MBD & DAC & MSP & MBD & DAC & MSP & MBD & DAC & MSP & MBD & DAC & MSP & MBD & DAC & MSP \\
\hline SKRC1 & $\sqrt{ }$ & $\sqrt{ }$ & M & $\sqrt{ }$ & $\sqrt{ }$ & $M$ & $\sqrt{ }$ & $\sqrt{ }$ & M & $\sqrt{ }$ & $\sqrt{ }$ & M & $\sqrt{ }$ & $\sqrt{ }$ & $M$ & $\sqrt{ }$ & $\sqrt{ }$ & M \\
\hline SKRC10 & $\sqrt{ }$ & $\sqrt{ }$ & M & $\sqrt{ }$ & $\sqrt{ }$ & $M$ & $\sqrt{ }$ & & M & $\sqrt{ }$ & & U & $\sqrt{ }$ & $\sqrt{ }$ & - & $\sqrt{ }$ & & M \\
\hline SKRC52 & & & U & $\sqrt{ }$ & & $U$ & & & U & $\sqrt{ }$ & $\sqrt{ }$ & $M$ & $\sqrt{ }$ & & - & $\sqrt{ }$ & $\sqrt{ }$ & $M$ \\
\hline SKRC59 & & & U & & & $U$ & & & U & & & U & & & U & $\sqrt{ }$ & $\sqrt{ }$ & $M$ \\
\hline
\end{tabular}

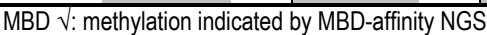

DAC $\sqrt{ }$ : methylation indirectly indicated by re-expression microarray data following demethylation treatment M: methylated by MSP, U: unmethylated by MSP

Gray highlight indicates MBD or DAC data validated by MSP 


\section{Discussion and conclusion}

The aim of this study was to compare the functional ccRCC hypermethylome with those of CRC and BC. The analysis that we present here provides a global picture of both the tumor-specific methylomes of $\mathrm{CCRCC}, \mathrm{CRC}$ and $\mathrm{BC}$ and the methylome shared by these three tumor types. Numbers of affected gene promoters within these three cancer types, identified using very stringent selection criteria, appear to be approximately similar, indicating that the size of the methylomes is in the same order of magnitude for renal, colorectal and breast cancer cells. Using this stringent approach, the number of genes affected by promoter hypermethylation forming the minimally sized functional cancer hypermethylomes, comprises about two to three percent of the number of estimated protein-coding genes in the human genome $(20,000-25,000 \mathrm{Hu}-$ man Genome Project). Objective comparison of data estimating methylome(s) (sizes) in literature is complicated as it is highly technique- and cell line/tissue-dependent. The data are based on the currently existing annotation databases and because of the stringent selection criteria used in the presented analyses, many interesting candidate genes, such as methylated genes that not become re-expressed upon DAC treatment etc, are being excluded from further analysis. Furthermore, variation between cell lines, like MSI and CIN in CRC, could significantly influence functional methylome sizes as observed for the MSI positive cell lines HCT116 and RKO which show the largest number of re-expressed genes. For $c \mathrm{RCC}$ and BC this is less clear. Further analyzing these data encloses possibilities to unravel such issues.

Our integrated approach has never been applied before, but we believe that the functional methylomes we identified are smaller in size yet more biologically significant than those methylomes identified in other epigenome-wide and whole epigenome studies which did not take gene re-expression into account. In this first analysis we focused on promoter hypermethylation thereby excluding other regions like gene body methylation. Evidence is emerging that regions outside the promoter also could regulate gene expression ${ }^{13}$, suggesting that our identified functional hypermethylome is incomplete. Again such information could be unraveled by further analyzing the data acquired by our approach, although this first requires a full elucidation of the functional locus (promoter, exon1, intron(s), gene body) and its specific effects of DNA methylation on gene expression.

Almost half of the identified genes also showed promoter methylation in normal kidney, colon or breast cells, which is indicative of tissue-specific epigenetic regulation in normal development or aging. On the other hand, the methylome was analyzed in only a small number of normal samples which preferentially needs to be extended. This underlines the importance to correct for methylation in non-cancerous tissues and to validate the hypermethylation status of identified genes in a large number of normal tissues by specific techniques, such as MSP.

$26 \%, 19 \%$, and $23 \%$ of the identified genes in CCRCC, CRC, and BC respectively, overlapped the three cancer types and were enriched in pathways related to carcinogenesis affecting many, if not all, hallmarks of cancer, like evading growth suppression and sustaining proliferative significance, resisting cell death, and activating invasion and metastasis $^{14}$. Interestingly, one of the recently emerged cancer hallmarks, a defective immune destruction ${ }^{15}$, comprised a common feature in all three cancer types. Immune 
response appeared to be the most affected pathway $(13 / 50 ; 26 \%)$ in the top 50 pathway list of commonly functionally methylated genes in CCRCC, CRC and BC (Figure 2B and Supplemental Table S2). In addition to the commonly affected gene promoters, specific components related to immune response were also heavily enriched for functional hypermethylation in each cancer type separately with 11, 10 and 8 genes involved in cCRCC, CRC and BC respectively (Figure 2A and Supplemental Table S3-5). Aberrant DNA methylation may influence signaling and expression of genes important for functioning of the innate and acquired immune systems ${ }^{16,17}$. Promoter hypermethylation of several genes has been suggested to help tumor cells escape from an immunological attack either by preventing an immune response (CIITA, HLA-A and -B genes) ${ }^{18-21}$ or by acquired resistance to products of the activated immune system or its activation self (IRF-7, STAT1, 2, and 3 genes, DAPK and multiple INF pathway genes) ${ }^{22-}$ 26. Important to note, our analysis based on cell lines excludes the possibility that stromal contamination from infiltrating immune cells, which may be present when analyzing primary tissues, could have distorted this result. Thus, our data underscore the importance of epigenetic deregulation of this novel hallmark in cancer by DNA hypermethylation and provide a basis for future cancer research.

Comprehensive analyses of the cancer-specific functional methylomes resulted in rather similar compositions of functional categories for $\mathrm{ccRCC}, \mathrm{CRC}$ and BC. We observed largely comparable enriched pathways within the three cancer types, with the two largest comprising development and immune response. Several pathways were epigenetically altered by promoter hypermethylation in all three cancer types, however by different genes, suggesting that several genes within the same group or pathway serve the same goal. In general, these analyses show conserved targeting of critical pathways through unique epigenetic events. For all these gene groups, new genes were identified that had not been implicated in epigenetic (DNA methylation) tumorigenesis in these cellular processes. These data forms a basis for future exploration of the cancer specific methylome, which contributes to the understanding of the cancer pathogenesis. This could also provide novel candidate biomarkers and potential drug targets, although clinical validation in multiple large series of cancers is required.

Here we focused on the renal cell cancer promoter hypermethylome hypothesizing that, based on the genetic differences, it could be distinguished from the CRC and BC hypermethylomes. In contrast to what we hypothesized, the functional ccRCC methylome was quite comparable to the $\mathrm{CRC}$ and $\mathrm{BC}$ ones, in terms of size, but also by equally affected pathways, as mentioned previously. However, the specific target(s) within those pathways was (were) mostly different per cancer type. Based on the histology and genetics of CCRCC, we expected involvement of genes related to hypoxia and angiogenesis. Strikingly, for ccRCC the most prominent identified pathway involved in apoptosis and survival specifically affected the nAChR pathway in apoptosis inhibition and cell cycle progression. In addition, nine of the top 50 pathways were enriched for functional hypermethylation with gene promoters linked to this pathway, like the PI3K and the calcium signaling pathway, implicating cross-talk of the PI3K/Akt pathway with other pathways relevant to ccRCC. One of these connections may result in $\mathrm{EMT}^{27,28}$, which is one of the characteristics of $\mathrm{ccRCC}^{29}$. The PI3K/Akt pathway has been emerged as a central feature of EMT and repression of the E-cadherin gene $(C D H 1)$ is one of its major characteristics ${ }^{27}$. During tumorigenesis EMT may increase the motility and inva- 
siveness of cancer cells, and malignant transformation may be associated with signaling pathways promoting EMT, however this is less characterized and represents an area of active investigation ${ }^{27,30}$. EMT has been suggested to play a role in RCC, however its mechanism remain elusive. Our analyses might indicate a novel path connecting epigenetic (indirect) regulation of the PI3K pathway and/or its cross-talk to other signaling pathways with EMT, which has not been described before.

It is becoming clear that genes involved in a pathway interact with a number of other pathways to create an extremely complex network. Because of this network it could be explained why a single inhibition can easily be circumvented by up-regulation of these interconnections, ultimately leading to failure of therapeutic strategies. The complexity of genetic and epigenetic alterations in human cancer increases when considering several changes. The genomic landscape has been described as a few commonly affected 'gene mountains' scattered among a much larger number of 'gene hills' that are infrequently genetically altered ${ }^{31,32}$. The vast majority of aberrations appear to occur in the 'hills', which is likely to explain the wide variation in tumor behavior and response to therapy. After establishing the frequency of hypermethylation of these genes in large series of primary tumors, we can determine whether this also holds true for the methylome of these cancers. Concerning DNA methylation aberrations (in CCRCC, CRC and BC), altered pathways rather than individual genes appear to direct tumorigenesis. Nevertheless, a similar design can be considered regarding DNA methylation profiles in cancer. Certain processes (mountains) are commonly deregulated during carcinogenesis in general, however due to different affected genes which eventually serve the same goal. Additionally multiple extra processes (hills) will be affected in each cancer type contributing to the heterogeneity and complexity of human neoplasia.

Although many of the known cancer genes that are frequently mutated in other than RCC cancers have not been reported to be affected otherwise in RCC, it might be that the pathways of which those genes are a component of, are disrupted in other ways, for instance silenced by DNA hypermethylation. Gene members of the PI3K/Akt signaling pathway for example, which is crucial to many aspects of cell growth and survival, are frequently mutated or amplified in a wide variety of solid tumors. Receptor tyrosine kinases upstream of PI3K, the $\mathrm{p} 110 \alpha$ catalytic subunit of PI3K, the downstream kinase, AKT, and the negative regulator, PTEN, are all frequently altered in cancer ${ }^{33}$, but information about the involvement in RCC is sparse. Although the PI3K pathway has been reported to be deregulated in renal cell carcinoma ${ }^{34,35}$, mutations have been detected only scarcely. PTEN gene mutation in ccRCC has been reported to be a rare event $^{36-38}$. The molecular basis for these observations has not been determined. Our analyses revealed several genes (ADSSL1, CHRNB1, PIK3CD, SFN and TRPC3) directly or indirectly linked to this pathway to be functionally methylated, which might alternatively deregulate this pathway in ccRCC. Whether inactivation of these genes by promoter hypermethylation indeed affects this signaling pathway, remains to be investigated further. 
In conclusion, these analyses provide a first global view of functionally methylated genes and processes affected by this epigenetic feature in CCRCC, CRC and BC. The combination of methylation-specific sequencing and re-expression analysis appeared powerful and permits the identification of genes and pathways that may not be easily detected by either analysis alone. These results lead to a deeper understanding of the methylation data and its implications for renal cell, colorectal and breast neoplasia and form a basis for future research. 


\section{Supplemental figure and tables}

A
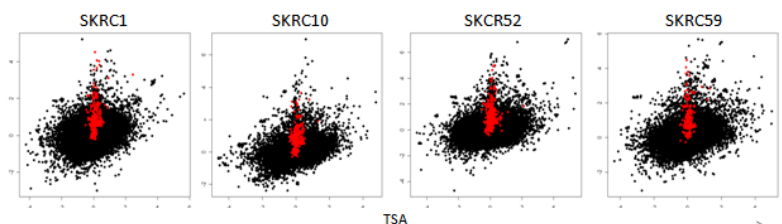

B
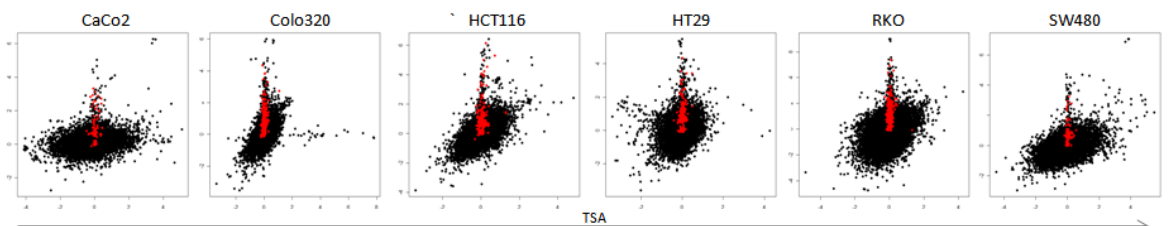

C
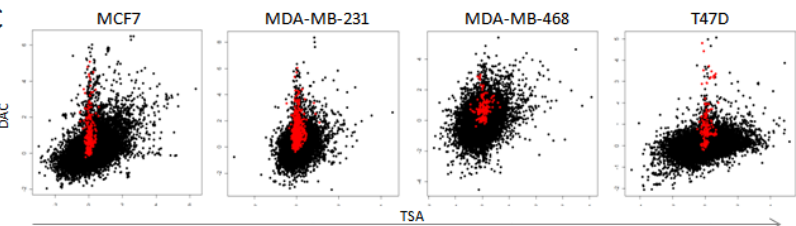

Supplemental Figure 1. Overlay of genes by MBD-binding and DAC re-expression per $c C R C C, C R C$ and $B C$ cell line Gene expression changes for the ccRCC cell lines SKRC1, SKRC10, SKRC52 and SKRC59 (A), the CRC cell lines CACO2, COLO320, HCT116, HT29, RKO, and SW480 (B), and the BC cell lines MCF-7, MDA-MB468, MDA-MB231 and T47-D (C) treated with TSA (x-axis) or DAC (y-axis) are plotted by log-fold change. Each dot represents an individual probe, which represents a gene (some genes were represented by several probes as a control) on the array. Overlapping genes within the spike, identified by MBD-sequencing are indicated in red, genes without overlap are depicted in black.

Supplemental Table S1. Gene lists of ccRCC, CRC and BC functional methylomes

\begin{tabular}{|c|c|c|c|}
\hline 3 cancer types $(n=61)$ & $\operatorname{ccRCC}(n=91)$ & CRC $(n=151)$ & $B C(n=112)$ \\
\hline PRTFDC1 & NEBL & UNC13D & HTR7 \\
\hline LIMD2 & LOXL4 & THBD & $B D N F$ \\
\hline ZIK1 & C10orf81 & CRYGD & $R R A D$ \\
\hline L1TD1 & CDC42BPG & C3orf14 & CCDC68 \\
\hline PHACTR 3 & PLEKHG6 & EPS8L2 & CNN1 \\
\hline CRYBA2 & ADSSL1 & EFS & CNTD2 \\
\hline CAND2 & RASGRP1 & FOXA1 & RCSD1 \\
\hline FBLN2 & $A L D H 1 A 3$ & GALC & GOLT1A \\
\hline FOXF2 & $\mathrm{CDH} 1$ & $E V L$ & SLC35F3 \\
\hline ANK1 & CHRNB1 & LTK & C2orf44 \\
\hline CYB5R2 & IGFBP4 & C15orf48 & ELOVL2 \\
\hline OVOL1 & COLEC12 & FBN1 & LAMA2 \\
\hline$B N C 1$ & C18orf1 & ISG20 & AKAP12 \\
\hline KRT16 & ICAM4 & SLC16A5 & SCIN \\
\hline TBX21 & KCNN1 & SPHK1 & HDAC9 \\
\hline CIDEA & SFN & LAMA3 & C7orf38 \\
\hline ELAVL3 & NES & COL16A1 & MKX \\
\hline PPP1R14A & CRABP2 & TEKT2 & TLL2 \\
\hline DLL3 & CACNA2D3 & OXCT2 & C10orf82 \\
\hline NPAS1 & MFI2 & S100A6 & PPAPDC1A \\
\hline ZNF542 & MY01G & C20orf103 & FAM24B \\
\hline AK5 & LAT2 & FKBP1B & C10orf88 \\
\hline ACTA1 & ADHFE1 & EGR4 & ZNF214 \\
\hline SLC32A1 & CA3 & $C D 8 B$ & $D E P D C 7$ \\
\hline
\end{tabular}


Supplemental Table S1. continued

\begin{tabular}{|c|c|c|c|}
\hline 3 cancer types $(n=61)$ & $\operatorname{ccRCC}(n=91)$ & CRC $(n=151)$ & $B C(n=112)$ \\
\hline KCNS1 & RIMS2 & CCDC37 & RASGRP2 \\
\hline TNNC2 & MAL2 & SLC7A14 & SUV420H1 \\
\hline EYA2 & SHC3 & KCTD8 & GPR83 \\
\hline POMC & BSPRY & HERC5 & SCN4B \\
\hline KCNG3 & BARHL1 & DDIT4L & TMTC1 \\
\hline$D L X 1$ & C10orf110 & SHROOM1 & HOXC9 \\
\hline HOXD13 & FLRT2 & HSPA1A & C12orf42 \\
\hline CCK & SHC4 & IL20RA & GLT8D2 \\
\hline ZIC1 & SLC6A4 & TWIST1 & NID2 \\
\hline EGFLAM & C1QTNF1 & $A K R 1 B 1$ & SEMA6D \\
\hline OTP & GNA15 & TP53INP1 & ISL2 \\
\hline BHMT & CD34 & NOTCH1 & SALL1 \\
\hline B3GALT4 & LAMA5 & C9orf167 & SLFN13 \\
\hline GDF6 & C21orf63 & FAM133A & FBXL20 \\
\hline GABBR2 & EDIL3 & NAP1L3 & SKAP1 \\
\hline$P R R X 2$ & $D G K I$ & $\mathrm{LRCH} 2$ & HOXB4 \\
\hline ME3 & $K L R G 2$ & PTF1A & CACNA1G \\
\hline TMEM25 & МАРЗК8 & PPP1R3C & KCNJ2 \\
\hline$K L$ & ELOVL3 & $E M X 2$ & $C C D C 11$ \\
\hline CSPG4 & PSTK & $\mathrm{RIC3}$ & CFD \\
\hline CHRNA3 & AMPD3 & NRIP3 & TNNI3 \\
\hline MT1M & SYT13 & $A B C C 8$ & ZNF329 \\
\hline PCSK9 & $S L C 43 A 3$ & WIT1 & GF/1 \\
\hline RASSF5 & LRMP & KCNE3 & NTNG1 \\
\hline DYSF & PTPRR & JAM3 & TBX15 \\
\hline MAL & $S L C 27 A 2$ & CCND2 & C1orf114 \\
\hline TMEM22 & PRSS22 & MANSC1 & RYR2 \\
\hline CXCL14 & DNAH3 & BCAT1 & PLCB4 \\
\hline PRDM13 & PRRT2 & GLS2 & L3MBTL \\
\hline PON3 & HS3ST3A1 & DPY19L2 & MATN4 \\
\hline PAX6 & SLFN11 & SALL2 & DPYSL5 \\
\hline POU2AF1 & HOXB13 & RIPK3 & $D L X 2$ \\
\hline PAPLN & PSTPIP2 & GPR68 & HOXD8 \\
\hline ZNF167 & HPN & $A D A L$ & PROK2 \\
\hline RBP1 & PIK3CD & TM6SF1 & PCSK1 \\
\hline NPFFR2 & PAX7 & ANPEP & C6orf114 \\
\hline C8G & C1orf172 & MPV17L & FAM8A1 \\
\hline & GJB3 & MYH11 & HIST1H1A \\
\hline & ST6GALNAC5 & YPEL3 & MDGA1 \\
\hline & PRMT6 & LRRC36 & PLA2G7 \\
\hline & NMNAT2 & FOXF1 & CD109 \\
\hline & G0S2 & NLRP1 & C6orf59 \\
\hline & MARK1 & RASD1 & TBX18 \\
\hline & PXDN & SSTR2 & MCHR2 \\
\hline & IGFBP2 & MATK & ULBP1 \\
\hline & SLC16A14 & ZNF439 & HOXA4 \\
\hline & CD200 & PSG9 & DPY19L2P1 \\
\hline & TRPC3 & FUZ & C7orf10 \\
\hline & $\mathrm{CDH} 18$ & KIF17 & PGAM2 \\
\hline & SMOC2 & RAB42 & PON1 \\
\hline & $B M P E R$ & KIAA1324 & VGF \\
\hline & RELN & PCP4L1 & KCND2 \\
\hline & CA8 & TDRD5 & LZTS1 \\
\hline & TRAF1 & AKT3 & MATN2 \\
\hline & PNPLA4 & RIMS4 & GLDC \\
\hline & MAGEB2 & $S L C 2 A 10$ & $R A B 39 B$ \\
\hline & EFHC2 & OLIG1 & FGFR2 \\
\hline & MAGIX & CBR1 & KCTD14 \\
\hline & WNK3 & KCNJ4 & KIF5A \\
\hline & TSPAN15 & EHD3 & PITPNM2 \\
\hline & EFEMP2 & ITGA4 & NEK9 \\
\hline & LRRC32 & $A C A D L$ & GRAMD2 \\
\hline
\end{tabular}


Supplemental Table S1. continued

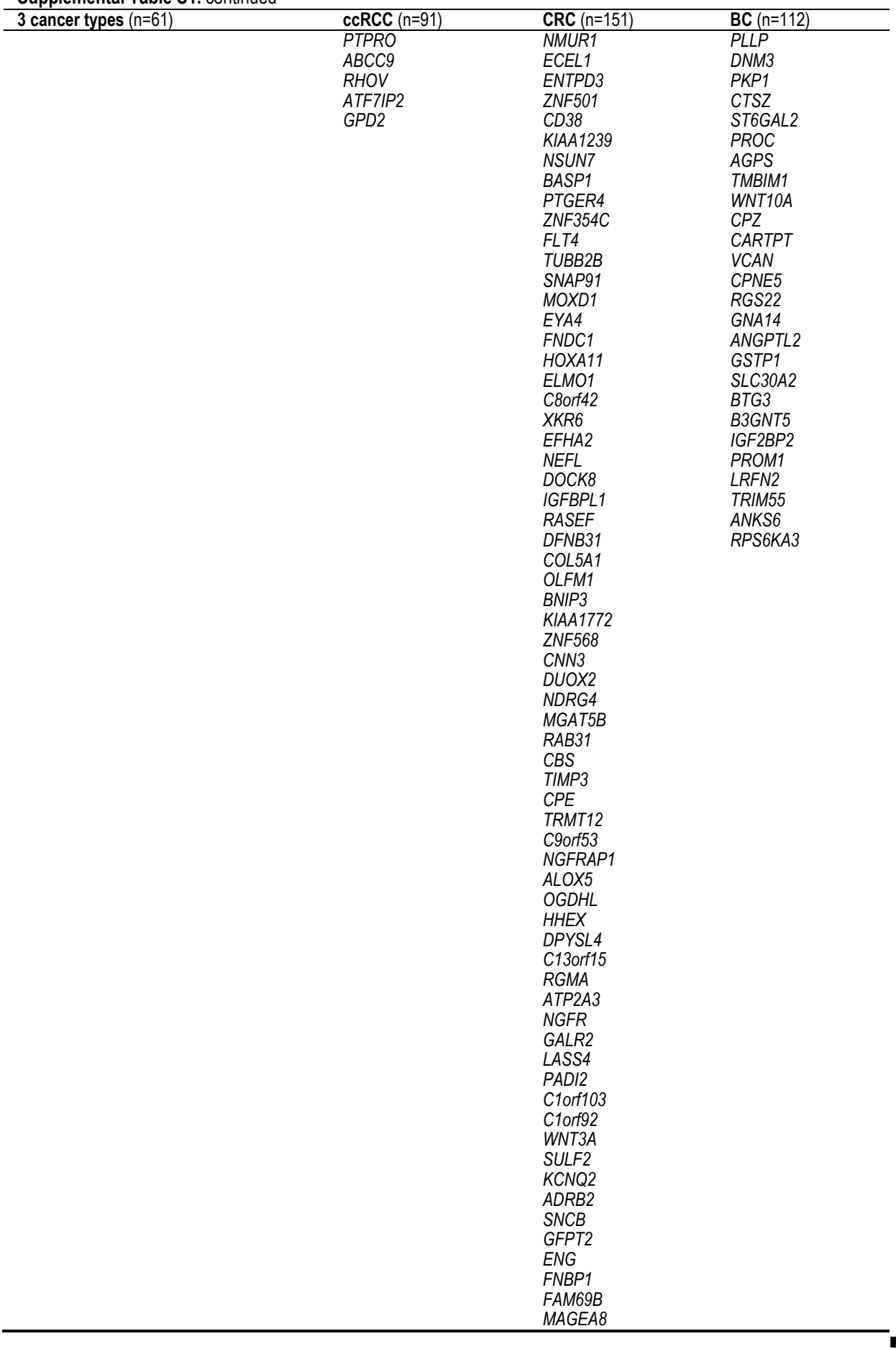


Supplemental Table S2. Pathway top 50 mutually involved in the three cancer types (ccRCC, CRC, BC)

\begin{tabular}{|c|c|c|c|c|}
\hline$\#$ & Pathway & p-value & Ratio & FDR \\
\hline 1 & Development_S1P2 and S1P3 receptors in cell proliferation and differentiation & $2,765 \mathrm{E}-03$ & 226 & $15 \%$ \\
\hline 2 & Immune response_Antigen presentation by MHC class I & $3,203 E-03$ & 228 & $15 \%$ \\
\hline 3 & Cell adhesion_Cell-matrix glycoconjugates & $5,848 \mathrm{E}-03$ & 238 & $15 \%$ \\
\hline 4 & Development_TGF-beta-dependent induction of EMT via RhoA, PI3K and ILK. & $8,483 \mathrm{E}-03$ & 246 & $15 \%$ \\
\hline 5 & Development_Melanocyte development and pigmentation & $9,585 \mathrm{E}-03$ & 249 & $15 \%$ \\
\hline 6 & Neurophysiological process_GABAergic neurotransmission & $9,966 \mathrm{E}-03$ & 250 & $15 \%$ \\
\hline 7 & Chemotaxis_Leukocyte chemotaxis & $2,155 \mathrm{E}-02$ & 275 & \\
\hline 8 & wtCFTR and delta508 traffic / Clathrin coated vesicles formation (norm and CF) & $5,634 \mathrm{E}-02$ & 119 & \\
\hline 9 & Immune response_TLR3 and TLR4 induce TICAM1-specific signaling pathway & $5,922 \mathrm{E}-02$ & 120 & \\
\hline 10 & Cytoskeleton remodeling_Regulation of actin cytoskeleton by Rho GTPases & $6,780 \mathrm{E}-02$ & 123 & \\
\hline 11 & Immune response_IL-27 signaling pathway & $7,065 \mathrm{E}-02$ & 124 & \\
\hline 12 & Development_Leptin signaling via JAK/STAT and MAPK cascades & $7,349 \mathrm{E}-02$ & 125 & \\
\hline 13 & Muscle contraction_Delta-type opioid receptor in smooth muscle contraction & $7,632 \mathrm{E}-02$ & 126 & \\
\hline 14 & Cell adhesion_Cadherin-mediated cell adhesion & $7,632 \mathrm{E}-02$ & & \\
\hline 15 & Muscle contraction_nNOS Signaling in Skeletal Muscle & $7,914 \mathrm{E}-02$ & 127 & \\
\hline 16 & Development_Mu-type opioid receptor regulation of proliferation & $8,195 \mathrm{E}-02$ & 128 & \\
\hline 17 & Apoptosis and survival_nAChR in apoptosis inhibition and cell cycle progression & $8,475 \mathrm{E}-02$ & 129 & \\
\hline 18 & Muscle contraction_S1P2 receptor-mediated smooth muscle contraction & $8,755 \mathrm{E}-02$ & & \\
\hline 19 & Chemotaxis_CCR4-induced leukocyte adhesion & $8,755 \mathrm{E}-02$ & 130 & \\
\hline 20 & Development_Slit-Robo signaling & $8,755 \mathrm{E}-02$ & & \\
\hline 21 & Neurophysiological process_Mu-type opioid receptor-mediated analgesia & $8,755 \mathrm{E}-02$ & 130 & \\
\hline 22 & Cytoskeleton remodeling_RalA regulation pathway & $8,755 \mathrm{E}-02$ & 130 & \\
\hline 23 & Cell adhesion_Gap junctions & $8,755 \mathrm{E}-02$ & 130 & \\
\hline 24 & Signal transduction_Activin A signaling regulation & $9,589 \mathrm{E}-02$ & 133 & \\
\hline 25 & Immune response_Role of the Membrane attack complex in cell survival & $9,865 \mathrm{E}-02$ & & \\
\hline 26 & Methionine metabolism & $9,865 \mathrm{E}-02$ & 134 & \\
\hline 27 & Development_TGF-beta-dependent induction of EMT via SMADs & $1,014 \mathrm{E}-01$ & & \\
\hline 28 & Cytoskeleton remodeling_Keratin filaments & $1,042 \mathrm{E}-01$ & & \\
\hline 29 & Cell adhesion_Tight junctions & $1,042 \mathrm{E}-01$ & & \\
\hline 30 & Immune response_IL-12-induced IFN-gamma production & $1,042 \mathrm{E}-01$ & 136 & \\
\hline 31 & G-protein signaling_G-Protein alpha-s signaling cascades & $1,042 \mathrm{E}-01$ & & \\
\hline 32 & Cell adhesion_Role of tetraspanins in the integrin-mediated cell adhesion & $1,069 \mathrm{E}-01$ & & \\
\hline 33 & Development_Mu-type opioid receptor signaling & $1,096 \mathrm{E}-01$ & 138 & \\
\hline 34 & Transcription_Sin3 and NuRD in transcription regulation & $1,096 \mathrm{E}-01$ & & \\
\hline 35 & Immune response_Alternative complement pathway & $1,123 \mathrm{E}-01$ & & \\
\hline 36 & Transcription_NF-kB signaling pathway & $1,123 \mathrm{E}-01$ & 139 & \\
\hline 37 & Immune response_Th1 and Th2 cell differentiation & $1,151 \mathrm{E}-01$ & 140 & \\
\hline 38 & Immune response_PGE2 in immune and neuroendocrine system interactions & $1,232 \mathrm{E}-01$ & & \\
\hline 39 & Cell adhesion_Histamine $\mathrm{H} 1$ receptor signaling in the interruption of cell barrier integrity & $1,285 \mathrm{E}-01$ & & \\
\hline 40 & Immune response_Bacterial infections in normal airways & 1,391E-01 & 149 & \\
\hline 41 & Immune response_Lectin induced complement pathway & $1,391 \mathrm{E}-01$ & & \\
\hline 42 & Mucin expression in CF via TLRs, EGFR signaling pathways & $1,444 \mathrm{E}-01$ & & \\
\hline 43 & Signal transduction_Activation of PKC via G-Protein coupled receptor & $1,470 \mathrm{E}-01$ & 152 & \\
\hline 44 & Immune response_Classical complement pathway & $1,470 \mathrm{E}-01$ & & \\
\hline 45 & Ganglioside Metabolism p1 & $1,522 \mathrm{E}-01$ & 154 & \\
\hline 46 & Muscle contraction_ACM regulation of smooth muscle contraction & $1,574 \mathrm{E}-01$ & 156 & \\
\hline 47 & Immune response_TLR signaling pathways & $1,574 \mathrm{E}-01$ & 156 & \\
\hline 48 & Bacterial infections in CF airways & $1,626 \mathrm{E}-01$ & 158 & \\
\hline 49 & Immune response_Immunological synapse formation & $1,652 \mathrm{E}-01$ & 159 & \\
\hline$\underline{50}$ & O-glycan biosynthesis & $1,753 \mathrm{E}-01$ & & \\
\hline
\end{tabular}


Supplemental Table S3. Pathway top 50 clear cell renal cell cancer-specific genes

\begin{tabular}{|c|c|c|c|c|c|}
\hline \# & Pathway & $p$-value & Ratio & & FDR \\
\hline 1 & $\begin{array}{l}\text { Apoptosis and survival_nAChR in apoptosis inhibition and cell cycle progres- } \\
\text { sion }\end{array}$ & $8,642 \mathrm{E}-03$ & 2 & 29 & $31 \%$ \\
\hline 2 & Development_Role of CDK5 in neuronal development & $1,176 \mathrm{E}-02$ & 2 & 34 & $31 \%$ \\
\hline 3 & G-protein signaling_H-RAS regulation pathway & $1,383 \mathrm{E}-02$ & 2 & 37 & $31 \%$ \\
\hline 4 & Development_Delta-type opioid receptor mediated cardioprotection & 1,383E-02 & 2 & 37 & $31 \%$ \\
\hline 5 & Apoptosis and survival_BAD phosphorylation & $1,761 \mathrm{E}-02$ & 2 & 42 & $31 \%$ \\
\hline 6 & Development_EPO-induced PI3K/AKT pathway and $\mathrm{Ca}(2+)$ influx & $1,841 \mathrm{E}-02$ & 2 & 43 & $31 \%$ \\
\hline 7 & Transcription_CREB pathway & 1,923E-02 & 2 & 44 & $31 \%$ \\
\hline 8 & $\begin{array}{l}\text { Immune response_Inhibitory action of Lipoxins on pro-inflammatory TNF-alpha } \\
\text { signaling }\end{array}$ & 2,007E-02 & 2 & 45 & $31 \%$ \\
\hline 9 & Immune response_ICOS pathway in T-helper cell & $2,091 \mathrm{E}-02$ & 2 & 46 & $31 \%$ \\
\hline 10 & Development_TGF-beta-dependent induction of EMT via RhoA, PI3K and ILK. & $2,091 \mathrm{E}-02$ & 2 & 46 & $31 \%$ \\
\hline 11 & Development_PIP3 signaling in cardiac myocytes & $2,178 \mathrm{E}-02$ & 2 & 47 & $31 \%$ \\
\hline 12 & Development_HGF signaling pathway & $2,178 \mathrm{E}-02$ & 2 & 47 & $31 \%$ \\
\hline 13 & ATP/ITP metabolism & $2,211 \mathrm{E}-02$ & 3 & 124 & $31 \%$ \\
\hline 14 & Development_IGF-1 receptor signaling & 2,537E-02 & 2 & 51 & $31 \%$ \\
\hline 15 & Some pathways of EMT in cancer cells & 2,537E-02 & 2 & 51 & $31 \%$ \\
\hline 16 & $\begin{array}{l}\text { Development_Role of HDAC and calcium/calmodulin-dependent kinase (CaMK) } \\
\text { in control of skeletal myogenesis }\end{array}$ & $2,822 \mathrm{E}-02$ & 2 & 54 & $31 \%$ \\
\hline 17 & Immune response_TREM1 signaling pathway & 3,019E-02 & 2 & 56 & $31 \%$ \\
\hline 18 & Development_Gastrin in cell growth and proliferation & $3,640 \mathrm{E}-02$ & 2 & 62 & $31 \%$ \\
\hline 19 & Immune response_CD40 signaling & $3,857 \mathrm{E}-02$ & 2 & 64 & $31 \%$ \\
\hline 20 & Cardiac Hypertrophy_NF-AT signaling in Cardiac Hypertrophy & $3,967 \mathrm{E}-02$ & 2 & 65 & $31 \%$ \\
\hline 21 & Cell adhesion_Role of CDK5 in cell adhesion & $4,301 \mathrm{E}-02$ & 1 & 9 & $31 \%$ \\
\hline 22 & Hypoxia-induced EMT in cancer and fibrosis & $4,301 \mathrm{E}-02$ & 1 & 9 & $31 \%$ \\
\hline 23 & Development_MicroRNA-dependent inhibition of EMT & 4,767E-02 & 1 & 10 & $31 \%$ \\
\hline 24 & Retinol metabolism & $5,013 \mathrm{E}-02$ & 2 & 74 & $31 \%$ \\
\hline 25 & Development_NOTCH-induced EMT & 8,868E-02 & 1 & 19 & $31 \%$ \\
\hline 26 & wtCFTR and delta508 traffic / Clathrin coated vesicles formation (norm and CF) & $8,868 \mathrm{E}-02$ & 1 & 19 & $31 \%$ \\
\hline 27 & $\begin{array}{l}\text { Cytoskeleton remodeling_ESR1 action on cytoskeleton remodeling and cell } \\
\text { migration }\end{array}$ & $9,313 \mathrm{E}-02$ & 1 & 20 & $31 \%$ \\
\hline 28 & Translation_IL-2 regulation of translation & $9,313 \mathrm{E}-02$ & 1 & 20 & $31 \%$ \\
\hline 29 & Development_FGF2-dependent induction of EMT & $9,313 \mathrm{E}-02$ & 1 & 20 & $31 \%$ \\
\hline 30 & $\begin{array}{l}\text { Atherosclerosis_Role of ZNF202 in regulation of expression of genes involved } \\
\text { in Atherosclerosis }\end{array}$ & $9,756 \mathrm{E}-02$ & 1 & 21 & $31 \%$ \\
\hline 31 & Cell cycle_Role of $14-3-3$ proteins in cell cycle regulation & $1,020 \mathrm{E}-01$ & 1 & 22 & $31 \%$ \\
\hline 32 & $\begin{array}{l}\text { Transcription_Role of heterochromatin protein } 1 \text { (HP1) family in transcriptional } \\
\text { silencing }\end{array}$ & $1,020 \mathrm{E}-01$ & 1 & 22 & $31 \%$ \\
\hline 33 & Development_EGFR signaling via PIP3 & 1,064E-01 & 1 & 23 & $31 \%$ \\
\hline 34 & G-protein signaling_Cross-talk between Ras-family GTPases & $1,064 \mathrm{E}-01$ & 1 & 23 & $31 \%$ \\
\hline 35 & Apoptosis and survival_NO signaling in survival & 1,107E-01 & 1 & 24 & $31 \%$ \\
\hline 36 & Cytoskeleton remodeling_Role of PDGFs in cell migration & $1,107 \mathrm{E}-01$ & 1 & 24 & $31 \%$ \\
\hline 37 & G-protein signaling_M-RAS regulation pathway & 1,107E-01 & 1 & 24 & $31 \%$ \\
\hline 38 & Development_Dopamine D2 receptor transactivation of EGFR & $1,107 \mathrm{E}-01$ & 1 & 24 & $31 \%$ \\
\hline 39 & Immune response_IL-23 signaling pathway & $1,151 \mathrm{E}-01$ & 1 & 25 & $31 \%$ \\
\hline 40 & G-protein signaling_R-RAS regulation pathway & $1,151 \mathrm{E}-01$ & 1 & 25 & $31 \%$ \\
\hline 41 & Cytoskeleton remodeling_Neurofilaments & 1,151E-01 & 1 & 25 & $31 \%$ \\
\hline 42 & G-protein signaling_TC21 regulation pathway & $1,151 \mathrm{E}-01$ & 1 & 25 & $31 \%$ \\
\hline 43 & G-protein signaling_K-RAS regulation pathway & 1,151E-01 & 1 & 25 & $31 \%$ \\
\hline 44 & Cell adhesion_Cadherin-mediated cell adhesion & $1,194 \mathrm{E}-01$ & 1 & 26 & $31 \%$ \\
\hline 45 & Immune response_IL-10 signaling pathway & 1,194E-01 & 1 & 26 & $31 \%$ \\
\hline 46 & Apoptosis and survival_NGF signaling pathway & $1,194 \mathrm{E}-01$ & 1 & 26 & $31 \%$ \\
\hline 47 & Immune response_CD137 signaling in immune cell & $1,322 \mathrm{E}-01$ & 1 & 29 & $31 \%$ \\
\hline 48 & NGF activation of NF-kB & $1,322 \mathrm{E}-01$ & 1 & 29 & $31 \%$ \\
\hline 49 & Apoptosis and survival_p53-dependent apoptosis & $1,322 \mathrm{E}-01$ & 1 & 29 & $31 \%$ \\
\hline 50 & DNA damage_Brca1 as a transcription regulator & $1,365 \mathrm{E}-01$ & 1 & 30 & $31 \%$ \\
\hline
\end{tabular}


Supplemental Table S4. Pathway top 50 colorectal cancer-specific genes

\begin{tabular}{|c|c|c|c|c|}
\hline \# & Pathway & $\mathrm{p}$-value & Ratio & FDR \\
\hline 1 & Development_MAG-dependent inhibition of neurite outgrowth & $1,243 \mathrm{E}-04$ & 437 & $5 \%$ \\
\hline 2 & Development_Notch Signaling Pathway & 2,251E-04 & 443 & $5 \%$ \\
\hline 3 & Development_NOTCH-induced EMT & $2,989 \mathrm{E}-04$ & 319 & $5 \%$ \\
\hline 4 & Cell cycle Regulation of $\mathrm{G} 1 / \mathrm{S}$ transition (part 2) & 7,744E-04 & 326 & $5 \%$ \\
\hline 5 & Transcription_Role of Akt in hypoxia induced HIF1 activation & $8,668 \mathrm{E}-04$ & 327 & $5 \%$ \\
\hline 6 & Hypoxia-induced EMT in cancer and fibrosis & 1,709E-03 & & $10 \%$ \\
\hline 7 & Development_NOTCH1-mediated pathway for NF-KB activity modulation & $1,712 \mathrm{E}-03$ & 334 & $10 \%$ \\
\hline 8 & Regulation of metabolism_Bile acids regulation of glucose and lipid metabolism via FXR & $2,190 \mathrm{E}-03$ & 337 & $10 \%$ \\
\hline 9 & Development_Regulation of epithelial-to-mesenchymal transition (EMT) & 1,027E-02 & 364 & \\
\hline 10 & Apoptosis and survival_Beta-2 adrenergic receptor anti-apoptotic action & 1,127E-02 & 223 & \\
\hline 11 & Proteolysis_Role of Parkin in the Ubiquitin-Proteasomal Pathway & 1,224E-02 & 224 & \\
\hline 12 & Cytoskeleton remodeling_Neurofilaments & $1,325 \mathrm{E}-02$ & 225 & \\
\hline 13 & Immune response_Antigen presentation by MHC class I & $1,647 \mathrm{E}-02$ & 228 & \\
\hline 14 & NGF activation of $\overline{N F}-\mathrm{kB}$ & 1,761E-02 & 229 & \\
\hline 15 & Apoptosis and survival_Granzyme B signaling & $2,123 \mathrm{E}-02$ & 232 & \\
\hline 16 & Apoptosis and survival_Role of CDK5 in neuronal death and survival & $2,379 \mathrm{E}-02$ & 234 & \\
\hline 17 & Development_Role of CDK5 in neuronal development & $2,379 \mathrm{E}-02$ & 234 & \\
\hline 18 & Development_TGF-beta-dependent induction of EMT via SMADs & $2,512 \mathrm{E}-02$ & & \\
\hline 19 & Development_SSTR2 in regulation of cell proliferation & $2,648 \mathrm{E}-02$ & & \\
\hline 20 & Cell cycle_Regulation of G1/S transition (part 1) & $2,929 \mathrm{E}-02$ & 238 & \\
\hline 21 & Translation_Non-genomic (rapid) action of Androgen Receptor & $3,220 \mathrm{E}-02$ & 240 & \\
\hline 22 & Neurophysiological process_ACM1 and ACM2 in neuronal membrane polarization & $3,220 \mathrm{E}-02$ & 240 & \\
\hline 23 & Development_Neurotrophin family signaling & $3,220 \mathrm{E}-02$ & & \\
\hline 24 & Development_VEGF-family signaling & $3,371 \mathrm{E}-02$ & & \\
\hline 25 & Apoptosis and survival_Apoptotic TNF-family pathways & $3,523 \mathrm{E}-02$ & & \\
\hline 26 & Immune response_IL-7 signaling in B lymphocytes & $3,679 \mathrm{E}-02$ & 243 & \\
\hline 27 & Signal transduction_AKT signaling & $3,679 \mathrm{E}-02$ & 243 & \\
\hline 28 & Development_VEGF signaling and activation & $3,679 \mathrm{E}-02$ & 243 & \\
\hline 29 & Transcription_CREB pathway & $3,837 \mathrm{E}-02$ & 244 & \\
\hline 30 & Development_Ligand-independent activation of ESR1 and ESR2 & $3,837 \mathrm{E}-02$ & 244 & \\
\hline 31 & Development_VEGF signaling via VEGFR2 - generic cascades & $3,997 \mathrm{E}-02$ & 245 & \\
\hline 32 & Development_Leptin signaling via PI3K-dependent pathway & $4,326 \mathrm{E}-02$ & 247 & \\
\hline 33 & Development_PIP3 signaling in cardiac myocytes & $4,326 \mathrm{E}-02$ & 247 & \\
\hline 34 & Development_Melanocyte development and pigmentation & $4,664 \mathrm{E}-02$ & & \\
\hline 35 & Immune response_IL-13 signaling via PI3K-ERK & $4,837 \mathrm{E}-02$ & & \\
\hline 36 & Development_IGF-1 receptor signaling & $5,012 \mathrm{E}-02$ & 251 & \\
\hline 37 & Some pathways of EMT in cancer cells & $5,012 \mathrm{E}-02$ & 251 & \\
\hline 38 & Immune response_PGE2 common pathways & $5,190 \mathrm{E}-02$ & 252 & \\
\hline 39 & Cell adhesion_ECM remodeling & $5,190 \mathrm{E}-02$ & 252 & \\
\hline 40 & PGE2 pathways in cancer & $5,735 \mathrm{E}-02$ & 255 & \\
\hline 41 & Immune response_CD40 signaling & $7,482 \mathrm{E}-02$ & & \\
\hline 42 & G-protein signaling_Rap1B regulation pathway & $7,504 \mathrm{E}-02$ & & \\
\hline 43 & CFTR folding and maturation (norm and CF) & $9,453 \mathrm{E}-02$ & 114 & \\
\hline 44 & Cell cycle_Nucleocytoplasmic transport of CDK/Cyclins & $9,453 \mathrm{E}-02$ & 114 & \\
\hline 45 & Beta-2 adrenergic-dependent CFTR expression & 1,009E-01 & 115 & \\
\hline 46 & wtCFTR and deltaF508 traffic / Late endosome and Lysosome (norm and CF) & $1,009 \mathrm{E}-01$ & & \\
\hline 47 & DNA damage_Role of SUMO in p53 regulation & $1,136 \mathrm{E}-01$ & 117 & \\
\hline 48 & Muscle contraction_GPCRs in the regulation of smooth muscle tone & $1,162 \mathrm{E}-01$ & 283 & \\
\hline 49 & Cytoskeleton remodeling_Alpha-1A adrenergic receptor-dependent inhibition of PI3K & 1,261E-01 & & \\
\hline 50 & wtCFTR and delta508 traffic / Clathrin coated vesicles formation (norm and CF) & $1,261 \mathrm{E}-01$ & & \\
\hline
\end{tabular}


Supplemental Table S5. Pathway top 50 breast cancer-specific genes

\begin{tabular}{|c|c|c|c|c|}
\hline \# & Pathway & $p$-value & Ratio & FDR \\
\hline 1 & Transcription_CREB pathway & $9,817 \mathrm{E}-04$ & 344 & $10 \%$ \\
\hline 2 & Neurophysiological process_Long-term depression in cerebellum & 1,345E-03 & 349 & $10 \%$ \\
\hline 3 & Development_EDNRB signaling & $1,426 \mathrm{E}-03$ & 350 & $10 \%$ \\
\hline 4 & Muscle contraction_Regulation of eNOS activity in cardiomyocytes & 1,783E-03 & 354 & $10 \%$ \\
\hline 5 & Transcription_Role of heterochromatin protein 1 (HP1) family in transcriptional silencing & $4,310 \mathrm{E}-03$ & 222 & \\
\hline 6 & Development_ERK5 in cell proliferation and neuronal survival & 4,707E-03 & 223 & \\
\hline 7 & $\begin{array}{l}\text { Neurophysiological process_NMDA-dependent postsynaptic long-term potentiation in CA1 hippo- } \\
\text { campal neurons }\end{array}$ & $5,449 \mathrm{E}-03$ & 380 & \\
\hline 8 & Cell cycle_Role of Nek in cell cycle regulation & 8,997E-03 & & \\
\hline 9 & Muscle contraction_Role of kappa-type opioid receptor in heart & 9,551E-03 & 233 & \\
\hline 10 & Immune response_Role of the Membrane attack complex in cell survival & $1,012 \mathrm{E}-02$ & 234 & \\
\hline 11 & Development_Activation of ERK by Kappa-type opioid receptor & $1,130 \mathrm{E}-02$ & 236 & \\
\hline 12 & Development_PACAP signaling in neural cells & $1,318 \mathrm{E}-02$ & 239 & \\
\hline 13 & Immune response_PIP3 signaling in B lymphocytes & $1,518 \mathrm{E}-02$ & 242 & \\
\hline 14 & Neurophysiological process_ACM regulation of nerve impulse & $1,805 \mathrm{E}-02$ & 246 & \\
\hline 15 & Immune response_MIF - the neuroendocrine-macrophage connector & $1,805 \mathrm{E}-02$ & 246 & \\
\hline 16 & Development_PEDF signaling & 2,033E-02 & 249 & \\
\hline 17 & Signal transduction_PKA signaling & 2,192E-02 & 251 & \\
\hline 18 & Development_Beta-adrenergic receptors signaling via cAMP & $2,274 \mathrm{E}-02$ & 252 & \\
\hline 19 & $\begin{array}{l}\text { Development_Role of HDAC and calcium/calmodulin-dependent kinase (CaMK) in control of skeleta } \\
\text { myogenesis }\end{array}$ & al2,440E-02 & 254 & \\
\hline 20 & Immune response_Immunological synapse formation & 2,877E-02 & 259 & \\
\hline 21 & Plasmalogen biosynthesis & $3,342 \mathrm{E}-02$ & 264 & \\
\hline 22 & Cardiac Hypertrophy_NF-AT signaling in Cardiac Hypertrophy & $3,439 \mathrm{E}-02$ & 265 & \\
\hline 23 & Reproduction_GnRH signaling & 4,144E-02 & 272 & \\
\hline 24 & Transport_Rab-9 regulation pathway & 4,417E-02 & 110 & \\
\hline 25 & Phosphatidylinositol metabolism & $5,817 \mathrm{E}-02$ & 287 & \\
\hline 26 & Transcription_Transcription factor Tubby signaling pathways & 7,396E-02 & 117 & \\
\hline 27 & Protein folding_Membrane trafficking and signal transduction of G-alpha (i) heterotrimeric G-protein & $8,230 \mathrm{E}-02$ & 119 & \\
\hline 28 & Cell cycle_Chromosome condensation in prometaphase & $9,057 \mathrm{E}-02$ & 121 & \\
\hline 29 & Cell cycle_Sister chromatid cohesion & $9,468 \mathrm{E}-02$ & 122 & \\
\hline 30 & Development_S1P4 receptor signaling pathway & $9,468 \mathrm{E}-02$ & 122 & \\
\hline 31 & Glycolysis and gluconeogenesis p. 3 / Human version & 1,028E-01 & 124 & \\
\hline 32 & Development_GDNF signaling & $1,028 \mathrm{E}-01$ & 124 & \\
\hline 33 & Development_Mu-type opioid receptor signaling via Beta-arrestin & $1,028 \mathrm{E}-01$ & 124 & \\
\hline 34 & Glycolysis and gluconeogenesis p.3 & $1,028 \mathrm{E}-01$ & 124 & \\
\hline 35 & Cell cycle_Initiation of mitosis & 1,069E-01 & 125 & \\
\hline 36 & G-protein signaling_R-RAS regulation pathway & 1,069E-01 & 125 & \\
\hline 37 & Cytoskeleton remodeling_Neurofilaments & 1,069E-01 & 125 & \\
\hline 38 & G-protein signaling_TC21 regulation pathway & $1,069 \mathrm{E}-01$ & 125 & \\
\hline 39 & G-protein signaling_K-RAS regulation pathway & 1,069E-01 & 125 & \\
\hline 40 & Neurophysiological process_GABA-A receptor life cycle & 1,149E-01 & 127 & \\
\hline 41 & Development_Regulation of CDK5 in CNS & $1,189 \mathrm{E}-01$ & 128 & \\
\hline 42 & Development_Delta-type opioid receptor signaling via G-protein alpha-14 & $1,189 \mathrm{E}-01$ & 128 & \\
\hline 43 & Chemotaxis_CCR4-induced leukocyte adhesion & 1,269E-01 & 130 & \\
\hline 44 & Apoptosis and survival_Granzyme A signaling & $1,269 \mathrm{E}-01$ & 130 & \\
\hline 45 & $\begin{array}{l}\text { Regulation of lipid metabolism_FXR-dependent negative-feedback regulation of bile acids concen- } \\
\text { tration }\end{array}$ & $1,308 \mathrm{E}-01$ & 131 & \\
\hline 46 & Development_HGF-dependent inhibition of TGF-beta-induced EMT & $1,348 \mathrm{E}-01$ & 132 & \\
\hline 47 & Development_Angiotensin signaling via STATs & $1,348 \mathrm{E}-01$ & 132 & \\
\hline 48 & Cell cycle_Start of DNA replication in early S phase & $1,348 \mathrm{E}-01$ & 132 & \\
\hline 49 & Development_Angiotensin activation of ERK & $1,387 \mathrm{E}-01$ & 133 & \\
\hline 50 & G-protein signaling_N-RAS regulation pathway & 1,387E-01 & 133 & \\
\hline
\end{tabular}




\section{References}

1. Nickerson, M.L., et al., Improved identification of von Hippel-Lindau gene alterations in clear cell renal tumors. Clin Cancer Res, 2008. 14(15): p. 4726-34.

2. Varela, I., et al., Exome sequencing identifies frequent mutation of the SWI/SNF complex gene PBRM1 in renal carcinoma. Nature, 2011. 469(7331): p. 539-542.

3. Xia, W., et al., BAF180 is a critical regulator of p21 induction and a tumor suppressor mutated in breast cancer. Cancer Res, 2008. 68(6): p. 1667-74.

4. Dalgliesh, G.L., et al., Systematic sequencing of renal carcinoma reveals inactivation of histone modifying genes. Nature, 2010. 463(7279): p. 360-3.

5. Schuebel, K.E., et al., Comparing the DNA hypermethylome with gene mutations in human colorectal cancer. PLoS Genet, 2007. 3(9): p. 1709-23.

6. McGarvey, K.M., et al., Defining a chromatin pattern that characterizes DNAhypermethylated genes in colon cancer cells. Cancer Res, 2008. 68(14): p. 5753-9.

7. Smyth, G.K., Limma: linear models for microarray data. Bioinformatics and Computational Biology Solutions using R and Bioconductor, R. 2005, Springer: New York. p. 397-420.

8. Langmead, B., et al., Ultrafast and memory-efficient alignment of short DNA sequences to the human genome. Genome Biol, 2009. 10(3): p. R25.

9. Derks, S., et al., Methylation-specific PCR unraveled. Cell Oncol, 2004. 26(5-6): p. 291-9.

10. Herman, J.G., et al., Methylation-specific PCR: a novel PCR assay for methylation status of CpG islands. Proc Natl Acad Sci U S A, 1996. 93(18): p. 9821-6.

11. van Engeland, M., et al., K-ras mutations and RASSF1A promoter methylation in colorectal cancer. Oncogene, 2002. 21(23): p. 3792-5.

12. Brinkman, A.B., et al., Whole-genome DNA methylation profiling using MethylCap-seq. Methods, 2010. 52(3): p. 232-236.

13. van Vlodrop, I.J., et al., Analysis of promoter CpG island hypermethylation in cancer: location, location, location! Clin Cancer Res, 2011.

14. Hanahan, D. and R.A. Weinberg, The hallmarks of cancer. Cell, 2000. 100(1): p. 57-70.

15. Hanahan, D. and R.A. Weinberg, Hallmarks of cancer: the next generation. Cell, 2011. 144(5): p. 646-74.

16. Reiner, S.L., Epigenetic control in the immune response. Hum Mol Genet, 2005. $14 \mathrm{Spec}$ No 1: p. R41-6.

17. Sigalotti, L., et al., Epigenetic modulation of solid tumors as a novel approach for cancer immunotherapy. Semin Oncol, 2005. 32(5): p. 473-8.

18. Meissner, M., et al., Loss of interferon- $\gamma$ inducibility of the MHC class II antigen processing pathway in head and neck cancer: evidence for post-transcriptional as well as epigenetic regulation. British Journal of Dermatology, 2008. 158(5): p. 930-940.

19. Serrano, A., et al., Rexpression of HLA class I antigens and restoration of antigen-specific CTL response in melanoma cells following 5-aza-2'-deoxycytidine treatment. International Journal of Cancer, 2001. 94(2): p. 243-251.

20. Mora-Garcia Mde, L., et al., Up-regulation of HLA class-I antigen expression and antigenspecific CTL response in cervical cancer cells by the demethylating agent hydralazine and the histone deacetylase inhibitor valproic acid. J Transl Med, 2006. 4: p. 55.

21. Schulz, W.A., et al., Factor interaction analysis for chromosome 8 and DNA methylation alterations highlights innate immune response suppression and cytoskeletal changes in prostate cancer. Mol Cancer, 2007. 6: p. 14.

22. Lu, R., et al., Regulation of the promoter activity of interferon regulatory factor-7 gene. Activation by interferon snd silencing by hypermethylation. J Biol Chem, 2000. 275(41): p. 31805-12. 
23. Karpf, A.R., et al., Inhibition of DNA methyltransferase stimulates the expression of signal transducer and activator of transcription 1, 2, and 3 genes in colon tumor cells. Proc Natl Acad Sci U S A, 1999. 96(24): p. 14007-12.

24. Katzenellenbogen, R.A., S.B. Baylin, and J.G. Herman, Hypermethylation of the DAP-kinase CpG island is a common alteration in B-cell malignancies. Blood, 1999. 93(12): p. 4347-53.

25. Kulaeva, O.I., et al., Epigenetic silencing of multiple interferon pathway genes after cellular immortalization. Oncogene, 2003. 22(26): p. 4118-4127.

26. Reu, F.J., et al., Overcoming resistance to interferon-induced apoptosis of renal carcinoma and melanoma cells by DNA demethylation. J Clin Oncol, 2006. 24(23): p. 3771-9.

27. Larue, L. and A. Bellacosa, Epithelial-mesenchymal transition in development and cancer: role of phosphatidylinositol 3' kinase/AKT pathways. Oncogene, 2005. 24(50): p. 7443-54.

28. Yan, W., et al., PI3 kinase/Akt signaling mediates epithelial-mesenchymal transition in hypoxic hepatocellular carcinoma cells. Biochem Biophys Res Commun, 2009. 382(3): p. 6316.

29. Tun, H.W., et al., Pathway signature and cellular differentiation in clear cell renal cell carcinoma. PLoS One, 2010. 5(5): p. e10696.

30. Boyer, B., A.M. Valles, and N. Edme, Induction and regulation of epithelial-mesenchymal transitions. Biochem Pharmacol, 2000. 60(8): p. 1091-9.

31. Leary, R.J., et al., Integrated analysis of homozygous deletions, focal amplifications, and sequence alterations in breast and colorectal cancers. Proc Natl Acad Sci U S A, 2008. 105(42): p. 16224-9.

32. Wood, L.D., et al., The genomic landscapes of human breast and colorectal cancers. Science, 2007. 318(5853): p. 1108-13.

33. Yuan, T.L. and L.C. Cantley, PI3K pathway alterations in cancer: variations on a theme. Oncogene. 27(41): p. 5497-5510.

34. Porta, C. and R.A. Figlin, Phosphatidylinositol-3-kinase/Akt signaling pathway and kidney cancer, and the therapeutic potential of phosphatidylinositol-3-kinase/Akt inhibitors. J Urol, 2009. 182(6): p. 2569-77.

35. Sourbier, C., et al., The phosphoinositide 3-kinase/Akt pathway: a new target in human renal cell carcinoma therapy. Cancer Res, 2006. 66(10): p. 5130-42.

36. Kondo, K.-i., et al., PTEN/MMAC1/TEP1 mutations in human primary renal-cell carcinomas and renal carcinoma cell lines. International Journal of Cancer, 2001. 91(2): p. 219-224.

37. Sükösd, F., et al., Allelic loss at 10q23.3 but lack of mutation of PTEN/MMAC1 in chromophobe renal cell carcinoma. Cancer Genetics and Cytogenetics, 2001. 128(2): p. 161-163.

38. Velickovic, M., et al., Intragenic PTEN/MMAC1 loss of heterozygosity in conventional (clearcell) renal cell carcinoma is associated with poor patient prognosis. Mod Pathol, 2002. 15(5): p. 479-85. 


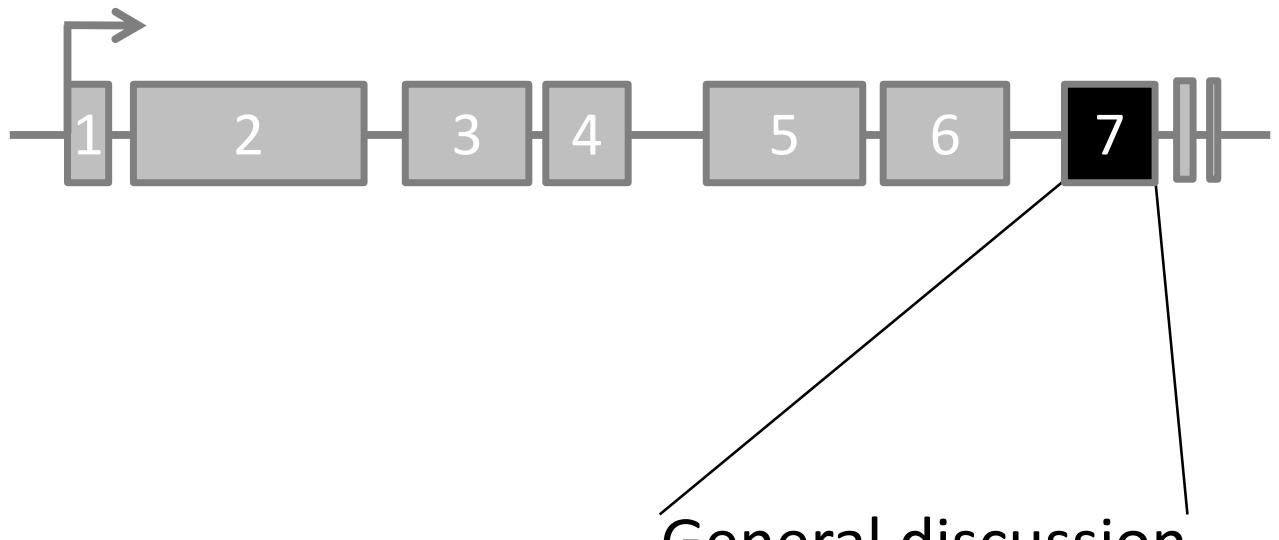

General discussion 


\section{General discussion and future research}

RCC is the most frequent malignant tumor of the kidney in adults. It has an unpredictable course and is the most lethal of all genitourinary malignancies, mostly because of a lack of clinical symptoms and diagnosis in a late stage. The classical triad (flank pain, hematuria and an abdominal mass) only occurs in about $10 \%$ of cases, and is generally indicative of advanced disease. The majority of renal tumors is asymptomatic and is detected incidentally by abdominal imaging, usually for an unrelated cause.

In the 1980s, genitourinary oncologists expressed skepticism about any success in the treatment of advanced RCC, as none of the current therapeutic options at that time could provide any clinical benefit ${ }^{1,2}$. Since then, major advances have been accomplished in the field of RCC, especially in the last two decades. In 1992, the use of highdose Interleukine-2 was approved for the treatment of advanced RCC patients. Just one year later, the $V H L$ gene was identified and linked to some forms of hereditary and sporadic renal cancer ${ }^{3}$, which, as we now know, drastically increased the knowledge on renal carcinogenesis and provided new therapeutic options for advanced RCC patients. Developing knowledge regarding genetic and epigenetic changes in oncogenesis and tumor progression is becoming increasingly important as a prerequisite for improved efficacy of disease management. While abnormal VHL functioning plays a key role, the variable nature of RCC is most likely determined by the complex interplay of additional (epi)genomic modifications, among which the role of epigenetic alteration of gene expression is becoming more and more acknowledged. VHL promoter hypermethylation and subsequent VHL silencing in RCC was one of the first examples of this phenomenon ${ }^{4}$ and so far approximately 60 genes have been suggested to be epigenetically dysregulated in $\mathrm{RCC}^{5}$. Our intention was to further elucidate functional DNA methylation modifications, as one of the major epigenomic players in clear cell renal cancer. This holds great promise to increase the knowledge on tumor biology which might translate into epigenetic biomarkers for early detection and diagnosis, and prediction of progression of the most common type of RCC.

As reviewed in chapter 2, RCC does not constitute one single entity since RCCs are highly heterogeneous in terms of histology, clinical behavior, genotype, prognosis and response to therapy. Therefore, subtyping of RCC is essential, specifically in basic and clinical studies, to elucidate biological characteristics and use these for marker- and therapy development for each of the RCC subtypes. Most studies are focused on the clear cell RCC as this is the most common subtype, allowing easier patient and sample collection. Other subtypes, like papillary type I and II or chromophobe RCC, are much less prevalent and therefore less frequently studied. As a result, guidelines for patient management are only available for ccRCC and the other subtypes are preferably treated in a trial and if such a trial is not available they are mostly treated with treatments initially developed for ccRCC. Nevertheless, in order to elucidate the specific characteristics of their biology study of subtypes needs to be undertaken. In this thesis, we focused on the clear cell subtype in view of the characteristics of the case series available.

In the past few years, investigators in the field of renal cancer mostly have focused, and will continue to focus, on the recently developed and approved targeted therapies. Dozens of randomized clinical trials (RCTs) have been conducted or are underway 
to improve response rates. New therapeutic approaches target the high angiogenic potential of ccRCC which is a result of the abnormal functioning of the VHL gene. Since the discovery of $V H L$ and its linkage to RCC in 1993, few additional abnormal genes or pathways have been identified in significant subgroups of (cc)RCC patients, despite recent technical developments that allow massive sequencing. Research targeting the $V H L$ pathway continues, but validated biomarkers to guide decisions on treatment of RCC patients through prognostic or predictive biomarkers are painfully lacking.

The genetic profile of (cc)RCC appears distinctive compared to other epithelial carcinomas, with aberrant $V H L$ signaling as a characteristic particular for ccRCC and lack of mutations in most known cancer genes. Except for the recently discovered PBRM1 gene ${ }^{6}$, previous exploration of the ccRCC genome has not yielded new major discoveries in the RCC biology or molecular biomarkers. Whether the epigenetic profile of RCC is also distinctive remains elusive and the epigenome has yet to be fully discovered. We decided to explore the so-called promoter hypermethylome and its role in ccRCC development and potentially clinical management of this neoplasm. In chapter 6 we initiated the comparison of the renal, colorectal and breast cancer methylomes. To this point, similar processes seem to be affected by DNA hypermethylation in cancer in general, which can be specifically regulated by several genes in different cancer types. The RCC methylome does not appear to be different in terms of size or affected processes, as analyzed thus far. Additional analyses will shed more extensive light on these issues.

The study of aberrant DNA methylation might yield novel biological insight as well as provide new biomarkers. In our initial experimental study (chapter 3), we used a pharmacological approach to indirectly identify putative tumor suppressor genes silenced by promoter CpG island hypermethylation in ccRCC. We identified the highly conserved Gremlin1 (GREM1) as a candidate gene involved in the development of cCRCC. Further investigation of GREM1 in renal cancer patients suggested that GREM1 has characteristics of a tumor suppressor gene in CCRCC, and that region-specific promoter hypermethylation of GREM1 has an impact on the biology and outcome of this type of cancer with good prospects for use as a prognostic biomarker. However, the details of the role of GREM1 inactivation in tumor progression needs to be further clarified. A first indication of its role in ccRCC carcinogenesis is described in chapter 5. We found that GREM1 attenuates the invasive behavior of the tumor cells, while cell proliferation did not seem to be affected. Expression of GREM1 in the ccRCC cells reduced their ability to (migrate and) invade in vitro. Silencing of GREM1 by promoter CpG island hypermethylation therefore might induce invasiveness and thus be involved in the progression of the ccRCC.

The observation that region-specific hypermethylation correlates with clinical parameters and prognosis for GREM1 suggests an extra layer of complexity in DNA methylation research. In order to elucidate the general importance of this phenomenon, we evaluated the current literature on the effects of location-specific DNA methylation on gene expression and/or associations with clinicopathological characteristics in cancer (chapter 4). The exact location of biologically and clinically relevant hypermethylation has not been identified for the majority of methylation markers, as the choice of the region to be studied was based upon considerations of primer design rather than biological relevance of the region. For validation and relevant interpretation of results, 
and for thoughtful design of future DNA methylation analyses, the classical dogma of promoter $\mathrm{CpG}$ island hypermethylation and gene silencing needs to be revised and detailed. In chapter 4 we clarify the misconception and oversimplification of hypermethylation and gene silencing in cancer, in an attempt to better understand the complexity and significance of location in DNA methylation. We expect that this approach will ultimately lead to accurate identification of biologically and clinically relevant location of DNA methylation and will enable translation of data into validated biomarker assays.

Once we realized the importance of location and disposed of novel technologies to study DNA methylation genome-wide, we extended our approach to identify biologically relevant DNA methylation markers in ccRCC. In chapter 5 we integrated the indirect pharmacological re-expression approach and the novel next-generation sequencing-based method to identify biological relevant progression markers. Methylated tumor DNA pulled down by methyl-binding proteins was massively sequenced and compared with methylation enriched DNA of normal kidney cells. Using this approach of gene selection, in combination with the expression status after demethylation of tumor DNA resulted in a list of candidate genes highly probably tumor-specifically silenced by DNA hypermethylation. In addition to GREM1, we identified promoter CpG island hypermethylation of Neuralized (NEURL), Ladinin1 (LAD1), and Neurofilament heavy polypeptide (NEFH) as potential biomarkers with prognostic value in cCRCC. Because of the known role of the Notch pathway in embryogenesis and nephrogene$\mathrm{sis}^{7}$, we investigated the role of NEURL (which is a relative minimal unraveled member of the Notch-pathway) in ccRCC, as we had done for GREM1 which is also known for its role in nephrogenesis ${ }^{8,9}$. Using several methods to assess tumor growth we found that expression of NEURL in CCRCC cells significantly reduced cell proliferation in vitro (chapter 5), but did not modify migration or invasion of the cells. Silencing of NEURL by promoter $\mathrm{CpG}$ island hypermethylation might stimulate proliferation and thus induce tumor growth, explaining the correlation with poor prognosis. The combined results of tumor suppressive activity of GREM1 (affecting (migration and) invasion) and NEURL (affecting proliferation) in ccRCC cells suggests a complementary role for these genes in tumor progression. Indeed, survival of cCRCC patients with both GREM1 and NEURL promoter hypermethylation in the tumor was significantly worse as compared to cCRCC patients without or with only one of the gene promoters methylated. Similarly, the risk of cancer-related death was increased in case of hypermethylation of both promoters. This suggests that the simultaneous hypermethylation of multiple promoters has a synergistic effect on tumor progression. Hypermethylation of both gene promoters was independent of $V H L$ mutation or hypermethylation, suggesting that VHL abnormalities can initiate neoplastic transformation, but additional aberrations are responsible for growth and further progression. Accumulation of disrupted pathways in the tumor can enhance the neoplastic propensity and create a microenvironment beneficial for the tumor to grow and metastasize. Furthermore, pathways could integrate downstream to regulate other or additional genes that enhance tumor progression. Although both Notch and the BMP signaling pathways are important in embryogenesis, details about the mechanisms involved and possible interactions between Notch and BMP signaling need to be clarified. In many cases the two pathways act similarly, but it is not known whether this is by distinct mechanisms or by interplay 
between Notch and BMP signaling. Few papers reported a cross-talk in downstream signaling and both synergy and antagonism has been described between these pathways $^{10-12}$. It is an emerging concept that cellular behavior not only depends on the effect of a particular signaling pathway, but possibly also on the integration of signals from multiple pathways. This enables the cell to respond to a more complex repertoire of signals, and to integrate this information into the large variety of responses a cell can elaborate. Our analyses in chapter 6 suggest a novel path connecting epigenetic (indirect) regulation of the PI3K pathway and/or its cross-talk to other signaling pathways with epithelial to mesenchymal transition (EMT), which has not been described before. The top 50 of pathways with genes specifically regulated by promoter hypermethylation in ccRCC, represented enrichment for genes in or linked to PI3K pathway, implicating cross-talk of the PI3K/Akt pathway with other pathways relevant to cCRCC. One of these connections may result in $\mathrm{EMT}^{13,14}$, which is one of the characteristics of CCRCC $^{15}$. The PI3K/Akt pathway has been emerged as a central feature of EMT and repression of the E-cadherin gene $(C D H 1)$ is one of its major characteristics ${ }^{13}$. This finding needs to be unraveled in the future.

Possible roles of $L A D 1$ and NEFH in RCC carcinogenesis or progression remain to be investigated. The neurofilament heavy chain encoded by NEFH is known to be one of the major components of the neuronal cytoskeleton neurofilaments ${ }^{16}$ and the relatively unknown protein Ladinin1 encoded by the $L A D 1$ gene is an anchoring filament that is a component of basement membranes ${ }^{17}$. These genes may contribute to cell structure and stability and/or the association with the surrounding mesenchyme. EMT has been suggested to be involved in progressed renal cancer via several processes ${ }^{15,}{ }^{18-20}$. Whether EMT as a putative consequence of loss of LAD1 and/or NEFH could be involved in RCC progression needs to be explored further. Together with the induction of proliferation, migration and invasion by NEURL and GREM1 promoter hypermethylation, respectively, hypermethylation of $L A D 1$ and NEFH might modify cell characteristics to stimulate motility. Combined, these pathways then enable the tumor to progress and metastasize with profound effects on patient survival.

$\angle A D 1$ and NEFH promoter hypermethylation indeed strongly amplified the association of GREM1 and NEURL promoter hypermethylation with prognosis. Hypermethylation of all four genes defines a highly significant prognostic event which is potentially clinically applicable for the management of ccRCC. As two-third of the ccRCC patients present without metastasis, these will undergo resection of the primary tumor with curative intention. Half of these patients will relapse, but currently there is no indicator that can predict how an individual patient will fare after surgery. Using the four marker panel, we might be able to divide ccRCC in different molecular diseases. This segmentation will make it possible to select those patients who have a strongly increased risk to cancer-related death, probably due to the existence of undetectable micrometastases. This simple molecular test could select those patients which are likely to benefit from adjuvant (targeted) therapy, improving renal cancer management. The significance of the four marker panel in daily clinical practice needs to be validated in tumor material from a prospectively collected cohort of ccRCC patients after surgery and subsequently in a large RCT.

Other potential biomarkers, related to the $V H L$ pathway (VHL, HIF, VEGF(R), and CAIX) or the mTOR pathway ( $p S 6, P T E N$, and $p A K T)$, have been studied for their prognostic or 
predictive value but all lack clinical impact and have not contributed to current clinical decision-making ${ }^{21}$. This is not only observed in renal cancer biomarker research but is a general phenomenon. Despite hundreds of reports on tumor markers, the number of markers that have emerged as clinically useful is small. Initial studies often show great promise, but inconsistent data of subsequent studies contradict the promising results. It is challenging to face the obstacles in translational research. Some researchers suggest that most published research findings are false, due to poor study design, which is sometimes unavoidable ${ }^{22}$. Methodological, biological and pathological hurdles hinder successful biomarker identification and clinical implementation. A robust biomarker should be specific, biologically relevant and expressed homogeneously. Firstly, the study design should include adequate and appropriate controls, sample collection, storage, and manipulation must be standardized, and statistical limitations by an underpowered study should be avoided. Furthermore, initial findings should be validated in independent cohorts or subsequent studies. The National Cancer Institute-European Organization for Research and Treatment of Cancer (NCl-EORTC) reported guidelines which have been written to enable uniform design and reporting of biomarker studies; the so-called REMARK (REporting recommendations for tumor MARKer prognostic studies) $)^{23}$.

Secondly, newly developed predictive or prognostic assays will need to be multiparametric, as tumor biology often relies on complex signaling pathways with extensive crosstalk and feedback and -forward control.

Thirdly, heterogeneity must be taken into account. It is quite clear that various histological subtypes are very different oncological entities. However, there is also interand intra-tumor heterogeneity within one subtype. Tumors from different patients with similar pathological stage and grade can be very heterogeneous and patients with similar presentations can have very different molecular tumor profiles at genomic or transcriptomic level ${ }^{24,25}$. Within one tumor morphological heterogeneity is also observed. There are areas of dedifferentiation or sarcomatoid changes, but also more subtle areas of morphological variability can occur, which can lead to sampling bias.

Promoter hypermethylation of the four genes we identified in the clear cell subtype of RCC could be a robust prognostic biomarker panel for ccRCC patients. Methylation of these genes is highly tumor specific, expected to be biologically relevant and because of the high-sensitivity of the methylation specific PCR to assess the methylation status, part of the heterogeneity problem becomes irrelevant. Furthermore, whereas a mutation spectrum causing tumor suppressor gene (TSG) inactivation is usually diverse (limiting the utility of mutation-specific detection strategies for tumor screening programs), TSG inactivation by promoter hypermethylation provides a more homogeneous target for molecular screening strategies. Though, sampling error cannot be completely prevented and must always be taken into account in biomarker research. As our initial findings could be validated in an independent population-based cohort and the four genes are involved in various pathways, it is feasible that this panel could succeed into clinical practice. Furthermore, Andre et al. suggested a molecular triage program for biology-driven clinical trials which should fulfill some criteria: 1) the test should be accurate and easy to implement, 2) molecular characterization of several molecular alterations, 3) molecular screening should be independent of the screening phase of the clinical trial, and finally high-throughput technologies are beneficial to 
identify such molecular events ${ }^{26}$. Again, our identified four-marker panel meets these criteria, suggesting a robust selection tool.

In current practice, the Leibovich risk model ${ }^{27}$ can be used to predict disease progression to some extent after patients undergo radical nephrectomy for clinically localized ccRCC. This model represents a scoring algorithm based on tumor stage, regional lymph node status, tumor size, nuclear grade, and histological tumor necrosis and can be used to stratify patients for adjuvant therapy. However, this model just broadly stratifies patients in a low, intermediate, or high risk group.

The currently available systemic therapies for ccRCC, such as the tyrosine kinase inhibitors (TKIs) sorafenib, sunitinib, and pazopanib, the anti-VEGF monoclonal antibody bevacizumab (in combination with IFN $\alpha$ ), and the mTOR inhibitors temsirolimus, everolimus are mostly used for treatment of patients with advanced disease. These palliative treatments elicit clinical benefit (stable disease or response) up to about $50 \%$. As so far predicting factors remain elusive, the different systemic therapies are used in a 'one shoe fit all'-based manner. Therefore, patients are often exposed to multiple treatments. Systemic RCC treatment is accompanied by (sometimes severe) toxicity. In VEGF-directed targeted therapy adverse effects like diarrhea, fatigue, nausea, edema, hypertension, hand-foot syndrome, hematological abnormalities or hypothyroidism are being reported ${ }^{28-30}$. Due to these adverse events a dose reduction is required in 35$50 \%{ }^{31-37}$ of the patients and discontinuation of the treatment is necessary in $15 \%{ }^{32,35}$ of the patients. Non-responding patients encounter a reduction in quality of life without compensation of disease stabilization, partial or complete response or improvement in terms of progression-free or overall survival.

Furthermore, TKls used in mRCC also target a number of tyrosine kinases that are not specifically associated with angiogenesis. The importance of these 'off target' effects in the efficacy and toxicity of the drug are unclear ${ }^{38}$.

Patient- and/or tumor heterogeneity and 'off target' effect might explain the diverse responses to therapy observed in patients with apparently similar tumors. This illustrates the urge to identify biomarkers of response and resistance as well as toxicity to RCC therapy. These will enable identification of those patients who will benefit from specific targeted therapy, thus giving tailored or personalized treatment. The proof of concept for prognostic marker identification using the novel MBD-NGS puts forward a promising tool to identify predictive markers, analyzing tumor tissue from respondingversus non-responding (to a specific therapy) patients.

In conclusion, over the last 20 years researchers have initiated a change in the paradigm of RCC as a disease that was perceived as resistant to any systemic treatment and had very poor outcomes. However, despite great improvements, renal cancer management as currently implemented in the year 2011 needs to be brought to the next level. Exploring the tumor biology will facilitate a basis to indentify biologically and clinically relevant biomarkers. Adequate biomarkers should guide the medical oncologist in decision-making for subsequent treatment after nephrectomy. Specific tumor markers, like our identified four marker panel of promoter methylated genes as described in chapter 5 , can predict patient outcome and patients with a high risk of recurrence or relapse should be selected for adjuvant therapy based on additional mark- 
ers (or marker panels) to predict response and treatment toxicity in a personalized manner. Integration of somatic mutations and/or aberrant DNA methylation and genetic variances could contribute to individualized management of RCC. This thesis provides novel insights in the biology of ccRCC and identified promising biomarkers that predict prognosis of ccRCC. Future in vitro-, in vivo- and marker validation studies are required to confirm the tumor suppressor function of the identified candidates, the biological role of these markers and their potential as biomarkers in ccRCC. 


\section{References}

1. Harris, D.T., Hormonal therapy and chemotherapy of renal-cell carcinoma. Semin Oncol, 1983. 10(4): p. 422-30.

2. Yagoda, A., Chemotherapy of renal cell carcinoma: 1983-1989. Semin Urol, 1989. 7(4): p. 199-206.

3. Latif, F., et al., Identification of the von Hippel-Lindau disease tumor suppressor gene. Science, 1993. 260(5112): p. 1317-20.

4. Herman, J.G., et al., Silencing of the VHL tumor-suppressor gene by DNA methylation in renal carcinoma. Proc Natl Acad Sci U S A, 1994. 91(21): p. 9700-4.

5. Morris, M. and E. Maher, Epigenetics of renal cell carcinoma: the path towards new diagnostics and therapeutics. Genome Med, 2010. 2(9): p. 59.

6. Varela, I., et al., Exome sequencing identifies frequent mutation of the SWI/SNF complex gene PBRM1 in renal carcinoma. Nature, 2011. 469(7331): p. 539-542.

7. Chen, L. and Q. Al-Awqati, Segmental expression of Notch and Hairy genes in nephrogenesis. American Journal of Physiology - Renal Physiology, 2005. 288(5): p. F939-F952.

8. Michos, O., et al., Reduction of BMP4 activity by gremlin 1 enables ureteric bud outgrowth and GDNF/WNT11 feedback signalling during kidney branching morphogenesis. Development, 2007. 134(13): p. 2397-405.

9. Michos, O., et al., Gremlin-mediated BMP antagonism induces the epithelial-mesenchymal feedback signaling controlling metanephric kidney and limb organogenesis. Development, 2004. 131(14): p. 3401-10.

10. Itoh, F., et al., Synergy and antagonism between Notch and BMP receptor signaling pathways in endothelial cells. Embo J, 2004. 23(3): p. 541-51.

11. Blokzijl, A., et al., Cross-talk between the Notch and TGF- $\left.\right|^{2}$ signaling pathways mediated by interaction of the Notch intracellular domain with Smad3. The Journal of Cell Biology, 2003. 163(4): p. 723-728.

12. Dahlqvist, C., et al., Functional Notch signaling is required for BMP4-induced inhibition of myogenic differentiation. Development, 2003. 130(24): p. 6089-99.

13. Larue, L. and A. Bellacosa, Epithelial-mesenchymal transition in development and cancer: role of phosphatidylinositol 3' kinase/AKT pathways. Oncogene, 2005. 24(50): p. 7443-54.

14. Yan, W., et al., PI3 kinase/Akt signaling mediates epithelial-mesenchymal transition in hypoxic hepatocellular carcinoma cells. Biochem Biophys Res Commun, 2009. 382(3): p. 6316.

15. Tun, H.W., et al., Pathway signature and cellular differentiation in clear cell renal cell carcinoma. PLoS One, 2010. 5(5): p. e10696.

16. Lee, M.K. and D.W. Cleveland, Neuronal intermediate filaments. Annu Rev Neurosci, 1996. 19: p. 187-217.

17. Moll, R. and I. Moll, Epidermal adhesion molecules and basement membrane components as target structures of autoimmunity. Virchows Archiv, 1998. 432(6): p. 487-504.

18. Das, S., et al., Complete reversal of epithelial to mesenchymal transition requires inhibition of both ZEB expression and the Rho pathway. BMC Cell Biology, 2009. 10(1): p. 94.

19. Pantuck, A.J., et al., NF-kappaB-dependent plasticity of the epithelial to mesenchymal transition induced by Von Hippel-Lindau inactivation in renal cell carcinomas. Cancer Res, 2010. 70(2): p. 752-61.

20. Rajasekaran, S.A., et al., Na,K-ATPase Subunits as Markers for Epithelial-Mesenchymal Transition in Cancer and Fibrosis. Molecular Cancer Therapeutics, 2010. 9(6): p. 1515-1524.

21. Stewart, G.D., et al., What can molecular pathology contribute to the management of renal cell carcinoma? Nat Rev Urol, 2011. advance online publication.

22. Ioannidis, J.P., Why most published research findings are false. PLoS Med, 2005. 2(8): p. e124. 
23. REporting recommendations for tumor MARKer prognostic studies (REMARK). Nat Clin Prac Oncol, 2005. 2(8): p. 416-422.

24. Dalgliesh, G.L., et al., Systematic sequencing of renal carcinoma reveals inactivation of histone modifying genes. Nature, 2010. 463(7279): p. 360-3.

25. Kan, Z., et al., Diverse somatic mutation patterns and pathway alterations in human cancers. Nature, 2010. 466(7308): p. 869-873.

26. Andre, F., S. Delaloge, and J.C. Soria, Biology-driven phase II trials: what is the optimal model for molecular selection? J Clin Oncol, 2011. 29(10): p. 1236-8.

27. Leibovich, B.C., et al., Prediction of progression after radical nephrectomy for patients with clear cell renal cell carcinoma. Cancer, 2003. 97(7): p. 1663-1671.

28. Di Lorenzo, G., et al., Toxicities of targeted therapy and their management in kidney cancer. Eur Urol, 2011. 59(4): p. 526-40.

29. Hutson, T.E., et al., Targeted therapies for metastatic renal cell carcinoma: an overview of toxicity and dosing strategies. Oncologist, 2008. 13(10): p. 1084-96.

30. Xu, C.F., et al., Pazopanib efficacy in renal cell carcinoma: evidence for predictive genetic markers in angiogenesis-related and exposure-related genes. J Clin Oncol, 2011. 29(18): p. 2557-64.

31. Akaza, H., et al., Phase II Study to Investigate the Efficacy, Safety, and Pharmacokinetics of Sorafenib in Japanese Patients with Advanced Renal Cell Carcinoma. 2007. 37(10): p. 755762.

32. Escudier, B., et al., Phase II Study of Sunitinib Administered in a Continuous Once-Daily Dosing Regimen in Patients With Cytokine-Refractory Metastatic Renal Cell Carcinoma. 2009. p. 4068-4075.

33. Escudier, B., et al., Randomized Phase II Trial of First-Line Treatment With Sorafenib Versus Interferon Alfa-2a in Patients With Metastatic Renal Cell Carcinoma. 2009. p. 1280-1289.

34. Gore, M.E., et al., Safety and efficacy of sunitinib for metastatic renal-cell carcinoma: an expanded-access trial. The Lancet Oncology, 2009. 10(8): p. 757-763.

35. Motzer, R.J., et al., Overall Survival and Updated Results for Sunitinib Compared With Interferon Alfa in Patients With Metastatic Renal Cell Carcinoma. 2009. 27(22): p. 3584-3590.

36. Motzer, R.J., et al., Sunitinib in Patients With Metastatic Renal Cell Carcinoma. 2006. 295(21): p. 2516-2524.

37. Zhang, H., et al., Efficacy of sorafenib on metastatic renal cell carcinoma in Asian patients: Results from a multicenter study. 2009. 9(1): p. 249.

38. Khurdayan, V.K., Take-home message: are we "off target"? Drug News Perspect, 2007. 20(5): p. 345-51. 


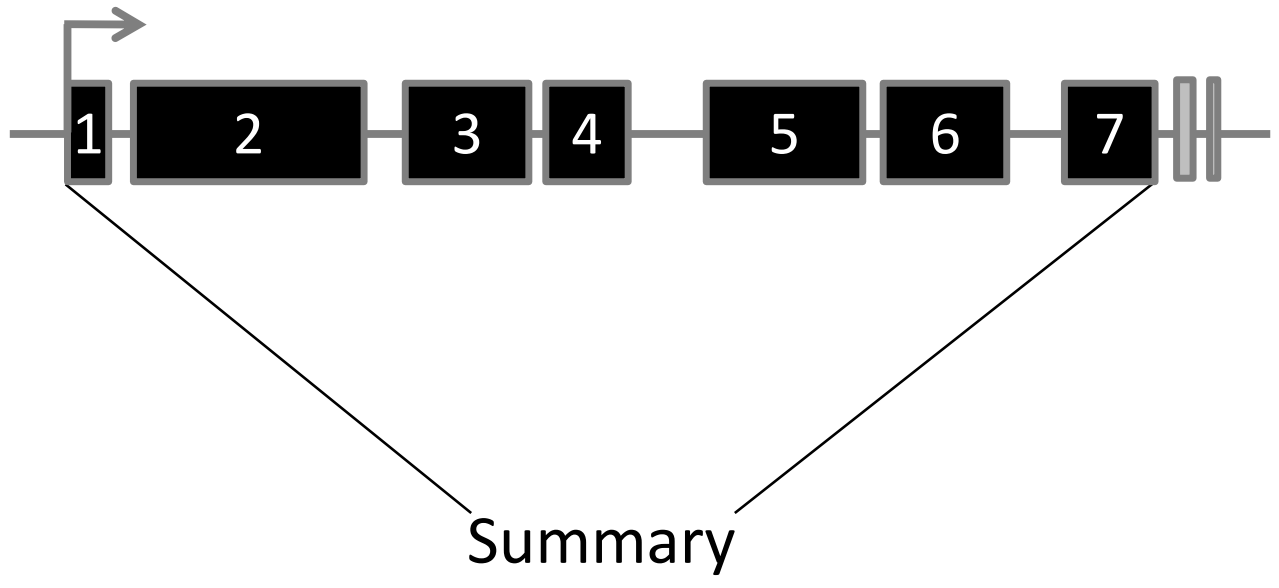


Renal cell cancer (RCC) represents the vast majority (80-85\%) of all kidney tumors in adults. Although it is the most common and best studied type of kidney cancer, it still has an unpredictable course. In case of localized disease, RCC can be curable with surgery, but for those patients with distant metastases the prognosis is poor. Because of lack of clinical symptoms RCC may be difficult to detect in an early stage. Approximately $30 \%$ of all RCC patients have metastatic disease at time of diagnosis and in another $30 \%$ of patients recurrence develops after complete resection of the primary tumor. Current surgical and pharmaceutical interventions have limited success in treating patients with advanced RCC. Thanks to improved understanding of the molecular biology of metastatic RCC (mRCC), since 2005, drugs have been developed specifically targeting angiogenesis. Developing knowledge of genetic and epigenetic changes implicated in tumor development and behavior is becoming increasingly important for advancing the efficacy of disease management. Chapter 1 enlightens the current situation in RCC management.

As the biology of RCC is incompletely understood and biomarkers for RCC are lacking, our main aim of this thesis was to address these issues. Defective VHL functioning appears to be the key event, in both hereditary and sporadic cases. However, the variable nature of the resulting neoplasm is most likely strongly determined by the complex interplay of additional downstream modifications, among which the role of epigenetic alteration of gene expression is becoming more and more acknowledged.

In chapter $\mathbf{2}$ we provide an overview of RCC, which comprises a group of tumors of renal epithelial origin, each with a different histology, displaying a different clinical course and caused by different genetic alterations. The histologically classified clear cell subtype (ccRCC) is the most frequent form (60-80\%) of RCC followed by papillary type I and type II (pRCC, 10-15\%) and the chromophobe subtype (chrRCC, 5-10\%). The background of RCC, as well as the genetics, epigenetics and the clinical applications are discussed.

Elucidation of epigenetic modifications in RCC holds great promise for novel insights in biology and identification of biomarkers. DNA methylation is the best known epigenetic alteration with promising biomarker potential. Substantial proof of principle for the clinical value of hypermethylation markers in cancer has been reported, with some already having demonstrated their importance in (pre)clinical practice. We hypothesized that genome-wide studying the DNA methylation changes in the most common type of RCC, the so-called ccRCC methylome, will gain insight into ccRCC biology and identify methylation marks that are associated with prognosis of RCC patients and can be developed into clinically useful disease markers. Using state of the art technologies to analyze tumor specific DNA methylation in ccRCC, we identified promoter hypermethylation of candidate tumor suppressor genes as described chapter $\mathbf{3}$ and $\mathbf{5}$. The four identified genes, Gremlin1 (GREM1), Ladinin1 (LAD1), neurofilament heavy polypeptide (NEFH), and Neuralized (NEURL), of which promoter CpG island hypermethylation was strongly predictive for ccRCC survival in two independent series ( $n=150$ and $n=185)$ of cCRCC primary samples, also indicated an increased prognostic effect when methylated simultaneously. The four markers combined are strongly associated with risk for cancer-related death in the test series as well as, independently of other clinicopathological characteristics, in the validation series. This results in a promising methylation 
marker panel to predict prognosis of ccRCC patients after surgery. Identification of this group of high risk patients could direct adjuvant treatment trials to patients with subclinical metastatic disease to improve disease management and increase RCC survival. Besides the prognostic effects of these genes, we also investigated their functional role in ccRCC in vitro (chapter 5), as robust biomarkers should be specific and biologically relevant. Biological assessment of GREM1 and NEURL in ccRCC cells suggested that these genes have complementary tumor suppressor activity in RCC. NEURL inhibited colony-formation and cell proliferation whereas GREM1 inhibited migration and invasion. Biological assessment of LAD1 and NEFH in RCC cells gave ambiguous results about the effect on proliferation, migration or invasion in vitro, providing only weak evidence for a tumor suppressor effect when compared to the data for GREM1 and NEURL. Therefore we should be careful in drawing conclusions from these latter data.

Comprehensively studying the promoter methylation pattern of GREM1 as described in chapter 3 showed that only region-specific hypermethylation correlates with clinical parameters and prognosis. This suggested an important extra layer of complexity in DNA methylation research. In order to elucidate the general importance of this phenomenon, we evaluated the current literature on the effects of location-specific DNA methylation on gene expression and/or associations with clinicopathological characteristics in cancer. In chapter 4 we clarify the misconception and oversimplification of hypermethylation and gene silencing in cancer, in an attempt to better understand the complexity and significance of location in DNA methylation. We expect that this approach will ultimately lead to accurate identification of biologically and clinically relevant location of DNA methylation and will enable translation of data into validated biomarker assays.

In the final experimental study of this thesis (chapter 6) we initiated to unravel the question whether the ccRCC methylome is distinctive from the methylomes of other epithelial cancers, as the genetic profile of (cc)RCC appears to be rather unique. Using the novel technologies as described in chapter 5 we compared the renal cell, colorectal and breast cancer methylomes. The ccRCC methylome does not appear to be different in terms of size or affected processes, as analyzed thus far. We identified conserved targeting of critical pathways through unique DNA hypermethylated events in the three analyzed cancer types. Additional analyses will shed more extensive light on these issues, however these initial analyses appeared powerful and permits the identification of genes and pathways that may not be easily detected by other approaches.

Chapter 7 summarizes the major findings of the presented studies and future directions are discussed. In conclusion, this thesis provides an overview of the current knowledge on RCC genetics and epigenetics with its implications for disease management. Despite great improvements, renal cancer management urgently needs to be brought to the next level. The work herein described provides novel insights in DNA methylation analyses, in the biology of $\mathrm{CCRCC}$ and identified promising biomarkers that predict prognosis of ccRCC. Future in vitro-, in vivo and marker validation studies are required to confirm the tumor suppressor function of the identified candidates, the biological role of these markers and their potential as biomarkers in ccRCC. The ulti- 
mate challenge will be to truly personalize RCC treatment using markers to predict not only prognosis but also response as well as toxicity to therapy. 


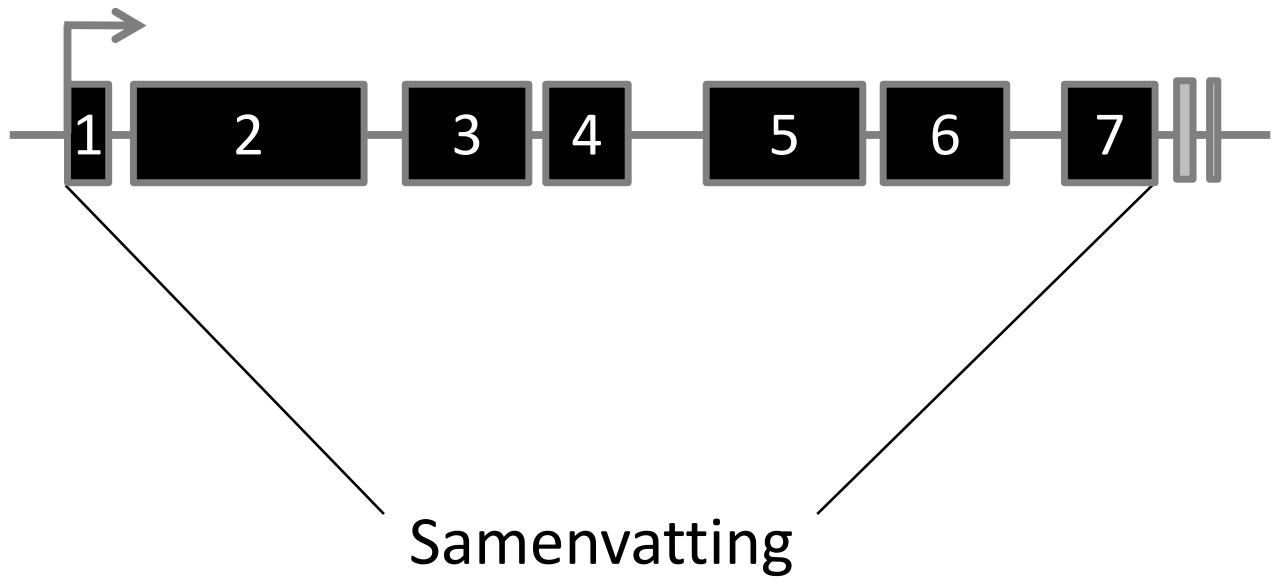


Niercelkanker is bij volwassenen de meest voorkomende (80-85\%) tumorsoort van de nier. Hoewel deze vorm van nierkanker het meest bestudeerd is, blijft het verloop onvoorspelbaar. Wanneer de ziekte beperkt blijft tot de nier zelf kan het genezen worden door chirurgie. Echter, patiënten met gemetastaseerde ziekte hebben een slechte prognose. Doordat klinische symptomen vaak afwezig zijn is het moeilijk om niercelkanker in een vroeg stadium te ontdekken. Ongeveer $30 \%$ van alle niercelkankerpatienten hebben al metastases op het moment van diagnose en daarnaast zal nog eens $30 \%$ van de patiënten recidiveren nadat de gehele primaire tumor chirurgisch verwijderd is. De huidige chirurgische en farmaceutische behandelingen zijn niet erg succesvol bij de behandeling van niercelkanker in een (ver)gevorderd stadium. Echter, dankzij recentelijk nieuwe inzichten in de moleculaire biologie van niercelkanker zijn sinds 2005 nieuwe therapieën ontwikkeld, die specifiek de vorming van nieuwe bloedvaten in de tumor remmen en daarmee de groei van de tumor belemmeren. Nieuwe ontwikkelingen op het gebied van de kennis over genetische en epigenetische veranderingen die van belang zijn bij het ontstaan en het gedrag van kanker worden steeds belangrijker voor het verbeteren van de behandeling van tumoren. Een uiteenzetting van de huidige situatie met betrekking tot de behandeling van niercelkanker is beschreven in hoofdstuk 1 van dit proefschrift.

De biologie van niercelkanker is nog niet volledig bekend en momenteel zijn er nog geen biomarkers beschikbaar om het beloop van de ziekte te voorspellen. De belangrijkste doelstelling van dit proefschrift was dan ook om dit te onderzoeken. Een verminderde of defecte functie van het VHL eiwit blijkt een sleutelrol te spelen in het ontstaan van zowel de erfelijke als de niet-erfelijke vorm van niercelkanker. Echter, het wisselend verloop van de ziekte bij patiënten die allen tumoren hebben die zijn ontstaan nadat VHL is uitgeschakeld, geeft aan dat een complex samenspel van bijkomende veranderingen gaande is. Meer en meer wordt hierbij een rol van de epigenetica erkend.

In hoofdstuk 2 wordt een overzicht gegeven van niercelkanker, dat uit een groep van tumoren bestaat die allen afkomstig zijn van het nierepitheel. Elke afzonderlijke groep heeft een andere histologie, heeft een ander beloop van de ziekte en wordt door verschillende genetische afwijkingen veroorzaakt. Het histologisch geclassificeerde heldercellig niercelcarcinoom is het meest voorkomende type niercelkanker, gevolgd door het papillaire type I en type II en het chromofobe type van niercelkanker. De achtergrond van niercelkanker, de genetica en de epigenetica wordt beschreven en de klinische toepasbaarheid hiervan wordt bediscussieerd.

Veelbelovende nieuwe inzichten in de epigenetische afwijkingen van niercelkanker kan de biologische achtergrond verduidelijken en kan leiden tot de identificatie van biomarkers. Afwijkingen in DNA methylering is de meest bekende en onderzochte epigenetische verandering in kanker en heeft veelbelovende mogelijkheden om als biomarker te dienen. Methylering van de promoter van een gen kan leiden tot uitschakeling van dit specifieke gen. Bevestiging van de theorie dat deze kenmerken in kanker van klinisch belang kunnen zijn is al uitgebreid beschreven in de literatuur en een aantal worden zelfs al in de kliniek gebruikt. Wij veronderstellen dat het bestuderen van alle veranderingen aan het DNA door methylering in het heldercellig niercelcarcinoom, het zogenaamde methyloom, zal zorgen voor een beter inzicht in de tumorbiologie en voor 
het ontdekken van kenmerken die geassocieerd zijn met prognose van niercelkankerpatiënten. Gebruikmakend van de nieuwste technologieën om tumorspecifieke DNA methylering in niercelkanker te analyseren hebben we genen ontdekt die specifieke methylering vertonen in de promoteren van deze genen, die mogelijk ook een tumoronderdrukkende functie bezitten. De identificatie van deze genen is beschreven in hoofdstuk 3 en 5. Van de vier genen die op deze manier ontdekt zijn, Gremlin1 (GREM1), Ladinin1 (LAD1), neurofilament heavy polypeptide (NEFH), and Neuralized (NEURL), heeft promoter methylering een sterk voorspellende waarde voor de overleving van nierkankerpatiënten. Dit is bewezen in twee grote onafhankelijke groepen ( $n=150$ en $n=185$ ) van primair nierkankerweefsel. Wanneer de promotoren van deze vier genen tegelijkertijd gemethyleerd zijn hebben patiënten een sterk verhoogd risico om aan de ziekte te overlijden. Dit is zowel in de eerste groep als ook, onafhankelijk van andere klinische en pathologische tumorkenmerken, in de tweede groep gevonden. Het resultaat is een veelbelovend methylerings-marker panel dat de prognose van niercelkankerpatiënten voorspelt nadat deze chirurgie hebben ondergaan. Het herkennen van deze groep patiënten met een hoog risico op overlijden kan bijdragen aan de ontwikkeling van nieuwe onderzoeken met patiënten die na de chirurgische ingreep adjuvant behandeld worden om de overlevingskansen te vergroten.

Aangezien we aannemen dat goede biomarkers ook biologisch relevant zijn, hebben we de functionele rol bestudeerd van deze genen in het heldercellig niercelcarcinoom (hoofdstuk 5). Deze data suggereren een complementaire tumoronderdrukkende rol van NEURL en GREM1. NEURL zorgt voor het remmen van de tumorgroei en GREM1 zorgt ervoor dat de tumorcellen minder goed zullen migreren en invaderen. Het uitschakelen van deze genen in de tumor door bijvoorbeeld promoter methylering zorgt er dus voor dat de tumor kan groeien en zich kan verspreiden. Het bestuderen van de biologische functie van $L A D 1$ en $N E F H$ in cellen van het heldercellig niercelcarcinoom gaf geen eenduidig resultaat betreffende hun rol in tumorgroei en/of verspreiding. Hierdoor kunnen momenteel geen duidelijke conclusies getrokken worden met betrekking tot hun functie in het heldercellig niercelcarcinoom.

Het uitgebreid bestuderen van de promoter methylering van het gen GREM1, zoals beschreven in hoofdstuk 3, laat zien dat regiospecifieke methylering van belang is bij de associatie met klinische parameters en prognose. Deze belangrijke observatie suggereert dat onderzoek doen naar methylering complexer blijkt dan voorheen gedacht. Om het belang van deze bevinding beter te bestuderen, hebben we de bestaande literatuur doorzocht op soortgelijke effecten van locatiespecifieke DNA methylering met betrekking tot genexpressie en/of associaties met klinische en pathologische kenmerken van kanker. In hoofdstuk 4 verklaren we de misvatting en het versimpelen van de link tussen methylering en het onderdrukken van de genexpressie, zoals die in de huidige literatuur vaak aanwezig is. Hierdoor willen we het begrip van de complexiteit verbeteren en het belang van locatie in onderzoek naar methylering toelichten en benadrukken. Uiteindelijk zal dit leiden tot zeer accurate identificatie van biologisch en klinisch relevante locaties van DNA methylering, wat deze data geschikt maakt voor gebruik in de kliniek. 
In het laatste experimentele onderzoek, beschreven in hoofdstuk 6, willen we analyseren of het methyloom van het heldercellig niercelcarcinoom verschilt van het methyloom van andere epitheliale kankersoorten, daar het genetische profiel van het heldercellig niercelcarcinoom uniek blijkt te zijn ten opzichte van andere tumoren. Gebruikmakend van dezelfde technologieën als beschreven in hoofdstuk 5 , vergelijken we het methyloom van het heldercellig niercelcarcinoom met dat van dikke darm- en endeldarmkanker en borstkanker. Zover we op dit moment kunnen concluderen, blijkt dat deze methylomen niet van elkaar verschillen wat betreft grootte of de processen waar ze bij betrokken zijn. We hebben belangrijke biologische cascades gevonden die in alle drie de kankersoorten aangedaan worden, echter door unieke veranderingen. Bijkomende analyses zullen nog gedaan moeten worden om dit te verduidelijken, maar uit deze eerste analyses zijn al diverse ziekte-gerelateerde genen geïdentificeerd.

Hoofdstuk 7 vat de belangrijkste bevindingen uit de gepresenteerde studies samen en bespreekt hoe deze data in de toekomst gebruikt kunnen worden in de klinische praktijk. Concluderend geeft dit proefschrift een overzicht van de huidige kennis betreffende de genetica en de epigenetica van het niercelcarcinoom en daarbij de toepassingen zoals die momenteel in de kliniek beschikbaar zijn. Ondanks de wetenschappelijke vooruitgang de afgelopen jaren blijft de behandeling van niercelkankerpatiënten verre van volmaakt en is er veel ruimte voor verbetering. Het werk beschreven in dit proefschrift biedt nieuwe inzichten in de manier van het verrichten van DNA methyleringonderzoek, in de biologie van het heldercellig niercelcarcinoom en heeft geleid tot de identificatie van veelbelovende biomarkers die de prognose van patiënten met een heldercellig niercelcarcinoom kunnen voorspellen. In de toekomst zullen deze markers in vitro en in vivo gevalideerd dienen te worden teneinde hun mogelijke tumoronderdrukkende rol alsook hun waarde voor de kliniek te bevestigen. Het blijft een uitdaging om een volledig individueel behandelingstraject compleet afgestemd op het (epi)genoom van de patiënt te realiseren om niet alleen de prognose te kunnen voorspellen, maar ook de effectiviteit van de behandeling evenals de te verwachte ernst van de bijwerkingen. 


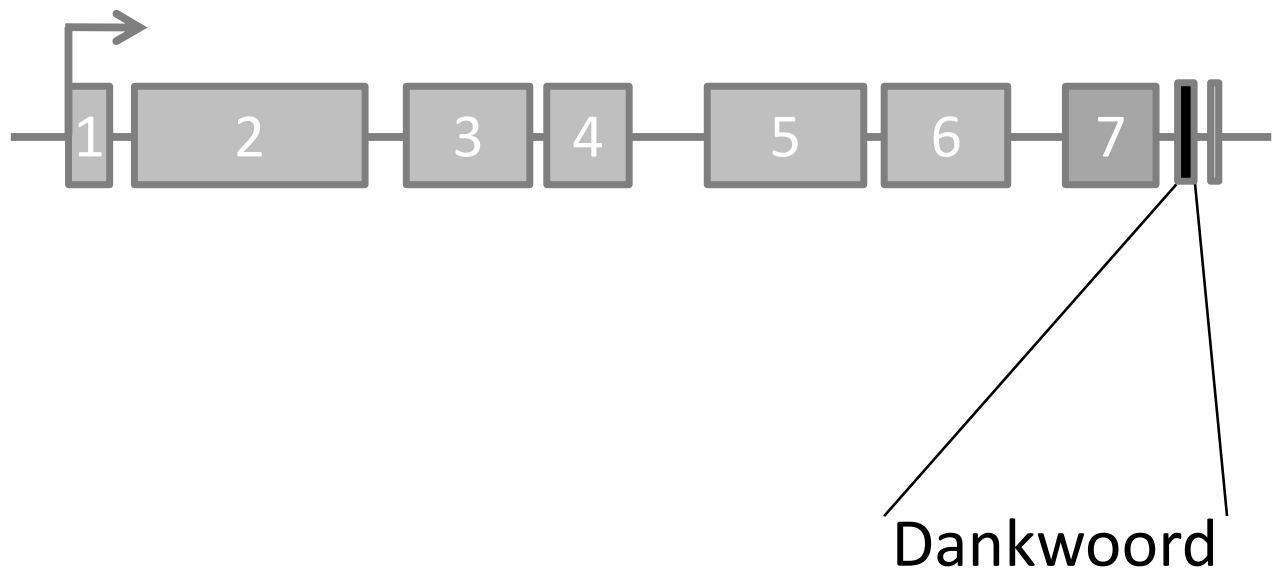


'Opeens' ben je zomaar aan het eind van je promotietraject, dan kijk je terug en dan besef je hoeveel mensen hier direct, indirect, links of rechts bij betrokken waren (en zijn). Nu is het de hoogste tijd om iedereen hiervoor te bedanken!

Uiteraard wil ik eerst het woord richten aan mijn gehele vrouwelijke promotieteam: Beste promotor Prof. van Engeland, beste Manon, jij hebt mij alle kansen gegeven en altijd een weg gevonden om een 'echt' AlO-bestaan voor mij te creëren. Bedankt voor alles!

Beste co-promotor Dr. Baldewijns, beste Marcella, ik mocht bij jou beginnen als student, werd je paranimf en ben nu jouw promovenda. Fijn dat jij mijn hele weg hebt bijgestaan! Bedankt en alle geluk voor de toekomst!

Beste co-promotor Dr. Soetekouw, beste Patricia, jouw blik vanuit de kliniek was onmisbaar! Bedankt voor al je input en veel gezondheid!

Gedurende het begin en het eind van mijn promotie-traject was er ook nog sprake van mannelijke invloeden in het team. Beste Prof. de Bruïne en Prof. Bosman, beste Adriaan en Fré, ik heb veel geleerd van jullie wetenschappelijke inzichten. Bedankt en succes in Venlo en $R^{\prime}$ dam.

Dear Prof. Herman, dear Jim, thanks for the opportunity to start my project in your lab! Thanks for staying in touch with the project and for your great input, so valuable! Of course also many thanks to all other 'Hopkins-people': Prof. Baylin, Kornel, Nita, Jana, Joo Mi, Marilia, Sabine and Kathy.

Veerle, Kim, Hanneke en Jürgen; de post-docs. Naast wetenschappelijke dank, ontzettend bedankt voor jullie gezelligheid en luisterend oor! We hebben heel wat leuke momenten gehad en heel wat afgekletst. Ik zal het niet snel vergeten!

Veerle, had ik maar een fractie van jouw energie! Respect! Alle gesprekken hebben heel wat teweeggebracht. Ontzettend bedankt voor de heerlijke momenten in binnen- en buitenland; hoe waardevol!! Succes met alles! Kim, jij hebt de 'geboorte' van Gremlin bijgestaan, zelfs al voordat je onze groep kwam versterken. Fijn om altijd op jou terug te kunnen vallen en superleuk dat je mijn paranimf wilt zijn $\odot$. Succes met je nieuwe baan! Hanneke, jij bracht heel wat gezelligheid in onze groep. Jij bent altijd in voor alles en het is altijd fijn om lekker laat nog bij te kletsen! Heel veel succes in de toekomst! Dames-drie-eenheid: geweldig bedankt voor alles! Ik blijf graag op de hoogte!

Jürgen, männliche Input ist nie schlecht in unserer Frauen-Welt von Epigenetica. Viel Glück in Aachen: Super ;-). Ook Debby mag niet ontbreken van wie ik nog snel in het $1^{e}$ jaar veel trucjes heb afgekeken! Succes als klinisch geneticus!

Alle (ex-)mede-AIO's, Sarah, Ingrid, Carolina, Marjolein: ex-kamergenootjes, in ons 'hok' op de UNS50 hebben we heel wat meegemaakt $;$, laten we alles binnenskamers houden! Bedankt voor de leuke tijd!

Karin en Joep: nieuwe kamergenootjes (tja eigenlijk nu ook ex-kamergenootjes) wij kregen een upgrade naar de UNS40. Luxe hoor, inclusief eigen koffie- en theehoekje. 
Het was redelijk kort maar zeker krachtig! Bedankt voor de gezelligheid en Karin succes in Dublin en met Joep ;-) en Joep succes met Karin, haha, groetjes aan Nicky. Alle andere mede-AIO's Muriel, Arjen, Dorian, Ivette, Eveline, Tjinta, Suzanne, Colinda and Laura. Succes!

Analisten zijn onmisbaar in een onderzoeksgroep. Kim W, Kathleen, Edith, Peter en nu ook Kim vS, jullie vormen de 'harde kern' en houden het lab draaiende, bedankt voor alle tijd en hulp! Peter, jij hebt je met volle overtuiging aangesloten bij ons 'niergroep$j e$ '. Zelfs op zondag naar het lab komen was geen enkel probleem als ik weer eens met een (te) strakke planning aankwam... Bedankt Peter! Ik blijf graag op de hoogte van al je wereldse belevenissen!

Ook Guido, Petra, Mat en Anique op de analistenkamer, bedankt dat jullie deur altijd open staat (letterlijk en figuurlijk)! Vele anderen zijn ondertussen verder gegaan, maar wel het bedanken waard: Fiona (met jou is het nog begonnen), Sandra, Angela, Iris, Sarah, Loes, Corinne. Ook studenten versterken regelmatig ons lab, dankeschön Johanna, thank you Sean and Musinu for working om the renal projects!

De 'cardio'-collega's weten de gezelligheidsfactor te verhogen: bedankt allemaal! Ook Anke en jouw groep: succes in de toekomst.

Naast Manon, Marcella, Patricia, Kim S, en Peter zijn ook Leo en Ivette onderdeel van de niergroep, hoewel onze meetings nogal eens opgeschort moesten worden was deze groep een enorm succes! Bedankt voor alle input! Ivette, succes met jouw promotie (wie weet komt er nog een hypothese-stuk)!

Cor, Elly, Matthijs en natuurlijk Audrey, bij jullie kun je altijd aankloppen: jullie maken het mogelijk! Merci! ledereen van het secretariaat: Bedankt!

De Gentse 'Genome Hackers' mogen ook zeker niet vergeten worden! Prof. van Criekinge en zijn mannen. Beste Wim, Leander, Tim, Geert en Jean-Pierre (en alle andere die zoveel achter de schermen doen), zonder mannen als jullie is de enorme snelheid in technologische vooruitgang niet bij te houden. Grote dank voor het 'bioinformatisch' verwerken van de enorme lawine aan data die we telkens weer op jullie bordje legden!

Everyone from the Weidhaas lab, thanks for having me in your lab, I had a great 'Yaleexperience'!

Natuurlijk zijn er buiten het werk ook heel wat mensen die een woord van dank verdienen op deze pagina's. Waar te beginnen?? $\rightarrow$ SAAI en SAAl+ zonder I..... dit heeft geen uitleg nodig. Heerlijk om alles van elkaar zonder blikken of blozen te begrijpen en om te klagen over die kleine teen die je gestoten hebt :) ! Simone en Daan, Anne en Marc, Annick en Tein en de rest van de kern van Nijmegen, Weerwolvers, (wanneer is eigenlijk weer een avondje?) BMW-ers (of overlopers), Maaike en Justus, Lieke en Sjoerd, Evelien en Rob, Koen en Marike, Willeke en Patrizio en Harm. Alles begon in Nijmegen en hoewel verspreid door heel NL, de groep blijft gewoon; bijzonder! Bedankt voor alle leuke avondjes, uitstapjes, feestjes, weekendjes, etentjes, gala's, en wat wel nog niet meer allemaal! Super! Dat nog maar veel mag volgen. 
Ruud en Kirsten, Paul, Sander en Kim en de anderen in het Sittardse, zonder jullie was Sittard nooit zo leuk! Bedankt voor alle gezelligheid! We gaan gewoon door (buiten of in Sittard).

Ger en Els, Iris en Dirk, jullie hadden altijd een blind vertrouwen dat het 'gewoon' tot deze dag zou komen: bedankt daarvoor!

Net als jullie, pap en mam. Ik was gewoon de jongste dochter die teveel werkte (volgens jullie). Die kleine schop om niet naar de HAVO te mogen gaan heeft nu zijn vruchten afgeworpen! Bedankt!

Nina, 'Niens', het enige dat jij wilde was dat ik Clint Punkass zou noemen, haha, nou bij dezen! Fijn dat je ook mijn paranimf wilt zijn. Rob, uiteindelijk is de cover het meest beoordeelde deel van een proefschrift. Bedankt voor je geweldig ontwerp (en je geduld met mij)!

Ja, Luc, vandaag is het feest, maar het is natuurlijk óns feest! Dat is het eigenlijk al meer dan 10 jaar! Wat jij allemaal doet, hebt gedaan, hebt moeten doorstaan, over hebt gehad, en wat nog allemaal meer, heeft ertoe geleid dat ik hier kan staan vandaag! Niets of niemand kan dat evenaren! $X$

\section{Jris:}




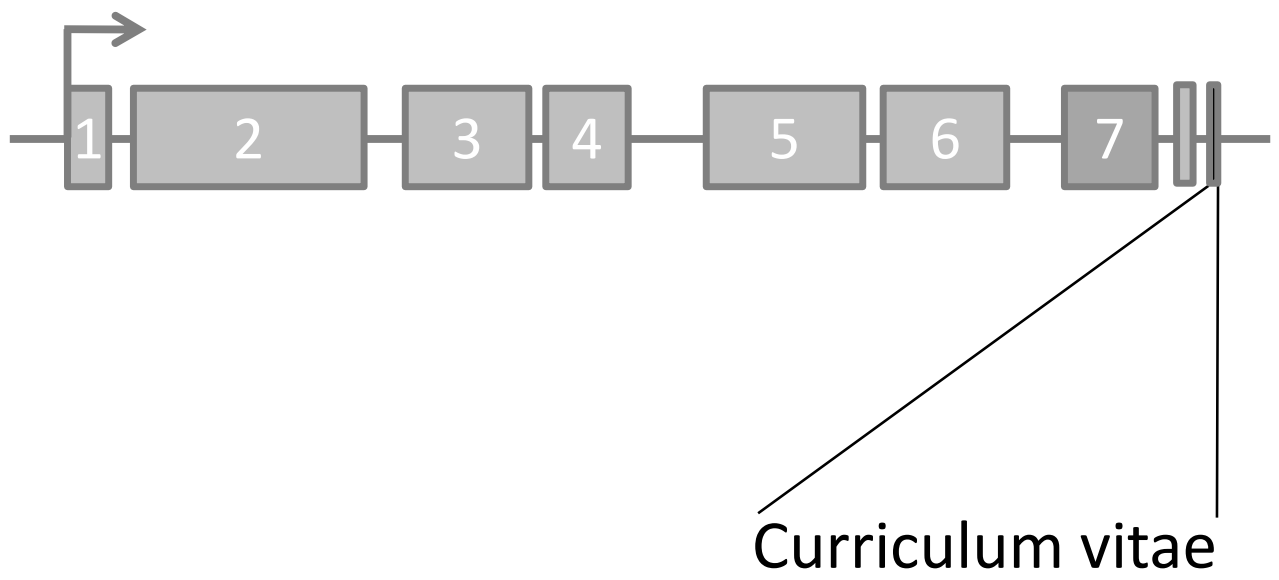




\section{About the author}

Iris van Vlodrop was born on February $20^{\text {th }} 1983$ in Heerlen, the Netherlands. She grew up in Landgraaf were she attended elementary school. After she graduated from secondary school (VWO, profile Nature and Health) at the Bernardinus college Heerlen in 2001, she went to the Radboud University Nijmegen to study Biomedical Sciences from 2001 until 2007. She finished her Bachelors study by completing her first internship in renal cell cancer at the Nijmegen Center for Molecular Life Sciences (NCMLS) in 2004 under supervision of Dr. Jongmans.

During her Masters study, Human Patho-biology, she completed a first internship at the department of Pathology of the Radboud University Medical Center Nijmegen, under supervision of Dr. Leenders. For her second and graduation internship, she moved back to the South of the Netherlands in 2006, where she worked at the department of Pathology of the Maastricht University Medical Center, under supervision of Dr. Baldewijns and Prof. dr. van Engeland who became her co-promotor and promotor for this dissertation. During this internship she got the opportunity to visit the laboratory of Prof. Herman of the Johns Hopkins University Baltimore, USA, which resulted in the start of her PhD-project.

In summer 2007, Iris obtained her Master's degree and was awarded with a 'Kootstra Talent Fellowship', which allowed her to continue her research in a PhD program. During her PhD studies, she worked on a project to unravel the renal cell cancer methylome for fundamental and clinical purposes, which resulted in this dissertation. In fall 2010 she was fortunate to work in the laboratory of Prof. Weidhaas at the Yale University School of Medicine to start a side-project on renal cell cancer. In December 2011 Iris started her training in Clinical Chemistry at the Albert Schweitzer Hospital in Dordrecht. 


\section{List of publications}

van Vlodrop IJ, van Neste L, de Meyer T, Trooskens G, Soetekouw PM, Baldewijns ML, Melotte V, Bosch L, Carvalho B, Meijer GA, Ahuja N, Baylin SB, Herman JG, van Engeland M, van Criekinge $W$, Veeck J. Comprehensive comparison of the of clear cell renal cell cancer methylome with the colorectal and breast cancer methylomes identifies conserved targeting of critical pathways through unique epigenetic events. Manuscript in preparation

van Vlodrop IJ, de Meyer T, Smits KM, van Neste L, Baldewijns ML, Moerkerk PT, Schouten LJ, van den Brandt PA, Yi JM, Jeschke J, de Freitas Calmon M, Schuebel KE, Baylin SB, Ahuja N, Herman JG, Soetekouw PM, Bosman FT, van Criekinge W, van Engeland M. A four gene promoter CpG island methylation marker panel predicts survival of clear cell renal cell cancer patients. Submitted

van Vlodrop IJ, van Engeland M, Weijenberg MP, Baldewijns MM, Schouten LJ, van den Brandt PA, Weidhaas J, Smits KM. A let-7 microRNA SNP in the KRAS 3'UTR is associated with an increased risk on clear cell renal cell cancer. Submitted

van Vlodrop IJ, Niessen HE, Derks S, Baldewijns ML, van Criekinge W, Herman JG, van Engeland M. Analysis of promoter CpG island methylation in cancer: location, location, location! Clin Cancer Res. 2011 Jul 1;17(13):4225-31.

Baldewijns MM, van Vlodrop IJ, Vermeulen PB, Soetekouw PM, van Engeland M, de Bruïne AP. VHL and HIF signalling in renal cell carcinogenesis. J Pathol. 2010 Jun;221(2):125-38.

van Vlodrop IJ, Baldewijns MM, Smits KM, Schouten LJ, van Neste L, van Criekinge W, van Poppel H, Lerut E, Schuebel KE, Ahuja N, Herman JG, de Bruïne AP, van Engeland M. Prognostic significance of Gremlin1 (GREM1) promoter CpG island hypermethylation in clear cell renal cell carcinoma. Am J Pathol. 2010 Feb;176(2):575-84.

Baldewijns MM, van Vlodrop IJ, Smits KM, Vermeulen PB, Van den Eynden GG, Schot F, Roskams $T$, van Poppel H, van Engeland M, de Bruïne AP. Different angiogenic potential in low and high grade sporadic clear cell renal cell carcinoma is not related to alterations in the von HippelLindau gene. Cell Oncol. 2009;31(5):371-82.

Baldewijns MM, van Vlodrop IJ, Schouten LJ, Soetekouw PM, de Bruïne AP, van Engeland M. Genetics and epigenetics of renal cell cancer. Biochim Biophys Acta. 2008 Apr;1785(2):133-55.

Jongmans W, Tiemessen DM, van Vlodrop IJ, Mulders PF, Oosterwijk E. Th1-polarizing capacity of clinical-grade dendritic cells is triggered by Ribomunyl but is compromised by PGE2: the importance of maturation cocktails. J Immunother. 2005 Sep-Oct;28(5):480-7. 